\title{
Report on FY15 Alloy 617 Code Rules Development
}

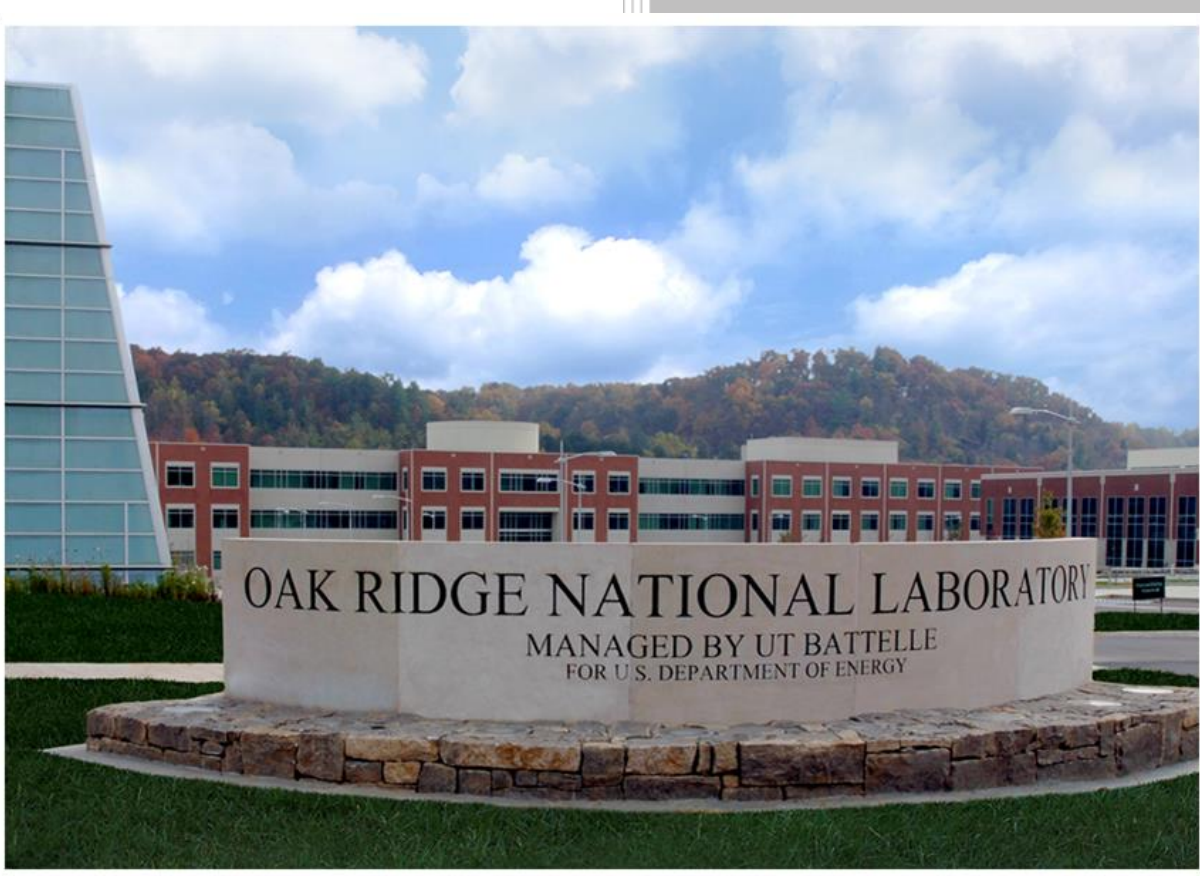

Approved for public release; distribution is unlimited.

T.-L. Sham

R.I. Jetter

G. Hollinger

D. Pease

P. Carter

C. $\mathrm{Pu}$

Y. Wang

September 9, 2015 


\title{
DOCUMENT AVAILABILITY
}

Reports produced after January 1, 1996, are generally available free via US Department of Energy (DOE) SciTech Connect.

Website http://www.osti.gov/scitech/

Reports produced before January 1, 1996, may be purchased by members of the public from the following source:

\author{
National Technical Information Service \\ 5285 Port Royal Road \\ Springfield, VA 22161 \\ Telephone 703-605-6000 (1-800-553-6847) \\ TDD 703-487-4639 \\ Fax 703-605-6900 \\ E-mail info@ntis.gov \\ Website http://www.ntis.gov/help/ordermethods.aspx
}

Reports are available to DOE employees, DOE contractors, Energy Technology Data Exchange representatives, and International Nuclear Information System representatives from the following source:

Office of Scientific and Technical Information

PO Box 62

Oak Ridge, TN 37831

Telephone 865-576-8401

Fax 865-576-5728

E-mail reports@osti.gov

Website http://www.osti.gov/contact.html

This report was prepared as an account of work sponsored by an agency of the United States Government. Neither the United States Government nor any agency thereof, nor any of their employees, makes any warranty, express or implied, or assumes any legal liability or responsibility for the accuracy, completeness, or usefulness of any information, apparatus, product, or process disclosed, or represents that its use would not infringe privately owned rights. Reference herein to any specific commercial product, process, or service by trade name, trademark, manufacturer, or otherwise, does not necessarily constitute or imply its endorsement, recommendation, or favoring by the United States Government or any agency thereof. The views and opinions of authors expressed herein do not necessarily state or reflect those of the United States Government or any agency thereof. 
Advanced Reactor Technologies Program

\title{
Report on FY15 Alloy 617 Code Rules Development
}

\author{
T.-L. Sham, R.I. Jetter ${ }^{1}$, G. Hollinger ${ }^{2}$, D. Pease ${ }^{2}$, P. Carter ${ }^{3}$, C. $\mathrm{Pu}^{4}$, and Y. Wang
}

${ }^{1}$ Consultant

${ }^{2}$ Becht Engineering Co., Inc.

${ }^{3}$ Stress Engineering Services, Inc.

${ }^{4}$ University of Tennessee

Date Published: September 9, 2015

Prepared under the direction of the

U.S. Department of Energy

Office of Nuclear Energy

Prepared by

OAK RIDGE NATIONAL LABORATORY

Oak Ridge, TN 37831-6283

managed by

UT-BATTELLE, LLC

for the

US DEPARTMENT OF ENERGY

under contract DE-AC05-00OR22725 
Intentionally Blank 


\section{CONTENTS}

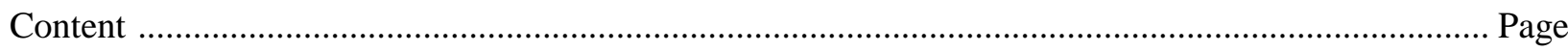

CONTENTS

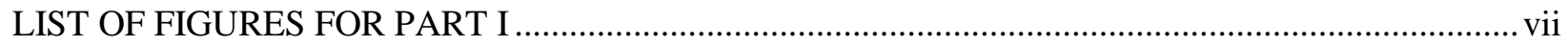

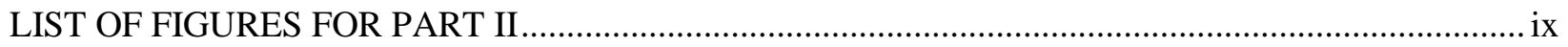

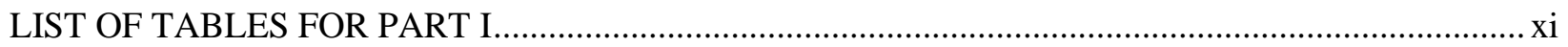

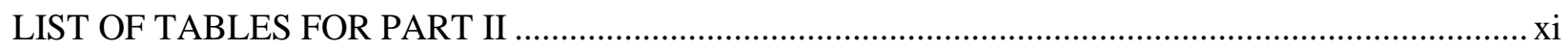

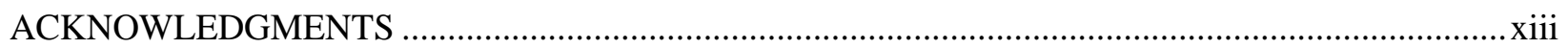

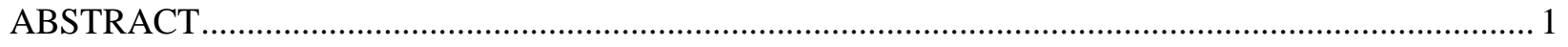

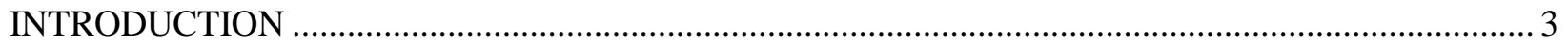

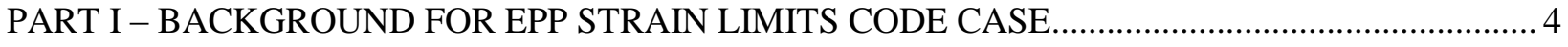

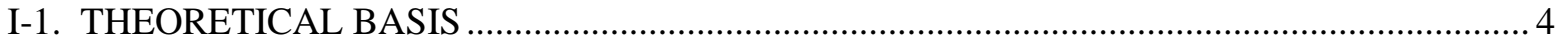

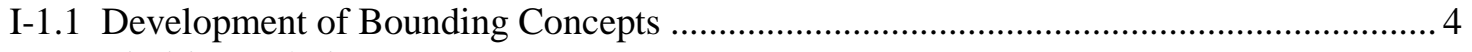

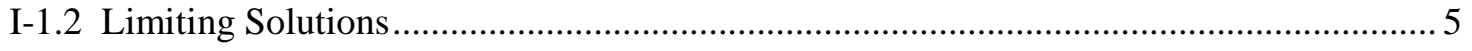

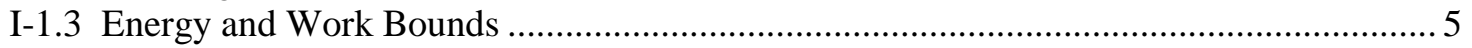

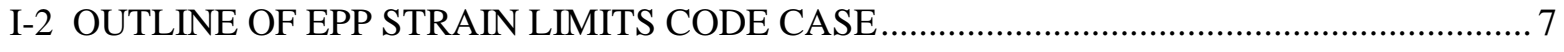

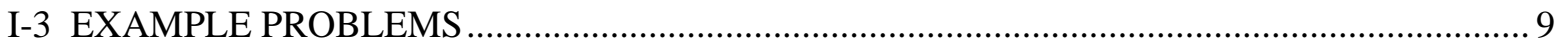

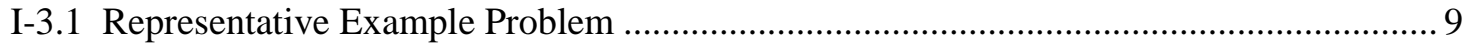

I-3.2 Strain Limits Code Case to Subsection HB, Subpart B Comparison ............................... 19

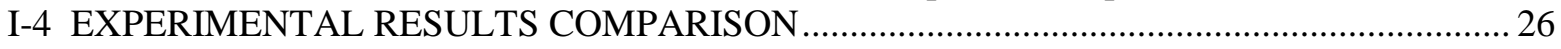

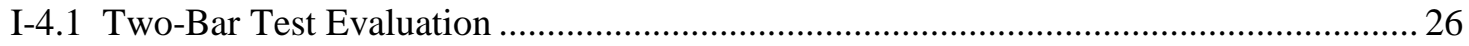

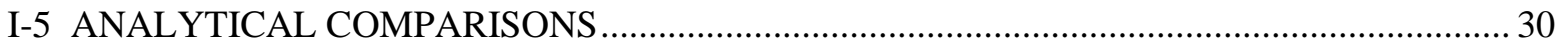

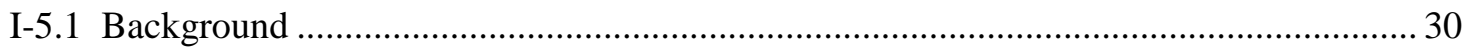

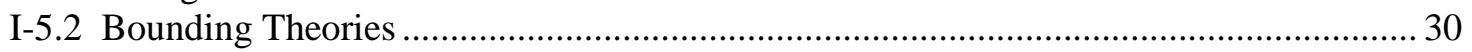

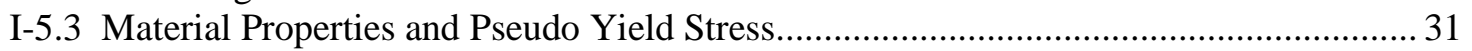

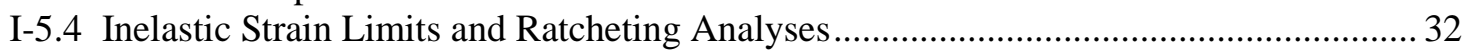

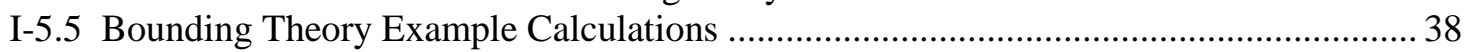

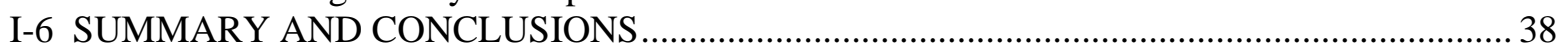

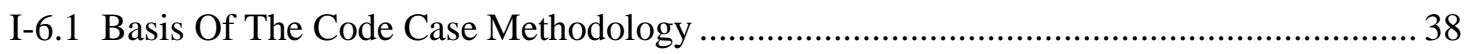

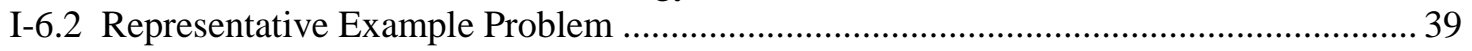

I-6.3 Strain Limits Code Case to Subsection HB, Subpart B Comparison .............................. 39

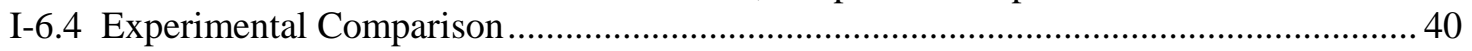

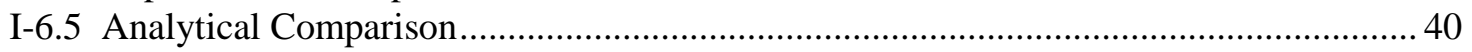

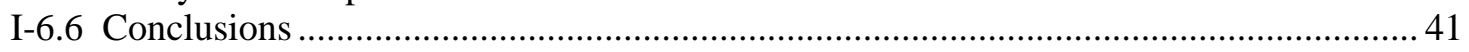

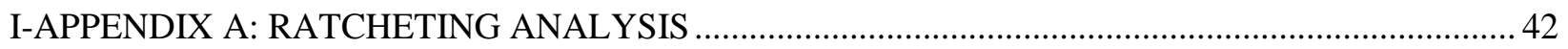

I-APPENDIX B: DRAFT EPP STRAIN LIMITS CODE CASE ....................................................... 44

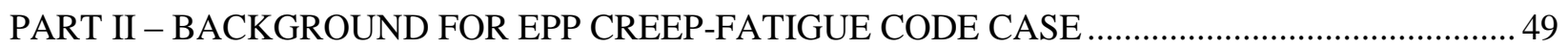

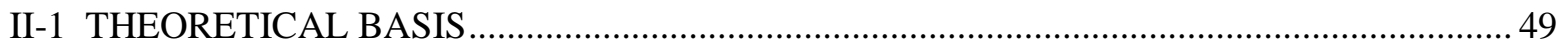

II-1.1 Shakedown Analysis for Cyclic Creep Damage ….................................................. 49

II-2. OUTLINE OF EPP CREEP-FATIGUE CODE CASE ................................................... 51

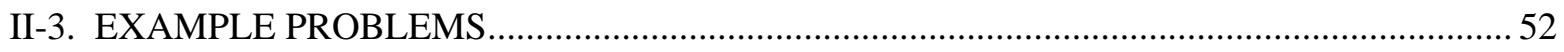

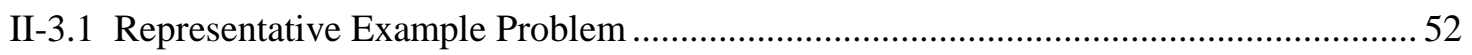

II-3.2 Creep-Fatigue Code Case to Subsection HB, Subpart B Comparison............................ 63

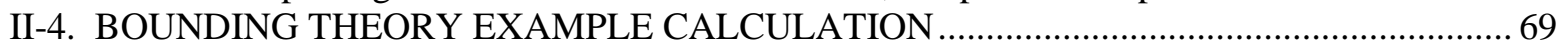

II-4.1 Analysis of Strain Controlled Creep-Fatigue Test Specimen ...................................... 69

II-4.2 Process Flow Procedure for Bounding Creep Damage in Creep-Fatigue Specimen ..... 71

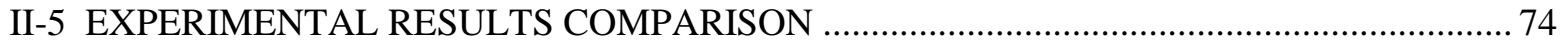




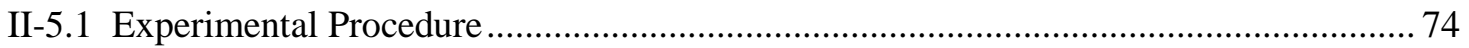

II-5.2 Elastic-Perfectly Plastic Simulation on Alloy 617 Creep-Fatigue ................................ 76

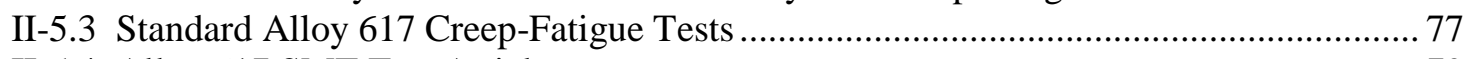

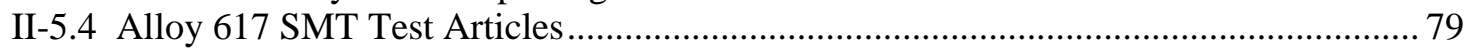

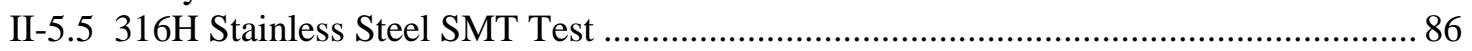

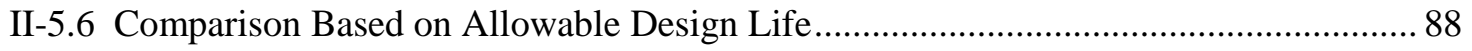

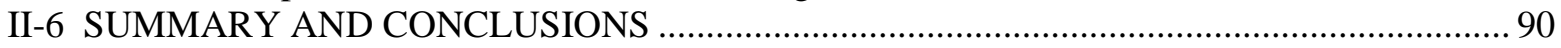

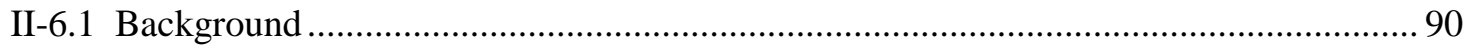

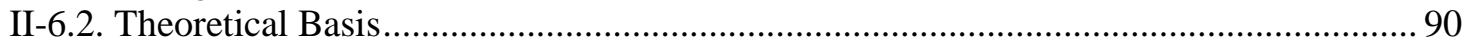

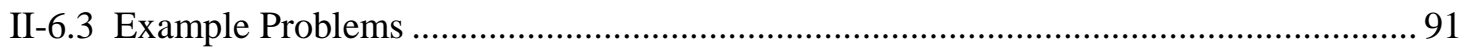

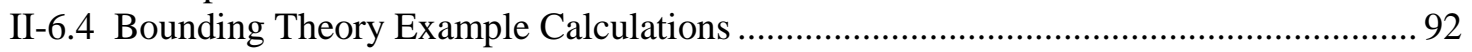

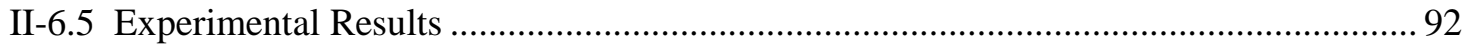

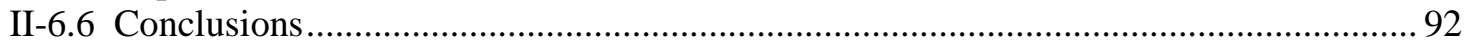

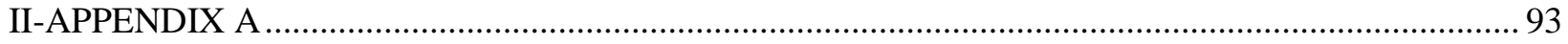

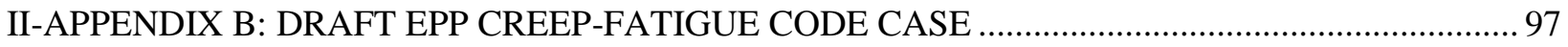

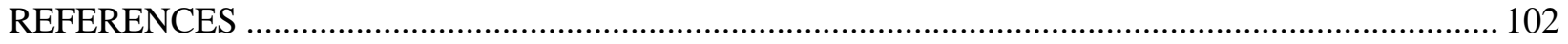




\section{LIST OF FIGURES FOR PART I}

Figure

Fig. I-1. Representative Example Problem Configuration (dimensions in inches) ................................. 10

Fig. I-2. Service Level A Loads and Load Combinations; loadings versus time.................................... 11

Fig. I-3. Service Level B Loads and Load Combinations; loadings versus time ................................... 11

Fig. I-4. Service Level C Loads and Load Combinations; loadings versus time .................................... 12

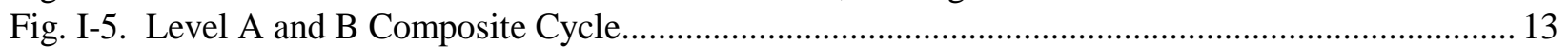

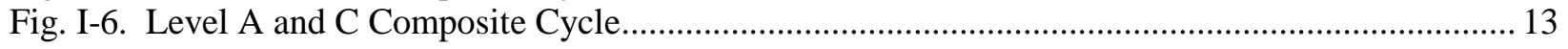

Fig. I-7. Nozzle to Sphere Example Problem FEA Mesh Without Weld Zone ........................................ 14

Fig. I-8. Nozzle to Sphere Example Problem FEA Mesh With Weld Zone ............................................. 15

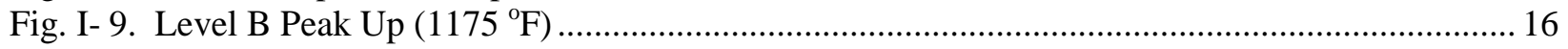

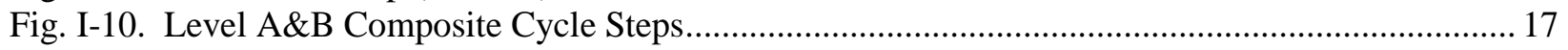

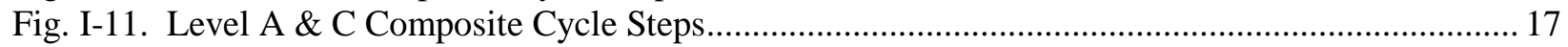

Fig. I-12. Case 3 Component Pipe Geometry and Steady State Temperature $\left({ }^{\circ} \mathrm{F}\right)$ Contours .................... 21

Fig. I-13. 316H SS Isochronous 1\% Inelastic Strain Data ................................................................. 22

Fig. I-14. Non Ratcheting Strain Histories for Tube 2 with Design and Thermal Stress x 1.0. Cyclic strain $(\mathrm{x})=0.095 . \mathrm{y}=$ Core $\operatorname{strain}(\mathrm{y})=0.0001 .1 \%$ Limit Demonstrated............................ 22

Fig. I-15. Contour Plot of Radial Deflection Differences Between Cycles. Design Pressure and Thermal Loading x 1. Apparent Differences not Numerically Significant. Ratcheting not Indicated.

Fig. I-16. Ratcheting Strain Histories for Tube 2 Intersection with Design and Thermal Stress x 1.2. Strain Limits Not Met.

Fig. I-17. Contour Plot of Radial Deflection Differences Between Cycles. Design Pressure and Thermal Stress x 1.2. Ratcheting in Intersection Indicates Strain Limits are Not Met.

Fig. I-18. Non-Ratcheting Strain Histories for Tube 1 and Tube 2 Respectively. From the Component Model. Design and Thermal Stress x 1.2. Cyclic Strain $(x)=0.096, y=$ Core Strain $(\mathrm{y})<0.0002 .1 \%$ Limit Demonstrated. .25

Fig. I-19. Schematic of Two-bar thermal ratcheting condition (a) and the equivalent boundary

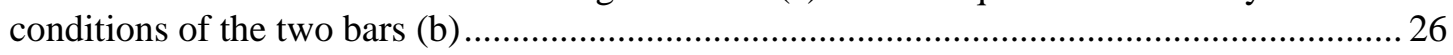

Fig. I-20. Temperature vs. time histogram for two-bar thermal ratcheting experiments on Alloy 617 ..... 27

Fig. I-21. The maximum and the minimum total strains in the two bars at temperature range $800^{\circ} \mathrm{C}$ to $950^{\circ} \mathrm{C}$ (heating and cooling rates were $5^{\circ} \mathrm{C} / \mathrm{min}$ ). ..................................................... 27

Fig. I-22. Two bar test data with $1 \%$ design envelope predictions from the strain limits code case

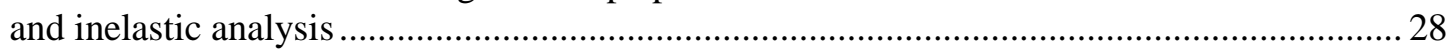

Fig. I-23. Alloy 617 Inelastic Stress - Strain Rates and Material Model Parameters (Units: ${ }^{\circ} \mathrm{F}$,

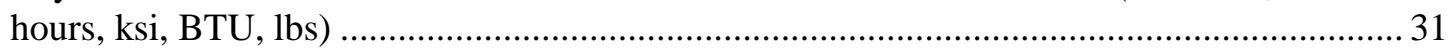

Fig. I-24. Alloy 617 Stress versus Temperature for Yield and 1\% Inelastic Strain in 200 Hours ............. 32

Fig. I-25. Through Wall Temperature Contours and Second Order Mesh .......................................... 33

Fig. I-26. Examples of Non-Ratcheting (a) and Ratcheting (b) Strain Histories ..................................... 33

Fig. I-27. EPP Ratcheting Analyses with Zero and Non-Zero Minimum Plastic Strain (y) ..................... 34

Fig. I-28. Tube Radial Nodal Displacements for Tube Case \#3 Negative Pressure Loading .................... 35

Fig. I-29. Summary of EPP and Creep Analysis Load Cases on Bree Plot of Normalized Primary

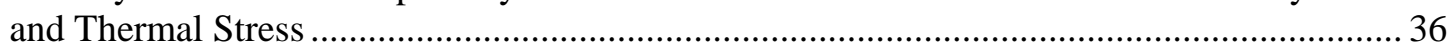

Fig. I-30. OD and Bore Temperature Histories: 1 Hour Hold and 10 Minute Delay Between Downshocks 
Intentionally Blank 


\section{LIST OF FIGURES FOR PART II}

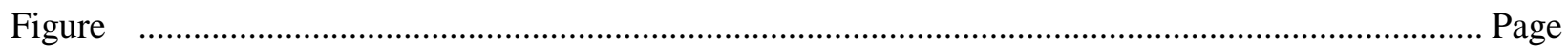

Fig. II-1. Representative Example Problem Configuration (dimensions are in inches).......................... 53

Fig. II-2. Service Level A Loads and Load Combinations; loadings versus time .................................. 54

Fig. II-3. Service Level B Loads and Load Combinations; loadings versus time....................................55

Fig. II-4. Service Level C Loads and Load Combinations; loadings versus time..................................... 55

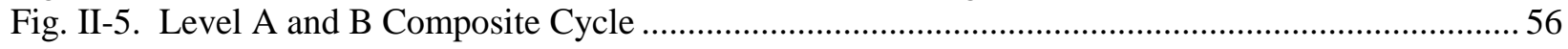

Fig. II-6. Level A and C Composite Cycle ....................................................................................... 57

Fig. II-7. Nozzle to Sphere Example Problem FEA Mesh Without Weld Zone ........................................58

Fig. II-8. Nozzle to Sphere Example Problem FEA Mesh Without Weld Zone ........................................ 58

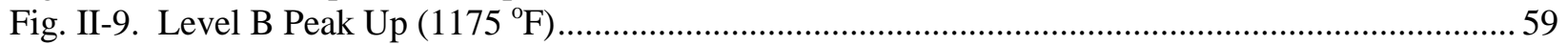

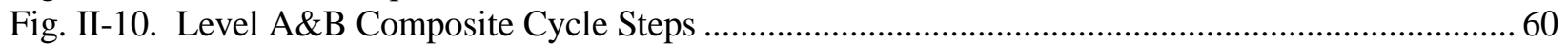

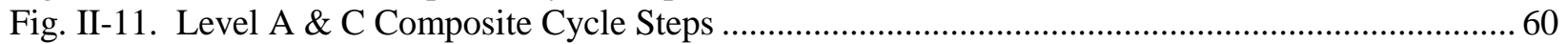

Fig. II-12. Hoop Pressure Plus Thermal Stress. Maximum Value of both Stresses is $44 \mathrm{ksi}$.

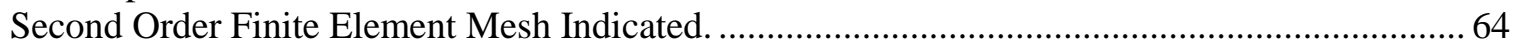

Fig. II-13. 316H Stainless Isochronous Creep Rupture Stress - Temperature Curves ............................ 67

Fig. II-14. Contours of Analysis Plastic Strain. Maximum value in the Bore of Tube \#2 2...................... 67

Fig. II-15. Plots of Cyclic Plastic Strain from Tube Bore. Shakedown Obtained for 10,000 Hours

Rupture Life, Failure to Shakedown for 12,000 Hours Rupture Life .........................................6 68

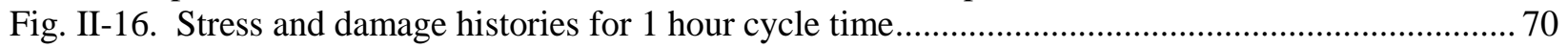

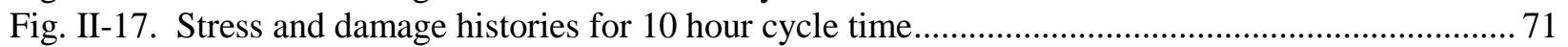

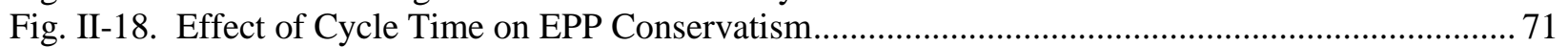

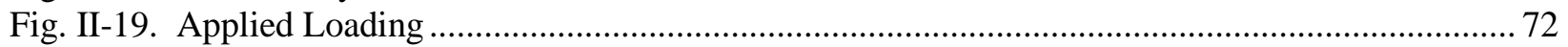

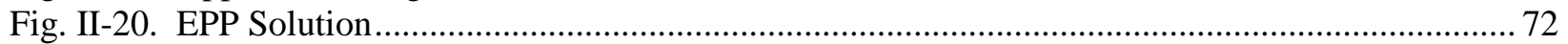

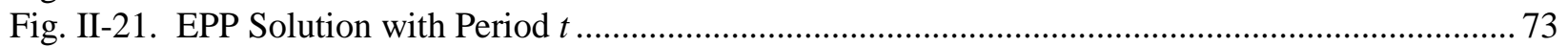

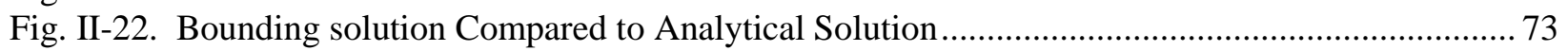

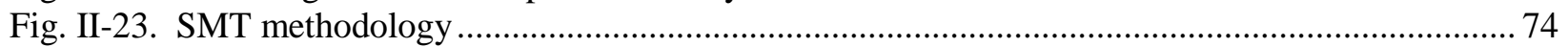

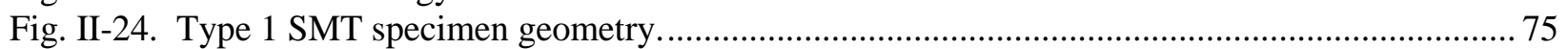

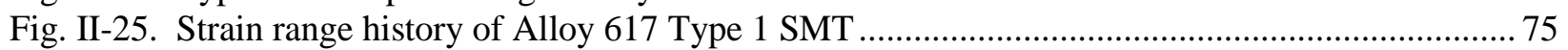

Fig. II-26. Stress relaxation during the hold period for Type 1 SMT necked test section and

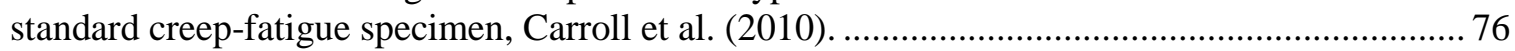

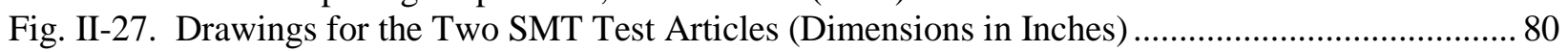

Fig. II-28. Test setup of the SMT specimen. ............................................................................. 81

Fig. II-29. Profiles of $\Delta \boldsymbol{L}$ for imposing the prescribed displacements over the gage length $\boldsymbol{L}$ for Alloy 617. Displacement hold was applied at the maximum tensile $\Delta \boldsymbol{L}$ value. Cycles

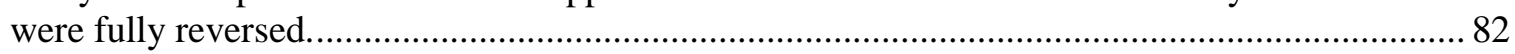

Fig. II-30. Typical axisymmetric finite element meshes for Type I and Type II SMT test articles...........83

Fig. II-31. Plots of ABAQUS active plasticity variable AC YIELD for Alloy 167. Essentially grey color indicates active plasticity and blue color denotes incremental elastic response........... 85

Fig. II-32. Profile of $\Delta \boldsymbol{L}$ for imposing the prescribed displacements over the gage length $\boldsymbol{L}$ for $316 \mathrm{H}$

Fig. II-33. Contour plot of ABAQUS active plasticity variable AC YIELD for 316H. Essentially grey color indicates active plasticity and blue color denotes incremental elastic response...........87

Fig. II-34. Creep-fatigue code case allowable life comparison to Alloy 617 SMT data .......................... 89

Fig. II-35. Creep-fatigue code case allowable life comparison to $316 \mathrm{H}$ stainless steel SMT data............ 89 
Intentionally Blank 


\section{LIST OF TABLES FOR PART I}

Table Page

Table I-1. Nature of work bounds for increasing different levels of problem complexity. 6

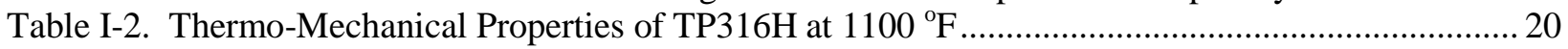

Table I-3. Summary of HBB-T-1332 Test B1 and B2 Strain Limits Calculations .................................. 20

Table I-4. Results of Ratcheting Calculations of Plain Tubes and Tapered Joined Tube ........................ 25

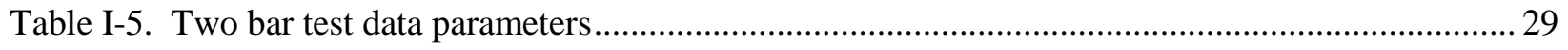

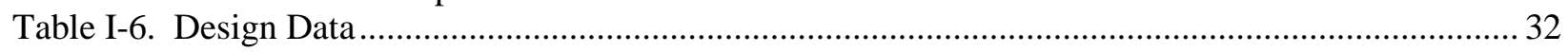

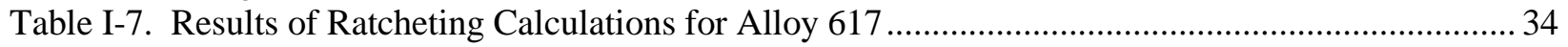

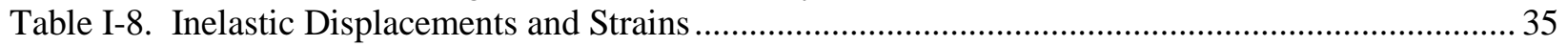

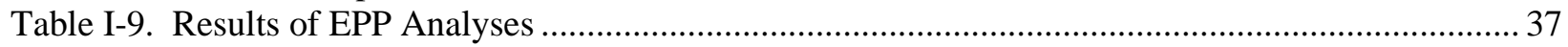

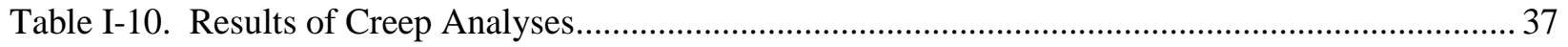

\section{LIST OF TABLES FOR PART II}

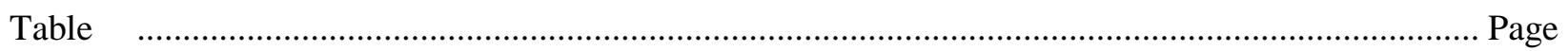

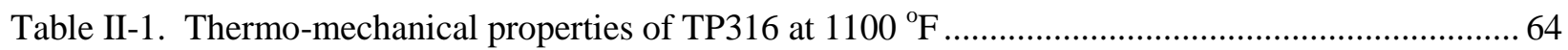

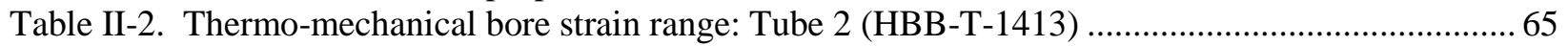

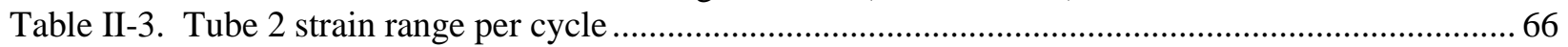

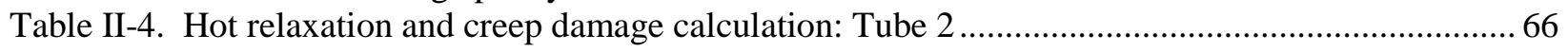

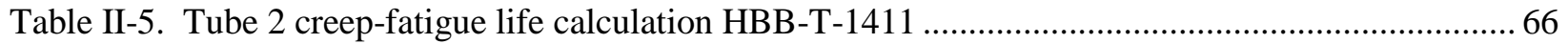

Table II-6. Tube 2 creep-fatigue life calculation EPP shakedown analysis ........................................... 68

Table II-7. Creep and damage constants for $316 \mathrm{H}$ stainless steel at $1400{ }^{\circ} \mathrm{F}$. Units: ksi, ${ }^{\circ} \mathrm{F}$, hours.......... 69

Table II-8. Test conditions and data of Alloy 617 standard ASTM creep-fatigue test specimens ............ 78

Table II-9. Evaluation of the elastic shakedown condition for the standard Alloy 617 creep-

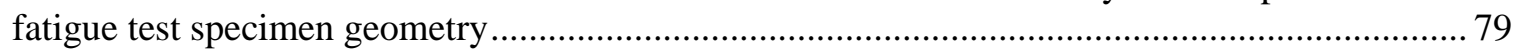

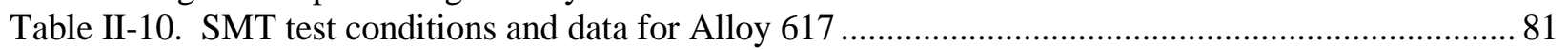

Table II-11. Material parameters used in the EPP finite element analyses for Alloy 617 ......................86

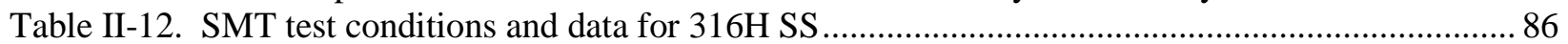

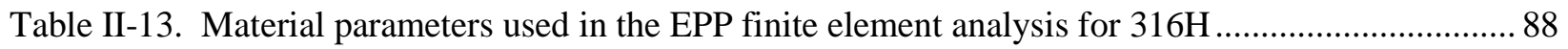

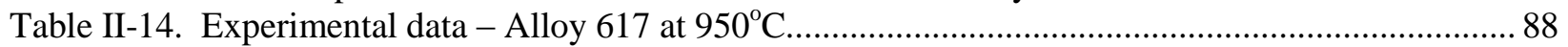

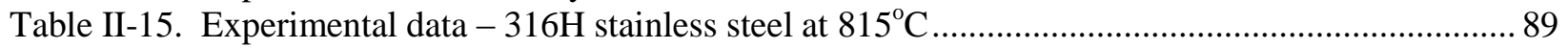


Intentionally Blank 


\section{ACKNOWLEDGMENTS}

This research was sponsored by the U.S. Department of Energy (DOE), Office of Nuclear Energy (NE), for the Advanced Reactor Technologies (ART) Program. We gratefully acknowledge the support provided by Carl Sink of DOE-NE, ART Program Manager; William Corwin of DOE-NE, ART Materials Technology Lead; David Petti of Idaho National Laboratory (INL), ART Co-National Technical Director; and Richard Wright of INL, Technical Lead, High Temperature Materials. The time spent by Hong Wang of ORNL in reviewing this report is greatly appreciated. 
Intentionally Blank 


\begin{abstract}
Due to its strength at very high temperatures, up to $950^{\circ} \mathrm{C}\left(1742^{\circ} \mathrm{F}\right)$, Alloy 617 is the reference construction material for structural components that operate at or near the outlet temperature of the very high temperature gas-cooled reactors. However, the current rules in the ASME Section III, Division 5 Subsection HB, Subpart B for the evaluation of strain limits and creep-fatigue damage using simplified methods based on elastic analysis have been deemed inappropriate for Alloy 617 at temperatures above $650^{\circ} \mathrm{C}\left(1200^{\circ} \mathrm{F}\right)($ Corum and Brass, Proceedings of ASME 1991 Pressure Vessels and Piping Conference, PVP-Vol. 215, p.147, ASME, NY, 1991). The rationale for this exclusion is that at higher temperatures it is not feasible to decouple plasticity and creep, which is the basis for the current simplified rules. This temperature, $650^{\circ} \mathrm{C}\left(1200^{\circ} \mathrm{F}\right)$, is well below the temperature range of interest for this material for the high temperature gas-cooled reactors and the very high temperature gas-cooled reactors. The only current alternative is, thus, a full inelastic analysis requiring sophisticated material models that have not yet been formulated and verified.

To address these issues, proposed code rules have been developed which are based on the use of elastic-perfectly plastic (EPP) analysis methods applicable to very high temperatures. The proposed rules for strain limits and creep-fatigue evaluation were initially documented in the technical literature (Carter, Jetter and Sham, Proceedings of ASME 2012 Pressure Vessels and Piping Conference, papers PVP 201228082 and PVP 2012-28083, ASME, NY, 2012), and have been recently revised to incorporate comments and simplify their application. Background documents have been developed for these two code cases to support the ASME Code committee approval process. These background documents for the EPP strain limits and creep-fatigue code cases are documented in this report.
\end{abstract}


Intentionally Blank 


\section{INTRODUCTION}

Due to its strength at very high temperatures, up to $950^{\circ} \mathrm{C}\left(1742^{\circ} \mathrm{F}\right)$, Alloy 617 is the reference construction material for structural components that operate at or near the outlet temperature of the very high temperature gas-cooled reactors (VHTRs). However, the current rules in Subsection HB, Subpart B for the evaluation of strain limits and creep-fatigue damage using simplified methods based on elastic analysis have been deemed inappropriate for Alloy 617 at temperatures above $650^{\circ} \mathrm{C}\left(1200^{\circ} \mathrm{F}\right)$ (Corum and Brass, 1991). The rationale for this exclusion is that at higher temperatures it is not feasible to decouple plasticity and creep, which is the basis for the current simplified rules. This temperature, $650^{\circ} \mathrm{C}$ $\left(1200^{\circ} \mathrm{F}\right)$, is well below the temperature range of interest for this material for the High Temperature Gas Cooled Reactor (HTGR) as well as the VHTR. The only current alternative is, thus, a full inelastic analysis requiring sophisticated material models that have not yet been formulated and verified.

To address these issues, proposed code rules have been developed which are based on the use of elastic-perfectly plastic (EPP) analysis methods applicable to very high temperatures. The proposed rules for strain limits and creep-fatigue evaluation were initially documented in the technical literature, Carter et al. (2012a) and Carter et al. (2012b), and have been recently revised to incorporate comments and simplify their application. Background documents have been developed for these two code cases to support the ASME Code committee approval process.

These background documents provide a summary and rationale of the actions taken to illustrate and verify the application of these code cases. Example problems have been defined to demonstrate the application of the code cases and to compare the results of the application of the proposed code cases with the results from the application of the current simplified rules in Subsection HB, Subpart B. Two types of example problems were defined; one to illustrate the applicability of the code cases to a representative geometry and cyclic thermal and mechanical loading. The second type of example problem is much more simplified with idealized cyclic loading to facilitate comparison with current Subsection HB, Subpart B "simplified" elastic analysis based evaluation procedures for strain limits and creep fatigue in Appendix HBB-T.

These example problem comparisons are based on $316 \mathrm{H}$ stainless steel because approved properties required to support a design evaluation for that material are available in Subsection HB, Subpart B whereas the properties for Alloy 617 are still being developed. In addition, to validate the applicability of these proposed code cases at very high temperatures, key feature tests which simulate ratcheting and elastic follow-up phenomena were conducted with Alloy 617 subjected to cyclic loading at very high temperatures to $950^{\circ} \mathrm{C}\left(1742^{\circ} \mathrm{F}\right)$.

Since the Code actions for these two code cases are under separate records, those discussions common to both code cases have been included in both background documents to avoid cross referencing. The background documents for the EPP strain limits and creep-fatigue code cases are included as Part I and Part II, respectively, in this report. 


\section{PART I - BACKGROUND FOR EPP STRAIN LIMITS CODE CASE}

\section{I-1. THEORETICAL BASIS}

\section{I-1.1 Development of Bounding Concepts}

Carter et al. (2012) provided details of the bounding arguments to justify the use of a cyclic, elastic, perfectly plastic ratcheting analysis to comply with code strain limits. The main points of the argument are summarized below.

The use of bounding simplified solutions to characterize complex structural creep problems is well established. The most widely used methods are for reference stress solutions to constant load problems as, for example, reviewed in Goodall et.al. (1979). The bounding nature of shakedown solutions for cyclic loading is also reviewed in Subsection HB, Subpart B. These ideas have been developed and implemented in this document with the use of a temperature-dependent material property as an artificial yield stress in limiting elastic-plastic calculations. This approach is common to low and high temperature primary load design methods (Carter 2005a; 2005b), and to high temperature cyclic load designs Carter et al. (2012a).

The use of simplified elastic-plastic analysis methods avoids the ${ }^{\circ}$ omplexities and limitations of the traditional ASME linear elastic stress classification design methods, particularly the current Tests in ASME Section III, Division 5, Appendix HBB-T. The simplified methods exploit the fact that elasticplastic methods naturally handle the stress redistribution which is the key to stress classification schemes. For high temperature design, creep strain and stress re-distribution occur naturally in service. The use of a time-independent analysis to characterize these processes is not necessarily intuitively obvious. Their justification by the judicious use of proofs based on general material models is therefore essential for complex high temperature design and life assessment.

In order to guarantee creep strain limits based on elastic-plastic analysis, the conservatism of the rapid cycle solution may be exploited. The physical principle here is that any stress history resulting from an elastic analysis, or from an elastic-plastic analysis that shakes down to elastic behavior, provides an upper bound to the creep deformation over time. The following sections give a summary of the justification of this assertion. The background is as follows. For a given load and temperature cycle, a number of solutions may be defined and calculated.

- Elastic shakedown solution with a constant residual stress (SD).

- Elastic-plastic solution for a perfectly plastic temperature dependent yield stress (CP).

- An optimum elastic-plastic solution, the rapid cycle solution (RC).

- Realistic steady cyclic creep solution (SC).

- Limiting slow cycle or steady state creep solution (SS).

From each of these we may use the temperature and respective stress histories to calculate creep strain rates, work done by boundary forces and energy dissipation rates over the volume. These may be compared and ranked. From this, a bounding cyclic solution associated with a simplified elastic-plastic analysis method may be identified. 


\section{I-1.2 Limiting Solutions}

Consider a general structural problem where cyclic mechanical and thermal loads with the same period $\mathrm{T}$ have been defined. The elastic solution is $\sigma_{e}(t)$.

The steady state (SS) solution is defined by the stress distribution $\sigma_{s s}$ such that the creep steady state strain is kinematically admissible. This solution represents the steady loading case after stress redistribution or the limiting case of very slow cycles.

The steady cyclic (SC) solution is the realistic limiting cyclic state with cyclic stress history

$$
\sigma_{s c}(t)=\sigma_{s c}(t+T)
$$

where $T=$ cycle period, and kinematically admissible cyclic strain increments and displacement increments.

The shakedown (SD) solution is not unique and refers to any elastic solution with a constant residual stress field $\rho$

$$
\sigma_{s d}(t)=\sigma^{e}(t)+\rho
$$

The elastic rapid cyclic (RC) solution is the optimum shakedown solution and is the most conservative physically achievable cyclic solution.

The elastic rapid cycle solution is defined by the constant residual stress $\rho_{r c}$ such that strain increments calculated over the cycle are kinematically admissible.

The plastic rapid cyclic (CP) solution is more general than the elastic rapid cycle which is only valid within the shakedown limit. The plastic rapid cycle solution will generally have elastic and plastic regions. In the elastic region the creep strain increments $\Delta \varepsilon^{c}$ are kinematically admissible as in the previous case. In the plastic zone, the stress history is unique, and so the rapid cycle solution is the same as the cyclic plastic solution.

The proposed method makes use of a cyclic plastic (CP) solution, which will provide an upper bound to energy, work, strains and displacements for the other solutions mentioned above.

\section{I-1.3 Energy and Work Bounds}

This section is a summary of results obtained in Goodall et al. (1979) and Carter (2005a; 2005b). The convexity of the yield, creep and energy dissipation functions may be used to obtain work bounds as follows:

For mechanical loading the work $W$ done by boundary forces over a cycle for these cases is ordered as follows:

$$
W_{C P} \geq W_{R C} \geq W_{S C} \geq W_{S S}
$$

For combined thermal-mechanical loading, the bounding statement is in terms of energy dissipation $D$ over the cycle: 


$$
D_{C P} \geq D_{R C} \geq D_{S C} \geq D_{S S}
$$

The key part of these inequalities for the simplified method used in the herein is the connection between any cyclic plasticity solution CP and the real steady cyclic solution SC. We will use the most advantageous cyclic plasticity solution, with the lowest stress histories and energy dissipation $D$ over the cycle, that does not ratchet, to bound the real steady cyclic strain accumulation.

In the analyses that follow, any elastic, perfectly plastic analysis using an artificial ("pseudo") yield stress derived from creep data, which does not ratchet, represents a "CP" case in inequalities (3) and (4). The greater the time used in defining the pseudo yield stress, the more likely the analysis will give a ratcheting result. With trial and error, it is possible to maximize the time to give a solution which does not ratchet and so complies with the strain limits. This would provide the "RC" solution in inequalities (3) and (4).

Table I-1 shows the nature of the possible bounds and the increasing difficulty of the proofs as loading and material models become more general. For example, for cyclic mechanical loading, bounds to external work may be calculated. For cyclic thermal-mechanical loading, bounds to internal energy dissipation, not to external work, may be calculated.

Table I-1. Nature of work bounds for increasing different levels of problem complexity.

\begin{tabular}{l|c|c}
\hline \multirow{2}{*}{ Cyclic load types } & \multicolumn{2}{|c}{ Material Model } \\
\cline { 2 - 3 } & Creep & Creep-plasticity \\
\hline Mechanical & External work & External work \\
\hline $\begin{array}{l}\text { Thermal- } \\
\text { mechanical }\end{array}$ & Internal energy & Deformation/work bound proved herein \\
\hline
\end{tabular}

For the most general case of thermal-mechanical loading on a creep-plasticity material, the bound is justified using the qualitative argument below. More detail is available in Carter (2005a; 2005b). The argument used for the general case of thermal-mechanical loading and creep-plasticity is based on the self-evident assumption for a structure under general loading:

\section{Reducing the perfectly plastic yield stress does not reduce the deformation.}

Applied to the plastic rapid cycle solution, this statement means that the cyclic increment in deformation of a structure is not reduced if the yield stress is reduced, all other factors being unchanged. Therefore, if the yield stress is reduced to the point where ratcheting in a cyclic problem is imminent, then the cyclic incremental deformation is not less than for the original yield stress. Therefore, the energy dissipation and deflection for the reduced yield stress case provides an upper bound of the energy dissipation and deflection in the original cases. This is the justification of the rapid cycle deformation reference stress. This may be expressed as follows.

Consider the lowest value of the yield stress, $\sigma_{\text {ref }}$, for which the ratcheting displacement

$$
\Delta u_{c p}^{p}=0
$$


The creep energy dissipation over the cycle is less than the energy dissipation rate associated with $\sigma_{\text {ref }}$ integrated over the volume and cycle.

In terms of the creep energy dissipation rate

$$
D=\sigma \dot{\varepsilon}^{c}
$$

this idea is expressed by

$$
D_{r c}=\iint D\left(\sigma_{r c}\right) d V d t \leq D\left(\sigma_{r e f}\right) V T
$$

This is equivalent to the statement that the rapid cycle reference stress defining structural energy dissipation and deformation is the lowest value of the yield stress for which the structure does not ratchet.

The strain limits code case exploits the rapid cycle concept to define a temperature dependent "pseudo" yield stress incorporating the desired strain limit. Non-ratcheting in a conventional analysis implies that the strain limit used to define the pseudo yield stress is satisfied.

\section{I-2 OUTLINE OF EPP STRAIN LIMITS CODE CASE}

A draft of the proposed Strain Limits Code Case is included in I-Appendix B. This code case is intended as an alternative to the rules in HBB-T-1320, Satisfaction of Strain Limits Using Elastic Analysis, and in HBB-T-1330, Satisfaction of Strain Limits Using Simplified Inelastic Analysis. It also includes provisions from HBB-T-1710, Special Strain Requirements at Welds. There are five parts to the code case and an appendix.

The objective is to comply with the Division 5, Appendix HBB-T requirements for inelastic strains, namely:

i) Strain averaged through the thickness, $1 \%$.

ii) Strains at the surface, due to an equivalent linear distribution of strain through the thickness, $2 \%$.

iii) Local strains at any point, $5 \%$.

These requirements are met by using an average, or reference, limit of $1 \%$ to define a general ratcheting stress limit. For the case of pure bending in a uniform section, this implies a $2 \%$ limit on the extreme fire strain.

A procedure to determine follow-up effects is used in conjunction with a local strain limit, including follow-up effects, of 5\%.

Part 1, General Requirements, describes the overall elastic-perfectly plastic ratcheting analysis and provides a general definition of the pseudo yield strength used in this code case.

Part 2, Load Definition, identifies the manner in which loads are categorized and grouped for this application. Code Case procedure requires that a composite cycle be defined which encompasses the critical features of the individually defined cycles. The reason for this is that the elastic perfectly plastic methodology used in the code case bounds the long term response independent of the number of applied cycles. In this respect it is similar to the current simplified rules in Subsection HB, Subpart B. 
Two sets of conditions are defined; one set for Service Levels A and B and the other for Service Levels A and C. A feature of the proposed code case is that, unlike the current version of Subsection HB, Subpart B, the worst case combinations of Service Level A and B do not need to be combined directly with Service Level C. The rationale for this is that in accordance with the definition of Service Levels, shutdown for inspection and repair or replacement is required after a Level $\mathrm{C}$ event whereas the reactor system may resume planned operation after Level A and B events. The number of Level C events is limited as it is in the lower temperature Division 1, Subsection NB rules, but, unlike the NB rules, assessment of the high temperature displacement controlled failure modes, strain limits and creep-fatigue, is required to guard against creep damage not measurable externally which might contribute to restraints on the remaining life when subjected to subsequent Level A and B conditions.

Part 3, Numerical Model, specifies that the finite element model used in the analysis (The code case is based on the use of FEA) should accurately represent the component geometry and loading conditions, transient and steady state, including details such as local stress risers and local thermal stresses.

Part 4, Requirements for Satisfaction of Strain Limits, provides the criteria for implementing the code case evaluation. The pseudo yield stress is obtained from the lower of the yield strength or the stress from the applicable isochronous stress strain curve (ISCC). The time duration for entering the ISCC is the total design life. The temperature is the local instantaneous temperature as determined from the transient thermal analysis. The strain used to determine the pseudo yield strength from the ISSC at a given time and temperature is an iterative procedure governed by the relationship that $0<x<\varepsilon_{\text {avg }}$ where $x$ is the target inelastic strain and $\varepsilon_{\text {avg }}$ is the strain limit, 0.01 for base metal and 0.005 for weldments.

The next step is a cyclic elastic-perfectly plastic (EPP) analysis using the above determined pseudo yield strengths that vary spatially and temporally. Shakedown for the strain limits code case is defined as the absence of incremental plasticity or deformation. Note that this permits stable hysteresis loops with plasticity. If the analysis shakes down, then the next step is to determine the local plastic strain, $\varepsilon_{p}$, from the EPP analysis, and add it to the target strain, $x$. The local plastic strain from the EPP shakedown analysis is added to the target inelastic to account for strain redistribution due to elastic follow up, redundancy, etc. The sum $\left(x+\varepsilon_{p}\right)$ must satisfy the following constraints: $\left(x+\varepsilon_{p}\right) \leq \varepsilon_{a v g}$ at least at one point for all through thickness locations where, as noted above, $\varepsilon_{\text {avg }}$ is 0.01 for base metal and 0.005 for weldments; and, $\left(x+\varepsilon_{p}\right) \leq \varepsilon_{\text {local }}$ at all points. $\varepsilon_{\text {local }}$ is equal to 0.05 for base metal and 0.025 for weldments. The strain limits noted above, $\varepsilon_{\text {avg }}$ and $\varepsilon_{\text {local }}$, are the same as those in Subsection HB, Subpart B.

Part 5, Weldments, provides guidelines for representing the boundary between the weldment and base metal. This is intended to be a reasonable approximation that captures the essential structural features of the weld including applicable stress concentrations.

The appendix provides guidance on how to define composite cycle load time-histories and stepping sequence, analysis types, material properties, ratcheting analysis and how to detect ratcheting. 


\section{I-3 EXAMPLE PROBLEMS}

There are two categories of example problems. The first category is a representative example which demonstrates the application of the code case(s) to a representative geometry with loading conditions representative of those which might be encountered in real design applications. The second category is simplified geometries and loading conditions to facilitate comparison with the current rules in Subsection HB, Subpart B.

\section{I-3.1 Representative Example Problem}

\section{I-3.1.1 Input parameters} (2014).

The following discussion is abstracted from a much more detailed report by Hollinger and Pease

There were considerable analytic studies of different trial configurations and loading conditions. The goal was to generate an example that would exercise relevant features of the strain limits and creepfatigue code cases with significant loading conditions and yet still be able to show compliance, at least for some loadings. As noted above, the same configuration and loadings were used for both the strain limits and creep-fatigue code cases.

The selected example problem is an integrally reinforced nozzle in a spherical shell. The weld centerline location represents a V groove, flush ground weld. The example configuration is shown in Fig. I-1.

The material selected for the representative example was $316 \mathrm{H}$ stainless steel. $316 \mathrm{H}$ SS was selected because it is a material of interest for advanced high temperature reactors and the relevant material properties are available. There was also an incentive to choose the same material for both the representative example and the simplified example problems. Since the goal of the simplified examples is a comparison to the requirements of Subsection HB, Subpart B, it was necessary to also use a material for which those rules were considered applicable.

The applied loads include thermal and mechanical cyclic loading and a representative seismic input. Internal pressure and nozzle shear, moment and torsion loads, both sustained and transient, and thermal transients were specified for Level A, B and C Service Loadings. An overview of these specified loading histories is shown schematically in Fig. I-2, Fig. I-3 and Fig. II-4 respectively. The detailed values are tabulated in Hollinger and Pease (2014). The total design life is 100,000 hours. 


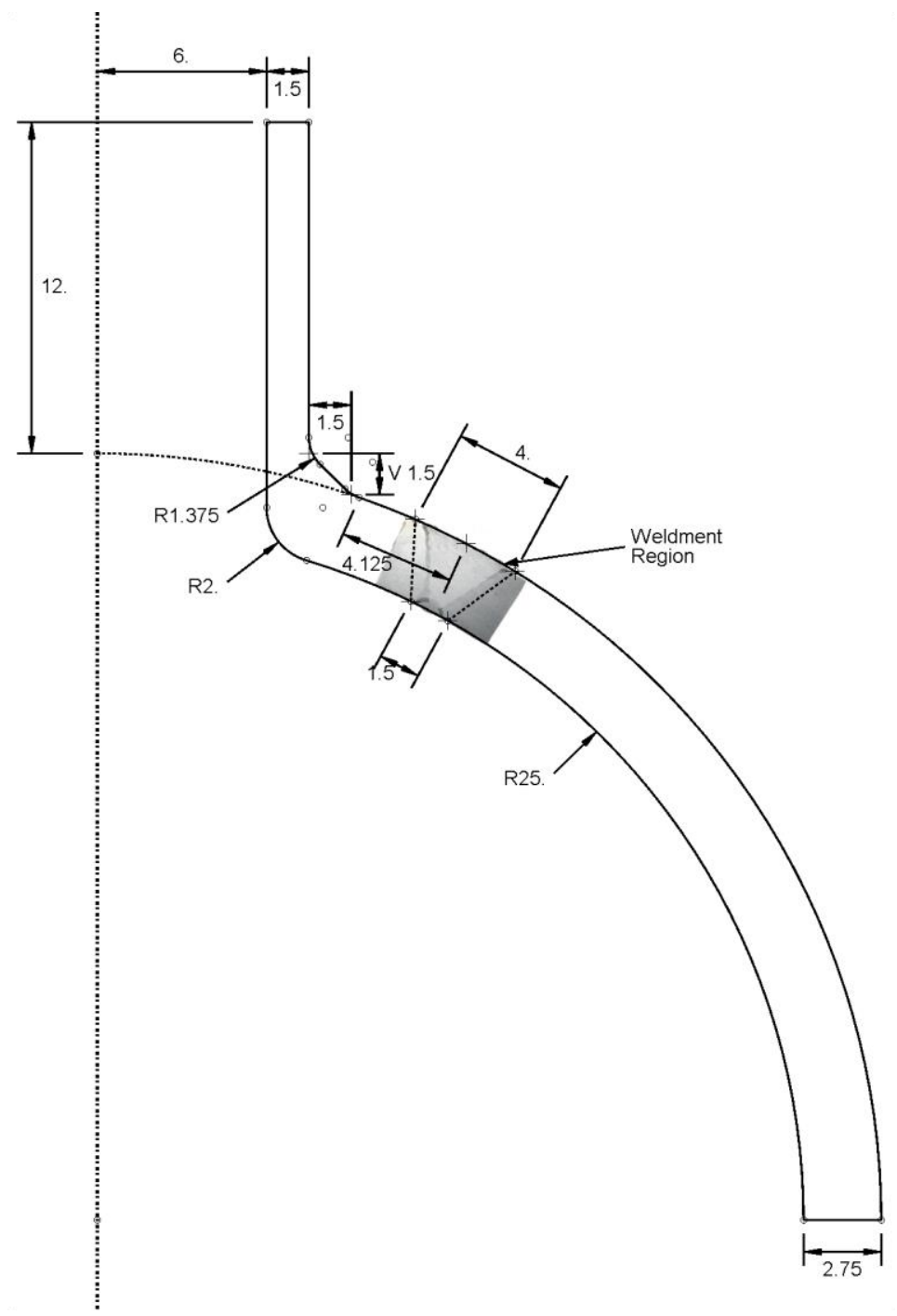

Fig. I-1. Representative Example Problem Configuration (dimensions in inches) 


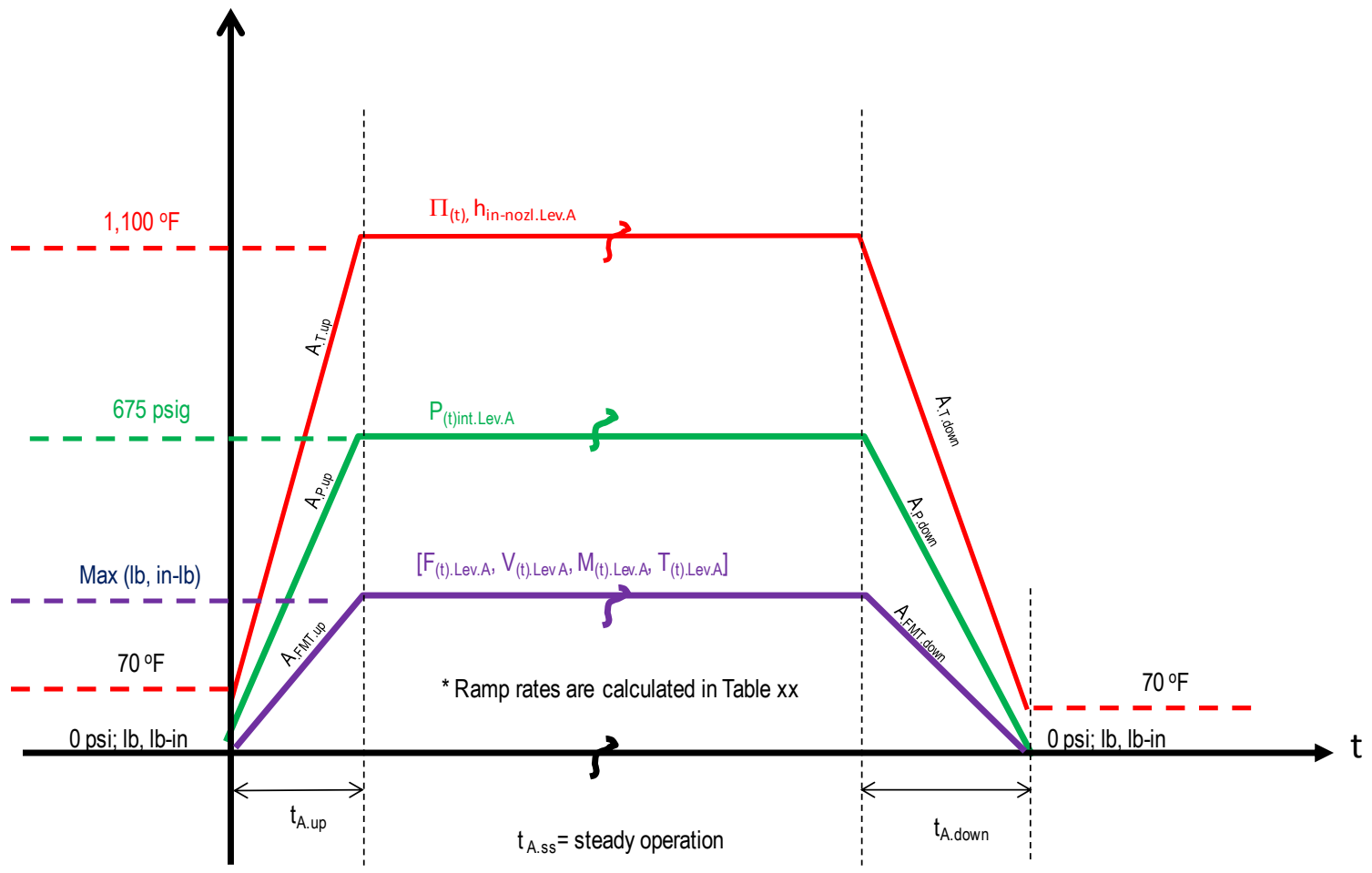

Fig. I-2. Service Level A Loads and Load Combinations; loadings versus time

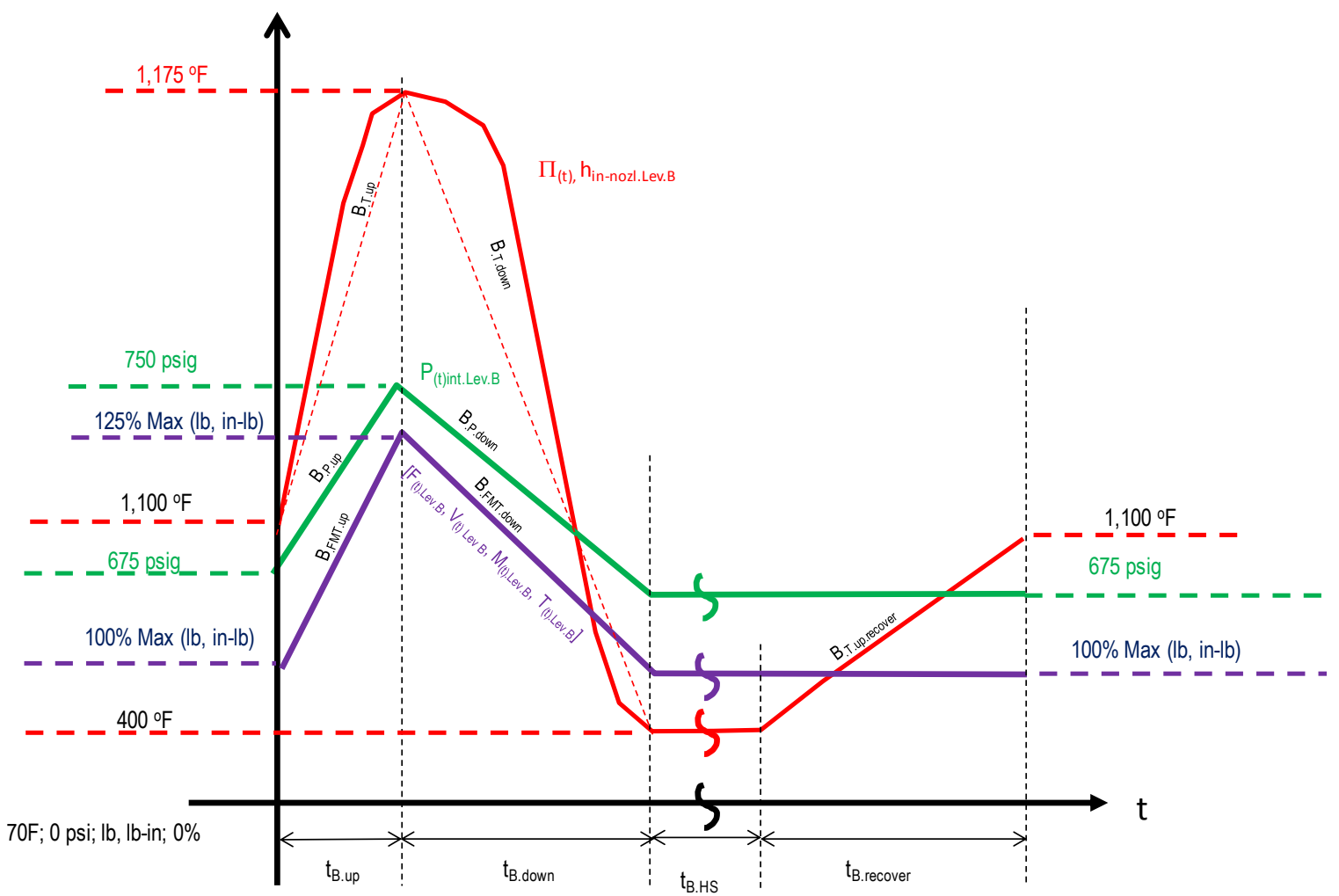

Fig. I-3. Service Level B Loads and Load Combinations; loadings versus time 


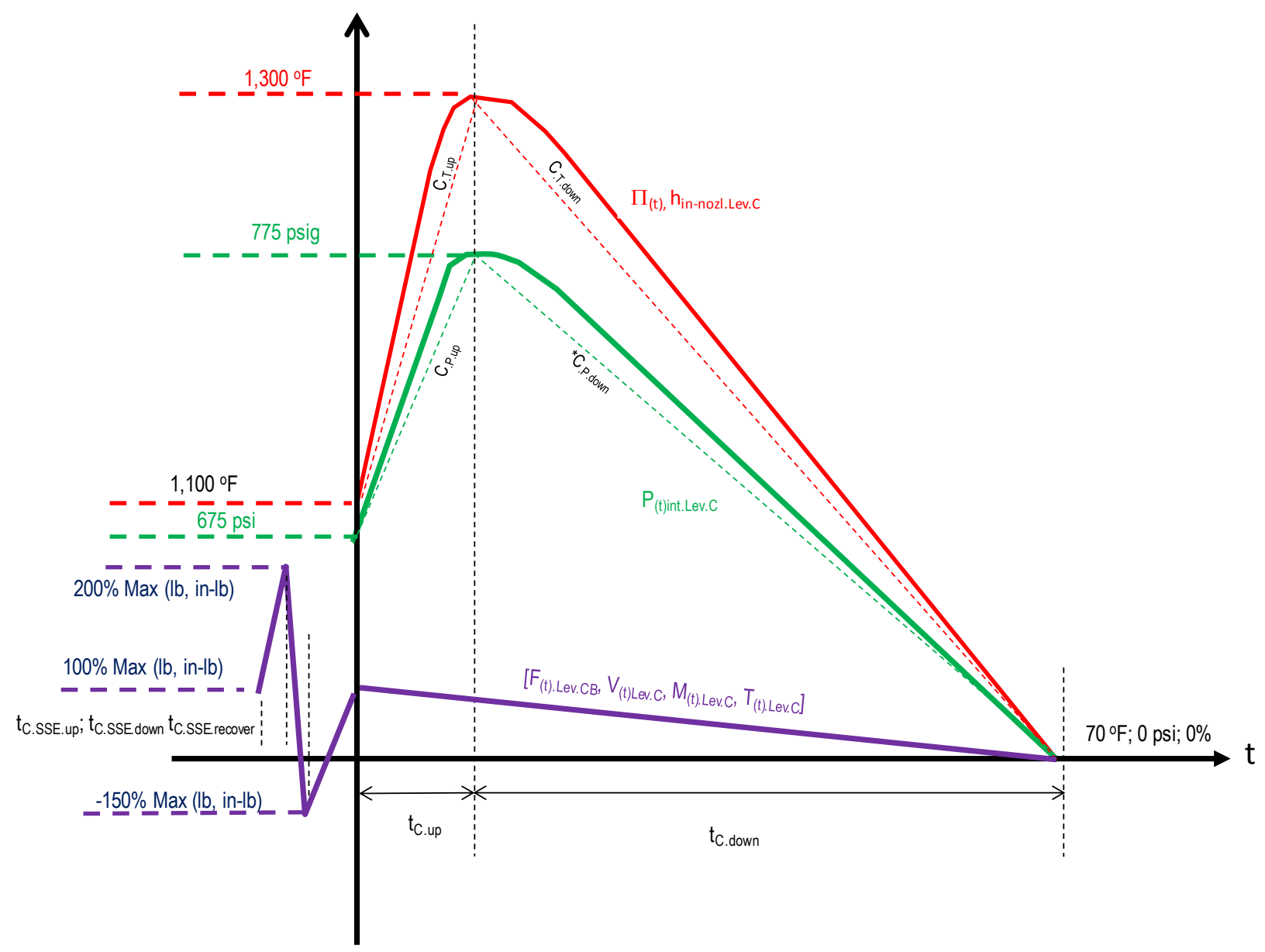

Fig. I-4. Service Level C Loads and Load Combinations; loadings versus time

From these specified loading conditions, the Code Case procedure requires that a composite cycle be defined which encompasses the critical features of the individually defined cycles. The reason for this is that the elastic perfectly plastic methodology used in the code case bounds the long term response independent of the number of applied cycles. In this respect it is similar to the current simplified rules in Subsection HB, Subpart B. The resultant composite cycle definition is shown in Fig. I-5 and Fig. I-6. 


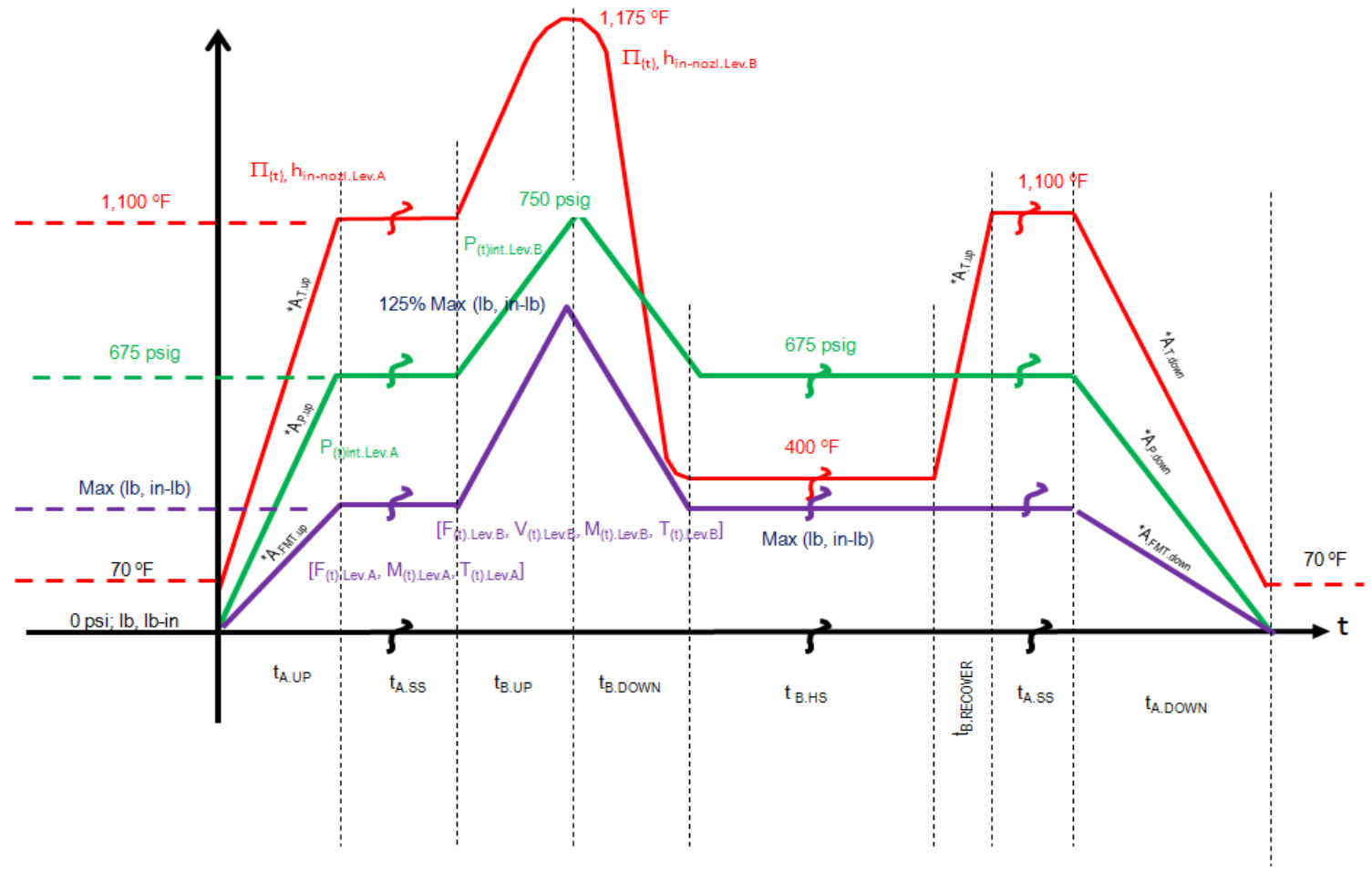

Fig. I-5. Level A and B Composite Cycle

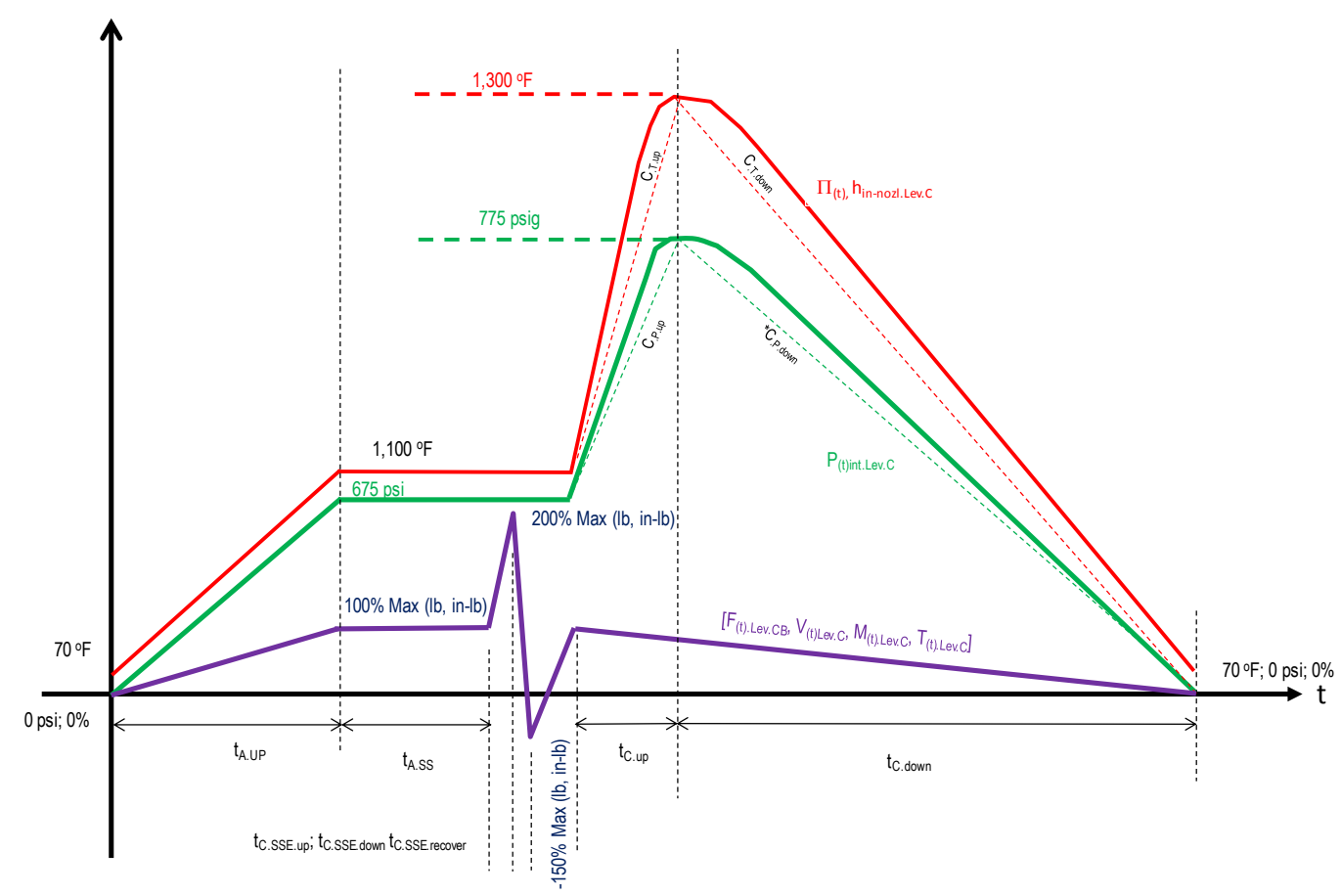

Fig. I-6. Level A and C Composite Cycle 
Note that two sets of conditions are defined; one set for Service Levels A and B and the other for Service Levels A and C. A feature of the proposed code case is that, unlike the current version of Subsection HB, Subpart B, the worst case combinations of Service Level A and B do not need to be combined directly with Service Level C. The rationale for this is that in accordance with the definition of Service Levels, shutdown for inspection and repair or replacement is required after a Level C event whereas the reactor system may resume planned operation after Level A and B events. The number of Level C events is limited as it is in the lower temperature Division 1, Subsection NB rules, but, unlike the NB rules, assessment of the high temperature displacement controlled failure modes, strain limits and creep-fatigue, is required to guard against creep damage not measurable externally which might contribute to restraints on the remaining life when subjected to subsequent Level A and B conditions.

\section{I-3.1.2 FEA model and material properties}

The FEA models are shown in Fig. I-7, without the weld zone, Fig. I-8, with the weld zone, from Hollinger and Pease (2014). The model consists of 8-node linear brick elements with full integration for stress analysis and 8-node linear heat transfer brick elements for that analysis. The same mesh is used for both the stress and heat transfer element types. The supporting mesh density study is shown in Appendix A of Hollinger and Pease (2014).

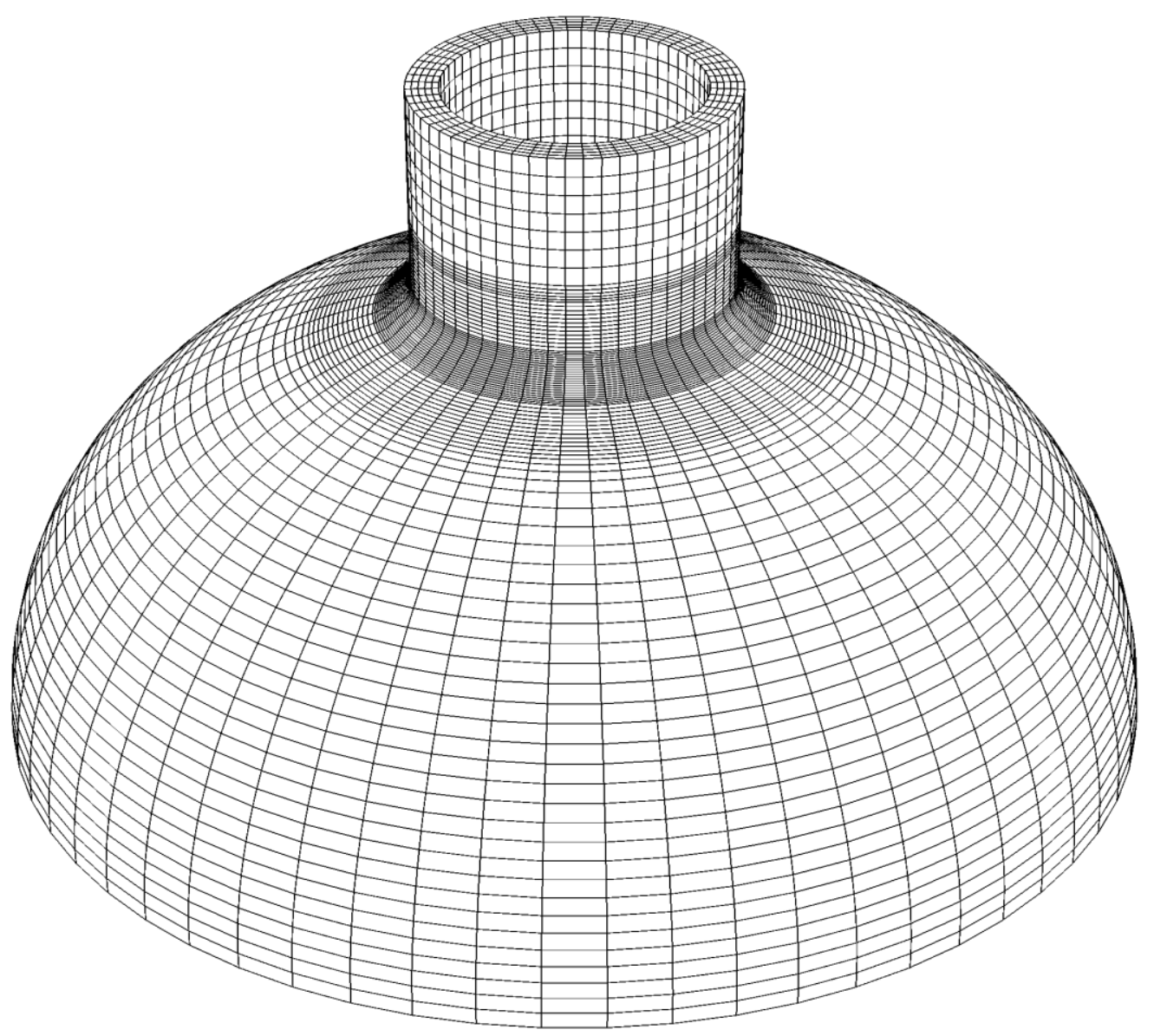

Fig. I-7. Nozzle to Sphere Example Problem FEA Mesh Without Weld Zone 


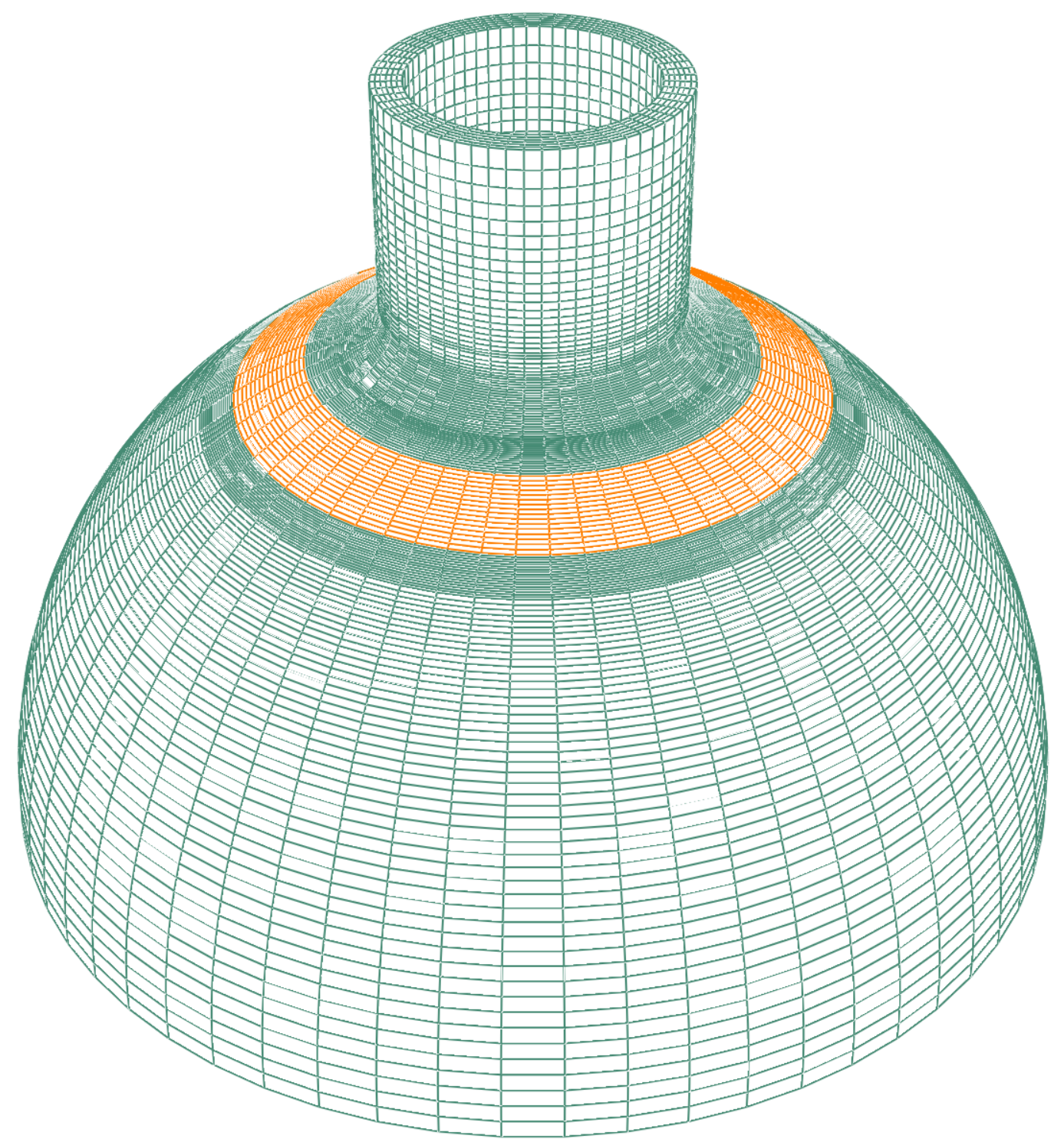

Fig. I-8. Nozzle to Sphere Example Problem FEA Mesh With Weld Zone

The representative example problem evaluation is based on $316 \mathrm{H}$ forged stainless steel; selected because it is currently included in Subsection HB, Subpart B and properties are readily available. The strain limits code case requires that a "pseudo yield stress" be defined with is based on the lower of the tabulated yield strength and the stress to achieve a selected target strain, $x$, based on the total duration of high temperature service. Although the code case references the isochronous stress-strain curves in Subsection HB, Subpart B to relate the strain to a given stress level and time, in practice the only practical way to implement this in a computer program is to have a creep equation. Determining the appropriate creep equation turned out to be more of a challenge than anticipated for two main reasons. First, identifying the equations used to define the isochronous curves in Subsection HB, Subpart B was not well documented as these curves were developed approximately 30 to 40 years ago. Second, $316 \mathrm{H}$ stainless steel has a dynamic strain aging effect in the temperature range of 1000 to $1100{ }^{\circ} \mathrm{F}$. This causes 
discontinuous changes in creep rate which distorts the pseudo yield strength as shown in Appendix B of Hollinger and Pease (2014).

\section{I-3.1.3 Methodology}

Two types of analyses are run for each set of composite cycles. A transient heat transfer analysis is performed to establish the temperature field in the vessel throughout the composite cycle. A representative FEA plot is shown below, Fig. I- 9, illustrating the temperature distribution at the end of the Service Level B peak up ramp to $1175^{\circ} \mathrm{F}$.

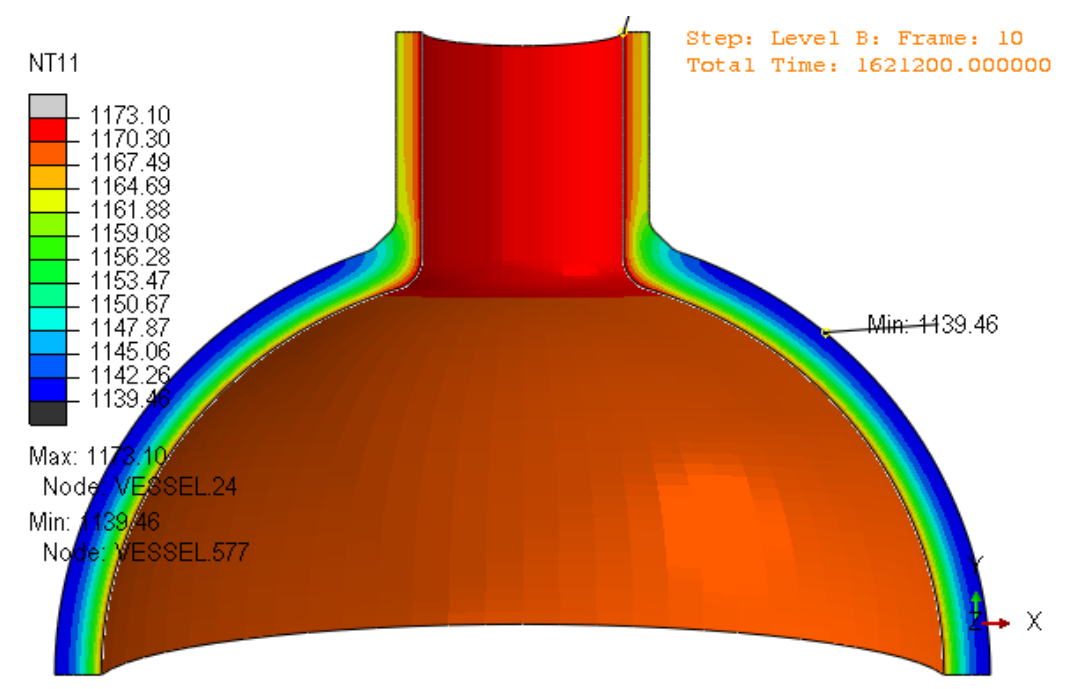

Fig. I- 9. Level B Peak Up $\left(1175{ }^{\circ}\right.$ F $)$

Stress analyses are performed with the time dependent temperature field results from the heat transfer analysis to obtain the stresses and strains in the vessel due to both mechanical loads and thermal. Note: Each cycle of a stress analysis using a "pseudo yield stress" has no direct correlation to the number of design or fatigue cycles and is hence defined as a "pseudo-cycle". Each composite cycle is broken up into discrete steps and when necessary limits to maximum time increments are applied to ensure that the analysis deals with all the changes within a cycle. The step names and durations are plotted with the time history amplitudes in Fig. I-10 and Fig. I-11 


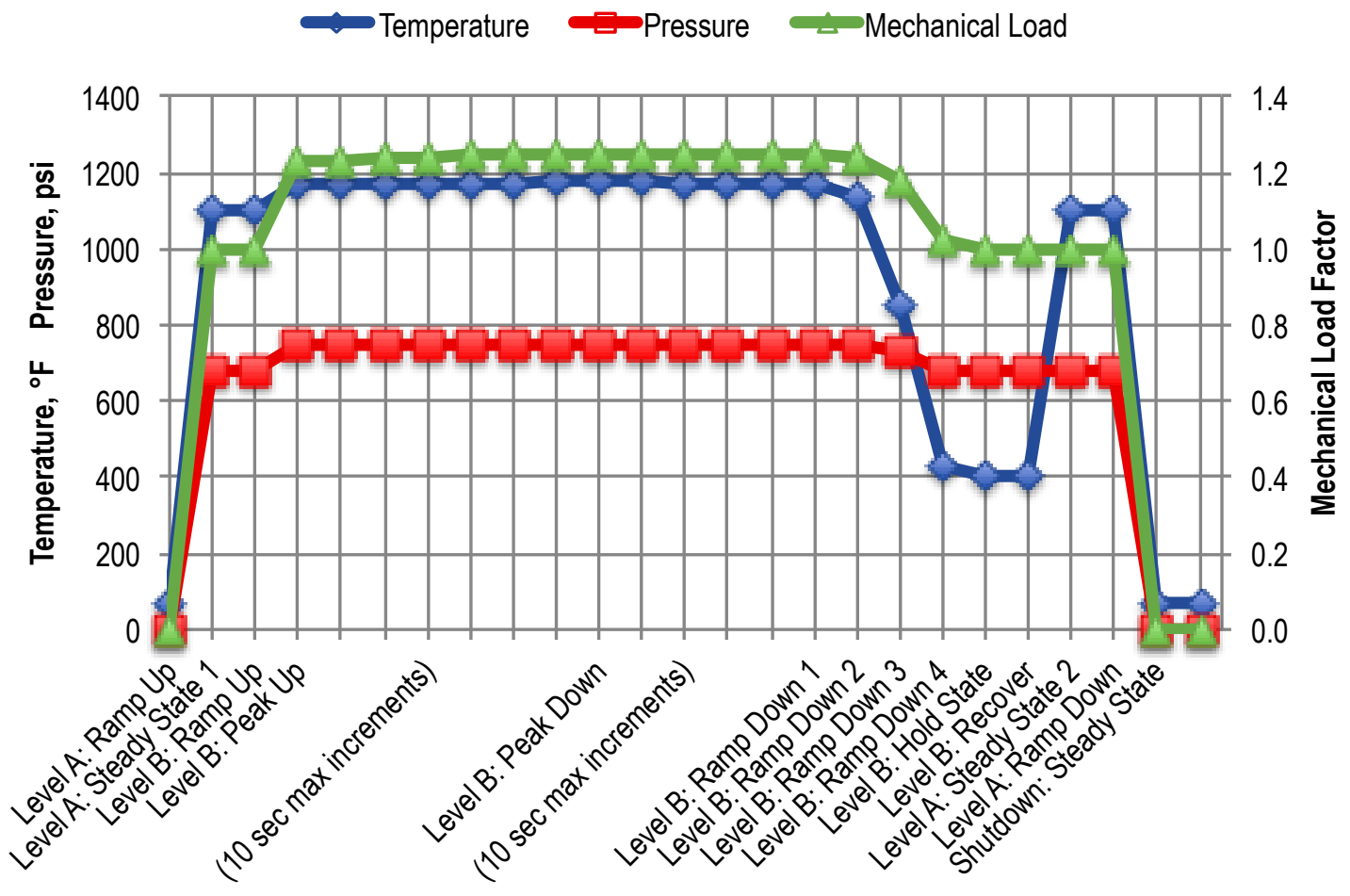

Fig. I-10. Level A\&B Composite Cycle Steps

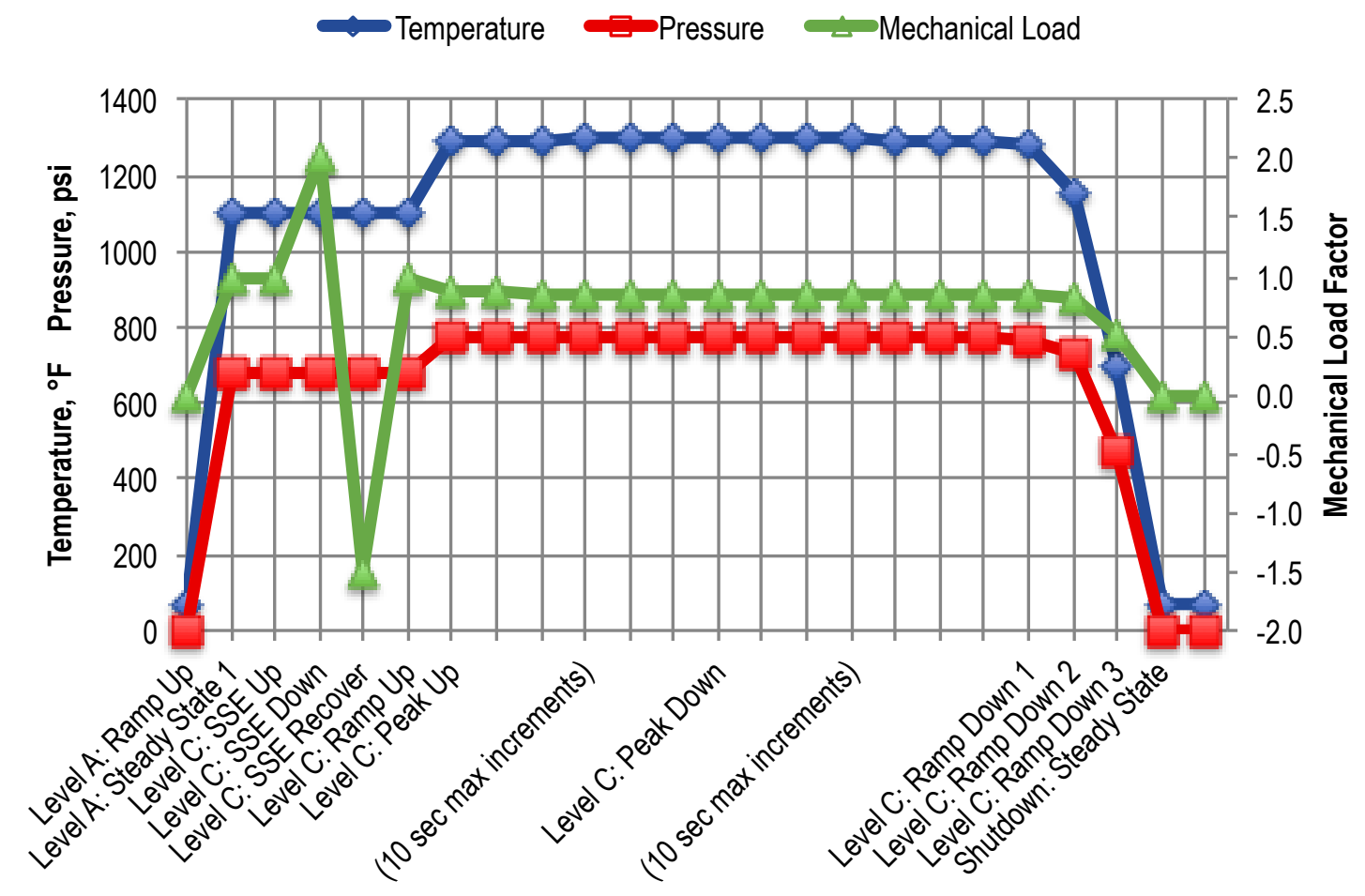

Fig. I-11. Level A \& C Composite Cycle Steps 
A pseudo-cyclic analysis is performed using the restart option to analyze multiple pseudo-cycles of a composite cycle. After the initial pseudo-cycle is analyzed, the analysis is restarted at the end of the previous pseudo-cycle to continue with another set of composite cycle loadings. This restart process is repeated until a sufficient number of pseudo-cycles have been reached. For the strain limits evaluation, stress analyses are performed where the "pseudo yield stress" is adjusted based on the selected target inelastic strains, $x$. Initially the target inelastic strain is selected as the averaged inelastic strain limit, $\varepsilon_{\text {avg }},(1 \%$ for base metal and $0.5 \%$ for weld metal).

With the target inelastic strain selected; a pseudo-cyclic analysis is performed where an intermediate check is performed at the end of each pseudo-cycle. If there exists a through thickness region where the total inelastic strain (target inelastic strain plus plastic strains) exceed the averaged inelastic strain limit, $x+\varepsilon_{p}>\varepsilon_{\text {avg }}$, then the target inelastic strain, $x$, is reduced. Some effort is made to maximize the region where total inelastic stains are less than the averaged inelastic strain limit before proceeding to the next pseudo-cycle. If further reduction of $x$ decreases this region then the target inelastic strain selection has been optimized. Once optimized, if there still exists a through thickness region where total inelastic strains exceed the averaged inelastic strain limit then it is concluded that the strain limits criteria cannot be met. Otherwise, additional pseudo-cycles are analyzed until ratcheting has ceased.

Ratcheting is evaluated at every location in the model by checking the change in plastic strain, $\Delta \varepsilon_{p}$, between the beginning and end of a single pseudo-cycle. Ratcheting has ceased when there is no change in plastic strain throughout the whole model between the beginning and end of a single pseudocycle.

Plastic strains are evaluated as:

$$
\varepsilon_{p}=\sqrt{\frac{2}{3}\left(\varepsilon_{x \cdot p}^{2}+\varepsilon_{y \cdot p}^{2}+\varepsilon_{z \cdot p}^{2}+2 \varepsilon_{x y . p}^{2}+2 \varepsilon_{y z . p}^{2}+2 \varepsilon_{z x \cdot p}^{2}\right)}
$$

Note: The ABAQUS output variable for this value is PEMAG.

The total inelastic strain is defined by adding the target inelastic strain, $x$, to the computed plastic strains, $\varepsilon_{p}$ :

$$
\varepsilon_{t o t}=x+\varepsilon_{p}
$$

The averaged strain limits are evaluated such that there exists at least one point for all throughthickness locations that meets the following criteria:

$$
\varepsilon_{t o t} \leq \varepsilon_{a v g}
$$

where $\varepsilon_{\text {avg }}=1 \%$ for base metal regions or $0.5 \%$ for weldment regions.

The local strain limits are evaluated such that all locations meet the following criteria:

$$
\varepsilon_{\text {tot }} \leq \varepsilon_{\text {local }}
$$


where $\varepsilon_{\text {local }}=5 \%$ for base metal regions or $2.5 \%$ for weldment regions.

Section 4.1.1 is repeated for different values of $x$ until criteria (10) and (11) have been met and ratcheting has ceased. If no value of $x$ meets these requirements then it is concluded that the strain limits criteria cannot be met.

\section{I-3.1.4 Results}

\section{Level A \& B composite cycle evaluation}

The FEA model without the weld zone strain limits evaluation for the Level A \& B Composite Cycle with a target base metal inelastic strain of $1 \%$ passes after two pseudo-cycles with a maximum total inelastic strain of $1.0006 \%$.

The FEA model with the weld zone strain limits evaluation for the Level A \& B Composite cycle with a target base metal inelastic strain of $1 \%$ and a target weldment inelastic strain of $0.5 \%$ passes after three pseudo-cycles with a maximum total inelastic strain of $1.0009 \%$ in the base metal at the nozzle to shell transition and $0.5 \%$ in the weldment, with no plastic strain in the weldment.

\section{Level A \& C composite cycle evaluation}

The base metal only strain limits evaluation for the Level A \& C Composite Cycle does not pass. With an optimized target base metal inelastic strain of $0.60 \%$, the region of total inelastic strains less than the average strain limit is maximized, but after two pseudo-cycles the total inelastic strain near the region of where shakedown would occur is well over the $1.0 \%$ limit.

Since the base metal only evaluation did not pass for the Level A \& C Composite Cycle it is concluded that the model with weldment evaluation will not pass either, and is thus not evaluated.

\section{I-3.2 Strain Limits Code Case to Subsection HB, Subpart B Comparison}

The overall goal of this phase is to assess the design margins in the EPP methodology. This is accomplished through the use of simplified example problem solutions which include comparison to current NH procedures. Simplified examples are used to avoid the complexities of Subsection HB, Subpart B simplified procedures, particularly when applied to representative geometries and loading.

\section{I-3.2.1 Geometry and material}

Case 1: Plain tube with $r / t=4.5$, Material: $316 \mathrm{H}$ stainless steel.

Case 2: Plain tube with $r / t=3.5$, Material: $316 \mathrm{H}$ stainless steel.

Case 3: Case 1 connected to Case 2, with a 3:1 external taper in wall thickness.

\section{I-3.2.2 Strain limits evaluation - level A/B service loadings}

The objective of this analysis is to calculate the maximum through wall temperature difference for tubes \#1 and \#2 and to calculate the operating time required to satisfy the $1 \%$ strain limits. The target life is 100,000 hours.

These calculations will be based on a design pressure of $1.3 \mathrm{ksi}$ in both tubes, and a temperature cycle defined by a uniform $1075{ }^{\circ} \mathrm{F}$ to the temperature distributions defined below. 
For tube \#1, consider steady state metal temperatures defined by $1200{ }^{\circ} \mathrm{F}$ in the bore, and $1075{ }^{\circ} \mathrm{F}$ on the OD. Using the formula for thermal stress in a tube with through-wall heat flux in Pitts and Sissom (1998), the radial steady state heat flux for these temperatures is $105 \mathrm{BTU} / \mathrm{in} / \mathrm{in} / \mathrm{hour}$. The steady state bore temperature in tube $\# 2$ for this heat flux and the $1075^{\circ} \mathrm{F}$ tube OD temperature is $1235^{\circ} \mathrm{F}$. A heat flux cycle from zero to $105 \mathrm{BTU} / \mathrm{in} / \mathrm{in} /$ hour is used in the following steady state thermal-mechanical calculations.

Thermal-mechanical properties at $1100{ }^{\circ} \mathrm{F}$ are given in Table I-2 Thermal and mechanical elastic stresses are obtained from thick-walled pipe formulas in Roark and Shaum.

Table I-2. Thermo-Mechanical Properties of TP316H at $1100{ }^{\circ} \mathrm{F}$

\begin{tabular}{c|c|c|c}
\hline $\begin{array}{c}\text { Spec. Heat } \\
\text { BTU/(lb· } \\
{ }^{\mathbf{0}} \text { F) }\end{array}$ & $\begin{array}{c}\text { Conductivity } \\
\text { BTU } /\left(\mathbf{h r} \cdot \text { in }^{\circ}{ }^{\circ} \mathbf{F}\right)\end{array}$ & $\begin{array}{c}\text { Exp. } \\
\text { Coefficient } \\
\text { in/in/ } /{ }^{\circ} \mathbf{F}\end{array}$ & $\begin{array}{c}\text { Young's } \\
\text { Modulus } \\
\text { ksi }\end{array}$ \\
\hline 143.14 & 1.1055 & $1.029 \mathrm{E}-05$ & 21928 \\
\hline
\end{tabular}

\section{I-3.2.3 Strain limits evaluation - Subsection HB, Subpart B simplified methods}

Table I-3 gives results of Tests B1 and B2; these are used to determine the strain limits and the times to exceed the $1 \%$ limit for through wall average strain.

Table I-3. Summary of HBB-T-1332 Test B1 and B2 Strain Limits Calculations

\begin{tabular}{|c|c|c|c|c|c|}
\hline$H B B-T-1330$ Strain & & \multicolumn{2}{|l|}{ Tube 1} & \multicolumn{2}{|l|}{ Tube 2} \\
\hline & & Test B1 & Test B2 & Test B1 & Test B2 \\
\hline & Load cases & $\begin{array}{c}1.3 \mathrm{ksi}, \\
1200^{\circ} \mathrm{F}-1075^{\circ} \mathrm{F}\end{array}$ & $\begin{array}{c}1.3 \mathrm{ksi}, \\
1200{ }^{\circ} \mathrm{F}-1075^{\circ} \mathrm{F}\end{array}$ & $\begin{array}{c}1.3 \mathrm{ksi}, \\
1235^{\circ} \mathrm{F}-1075^{\circ} \mathrm{F}\end{array}$ & $\begin{array}{c}1.3 \mathrm{ksi}, \\
1235^{\circ} \mathrm{F}-1075^{\circ} \mathrm{F}\end{array}$ \\
\hline ID Temperature $\mathrm{F}$ & & 1200 & 1200 & 1235 & 1235 \\
\hline OD Temperature F & & 1075 & 1075 & 1075 & 1075 \\
\hline Yield stress ksi & $\begin{array}{c}\text { Sy (mean hot wall } \\
\text { temp) }\end{array}$ & 16.55 & 16.55 & 16.45 & 16.45 \\
\hline Yield stress ksi & $\begin{array}{c}\text { SyL (lower cycle } \\
\text { temp) }\end{array}$ & 16.67 & 16.67 & 16.8 & 16.8 \\
\hline Pressure stress ratio & $X$ & 0.41 & 0.41 & 0.39 & 0.39 \\
\hline & Thermal stress & 19.94 & 19.94 & 25.4 & 25.4 \\
\hline Thermal stress ratio & $\mathrm{Y}$ & 1.19 & 1.19 & 1.53 & 1.5 \\
\hline Creep stress parameter & $\mathrm{Z}(\mathrm{s} 2)$ & 0.49 & 0.60 & 0.59 & 0.75 \\
\hline Creep stress parameter & Z (s1) & 0.51 & & 0.59 & \\
\hline & $\begin{array}{c}\text { sigmac with factor } \\
1.25\end{array}$ & 10.24 & 12.58 & 12.4 & 15.73 \\
\hline НВВ-Т-1800 В7 - В9 & Hours - $1 \%$ strain & $5.50 \mathrm{E}+05$ & $1.10 \mathrm{E}+05$ & $1.10 \mathrm{E}+05$ & $1.40 \mathrm{E}+04$ \\
\hline
\end{tabular}

Test B2 would be necessary if there was a significant peak stress component of thermal stress. The use of the HBB-T-1325 formula for piping thermal stress means that any peak thermal stress due to the relatively thick sections is effectively ignored. The difference between the thermal stress from this 
formula and the correct calculation for a thick tube (Roark and Young, 1989) is 7.5\%. The NH code states that test B1 can only be used if the peak stress is negligible. For comparison, results from both tests B1 and $\mathrm{B} 2$ are presented.

\section{I-3.2.4 Strain limits evaluation - EPP Code Case methodology}

Consider Case 3 from section 4.2.1 for this analysis. Loading: Pressure $=1.3 \mathrm{ksig}$, thermal cycles with maximum heat flux $=105 \mathrm{BTU} / \mathrm{in} / \mathrm{in} /$ hour.

Fig. I-12 shows the combined component cross-section with a 3:1 taper, and the steady state temperature distribution. The EPP cyclic analysis code case requires that a ratcheting analysis performed for service level loading should not generate ratcheting behavior, that is, repeated increases in deformation from cycle to cycle. The temperature-dependent "pseudo" yield stress used in the analysis is associated with a value of creep strain over the component life, or time of interest, which when added to the minimum or core plastic strain in the cyclic analysis, must not be greater than $1 \%$ for a base material. The elastic, perfectly plastic properties used in the analysis reflect the code's long term strain limits. The minimum or core value of plastic strain in a section in the EPP analysis reflects the inelastic strain required to achieve steady cyclic behavior. It is emphasized that this calculation demonstrates compliance with strain limits and is not intended to be a realistic calculation of ratcheting. The elastic, perfectly plastic properties used in the analysis reflect the NH code long term strain limits.

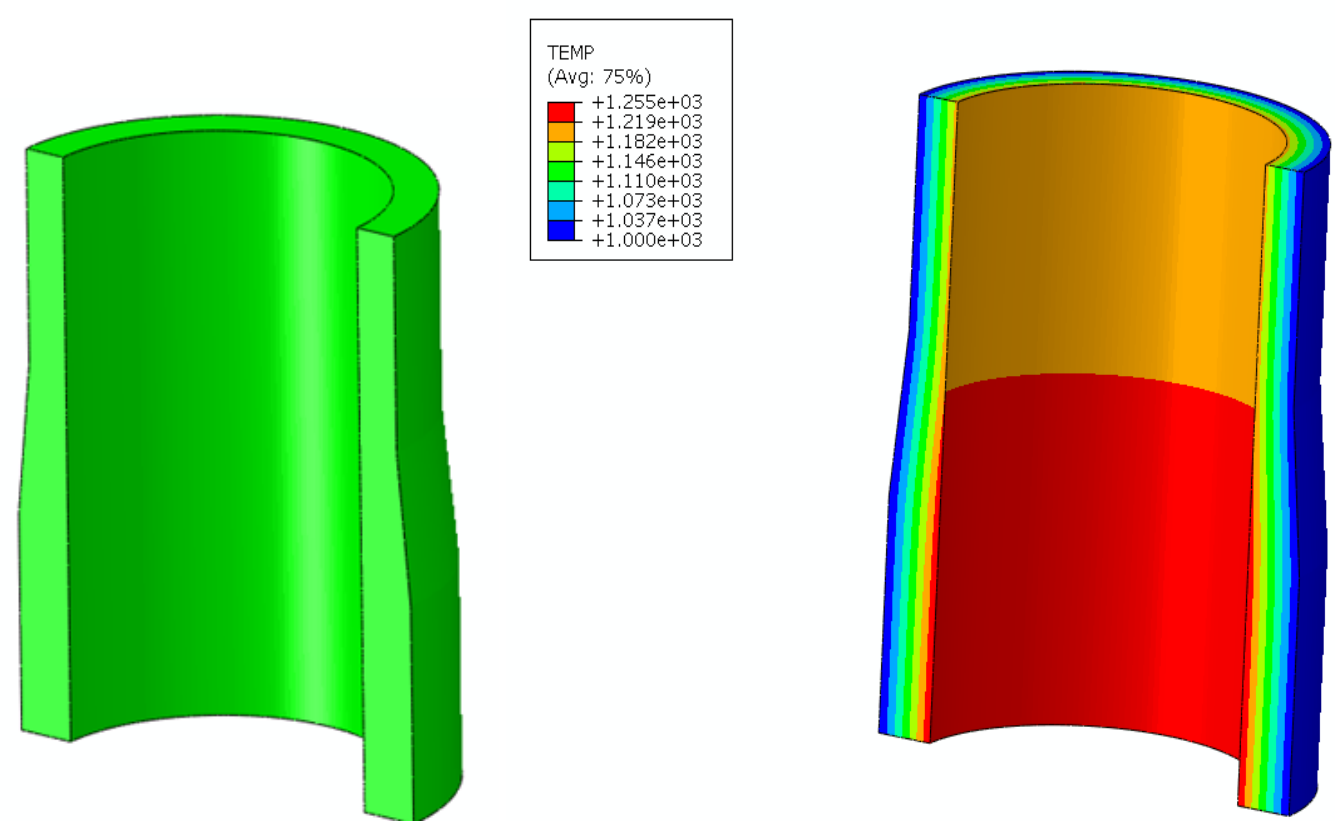

Fig. I-12. Case 3 Component Pipe Geometry and Steady State Temperature $\left({ }^{0} \mathbf{F}\right)$ Contours

Fig. I-13 shows a series of isochronous stress-temperature data giving $1 \%$ creep strain in the respective times. 


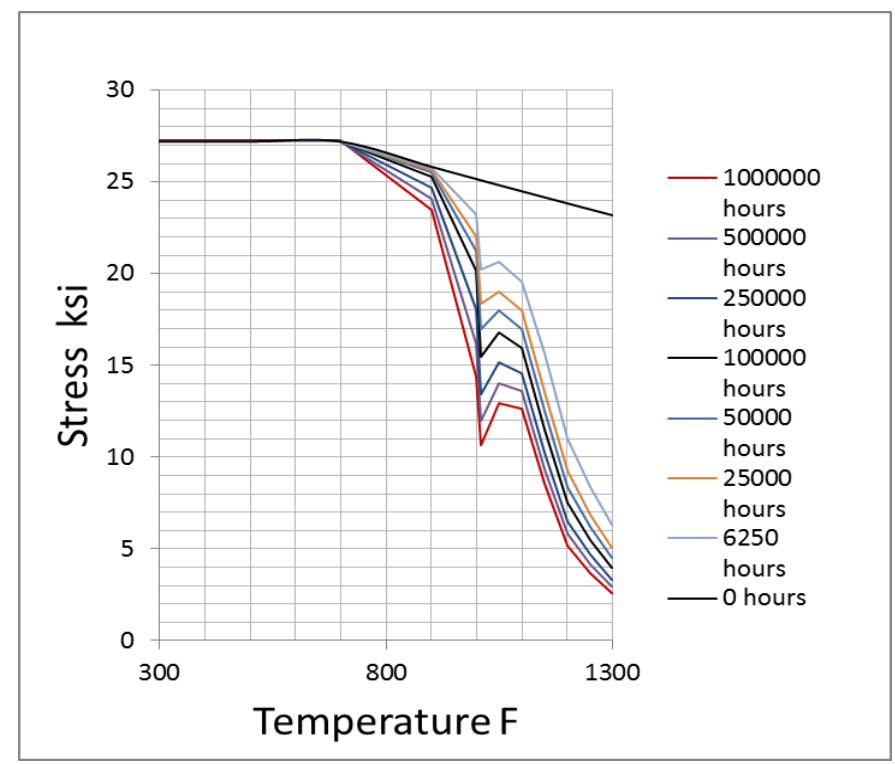

Fig. I-13. 316H SS Isochronous 1\% Inelastic Strain Data

Fig. I-14, Fig. I-15, Fig. I-16 and Fig. I-17 show results of ratcheting analyses. Ratcheting is indicated by a clear increase in strain from cycle to cycle. Strain limits require consideration of cyclic strain accumulation as well as the strain accumulated in order to achieve the steady cyclic state. Fig. I-14 and Fig. I-15 show no ratcheting with the basic design loads. Fig. I-16 and Fig. I-17 show ratcheting (that is, failure to demonstrate strain limits) for the tube intersection. Fig. I-18 shows that the plain tubes can satisfy the strain limits criterion on their own, with a factor of 1.2 on pressure and heat flux. Note that this factor changes the magnitude of stress and increases temperatures.

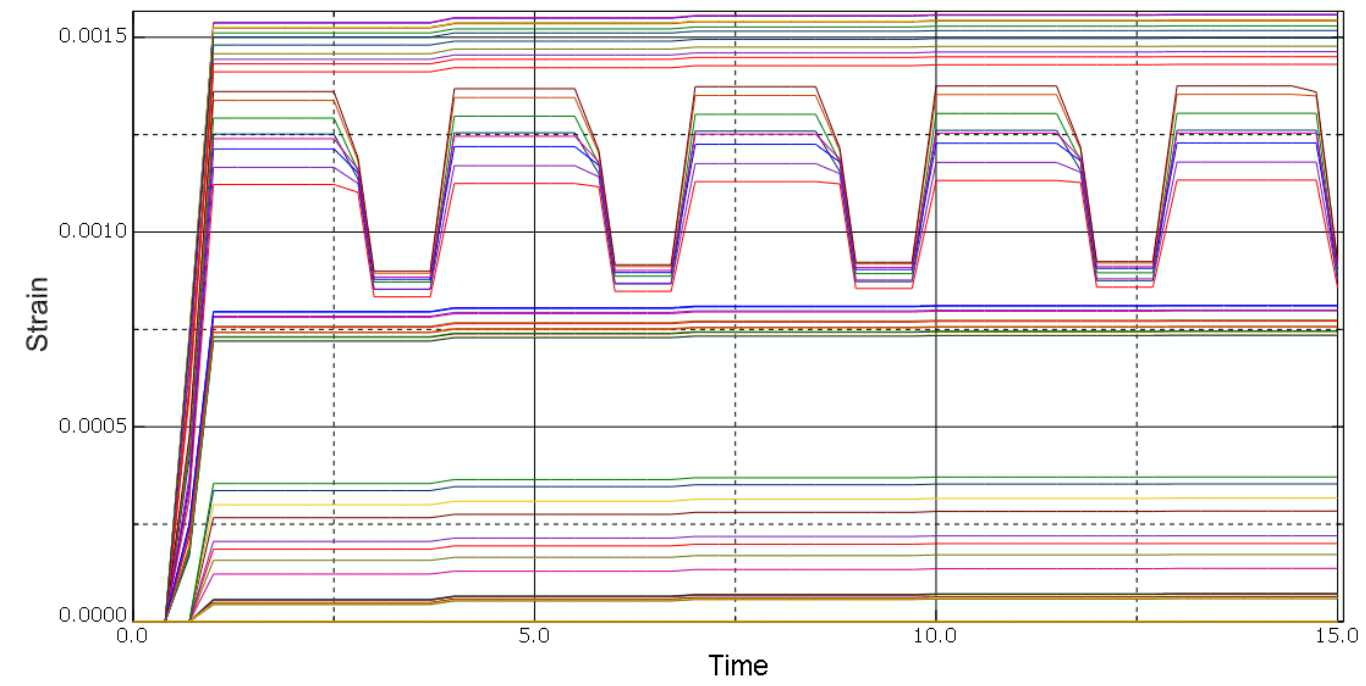

Fig. I-14. Non Ratcheting Strain Histories for Tube 2 with Design and Thermal Stress $x$ 1.0. Cyclic strain (x) $=0.095$. $y=$ Core strain $(y)=0.0001 .1 \%$ Limit Demonstrated. 

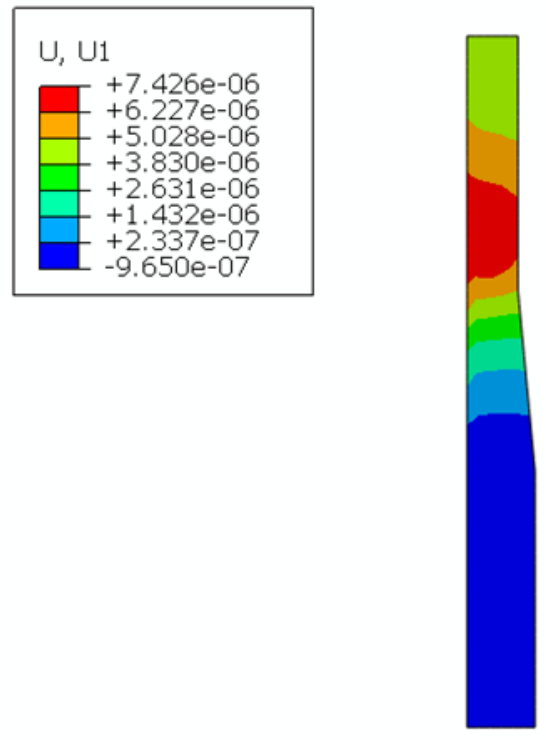

Fig. I-15. Contour Plot of Radial Deflection Differences Between Cycles. Design Pressure and Thermal Loading x 1. Apparent Differences not Numerically Significant. Ratcheting not Indicated.

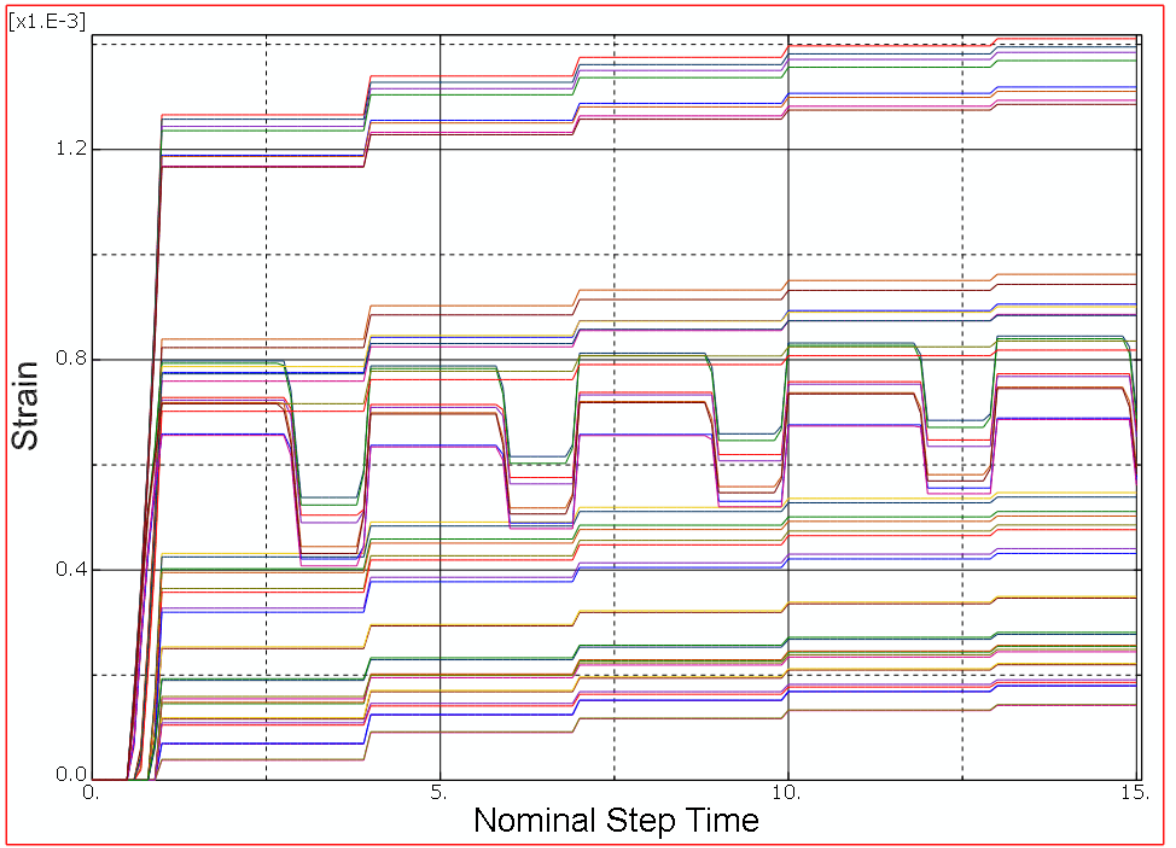

Fig. I-16. Ratcheting Strain Histories for Tube 2 Intersection with Design and Thermal Stress $x$ 1.2. Strain Limits Not Met. 

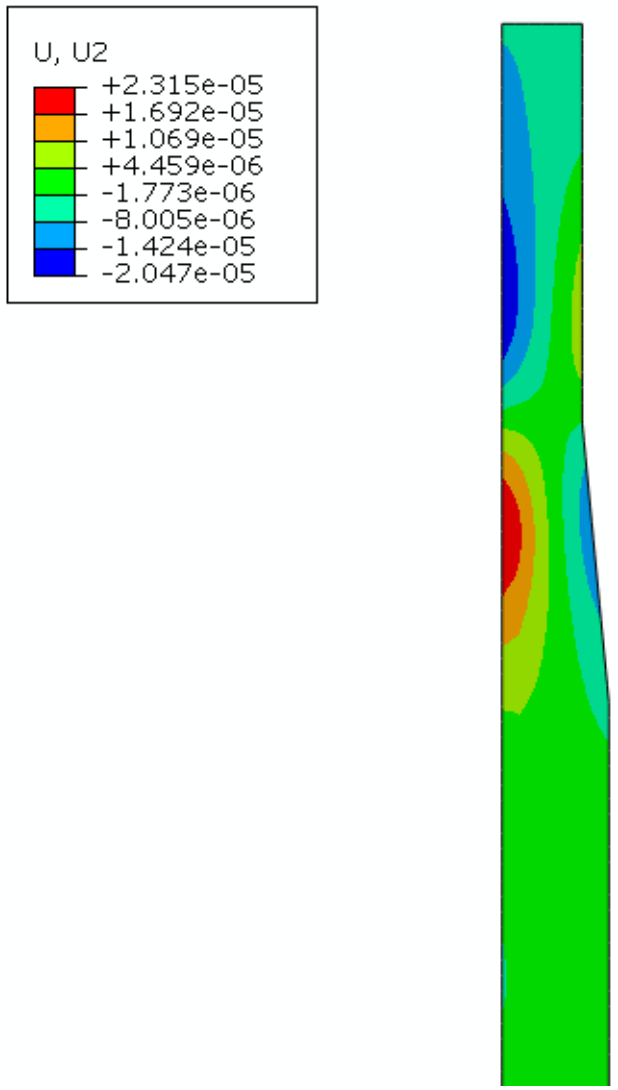

Fig. I-17. Contour Plot of Radial Deflection Differences Between Cycles. Design Pressure and Thermal Stress $x$ 1.2. Ratcheting in Intersection Indicates Strain Limits are Not Met. 

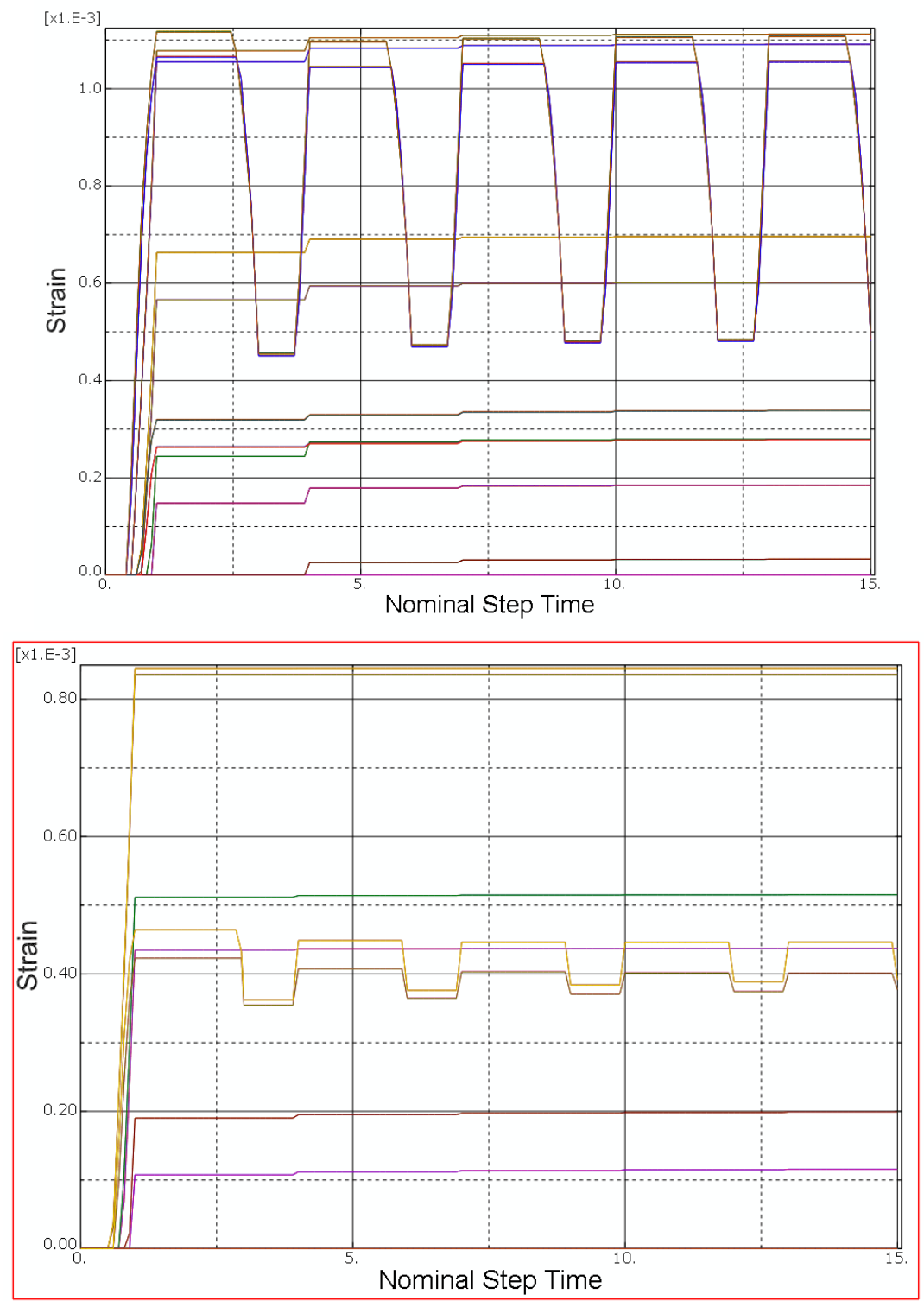

Fig. I-18. Non-Ratcheting Strain Histories for Tube 1 and Tube 2 Respectively. From the Component Model. Design and Thermal Stress $x$ 1.2. Cyclic Strain $(x)=0.096, y=$ Core Strain $(y)<0.0002 .1 \%$ Limit Demonstrated.

Table I-4 summarizes results of ratcheting calculations on plain tubes and tapered joined tubes expressed as margins on design conditions which generate $1 \%$ inelastic strain in $1 \times 10^{5}$ hours.

Table I-4. Results of Ratcheting Calculations of Plain Tubes and Tapered Joined Tube

\begin{tabular}{l|l|l|l|l}
\hline & $\begin{array}{l}\text { Case 1. Thinner } \\
\text { tube }\end{array}$ & $\begin{array}{l}\text { Case 2. Thicker } \\
\text { tube }\end{array}$ & $\begin{array}{l}\text { Case 3. Joined } \\
\text { tubes }\end{array}$ \\
\hline $\begin{array}{l}\text { Margins on design cycles } \\
\text { shown to satisfy strain limits }\end{array}$ & 1.2 & 1.2 & 1.0 & \\
\hline
\end{tabular}




\section{I-4 EXPERIMENTAL RESULTS COMPARISON}

\section{I-4.1 Two-Bar Test Evaluation}

The two-bar test concept was initiated a number of years ago to support high temperature design criteria for the Clinch River Breeder Reactor (CRBR). The goal of the two-bar test is to simulate the thermal ratcheting failure mode which is the basis of the strain limits design criteria in Subsection HB, Subpart B of Section III. This type of testing was originally performed on $2 \frac{1}{4} \mathrm{Cr}$ - 1 Mo steel (Swindeman et al., 1982) to support the verification of the recommended constitutive equations for liquid metal-cooled fast breeder reactor (LMFBR) applications. However, the current very high temperature two-bar test results on Alloy 617 will also, initially, be used to validate the newly proposed simplified methodology for assessment of strain limits at very high temperatures where the current $\mathrm{NH}$ methodology has been deemed inappropriate for Alloy 617.

In the two-bar test methodology, the two bars are alternately heated and cooled under sustained axial loading to generate ratcheting. A sustained hold time is introduced at the hot extreme of the cycle to capture the accelerated ratcheting and strain accumulation due to creep. Since the boundary conditions are a combination of strain control and load control it is necessary to use two coupled servo-controlled testing machines to achieve the key features of the two-bar representation of actual component behavior.

In this method, the two bars can be viewed as specimens taken out of a tubular component across the wall thickness representing the inner wall element and the outer wall element. During operation, a constant mean stress is applied on to the tube represented by the two bars. A schematic of the two-bar system is shown in Fig. I-19(a). There are two boundary conditions to tie these two bars together in order to represent the real component loading conditions. As shown in Fig. I-19(b), the two bars experience equal total displacements at all time, and the total load applied to the two bars is constant.

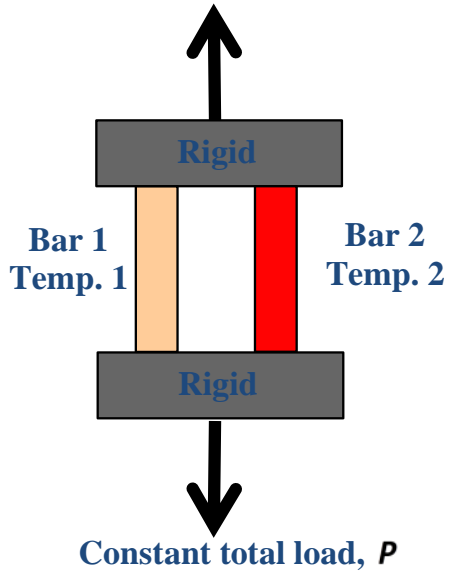

(a)

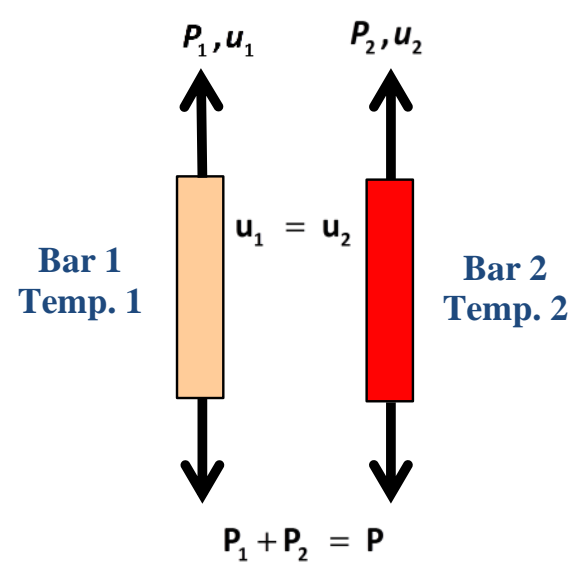

(b)

Fig. I-19. Schematic of Two-bar thermal ratcheting condition (a) and the equivalent boundary conditions of the two bars (b)

Conceptually, the two bars in parallel can be thought of as representing the inner and outer wall of a pressurized cylinder subjected to a cyclic through wall temperature gradient, e.g. a Bree type geometry.

The two-bar tests on Alloy 617 were performed by Wang et al. (2013). Fig. I-20 shows the temperature versus time histogram which was used in this study. Fig. I-21 shows the resulting strain 
history under several constant applied loads. A moderate tensile load for a 4 ksi average stress in the bars results in accelerated tensile elongation and the same load in compression generates an even higher compressive strain per cycle. These initial scoping tests were conducted at a relatively slow heating and cooling rate of $5{ }^{\circ} \mathrm{C} / \mathrm{min}\left(9^{\circ} \mathrm{F} / \mathrm{min}\right)$.

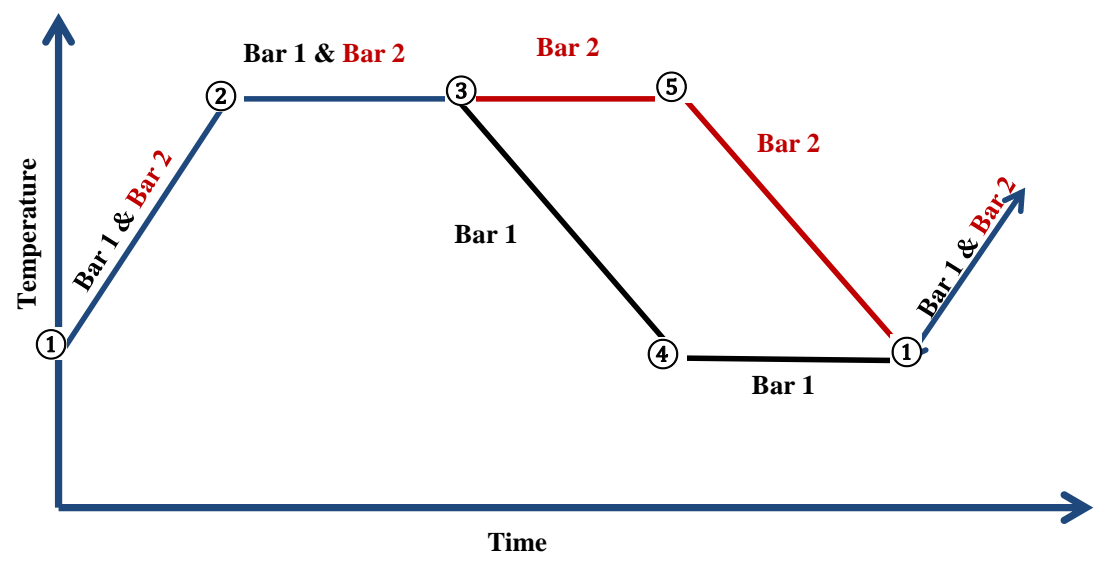

Fig. I-20. Temperature vs. time histogram for two-bar thermal ratcheting experiments on Alloy 617

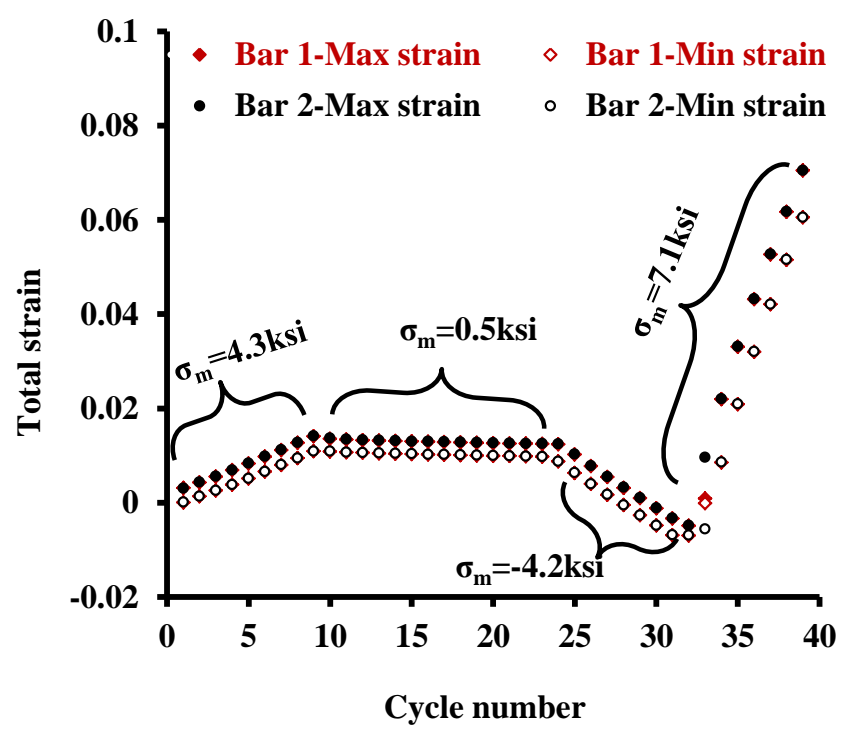

Fig. I-21. The maximum and the minimum total strains in the two bars at temperature range $800^{\circ} \mathrm{C}$ to $950^{\circ} \mathrm{C}$ (heating and cooling rates were $5{ }^{\circ} \mathrm{C} / \mathrm{min}$ ).

Further two-bar test results were conducted with a more severe temperature difference and higher heating and cooling rate, $30{ }^{\circ} \mathrm{C} / \mathrm{min}\left(54^{\circ} \mathrm{F} / \mathrm{min}\right)$. These test results showed an anomaly when compared to strain limit predictions based on the EPP strain limits code case. Fig. I-22 is a plot of two-bar test data compared with two methods for predicting allowable loading that would result in $1 \%$ or less creep strain. The vertical axis is the time delay from point 3 on Fig. I-20, the initiation of the thermal down ramp in bar 1 , and point 5 , the initiation of the thermal down ramp in bar 2 . The tested temperature range was $650{ }^{\circ} \mathrm{C}$ to $950{ }^{\circ} \mathrm{C}\left(1202{ }^{\circ} \mathrm{F}\right.$ to $\left.1742{ }^{\circ} \mathrm{F}\right)$. The total temperature change and ramp rates are the same for the tests 
shown, $300{ }^{\circ} \mathrm{C}\left(540{ }^{\circ} \mathrm{F}\right)$ and $30{ }^{\circ} \mathrm{C} / \mathrm{min}\left(54{ }^{\circ} \mathrm{F} / \mathrm{min}\right)$, respectively. The variables are the nominal applied load and the delay time, or thermal stress, in the bars. A shorter delay time results in a lower thermal stress and the maximum delay time, 10min, maximizes the thermal stress. Additional test information is tabulated in Table I-5.

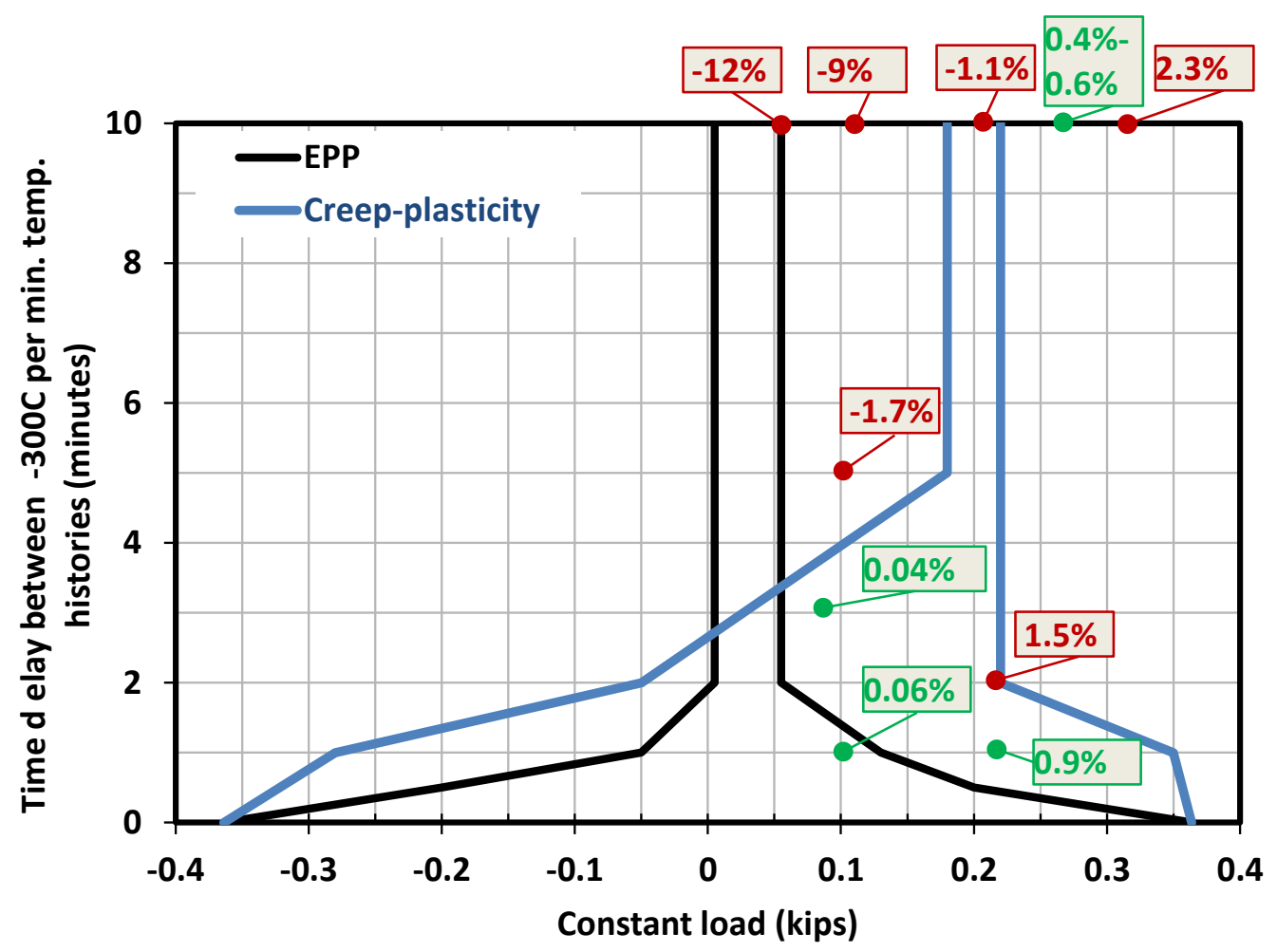

Fig. I-22. Two bar test data with $1 \%$ design envelope predictions from the strain limits code case and inelastic analysis 
Table I-5. Two bar test data parameters

\begin{tabular}{c|c|c}
\hline Nominal Combined load, lbs & $\begin{array}{c}\text { Actual Applied } \\
\text { Combined Load, } l b s\end{array}$ & Delay time \\
\hline 100 & $85-125$ & $10 \mathrm{~min}$ \\
\hline 100 & $90-130$ & $5 \mathrm{~min}$ \\
\hline 100 & $90-130$ & $3 \mathrm{~min}$ \\
\hline 200 & $195-240$ & $1 \mathrm{~min}$ \\
\hline 200 & $195-240$ & $2 \mathrm{~min}$ \\
\hline 100 & $90-130$ & $5 \mathrm{~min}$ \\
\hline 50 & $40-80$ & $10 \mathrm{~min}$ \\
\hline 200 & $195-245$ & $10 \mathrm{~min}$ \\
\hline 250 & $255-295$ & $10 \mathrm{~min}$ \\
\hline 300 & $305-345$ & $10 \mathrm{~min}$ \\
\hline
\end{tabular}

The allowable load combinations resulting in less than or equal to $1 \%$ strain shown on Fig. I-22 are based on the EPP methodology in the strain limits code case on the left side and inelastic analysis on the right. In both cases, the limits have a stovepipe appearance with a narrow range of sustained loading effectively balancing an enhanced deformation proportional to the applied cyclic thermal stress. However, in the case of the EPP prediction, the axis of the stove pipe occurs at a mean load that is too low compared to the experimental results. At a 10 min time delay, the projected strain accumulation is about $12 \%$ in compression with a tensile load of 50lb. On the other hand, the inelastic analysis stove pipe roughly centered at 200lb nominal load is in fair, but much better, agreement with the measured compressive strain of $1.1 \%$ at a 10 min delay.

Although the $10 \mathrm{~min}$ delay results with a $300{ }^{\circ} \mathrm{C}\left(540{ }^{\circ} \mathrm{F}\right)$ temperature difference would represent an unrealistically extreme through wall thermal gradient for an actual component, it illustrates the potentially unconservative results from the EPP model when applied to skeletal structures for some loading conditions, e.g. relatively low nominal load, and overly conservative results for other conditions, e.g. higher nominal load, for this test configuration.

In response to this observation it was postulated that there are limitations on the ability of a two bar representation of more prototypic real structures which have continuously varying geometry and load as opposed to the discontinuous step changes associated with the two bar configuration. This conclusion was assessed by a simplified inelastic analysis of a Bree type model, using the same inelastic analysis model that showed agreement with the two-bar experimental results, to compare with predictions from the EPP strain limits code case. 


\section{I-5 ANALYTICAL COMPARISONS}

\section{I-5.1 Background}

As discussed above, two-bar Alloy 617 high temperature ratcheting tests were performed to test predictions of proposed simplified elastic, perfectly plastic (EPP) analysis methods. Differences between tests and the simplified method predictions led to the use of detailed inelastic analyses which were more successful in explaining the two-bar cyclic ratcheting behavior. The objective of this task is to determine if there are differences between the predictions from these two methods for a typical plant pressure part, such as a pressurized pipe subject to cyclic through-wall thermal loading. A case was analyzed with stresses and cycles for the pipe problem similar in magnitude to those for the two-bar tests. Included is background to the use of a simplified elastic, perfectly plastic analysis method for the assessment of strain limits.

\section{I-5.2 Bounding Theories}

The basis for simplified methods is generally expressed in terms of energy bounding theorems. There is a "hierarchy" of bounding concepts which reflects the trade-off between problem complexity and bounding accuracy.

- Problems with mechanical load cycles may be bounded by external work bounds.

- Problems with thermal and mechanical load cycles may be bounded by internal energy dissipation. This is generally more conservative than for purely mechanical problems, since high internal energy dissipation may be associated with zero net deflection.

In both cases, the opportunity for a simplified analysis arises from the use of the "rapid cycle" concept. Rapid cycles have no creep relaxation during the cycle, but generally have the most advantageous residual stress system which ensures that deformation rates over the cycle are as low as possible.

It is clear that "average" quantities in these arguments, such as external work, are important. This may point to the reason why the application to the two-bar problem is more difficult than for continuum problems.

In terms of deformation and strain accumulation over time, rapid cycles are more conservative than slow cycles. Therefore, if strain limits can be demonstrated for rapid cycles, slower cycles with relaxation will also satisfy the strain limits.

- The use of elastic, perfectly plastic (EPP) analysis using an artificial or pseudo yield stress is based on a third assumption, that reducing the yield stress in an analysis is conservative, that is, does not reduce the deformation rates.

Thus, if the temperature-dependent "pseudo" yield stress in a rapid cyclic analysis is reduced to the point where ratcheting is imminent, then the deformation will not be less than with the realistic yield property. If this pseudo yield stress is based on the stress to give $1 \%$ inelastic strain, then it is possible for stress and temperature cycles to exist everywhere in the structure which do not produce more than the $1 \%$ inelastic strain limit in the specified time. This argument presents a possibility and is not a proof. It is consistent with the ASME Section III, NH, Test B1 iso-strain contours within the non-ratcheting region of the Bree diagram used in this test. There is reason to suppose that it is more applicable in a continuum than in a skeletal structure. 
Proofs of the work bound theorems rely on a convexity property of the creep constitutive law which is unlikely to be a restriction or inapplicable for Alloy 617. These proofs are more straightforward for purely time-dependent materials than for materials with creep behavior within a plastic yield surface. A significant effort has been made to generalize the purely creep, cyclic bounding arguments to deal with a yield surface in a creep-yielding material model. The key property for a purely time-dependent material is that cyclic loading sets up cyclic stress histories for which creep energy dissipation is a minimum compared with non-cyclic stress histories. For a rapid cycle with purely time-dependent behavior, the stress history may be represented by the sum of elastic stress, plus a residual stress. The rapid cycle residual stress is the unique value which provides a kinematically admissible cyclic creep strain increment over the cycle. The conservative (bounding) nature of the rapid cycle only depends on a convexity property of the inelastic strain rate constitutive law.

\section{I-5.3 Material Properties and Pseudo Yield Stress}

Fig. I-23 shows stress - inelastic strain rate plots at $1200{ }^{\circ} \mathrm{F}, 1500{ }^{\circ} \mathrm{F}$ and $1800{ }^{\circ} \mathrm{F}$. These plots were constructed by assuming a linear relationship for the correlation of time to $1 \%$ total strain of Eno et al. (2008) for Alloy 617. It also shows a hyperbolic sine ("ksn") model fit to these relations, with the Abaqus constants for this model tabulated in the figure. The hyperbolic sine model for the creep strain rate is given as

$$
\dot{\varepsilon}_{c}=A\left[\exp \left(\frac{-Q}{R T}\right)\right][\sinh (B \sigma)]^{n}
$$

Fig. I-24 shows pseudo yield stress for $1 \%$ inelastic strain accumulation in 200 hours based on the hyperbolic sine model. The pseudo yield stress needs to be calculated for $1 \%$ inelastic strain in 200 hours. This is done on the basis that inelastic strain is proportional to time for constant stress and temperature loading. The only correction required is for elastic strain, since Alloy 617 does not have a defined plastic strain at high temperatures. The pseudo yield stress shown in Fig. I-24 is used in analyses for Fig. I-22 and Fig. I-29.

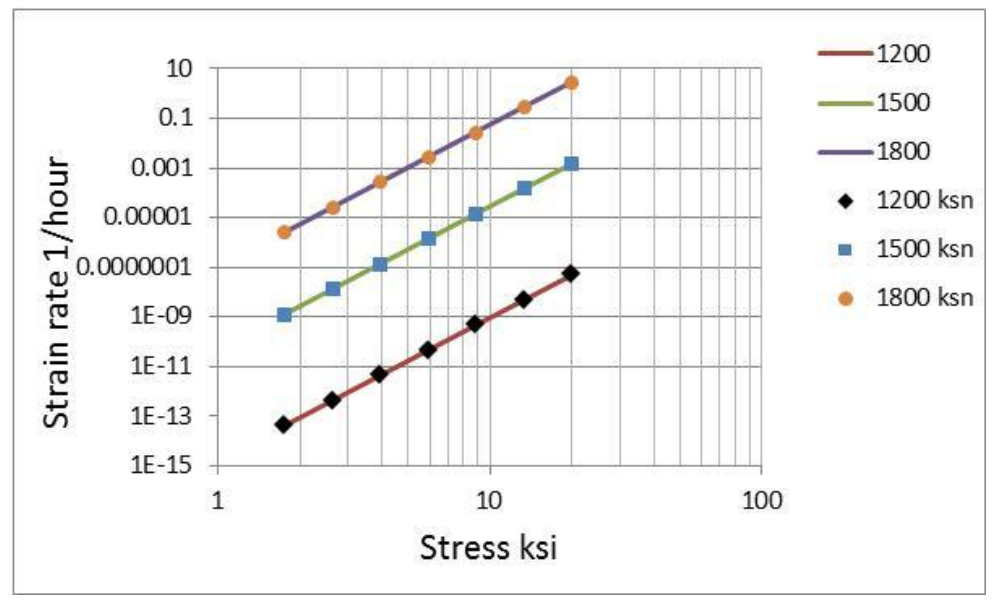

\begin{tabular}{|l|c|}
\hline $\begin{array}{l}\text { Power Law } \\
\text { Multiplier, } A\end{array}$ & $3.0158 \mathrm{E}+25$ \\
\hline $\begin{array}{l}\text { Hyperb. Law } \\
\text { Multiplier, } B\end{array}$ & 0.01201 \\
\hline Eqn. Order, $n$ & 5.7180 \\
\hline $\begin{array}{l}\text { Activation } \\
\text { Energy, } Q\end{array}$ & 516622 \\
\hline Gas Constant, $R$ & 4.619 \\
\hline
\end{tabular}

Fig. I-23. Alloy 617 Inelastic Stress - Strain Rates and Material Model Parameters (Units: ${ }^{0}$ F, hours, ksi, BTU, lbs). 


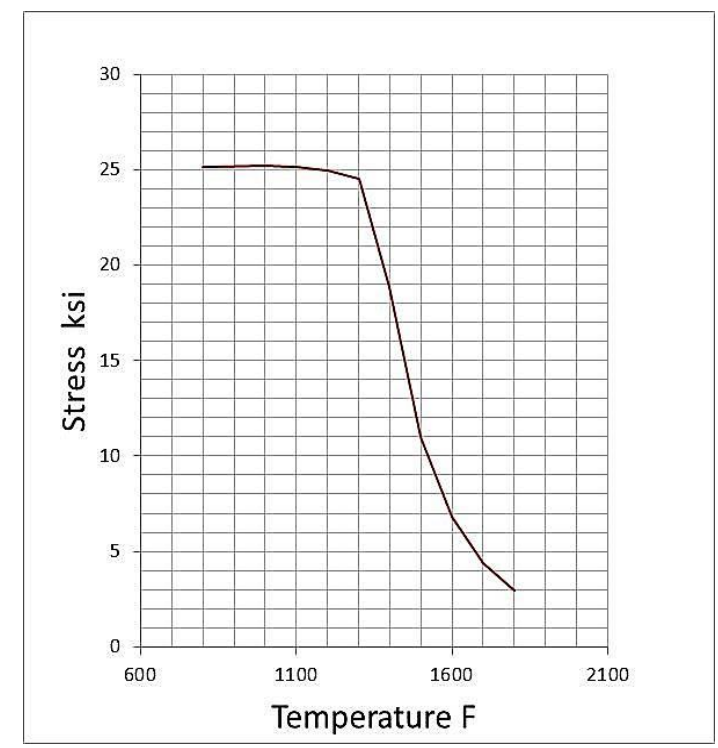

Fig. I-24. Alloy 617 Stress versus Temperature for Yield and 1\% Inelastic Strain in 200 Hours

\section{I-5.4 Inelastic Strain Limits and Ratcheting Analyses}

Consider the problem summarized in Table I-6. A pipe is required to survive thermal cycles for 200 hours without violating a $1 \%$ inelastic strain limit. In this case, the strain limit refers to the hoop strain in the center of the pipe wall. This reflects the requirement for a $1 \%$ inelastic strain limit on average or membrane strain.

The first objective is to use the EPP analysis method to determine acceptable pressures (negative and positive) for which the $1 \%$ inelastic strain limit is satisfied. The second objective is to verify the design calculations with a detailed cyclic inelastic analysis.

The maximum through wall temperature distribution is illustrated in Fig. I-25. The criterion for acceptable stain accumulation based on the EPP cyclic analysis requires consideration of cyclic strain accumulation and the strain required to achieve the steady cyclic state. The inelastic strain requirement is that cyclic strain accumulation $x$ (which defines the pseudo yield stress) plus inelastic strain required for re-distribution $y$ (defined by the minimum EPP non-ratcheting analysis plastic strain in the section), should be less than $1 \%$.

Table I-6. Design Data

\begin{tabular}{c|c|c|c|c|c}
\hline Material & Pipe OD " & Pipe ID " & $\begin{array}{c}\text { OD } \\
\text { Temperature } \\
\left({ }^{0} \mathrm{~F}\right)\end{array}$ & $\begin{array}{c}\text { ID } \\
\text { Temperature } \\
\text { Max. Range } \\
\left({ }^{0} \mathrm{~F}\right)\end{array}$ & Hours \\
\hline Alloy 617 & 14 & 12 & 1742 & $1202-1742$ & 200 \\
\hline
\end{tabular}




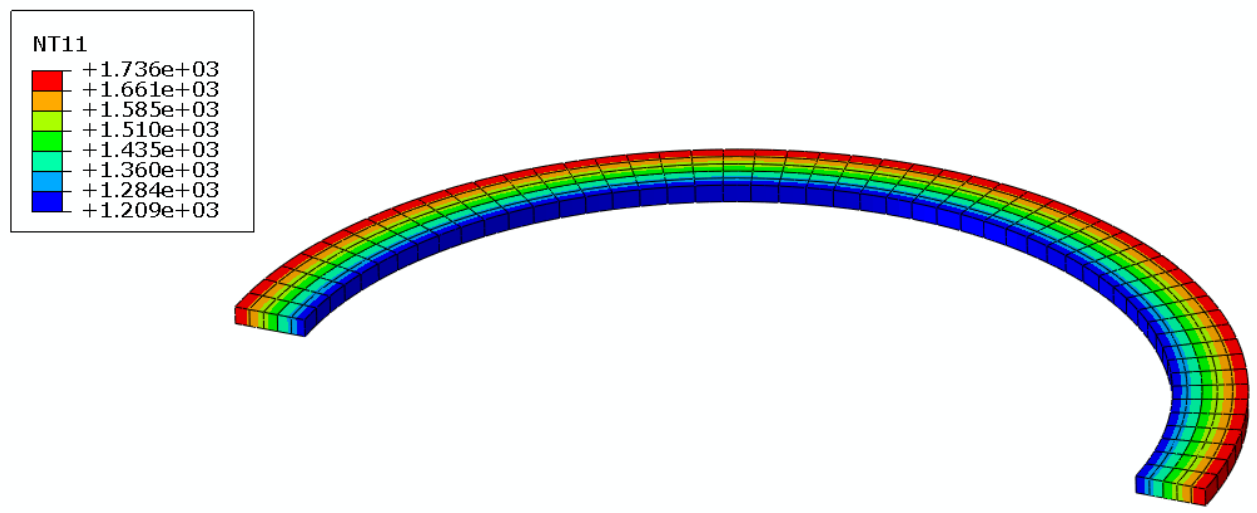

Fig. I-25. Through Wall Temperature Contours and Second Order Mesh

\section{I-5.4.1 EPP ratcheting analysis}

Fig. I-26 shows examples of EPP cyclic analyses, exhibiting non-ratcheting and ratcheting. Ratcheting is indicated by a clear increase in strain from cycle to cycle. Evidence of overall nonratcheting is required for an acceptable design. Strain limits require consideration of cyclic strain accumulation $(x)$ as well as the strain accumulated in order to achieve the steady cyclic state (y). Fig. I-27 shows EPP examples with zero and non-zero plastic strain values y.

Table I-7 is a summary of EPP calculations and the cyclic and re-distribution strains, $x$ and $y$, respectively. In the one case where the y strain is non-zero, the effect on hours to guarantee the $1 \%$ limit is not significant.

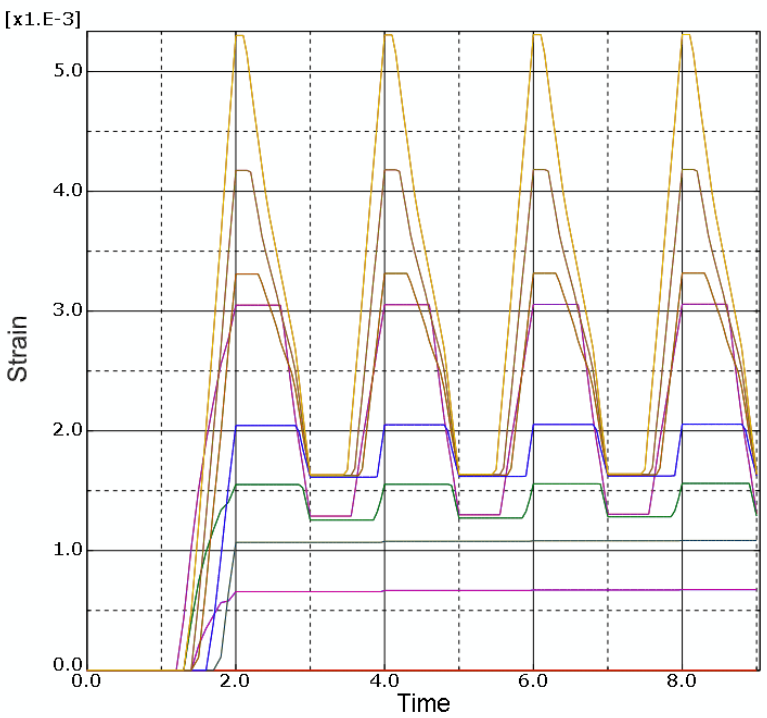

(a)

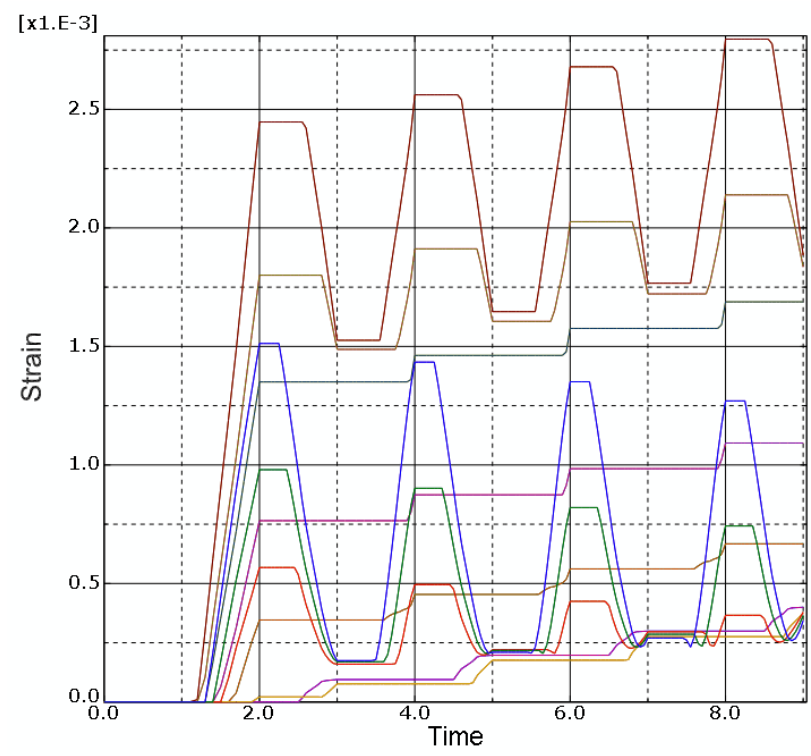

(b)

Fig. I-26. Examples of Non-Ratcheting (a) and Ratcheting (b) Strain Histories 

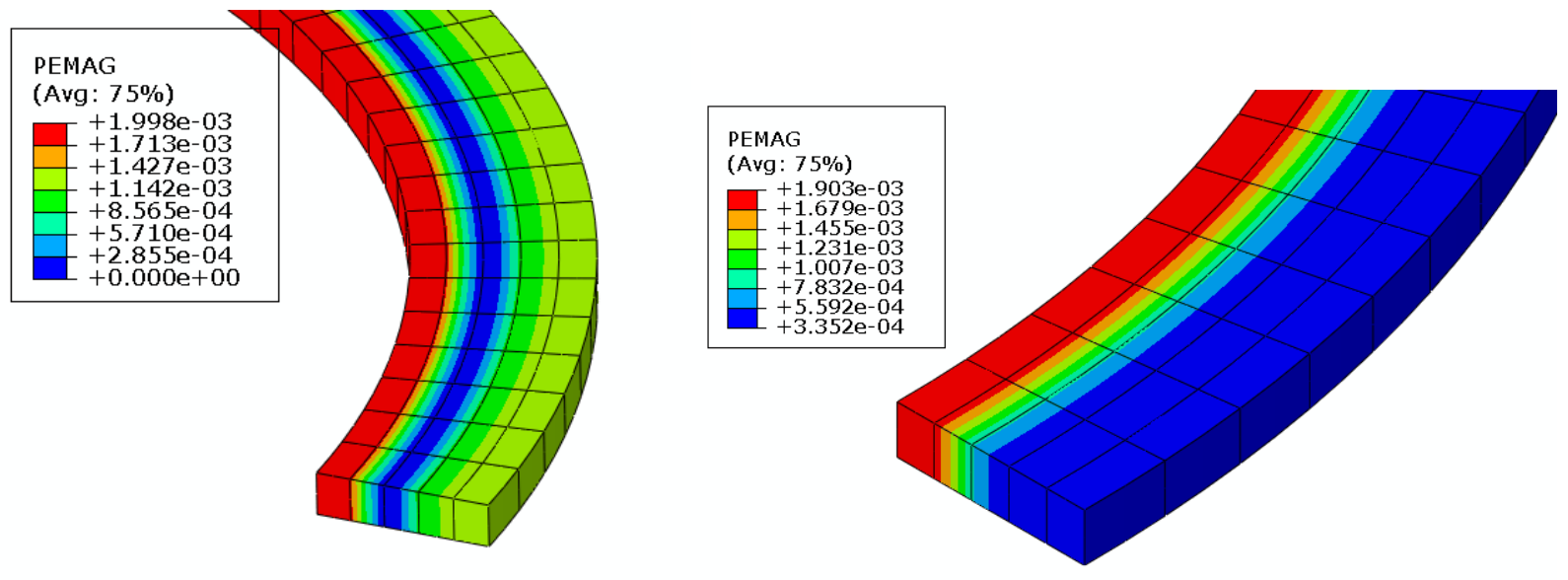

Fig. I-27. EPP Ratcheting Analyses with Zero and Non-Zero Minimum Plastic Strain (y)

Table I-7. Results of Ratcheting Calculations for Alloy 617

\begin{tabular}{c|c|c|c|c|c|c|c|c|c}
\hline $\begin{array}{c}\text { Tube, } \\
\text { Case }\end{array}$ & $\begin{array}{c}\text { OD } \\
(\text { Inches } \\
)\end{array}$ & $\begin{array}{c}\text { ID } \\
(\text { Inches })\end{array}$ & $\begin{array}{c}\text { Pressure } \\
(\text { ksi })\end{array}$ & $\begin{array}{c}\text { Tresca } \\
\text { Stress } \\
(k s i)\end{array}$ & $\begin{array}{c}\text { Int. } \\
\text { Temp. } \\
\left({ }^{0} F\right)\end{array}$ & $\begin{array}{c}\text { Ext } \\
\text { Temp. } \\
\left({ }^{0} F\right)\end{array}$ & X Strain & Y Strain & $\begin{array}{c}\text { Allowabl } \\
\text { e Hours: } \\
1 \%\end{array}$ \\
\hline \#1 EPP & 14 & 12 & 1.1 & 7.1 & 1202 & 1742 & 0.0100 & 0.0000 & 200 \\
\hline \#1 EPP & 14 & 12 & 0.1 & 0.6 & 1202 & 1742 & 0.0100 & 0.0000 & 200 \\
\hline \#2 EPP & 14 & 12 & 0.45 & 2.9 & 1500 & 1742 & 0.0099 & 0.0001 & 199 \\
\hline \#2 EPP & 14 & 12 & -0.1 & -0.6 & 1500 & 1742 & 0.0100 & 0.0000 & 200 \\
\hline$\# 3$ EPP & 14 & 12 & 0.35 & 2.3 & 1680 & 1742 & 0.0100 & 0.0000 & 200 \\
\hline \#3 EPP & 14 & 12 & -0.3 & -1.9 & 1680 & 1742 & 0.0100 & 0.0000 & 200 \\
\hline
\end{tabular}

\section{I-5.4.2 Inelastic analyses}

Inelastic analyses have been performed to confirm the EPP design calculations. One hour cycles with the same extreme temperatures as the EPP analyses, and a 0.5 hour high temperature hold per cycle are used. Fig. I-23.

Creep properties are defined by the hyperbolic sine constitutive equation and data shown above in

Table I-8 gives results of cyclic inelastic calculations. Fig. I-28 shows a typical history plot of pipe wall center nodal displacements and calculated times to $1 \%$ hoop inelastic strain. Negative times refer to compression strains. 
Table I-8. Inelastic Displacements and Strains

\begin{tabular}{c|c|c|c|c|c|c}
\hline Tube, Case & $\begin{array}{c}\text { Pressure } \\
(\mathrm{ksi})\end{array}$ & $\begin{array}{c}\text { Int. Temp } \\
\left({ }^{0} \mathrm{~F}\right)\end{array}$ & $\begin{array}{c}\text { Ext. Temp } \\
\left({ }^{0} \mathrm{~F}\right)\end{array}$ & $\begin{array}{c}\text { Step 4 Node } \\
\text { Disp. Ins }\end{array}$ & $\begin{array}{c}\text { Step 5 Node } \\
\text { Disp. Ins }\end{array}$ & $\begin{array}{c}\text { Hours: 1\% } \\
\text { Inelastic Strain }\end{array}$ \\
\hline$\# 1$ creep & 1.2 & 1202 & 1742 & 0.0057825 & 0.005988 & 288 \\
\hline$\# 1$ creep & -0.2 & 1202 & 1742 & -0.0041267 & -0.004358 & -299 \\
\hline$\# 2$ creep & 0.7 & 1500 & 1742 & 0.0029036 & 0.003155 & 247 \\
\hline$\# 2$ creep & -0.3 & 1500 & 1742 & -0.004456 & -0.004768 & -223 \\
\hline$\# 3$ creep & 0.65 & 1680 & 1742 & 0.003062 & 0.00341 & 178 \\
\hline$\# 3$ creep & -0.6 & 1680 & 1742 & -0.002849 & -0.003173 & -209 \\
\hline
\end{tabular}

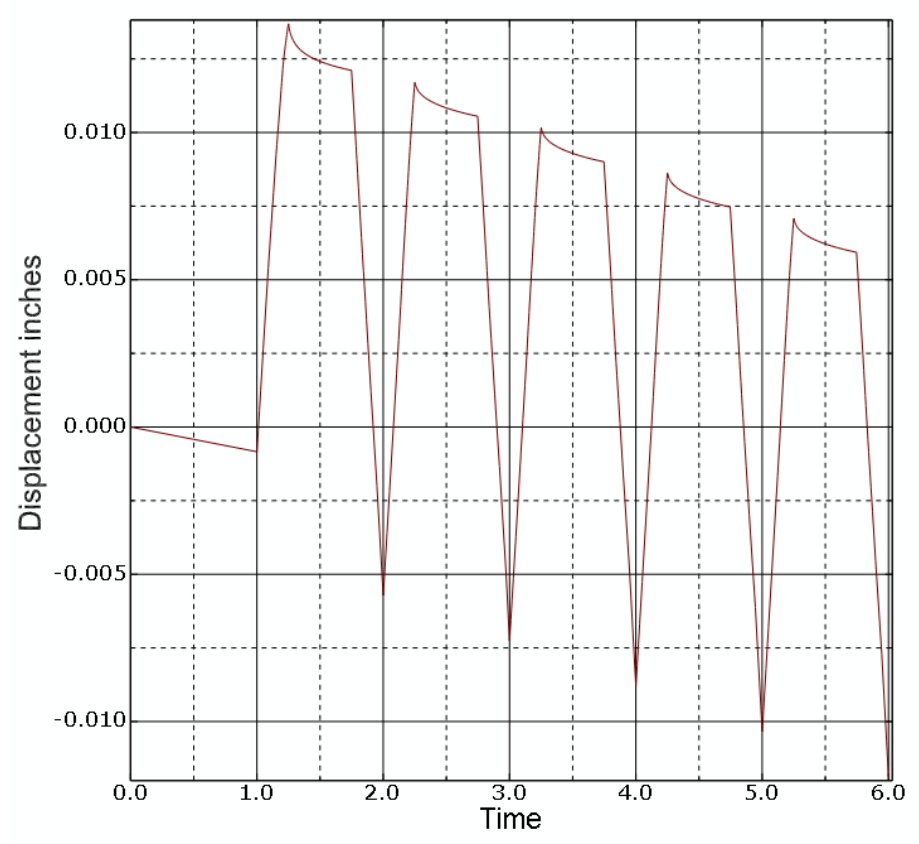

Fig. I-28. Tube Radial Nodal Displacements for Tube Case \#3 Negative Pressure Loading

\section{I-5.4.3 Summary of EPP ratcheting and inelastic analyses}

Fig. I-29 is a summary of all load cases with stress normalized by the mean wall temperature yield stress at the maximum thermal stress. Design points are calculated so that the pressure load is as close as possible to the ratchet limits based on the pseudo yield stress and the Eno et al. (2008) correlation. Inelastic calculations have been extrapolated from the first five cycles and give lives to $1 \%$ inelastic strain of $200-300$ hours. The usual Bree diagram limits for ratcheting and shakedown are shown to indicate regions of behavior. The results for zero thermal stress are based on spreadsheet calculations, and reflect both methods.

It may be seen that that all the inelastic calculations with lives of $200-300$ hours are less conservative then the EPP design calculations, but not excessively so; thus the EPP methodology may be concluded to provide a reasonable design bound for the response of representative structures with distributed properties and temporal and spatially varying structural response. 


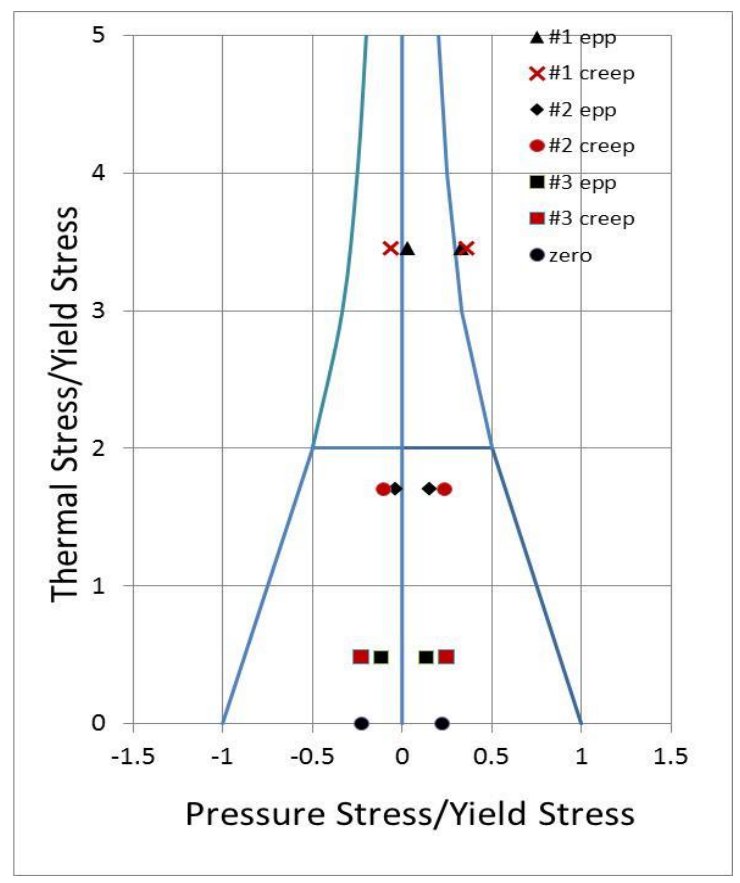

Fig. I-29. Summary of EPP and Creep Analysis Load Cases on Bree Plot of Normalized Primary and Thermal Stress

\section{I-5.4.4 Analysis of two-bar temperature cycles applied to Bree problem}

To reinforce the above conclusion and to provide a direct link back to the two-bar test results, an additional more severe thermal load case for the pipe geometry defined above in Table I- 6 was evaluated, again by comparing the result of an EPP evaluation to inelastic analysis results. Fig. I-30 shows bore and OD cyclic temperatures similar to those used in the two-bar ratcheting tests. Steady state temperature distributions in the wall are assumed. Internal pressure is the design variable, which is constant over the cycles.

EPP analyses are performed to obtain design pressures which satisfy the $1 \%$ inelastic strain criterion. Creep analyses are performed to obtain as realistic predictions as possible with current data. Table I-9 and Table I-10 summarize the results of the EPP and inelastic analysis respectively. 


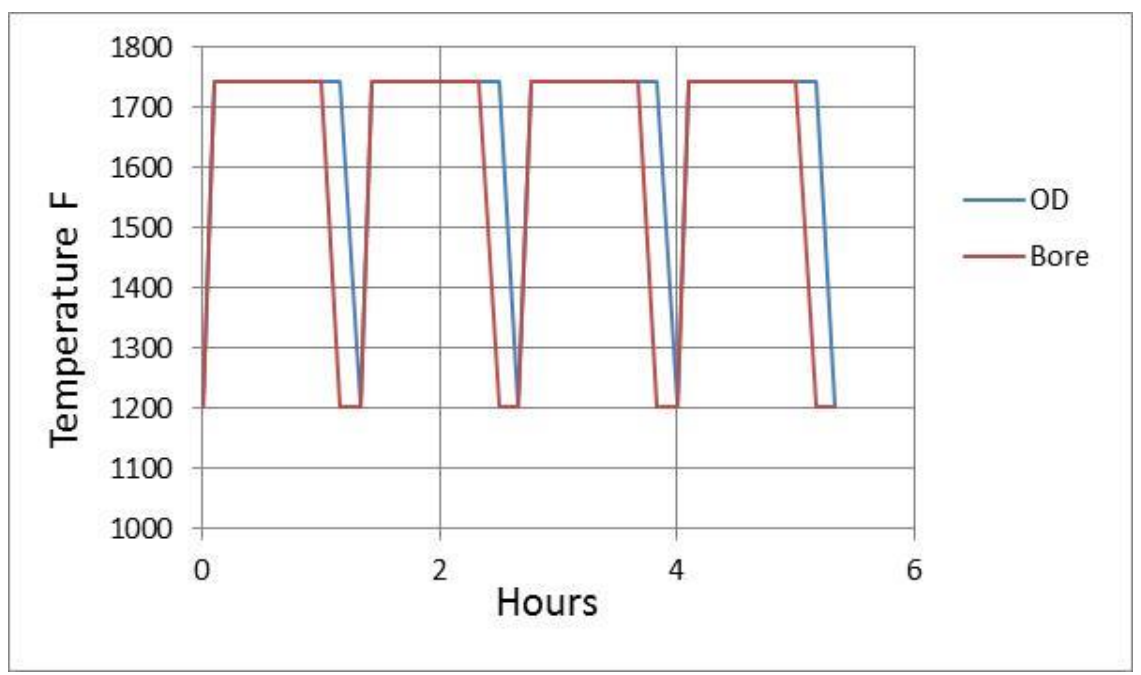

Fig. I-30. OD and Bore Temperature Histories: 1 Hour Hold and 10 Minute Delay Between Downshocks

Table I-9. Results of EPP Analyses

\begin{tabular}{c|c|c|c}
\hline Load case & 1 & 2 & 3 \\
\hline Pressure psig & 230 & 240 & 260 \\
\hline Result & $\begin{array}{c}\text { Negative radial } \\
\text { ratchet }\end{array}$ & $\begin{array}{c}\text { Axial } \\
\text { ratchet }\end{array}$ & $\begin{array}{c}\text { Positive radial } \\
\text { ratchet }\end{array}$ \\
\hline
\end{tabular}

Table I-10. Results of Creep Analyses

\begin{tabular}{c|c|c|c}
\hline Load case & 1 & 2 & 3 \\
\hline Pressure psig & 0 & 230 & 300 \\
\hline $\begin{array}{c}\text { Hours for } 1 \% \\
\text { inelastic strain }\end{array}$ & 200 & 500 & 200 \\
\hline
\end{tabular}

The following conclusions may be drawn with respect to the response of the Bree type cylinder to the more severe two-bar test type transients:

- The EPP analyses indicate that acceptable design pressures, which satisfy the zero-ratcheting criterion, do not exist for this problem.

- The inelastic analyses of a limited number of cycles indicate that pressures between zero and 300 psi produce strain rates, which when extrapolated to 200 hours, imply inelastic strains in the center of the pipe wall less than $1 \%$.

- The conservatism of the EPP analysis is therefore demonstrated 


\section{I-5.5 Bounding Theory Example Calculations}

To date, example calculations have not been developed to illustrate the application of bounding concepts with an analytical solution of a simplified strain limits problem. However, such calculations have been developed for a simplified creep-fatigue problem and are documented in the creep-fatigue background document.

\section{I-6 SUMMARY AND CONCLUSIONS}

The goal of this report is to provide a summary and rationale of the actions taken to illustrate and verify the application of one of the two code cases developed to permit evaluation of strain limits and creep-fatigue damage that take advantage of the unique features of elastic-perfectly plastic analysis methods for Section III, Division 5 Subsection HB, Subpart B applications. This report focuses on the strain limits code case. A motivating factor in developing the code cases is the restriction on the application of current Subsection HB, Subpart B simplified methods to Alloy 617 at very high temperature. The overall strategy is to (1) illustrate the application the code case(s) to an example problem representative of a realistic component with realistic loading conditions, (2) compare the results of an evaluation based on the proposed code case methods to the results from a Subsection HB, Subpart B evaluation using an example(s) with simplified geometry and loading conditions, and (3) compare the code case predictions with test data from key feature experiments primarily on Alloy 617 at very high temperature simulating ratcheting and elastic follow-up phenomena.

\section{I-6.1 Basis Of The Code Case Methodology}

The basis for the proposed simplified methods is generally expressed in terms of energy bounding theorems. There is a "hierarchy" of bounding concepts which reflects the trade-off between problem complexity and bounding accuracy. Problems with mechanical load cycles may be bounded by external work bounds and those with thermal and mechanical load cycles may be bounded by internal energy dissipation. This is generally more conservative than for purely mechanical problems, since high internal energy dissipation may be associated with zero net deflection. In both cases, the opportunity for a simplified analysis arises from the use of the "rapid cycle" concept.

Rapid cycles have no creep relaxation during the cycle, but generally have the most advantageous residual stress system which ensures that deformation rates over the cycle are as low as possible. In terms of deformation and strain accumulation over time, rapid cycles are more conservative than slow cycles. Therefore, if strain limits can be demonstrated for rapid cycles, slower cycles with relaxation will also satisfy the strain limits.

The use of elastic, perfectly plastic (EPP) analysis using an artificial or pseudo yield stress is based on a third assumption - that reducing the yield stress in an analysis is conservative, that is, does not reduce the deformation rates. Thus, if the temperature-dependent "pseudo" yield stress in a rapid cyclic analysis is reduced to the point where ratcheting is imminent, then the deformation will not be less than with the realistic yield property. If this pseudo yield stress is based on the stress to give $1 \%$ inelastic strain, then it is possible for stress and temperature cycles to exist everywhere in the structure which do not produce more than the $1 \%$ inelastic strain limit in the specified time.

Note that there is no requirement for a high temperature yield property in these arguments. The restriction on the use of current simplified methods is, essentially, that they are based on yield properties and the separation of plasticity and creep. 


\section{I-6.2 Representative Example Problem}

The goal of the representative example is to illustrate the code case(s) application to a realistic geometry and loading conditions. The selected geometry is a spherical head with an integrally reinforced nozzle with a flush ground connecting weld. The applied loads are internal pressure and shear and moment loads on the nozzle. Cyclic and sustained loading conditions are evaluated with imposed thermal transients. The material is $316 \mathrm{H}$ stainless steel.

The implementation evaluation of the strain limits code case is successful. The implementation requires trial- and-error finite element EPP runs with starting target inelastic strains (for strain limits evaluation) iterated with successively smaller values and adjusted pseudo yield stress curves until the criteria in the code cases are met.

The accumulated strain is bounded by $1.0006 \%$ for the Level A\&B Composite cycle with the critical location being the base metal at the outer surface of the shell to nozzle transition. The Level A \& B Composite Cycle is evaluated using both the base metal only model and model with the weldment included. Both evaluations meet the strain limits code case evaluation criteria. The controlling base metal location for both models is at the outer surface of the shell-to-nozzle transition where nozzle bending due to the nozzle end shear load produces maximum strains. The EPP plastic strain developed at this location for the base metal only model and the model with the weldment is small -- $0.0006 \%$ and $0.0009 \%$, respectively. Furthermore, since the weldment behaves elastically with the same properties as the base metal, both models behave with only a slight difference in base metal plastic strains. That difference is attributed to the differences in the model meshes.

There is no yielding in the weld region so this is not a controlling location.

The Level A \& C Composite Cycle is evaluated using only the base metal model. The evaluation exceeds the strain limits code case evaluation criteria due to significant plastic strains developing within 2 pseudo-cycles. No evaluation with the weldment model is performed since, based on the criteria not being met for the base metal model, the criteria would not be met for the more restrictive weldment model.

\section{I-6.3 Strain Limits Code Case to Subsection HB, Subpart B Comparison}

The simplified example problem focused on evaluations comparing the results of the application of Subsection HB, Subpart B procedures to the results of the EPP procedure.

The simplified example configuration is a pressurized cylinder with cyclic radial thermal gradients. Two wall thicknesses, $\mathrm{r} / \mathrm{t}=3.5$ and 4.5 are joined with a $3: 1$ taper. The material is $316 \mathrm{H}$ stainless steel.

Due to the differences in the respective design evaluation procedures for strain limits, a direct comparison was not feasible. However, a general sense of the relative conservatism is achievable. For the $1 \%$ inelastic strain limit, the NH elastic strain limits calculation gives 550,000 and 110,000 hours for the two separate cylinder designs, respectively. For a 100,000 hours target life, this is approximately equivalent to an additional margin on loading of 1.22 and 1.02 for the two designs, respectively. When analyzed with the EPP method with additional factors of 1.2 on load and heat flux, the joined cylinder design shows ratcheting behavior in the tapered joint section, but not in the cylindrical sections. This illustrates the ability of the EPP methodology to capture the strain concentrating effect of the tapered joint discontinuity. Analysis of design conditions with no additional factor does not cause ratcheting in the tapered joint in the composite model. This indicates that 100,000 hour strain limits can be met in the composite model under design conditions. In summary, the results from the NH type analysis and EPP 
analysis are approximately equivalent, which is an important step in establishing the credibility of the EPP procedure.

\section{I-6.4 Experimental Comparison}

The experimental configuration is two bars tested in parallel in two linked servo-controlled test frames. The boundary conditions applied to the test specimens require that the total displacement, thermal plus mechanical, is equal in each bar and the total load shared by the two bars is constant. A thermal cycle is applied separately to each bar to generate thermal transient stress levels. Conceptually, this represents the inner and outer sections of a pressurized cylinder subjected to cyclic thermal gradients. The tests were conducted with Alloy 617 at a maximum temperature of $950{ }^{\circ} \mathrm{C}\left(1742{ }^{\circ} \mathrm{F}\right)$.

The test results indicated there is a narrow range of applied mean stress inside of which it is possible to have high thermal transient stress levels without accumulating significant strain. In essence, the ratcheting mechanism for strain accumulation, which tends to be compression, is offset by the tensile mean stress in this narrow region. This behavior was captured by the $1 \%$ strain limit from application of the code case rules. However, the applied sustained stress for this narrow region as predicted by the code case did not agree with the experimental results which were at a significantly higher mean stress level. It was postulated that the elastic-perfectly plastic analysis model in the code case, while accurate for general behavior representation, was not sufficiently precise for skeletal structure where the properties, stress, strain and temperature do not vary throughout the structure.

To test this concept, the two-bar test results were compared to the strain limits prediction from an inelastic analysis with good agreement between analysis and test. Then, using that test qualified inelastic analysis methodology, a Bree type structure with sustained pressure load and transient thermal loading was evaluated and compared to the results generated by the code case EPP methodology. Two types of thermal transient were considered, one with a cyclic through wall thermal gradient with the outer wall held at $950{ }^{\circ} \mathrm{C}\left(1742{ }^{\circ} \mathrm{F}\right)$; and the other, where more severe two-bar type thermal transients with both inner and outer wall thermal cycling. For the Bree type case the code case and inelastic analysis predictions were in close agreement with the code case being somewhat more conservative. For the more severe two-bar case, the code case prediction was significantly more conservative. Thus, the overall conclusion from the test data and inelastic analysis was that the EPP code case methodology could adequately represent the strain accumulation behavior of Alloy 617 at very high temperatures, subject to the limitation that it was not applicable to skeletal structures.

\section{I-6.5 Analytical Comparison}

To test this concept, the two-bar test results were compared to the strain limits prediction from an inelastic analysis with good agreement between analysis and test. Then, using that test qualified inelastic analysis methodology, a Bree type structure with sustained pressure load and transient thermal loading was evaluated and compared to the results generated by the code case EPP methodology. Two types of thermal transient were considered, one with a cyclic through wall thermal gradient with the outer wall held at $950{ }^{\circ} \mathrm{C}\left(1742{ }^{\circ} \mathrm{F}\right)$; and the other, where more severe two-bar type thermal transients with both inner and outer wall thermal cycling. For the Bree type case the code case and inelastic analysis predictions were in close agreement with the code case being somewhat more conservative. For the more severe two-bar case, the code case prediction was significantly more conservative. Thus, the overall conclusion from the test data and inelastic analysis was that the EPP code case methodology could adequately represent the strain accumulation behavior of Alloy 617 at very high temperatures, subject to the limitation that it was not applicable to skeletal structures. 


\section{I-6.6 Conclusions}

As summarized above, the strain limits code case, (1) can be implemented on a representative component configuration with realistic loading conditions, (2) provides comparable results to current $\mathrm{NH}$ procedures at moderate creep temperatures, and, (3) with a combination of test data and inelastic analysis, can represent the strain accumulation bounds for Alloy 617 at very high temperatures. 


\section{I-APPENDIX A: RATCHETING ANALYSIS}

The steps to perform a ratcheting analysis to demonstrate compliance with strain limits are as follows:

\section{A1 Define Composite Cycle Load Time-Histories and Step(s)}

A1.1. It may consist of histories of mechanical loads, pressure loads, displacements, temperatures and thermal boundary conditions.

A1.2. Time-independent parts of the cycle may be truncated.

A1.3. The cycle should not have discontinuities. Discontinuities arising from the selection of the specified cycles to form a composite cycle should be eliminated by a simple and reasonable transition from one state to the next.

A1.4. Subject to the requirements in (A2), the composite cycle time does not affect the result of the ratcheting analysis.

A1.5. Temperatures, thermal boundary conditions, boundary displacements and mechanical loads over a cycle should be cyclic; that is, begin and end at the same value.

A1.6. A single analysis step may represent one cycle. Dividing a single cycle into more than one step to facilitate definition of the load cycle, and to ensure that maximum loads are analyzed, is often helpful.

\section{A2 Define Analysis Types.}

A2.1. A sequentially coupled thermal-mechanical analysis of the composite cycle may be performed. First a thermal analysis is performed to generate temperature histories. Next the mechanical analyses are performed using these temperature histories as inputs. Care must be taken that times in the mechanical analysis step and in the previous thermal analysis are the same or do not conflict, depending on the requirements of the analysis software.

A2.2. Alternatively, a coupled thermal-mechanical analysis may be performed. The composite temperature history to be used in the mechanical analysis should be cyclic, that is the beginning and end temperature distributions should be the same.

\section{A3 Define Material Properties.}

A3.1. For the thermal analyses, density, and temperature-dependent specific heat and conductivity will in general be required.

A3.2. For the mechanical analyses the temperature-dependent properties required are modulus, Poisson's ratio and mean expansion coefficient. Density may also be required.

A3.3. In addition the mechanical analyses temperature-dependent yield stress will need to be adjusted based on the selected pseudo yield stress $S_{x T}$ defined in I-Appendix B, paragraph 4.4.2.

\section{A4 Perform Analyses.}

A4.1. Perform an elastic-perfectly plastic cyclic mechanical and thermal stress analysis using the temperature-dependent pseudo yield property defined above. Enough cycles are required to demonstrate ratcheting or the absence of ratcheting.

A4.2. Care must be taken to ensure that the analysis deals with all the changes within a cycle. Elastic-plastic routines increase increment size where possible, and may miss a detail in the loading. A conservative limit to maximum increment size can address this problem, or division of the cycle into more than one step as in paragraph A1.6 of this appendix. 


\section{A5 Detect Ratcheting.}

A5.1. Ratcheting is defined as repeated non-cyclic deflections, that is between the beginning and end of a cycle, a repeated finite displacement change occurs somewhere in the structure.

A5.2. Detecting ratcheting is most easily done by plotting nodal deflections over time. Cyclic (repeated) behavior indicates non-ratcheting. History plots of equivalent plastic strains will also identify ratcheting. 


\section{I-APPENDIX B: DRAFT EPP STRAIN LIMITS CODE CASE}

The draft EPP strain limits code case is presented in this appendix. It is anticipated that revision will be made to this draft to address comments as the Code committee approval process proceeds.

\section{Code Case XXXX. Satisfaction of Strain limits for Division 5 Class A Components at Elevated Temperature Service Using Elastic-Perfectly Plastic Analysis.}

Inquiry: What alternative rules may be used for the evaluation of strain limits in compliance with HBB3252 and Appendix HBB-T of Section III, Division 5, Subsection HB, Subpart B?

Response: Strain limits for the materials shown below may be evaluated using elastic-perfectly plastic material models instead of the procedures of HBB-T-1320, HBB-T-1330 and HBB-T-1713 when performed in accordance with the requirements of this Code Case.

- $\quad$ Type 304 SS and 316 SS per Table HBB-I-14.1(a)

\section{General Requirements.}

Except as identified herein, all requirements of Section III, Division 5, Subsection HB, Subpart B apply to components designed in accordance with this Code Case.

The design methodology employed for evaluation of strain limits is based on ratcheting analyses using a small strain theory elastic-perfectly plastic material model where the yield stress is adjusted based on a pseudo yield stress selected to bound accumulated inelastic strain. Guidance on ratcheting analysis is provided in Appendix 1. In this code case the term "pseudo yield stress" refers to a temperature dependent isochronous stress based on the total time duration of high temperature service and a target inelastic strain, not to exceed the yield strength of the material at temperature and is explicitly defined in paragraph 4.2. of this code case.

(a) This design methodology is not applicable to skeletal structures, e.g. a bar with uniform axial load throughout, nor to structures where geometrical nonlinearities exist, e.g. canopy or omega seals.

(b) The stamping and data reports shall indicate the Case number and applicable revision.

\section{Load Definition.}

Define all applicable loads and load cases per HBB-3113.2 Service Loadings.

\subsection{Composite cycle definition.}

For the purpose of performing an elastic-perfectly plastic ratcheting analysis, an overall cycle must be defined that includes all relevant features from the individual Level A, B and C Service Loadings identified in the Design Specification. Relevant features include, as a minimum, the time dependent sequence of thermal, mechanical and pressure loading including starting and ending conditions. Such an overall cycle is defined herein as a composite cycle subject to the following requirements.

2.1.1. An individual cycle as defined in the Design Specifications cannot be further subdivided into individual cycles to satisfy these requirements.

2.1.2. Except as described in paragraph 2.1.3, below, a single cycle from each Level A, B and C Service Loading cycle type shall be included in the composite cycle for evaluation of strain limits.

2.1.3. Level C Service Loadings may be combined with the applicable Level A and B Service Loadings to define an additional composite cycle(s) to be evaluated separately from the composite cycle defined in paragraph 2.1.2. Multiple composite cycles that include Level C Service Loadings may be defined for separate evaluation. The total number of Level C Service Loading cycles shall not exceed 25. 


\section{Numerical Model.}

Develop a numerical model of the component, including all relevant geometry characteristics. The model used for the analysis shall be selected to accurately represent the component geometry, boundary conditions, and applied loads. The model must also be accurate for small details, such as small holes, fillets, corner radii, and other stress risers. The local temperature history shall be determined from a thermal transient analysis based on the thermal boundary conditions determined from the loading conditions defined in paragraph 2.

\section{Requirements for Satisfaction of Strain Limits.}

Perform a ratcheting analysis for each of the composite cyclic histories defined in paragraph 2.1. Each of these cyclic histories must be shown to be free from ratcheting based on the pseudo yield stress $S_{x T}$ as defined in paragraph 4.2. In the following steps, inelastic strain for a particular stress, time and temperature is obtained by subtracting the elastic strain from the total strain as given by the isochronous stress strain curve at the same stress, time and temperature. Additional requirements for weldments are shown in paragraph 5 .

4.1. Step 1: Define $t_{d e s i g n}$ as the total time duration of high temperature service for all Level A, B, and C Service Loadings when the temperature is above the range covered by Tables $2 \mathrm{~A}, 2 \mathrm{~B}$, and 4 of Section II, Part D.

4.2. Step 2: Select a target inelastic strain, $x$, where $0<x<\varepsilon_{\text {avg }}$ and $\varepsilon_{\text {avg }}$ is equal to 0.01 for base metal or 0.005 for weldments. Define a pseudo yield stress $S_{x T}$ at each location ${ }^{1}$, using the temperature determined from the transient thermal analysis. This pseudo yield stress is equal to the lesser of the quantities defined below in 4.2.1. and 4.2.2.

4.2.1. The yield strength $S_{y}$ given in Table HBB-I-14.5.

4.2.2. The stress to cause $x$ inelastic strain in time $t_{\text {design }}$, as determined from the isochronous stress strain curves in Figure HBB-T-1800.

4.3. Step 3: Perform a cyclic elastic-perfectly plastic analysis for each composite cycle defined in paragraph 2.1.2 above with temperature-dependent pseudo yield stress $S_{x T}$. If ratcheting does not occur, obtain the plastic strain distribution throughout the component. The plastic strain, $\varepsilon_{p}$, is evaluated according to

$$
\varepsilon_{p}=\sqrt{\frac{2}{3}\left[\left(\varepsilon_{x}^{p}\right)^{2}+\left(\varepsilon_{y}^{p}\right)^{2}+\left(\varepsilon_{z}^{p}\right)^{2}+2\left(\varepsilon_{x y}^{p}\right)^{2}+2\left(\varepsilon_{y z}^{p}\right)^{2}+2\left(\varepsilon_{z x}^{p}\right)^{2}\right]}
$$

where the plastic strain components, $\varepsilon_{x}^{p}, \varepsilon_{y}^{p}, \varepsilon_{z}^{p}, \varepsilon_{x y}^{p}, \varepsilon_{y z}^{p}$ and $\varepsilon_{z x}^{p}$, are those accumulated at the end of the composite cycle.

4.4. Step 4. Assess acceptability in accordance with 4.4.1. and 4.4.2. below by using the plastic strains, $\varepsilon_{p}$, from Step 3. If the requirements of both 4.4.1. and 4.4.2. are satisfied, then the strain limits of HBBT-1310 for base metal and HBB-T-1713 for weldments are also considered satisfied. This condition is illustrated in Figure 1(a).

\footnotetext{
${ }^{1}$ The term "each location" refers to nodal points or integration points in the finite element mesh where the calculations are performed.
} 
4.4.1. The requirement, $x+\varepsilon_{p} \leq \varepsilon_{\text {avg }}$, must be satisfied at least at one point for all through-thickness locations. As defined in Step 2, $\varepsilon_{\text {avg }}$ is equal to 0.01 for base metal or 0.005 for weldments. Failure of this requirement is illustrated in Figure 1(b).

4.4.2. The requirement, $x+\varepsilon_{p} \leq \varepsilon_{\text {local }}$, must be satisfied at all points. The local strain limit, $\varepsilon_{\text {local }}$, is equal to 0.05 for base metal and 0.025 for weldments. Failure of this requirement is illustrated in Figure 1(c).

4.4.3. In order to proceed if either of the requirements of 4.4.1. or 4.4.2. are not satisfied, return to Step 2 and select a smaller value of the target inelastic strain, $x$. If it is not possible to find a value of $x$ that does not ratchet and also satisfies the requirements of Step 4, then the loading conditions of paragraph 2 applied to the component configuration defined in paragraph 3 do not meet the requirements of this Code Case.

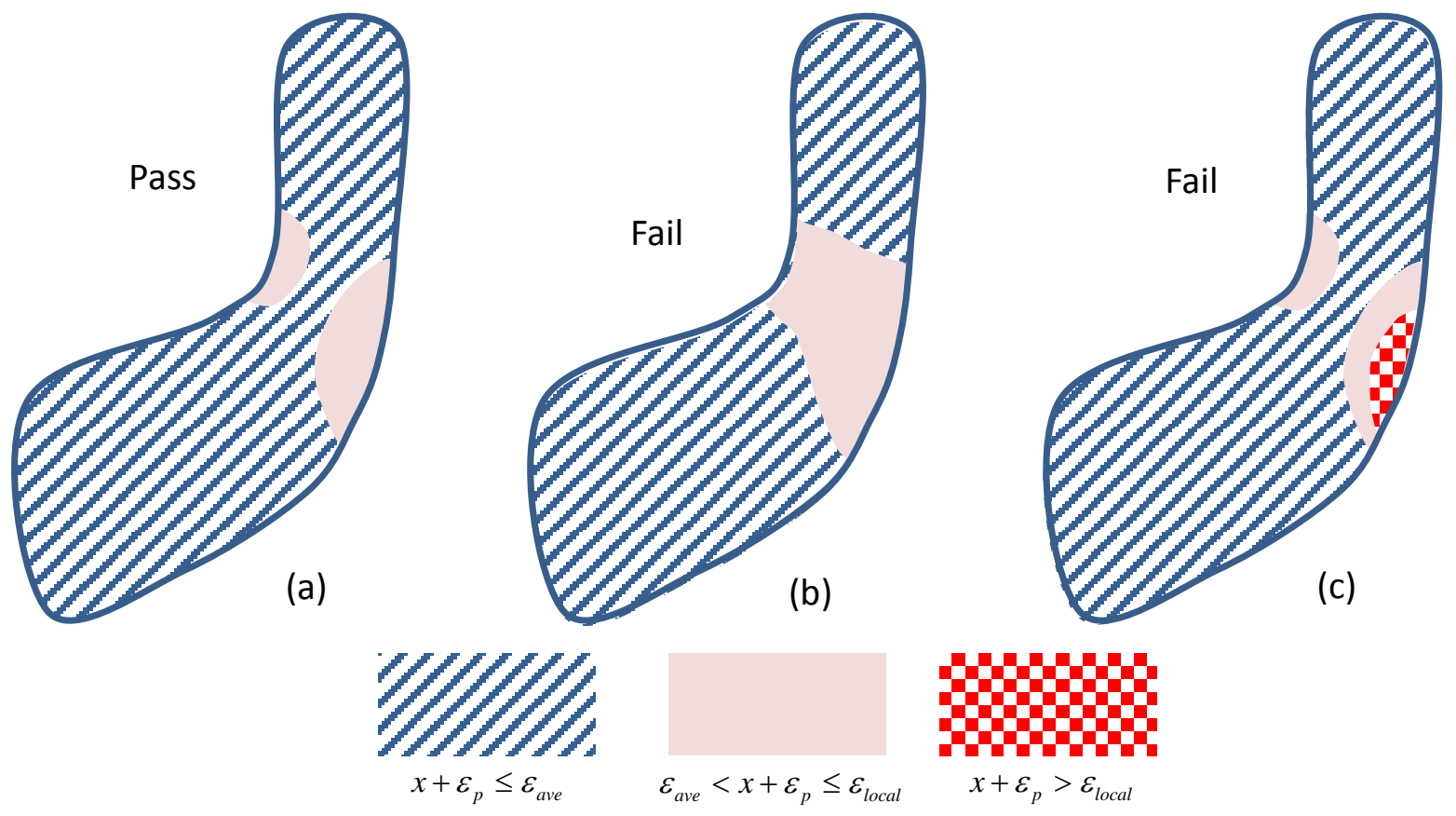

Figure 1. Strain limits Pass/Fail criteria illustrated

\section{Weldments.}

Implementation of the strain limits for weldments defined above in paragraph 4 requires additional consideration.

\subsection{Weld region model boundaries.}

The weld shown in Figure 2 represents a general full-penetration butt weld in a shell. Other weld configurations are needed for construction of an elevated temperature component in accordance with Subsection HB, Subpart B. HBB-4200 refers to various Division 1, NB-4000 paragraphs for weld configurations and requirements. These NB-4000 weld configurations are represented by the shaded region.

Figure 2 shows a full-penetration butt weld as an example. As shown, $w_{1}$ and $w_{2}$, as needed to define the weld region for use of this Case, are approximations consistent with the specified weld configuration and 
parameters. The specified weld region must include applicable stress concentrations in accordance with the requirements for analysis of geometry of Subparagraph HBB-T-1714.

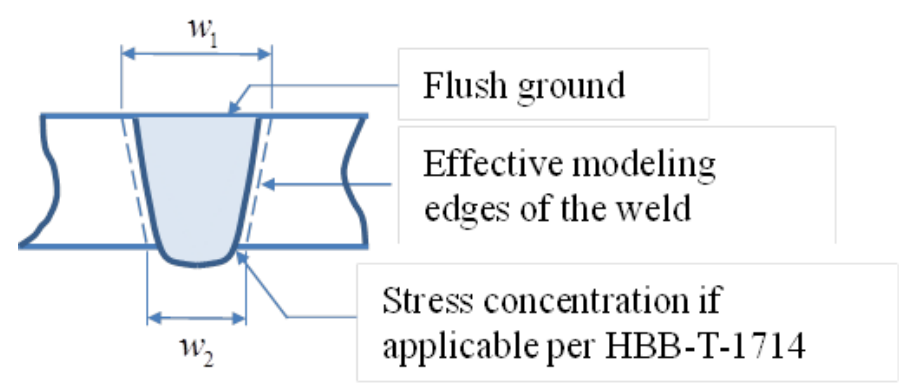

Figure 2. Weld region model boundaries

5.2. The requirements for analysis of geometry of HBB-T-1714 are applicable for satisfaction of the requirements of this Code Case.

5.3. The thermal/physical properties of weldments may be assumed to be the same as the corresponding base metal for the base metal - weld combinations listed in Table HBB-I-14.10.

5.4. Dissimilar metal welds.

5.4.1. Requirements for dissimilar metal welds are in the course of preparation.

\section{APPENDIX 1 - RATCHETING ANALYSIS}

The steps to perform a ratcheting analysis to demonstrate compliance with strain limits are as follows:

i) Define Composite Cycle Load Time-Histories and Step(s).

a. It may consist of histories of mechanical loads, pressure loads, displacements, temperatures and thermal boundary conditions.

b. Time-independent parts of the cycle may be truncated because the elastic-perfectly plastic analysis is not time dependent.

c. The cycle should not have discontinuities. Discontinuities arising from the selection of the specified cycles to form a composite cycle should be eliminated by a simple and reasonable transition from one state to the next.

d. Subject to the requirements in (ii), the composite cycle time does not affect the result of the ratcheting analysis.

e. Temperatures, thermal boundary conditions, boundary displacements and mechanical loads over a cycle should be cyclic; that is, begin and end at the same value.

f. A single analysis step may represent one cycle. Dividing a single cycle into more than one step to facilitate definition of the load cycle, and to ensure that maximum loads are analyzed, is often helpful.

ii) Define Analysis Types.

a. A sequentially coupled thermal-mechanical analysis of the composite cycle may be performed. First, a thermal analysis is performed to generate temperature histories. Next, the mechanical analyses are performed using these temperature histories as inputs. Care must be taken that times 
in the mechanical analysis step and in the previous thermal analysis are the same or do not conflict, depending on the requirements of the analysis software.

b. Alternatively, a coupled thermal-mechanical analysis may be performed. The composite temperature history to be used in the mechanical analysis should be cyclic, that is the beginning and end temperature distributions should be the same.

iii) Define Material Properties.

a. For the thermal analyses, density and temperature-dependent specific heat and conductivity will in general be required.

b. For the mechanical analyses, the temperature-dependent properties required are elastic modulus, Poisson's ratio and the mean expansion coefficient. Density may also be required.

c. In addition, the mechanical analyses temperature-dependent yield stress will need to be adjusted based on the selected pseudo yield stress $S_{x T}$ defined in paragraph 4.2.

iv) Perform Analyses.

a. Perform an elastic-perfectly plastic cyclic mechanical and thermal stress analysis using the temperature-dependent pseudo yield property defined above. Enough cycles are required to demonstrate ratcheting or the absence of ratcheting.

b. Care must be taken to ensure that the analysis deals with all the changes within a cycle. Elasticplastic analysis routines increase increment size where possible, and may miss a detail in the loading. A conservative limit to maximum increment size can address this problem, or division of the cycle into more than one step as in paragraph (i)(f) of this appendix.

v) Detect Ratcheting.

a. Ratcheting is defined as repeated non-cyclic deflections, that is between the beginning and end of a cycle, a repeated finite displacement change occurs somewhere in the structure.

Detecting ratcheting is most easily done by plotting nodal deflections over time. Cyclic (repeated) behavior indicates non-ratcheting. History plots of equivalent plastic strains will also identify ratcheting. 


\section{PART II - BACKGROUND FOR EPP CREEP-FATIGUE CODE CASE}

\section{II-1 THEORETICAL BASIS}

The basis for the proposed simplified methods is generally expressed in terms of energy bounding theorems. There is a "hierarchy" of bounding concepts which reflects the trade-off between problem complexity and bounding accuracy. Problems with mechanical load cycles may be bounded by external work bounds and those with thermal and mechanical load cycles may be bounded by internal energy dissipation. This is generally more conservative than for purely mechanical problems, since high internal energy dissipation may be associated with zero net deflection. In both cases, the opportunity for a simplified analysis arises from the use of the "rapid cycle" concept.

Rapid cycles have no creep relaxation during the cycle, but generally have the most advantageous residual stress system which ensures that deformation rates over the cycle are as low as possible. In terms of deformation and strain accumulation over time, rapid cycles are more conservative than slow cycles. Therefore, if creep-fatigue limits can be demonstrated for rapid cycles, slower cycles with relaxation will also satisfy the creep-fatigue limits. The application of this concept is discussed below in II-1.1 and illustrated in II-5 and II-Appendix A.

Note that there is no requirement for a high temperature yield property in these arguments. The restriction on the use of current simplified methods is, essentially, that they are based on yield properties and the separation of plasticity and creep.

\section{II-1.1 Shakedown Analysis for Cyclic Creep Damage}

The proposed creep-fatigue code case uses a conventional (Subsection HB, Subpart B) creepfatigue damage summation. The cyclic creep component of damage is defined by an elastic-perfectly plastic (EPP) shakedown calculation.

Consider a generic high temperature cyclic thermal-mechanical problem, for which thermal and mechanical cycles have the same period $T$. There are a number of limiting solutions.

- The realistic steady cyclic creep solution (SC) which satisfies $\sigma_{s c}(t)=\sigma_{s c}(t+T)$ and $\int_{c y c l e} \dot{\varepsilon}_{c} d t$ is kinematically admissible.

- The limiting slow cycle or steady state creep solution (SS) for which creep strain rates are kinematically admissible.

- An EPP shakedown solution (SD) is $\sigma_{s d}(t)=\sigma_{e}(t)+\rho$ where $\sigma_{e}(t)$ is the elastic solution and $\rho$ is a constant residual stress field. SD solutions are not unique.

- The rapid cycle creep solution (RC) $\sigma_{r c}(t)=\sigma_{e}(t)+\rho_{r c}$ is defined by the residual stress $\rho_{r c}$ for which energy dissipation over a cycle $\int_{\text {cycle }} \dot{\varepsilon}_{c} d t$ is minimized, and $\int_{\text {cycle }} \dot{\varepsilon}_{c} d t$ is kinematically admissible.

These solutions may be ranked in terms of energy dissipation per cycle as follows (Carter, 2005):

$$
\sigma_{s s} \leq \sigma_{s c} \leq \sigma_{r c} \leq \sigma_{s d}
$$


The steady cyclic solution and the limiting case of the rapid cycle solution are physically realistic and achievable, the latter in the limit of short cycle times. The EPP strain limits analysis for the maximum acceptable design life bears a similar relationship to the $\mathrm{RC}$ solution that a reference stress limit analysis bears to a steady state creep solution.

Because of the point-wise nature of the cyclic creep-fatigue damage EPP calculation, damage and energy dissipation integrated over the volume are not directly used for prediction of cyclic creep damage.

The example of uniaxial creep-fatigue specimen test is analyzed in II-4, because of its simple geometry and loading, does have the same connection between the SD and RC solutions that for the more general problem, only occurs for the strain limits analysis. RC and EPP solutions are illustrated in Fig. II16 and Fig. II-17.

As the name implies, the rapid cycle calculation is time-independent. It will be shown that a shakedown calculation which obtains the maximum point-wise cyclic creep life is effectively making use of the rapid cycle solution. Any shakedown calculation which obtains an acceptable cyclic creep life is equal to or more conservative than the rapid cycle solution.

This assertion is checked in detail in calculations for cyclic creep damage in a strain-controlled creep-fatigue test in II-4.

The use of a time-independent shakedown analysis to bound cyclic creep damage depends on the similarity between the mathematical descriptions of secondary creep strain rates and average creep damage rates. Both may be well-characterized by Arrhenius temperature dependencies, and n-power or hyperbolic sine power laws for stress dependencies.

This means that the creep and rupture behaviors have common features. For a constant load problem, strain rates generally decrease as the steady state stress distribution is approached in time. If the creep and damage rates exponents $n$ and $n^{\prime}$ for creep rate and damage rates, are identical, then creep damage accumulation rate will also be a minimum for the steady state stress distribution. As shown later, in practice the exponents have to be significantly different for the damage rate not to be a minimum for cyclic (or steady) conditions.

The intent of the shakedown analysis is to conservatively calculate cyclic creep damage. It may be summarized as follows. For a defined load cycle:

- Define a design rupture time $t$.

- Define a temperature dependent "pseudo" yield stress $S_{c t}$ as the lesser of material minimum yield stress and stress to cause rupture in time $t$.

- Perform a cyclic elastic-plastic analysis to demonstrate shakedown or otherwise of the component.

- If shakedown occurs, then cyclic creep damage is $D_{c}=$ design life/ $t$.

The example of a creep-fatigue test analyzed is given in II-4 and II-Appendix A. It shows the conservatism of the shakedown solution is consistent and reasonable. This covers two aspects.

- Average damage rates increase as cycle time is reduced.

- The shakedown solution is the realistic limiting case of rapid cycle behavior. 


\section{II-2. OUTLINE OF EPP CREEP-FATIGUE CODE CASE}

A draft of the proposed Creep-Fatigue Code Case is included in II-Appendix B. This code case is intended as an alternative to the rules in HBB-T-1420 Limits Using Inelastic Analysis, HBB-T-1430 Limits Using Elastic Analysis, and HBB-T-1715 Creep-Fatigue Reduction Factors. There are six parts to the code case and an appendix. The objective is to comply with the Subsection HB, Subpart B, Appendix $\mathrm{T}$ requirements for creep-fatigue damage evaluation. Namely, that the bounding value of creep damage fraction combined with the calculated fatigue damage fraction satisfies the allowable creep-fatigue damage interaction diagram.

Part 1, General Requirements, describes the overall elastic-perfectly plastic shakedown analysis and provides a general definition of the pseudo yield strength used in this code case. In this code case, the pseudo yield stress is a temperature dependent, adjusted minimum stress-to-rupture value based on a selected trial time duration. Also, in this code case, "shakedown" refers to the achievement of cyclic elastic behavior, without plasticity, throughout the part. The allowable damage due to the combined effects of the creep damage, $D_{c}$, calculated as described in Part 4, and the fatigue damage, $D_{f}$, calculated per Part 5, is limited to $D$ as defined by Figure HBB-T-1420-2 Creep-Fatigue Damage Envelope in Subsection HB, Subpart B

Part 2, Load Definition, identifies the manner in which loads are categorized and grouped for this application. Code Case procedure requires that a composite cycle be defined which encompasses the critical features of the individually defined cycles. The reason for this is that the elastic perfectly plastic methodology used in the code case bounds the long term response independent of the number of applied cycles. In this respect it is similar to the current simplified rules in Subsection HB, Subpart B.

Two sets of conditions are defined; one set for Service Levels A and B and the other for Service Levels A and C. A feature of the proposed code case is that, unlike the current version of Subsection HB, Subpart B, The worst case combinations of Service Level A and B do not need to be combined directly with Service Level C. The rationale for this is that in accordance with the definition of Service Levels, shutdown for inspection and repair or replacement is required after a Level $\mathrm{C}$ event whereas the reactor system may resume planned operation after Level A and B events. The number of Level C events is limited as it is in the lower temperature Division 1, Subsection NB rules, but, unlike the NB rules, assessment of the high temperature displacement controlled failure modes, strain limits and creep-fatigue, is required to guard against creep damage not measurable externally which might contribute to restraints on the remaining life when subjected to subsequent Level A and B conditions.

Part 3, Numerical Model, specifies that the finite element model used in the analysis (The code case is based on the use of FEA) should accurately represent the component geometry and loading conditions, transient and steady state, including details such as local stress risers and local thermal stresses.

Part 4, Calculation of Cyclic Creep Damage, provides the criteria for implementing the code case evaluation of creep damage based on the use of a pseudo yield stress in a shakedown analysis. The pseudo yield stress is obtained from the lower of the yield strength adjusted for the aging effects of long time service at elevated temperature or the minimum stress-to-rupture strength adjusted for the design factor $\mathrm{K}^{\prime}$ using the values for Elastic Analysis in Table HBB-T-1411-1 of Subsection HB, Subpart B. The time duration for the stress-to-rupture strength is a trial value equal to or greater than the total design life. The next step is an elastic-perfectly plastic shakedown analysis using the pseudo yield strength. If shakedown is achieved, the creep damage, $D_{c}$, is the design life divided by the trial time duration. Note that this is a bounding value for all locations and not the actual creep damage at a specific location. The calculated 
bounding value of the creep damage may be reduced by increasing the trial life but this also reduces the pseudo yield strength and makes shakedown to elastic behavior more difficult.

Part 5, Calculation of Fatigue Damage, directs that the fatigue damage is determined from the total strain components for the composite cycle at each location of interest from the shakedown analysis. The equivalent strain ranges are calculated from the strain components in accordance with Appendix HBB-T of Subsection HB, Subpart B. The fatigue damage is given by the summation of the ratio of actual cycles to allowable cycles as determined from the applicable design fatigue curve. The value of fatigue damage to be combined with the creep damage is the maximum value occurring at any point.

Part 6, Weldments, provides additional consideration for weldments. The pseudo yield stress is reduced by the applicable weld strength reduction factors and the allowable number of cycles is reduced by a factor of two. Guidance is provided on definition of the weldment boundaries, which are intended to be a nominal representation.

The appendix provides guidance on how to define composite cycle load time-histories and stepping sequence, analysis types, material properties, shakedown analysis and how to detect shakedown.

\section{II-3. EXAMPLE PROBLEMS}

There are three categories of example problems. The first category demonstrates the application of the code case(s) to a representative geometry with loading conditions representative of those which might be encountered in real design applications. The second category uses simplified geometries and loading conditions to facilitate comparison with the current rules in Subsection HB, Subpart B. The third deals with the application of the EPP method to a cyclic strain-controlled test.

\section{II-3.1 Representative Example Problem}

\section{II-3.1.1 Input parameters} (2014).

The following discussion is abstracted from a much more detailed report by Hollinger and Pease

There were considerable analytic studies of different trial configurations and loading conditions. The goal was to generate an example that would exercise relevant features of the strain limit creep-fatigue code cases with significant loading conditions and yet still be able to show compliance, at least for some loadings. As noted above, the same configuration and loadings were used for both the strain limit and creep-fatigue code cases.

The selected example problem is an integrally reinforced nozzle in a spherical shell. The weld centerline location represents a V groove, flush ground weld. The example configuration is shown in Fig. $\mathrm{I}-1$. 


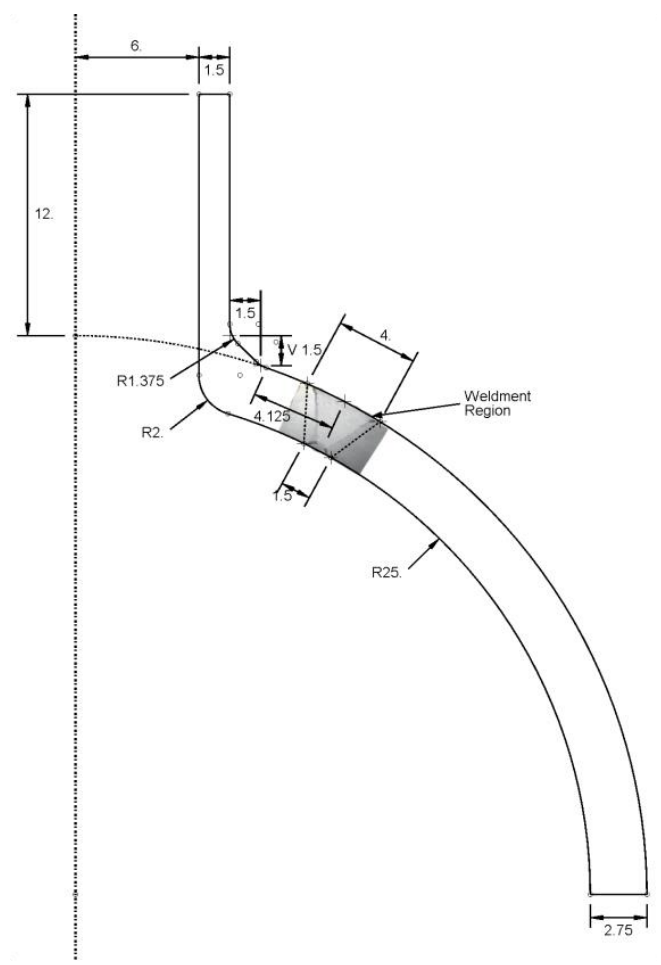

Fig. II-1. Representative Example Problem Configuration (dimensions are in inches)

The material selected for the representative example is $316 \mathrm{H}$ stainless steel. $316 \mathrm{H}$ SS was selected because it is a material of interest for advanced high temperature reactors and the relevant material properties are available. There was also an incentive to choose the same material for both the representative example and the simplified example problems. Since the goal of the simplified examples is a comparison to the requirements of Subsection HB, Subpart B, it was necessary to also use a material for which those rules were considered applicable.

The applied loads include thermal and mechanical cyclic loading and a representative seismic input. Internal pressure and nozzle shear, moment and torsion loads, both sustained and transient, and thermal transients were specified for Level A, B and C Service Loadings. An overview of these specified loading histories is shown schematically in Fig. II-2, Fig. I-3 and Fig. II-4, respectively. The detailed values are tabulated in Hollinger and Pease (2014). 


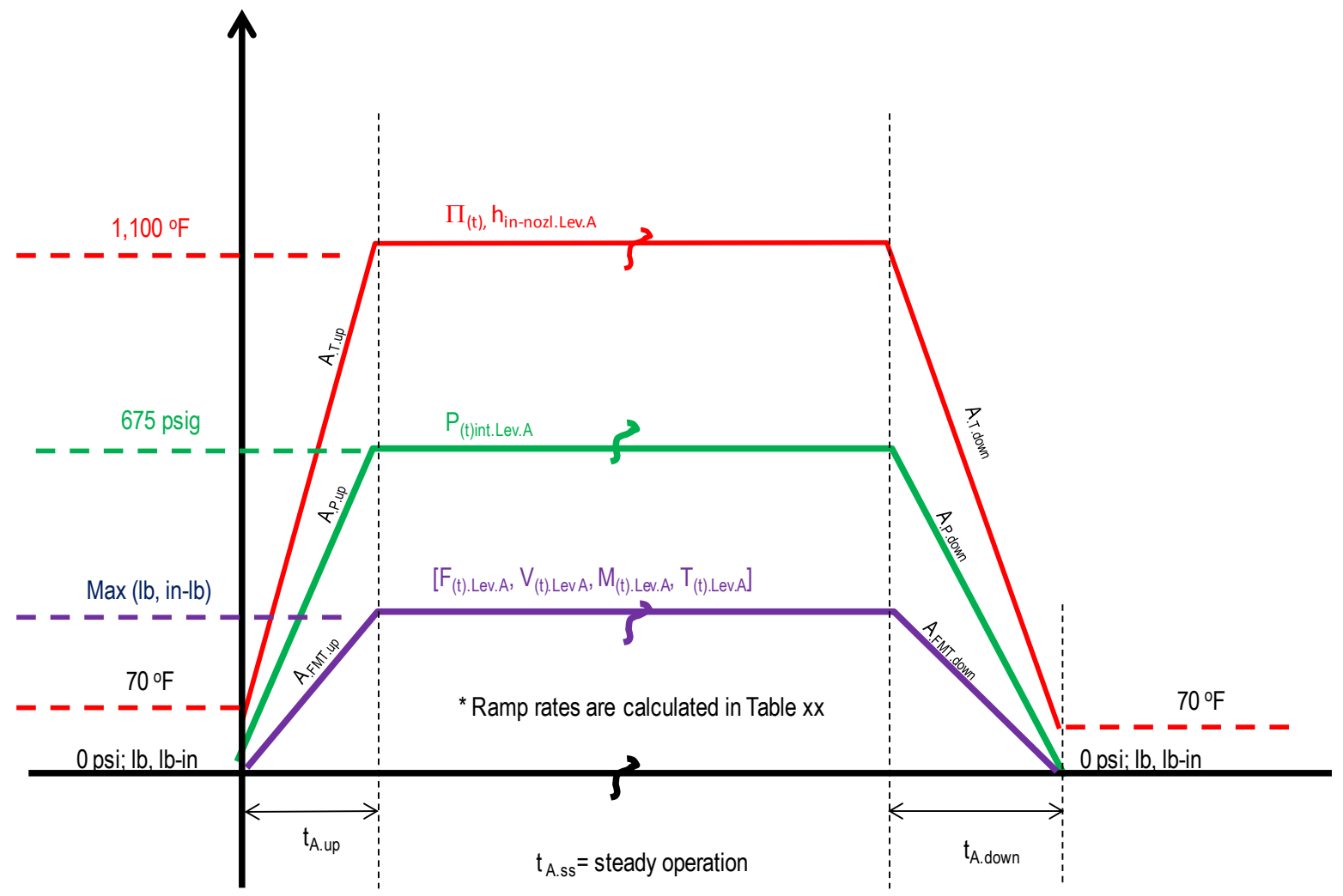

Fig. II-2. Service Level A Loads and Load Combinations; loadings versus time 


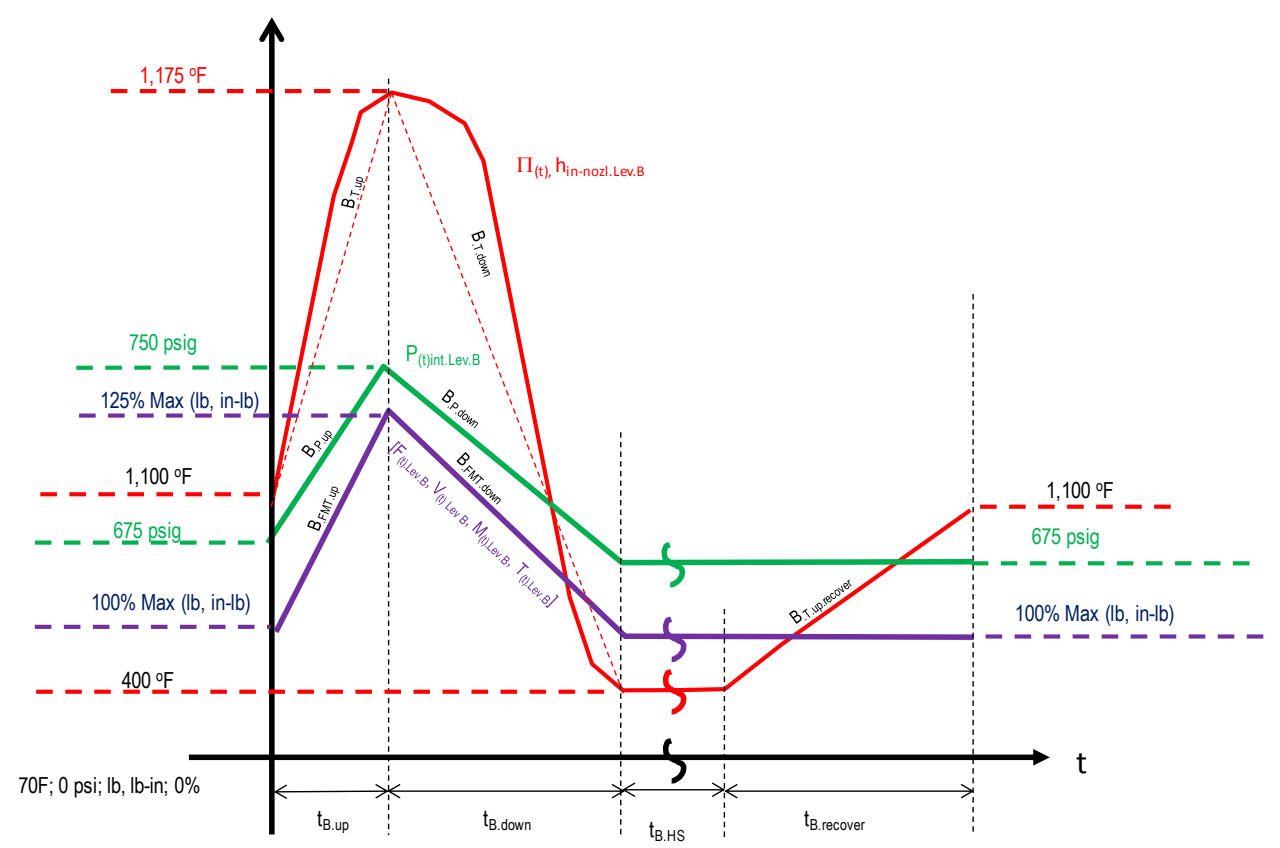

Fig. II-3. Service Level B Loads and Load Combinations; loadings versus time

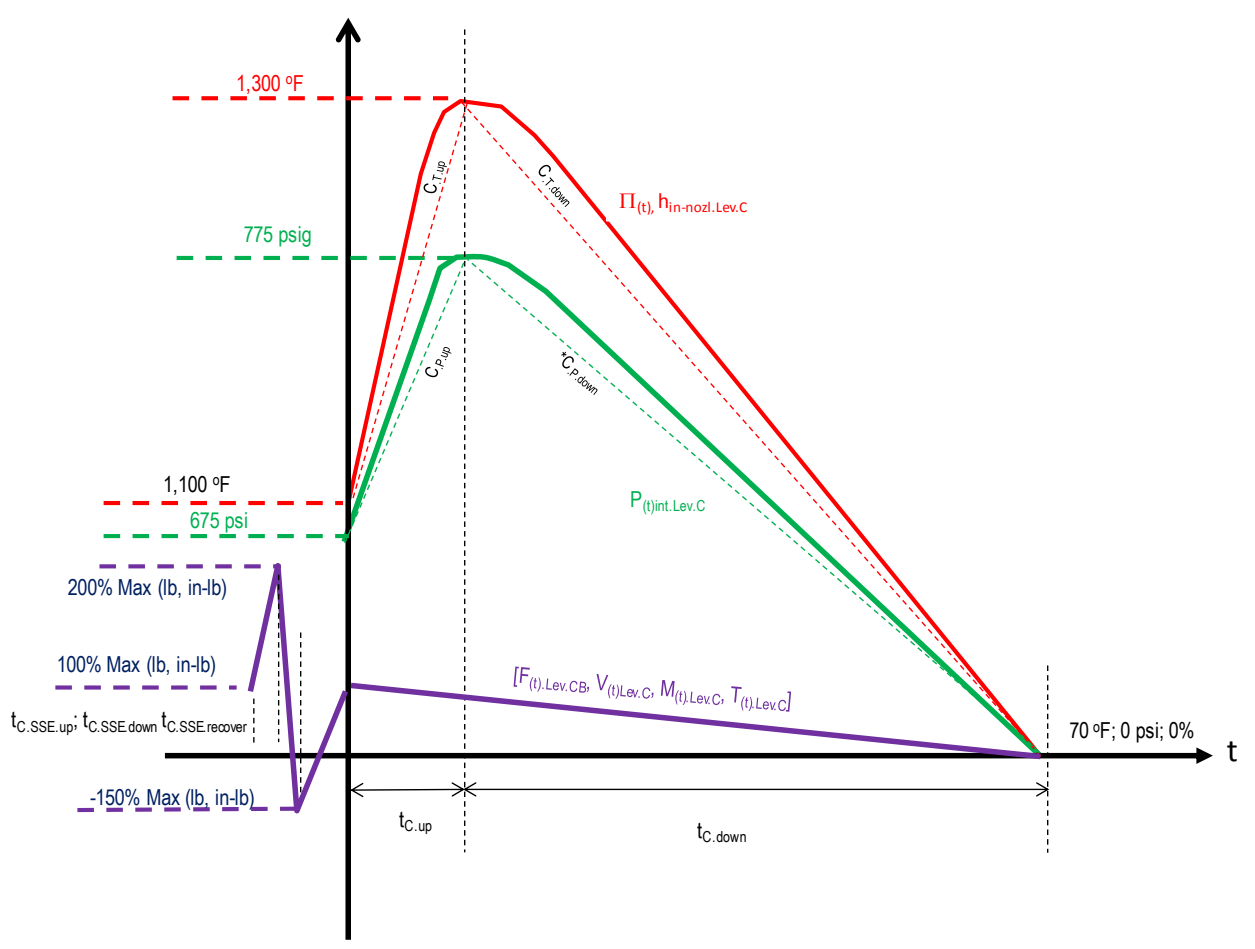

Fig. II-4. Service Level C Loads and Load Combinations; loadings versus time 
From these specified loading conditions, the Code Case procedure requires that a composite cycle be defined which encompasses the critical features of the individually defined cycles. The reason for this is the elastic-perfectly plastic methodology used in the code case bounds the long term response independent of the number of applied cycles. In this respect it is similar to the current simplified rules in Subsection HB, Subpart B. The resultant composite cycle definitions are shown in Fig. I-5 and Fig. I-6 for Level $\mathrm{A}$ and $\mathrm{B}$ and Level $\mathrm{A}$ and $\mathrm{C}$ respectively.

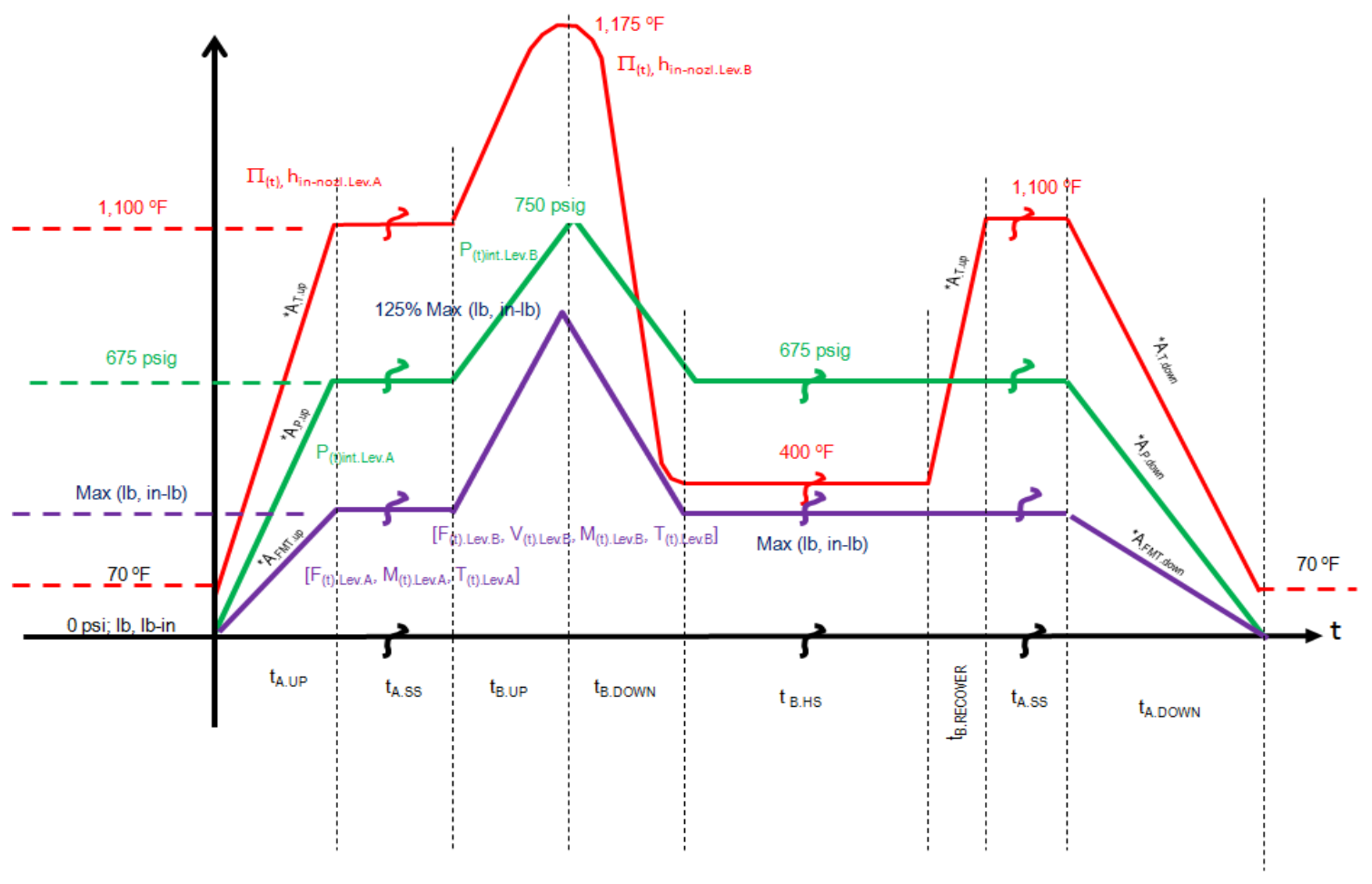

Fig. II-5. Level A and B Composite Cycle 


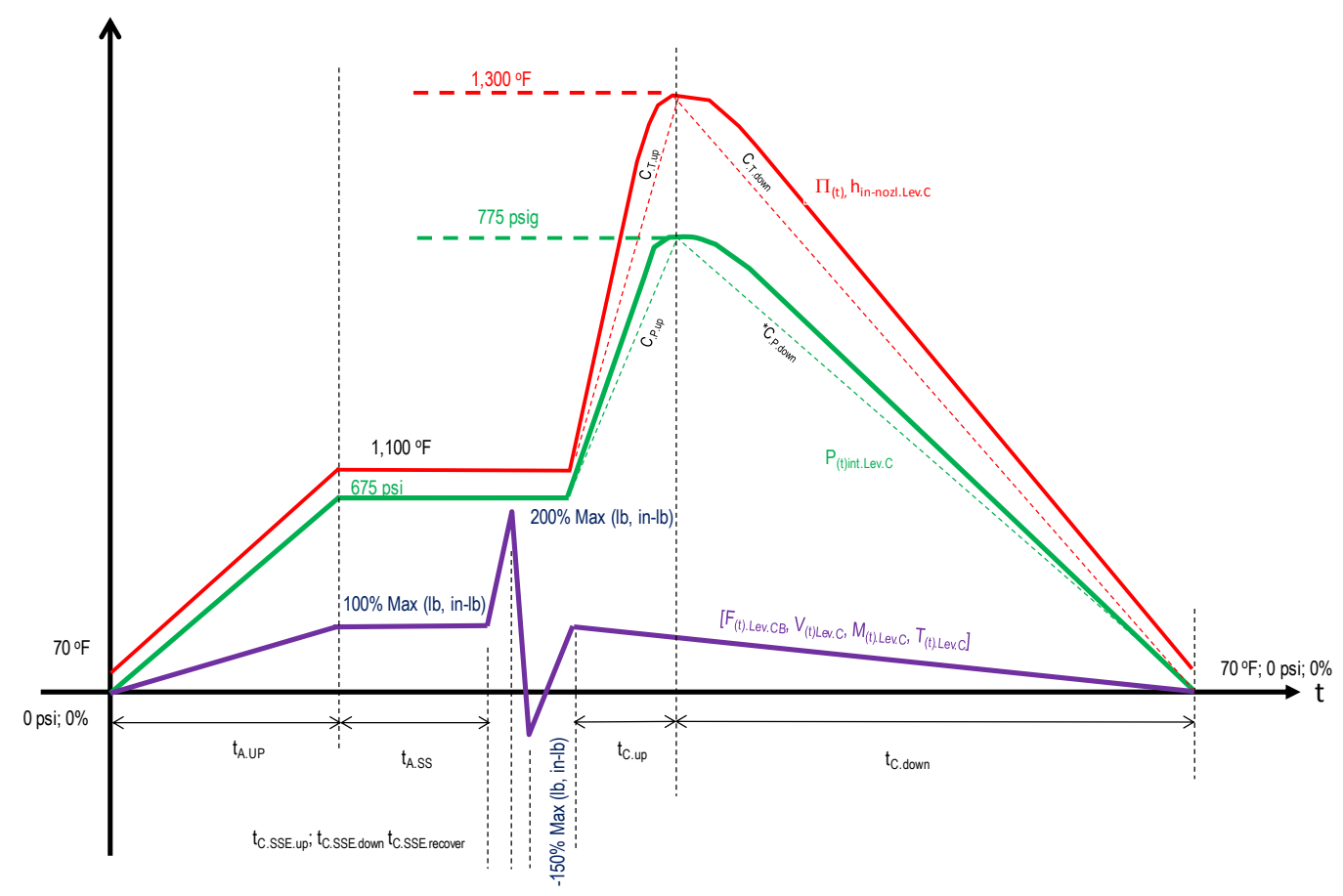

Fig. II-6. Level A and C Composite Cycle

Note that two sets of conditions are defined; one set for Service Levels A and B and the other for Service Levels A and C. A feature of the proposed code case is that, unlike the current version of Subsection HB, Subpart B, the worst case combinations of Service Level A and B do not need to be combined directly with Service Level C. The rationale for this is that, in accordance with the definition of Service Levels, shutdown for inspection and repair or replacement is required after a Level C event whereas the reactor system may resume planned operation after Level A and B events. The number of Level C events is limited as it is in the lower temperature Division 1, Subsection NB rules, but, unlike the NB rules, assessment of the high temperature displacement controlled failure modes, strain limits and creep-fatigue, is required to guard against creep damage not measurable externally which might contribute to restraints on the remaining life when subjected to subsequent Level A and B conditions.

\section{II-3.1.2. FEA model and material properties}

The FEA models are shown in Fig. I-7, without the weld zone, Fig. I-8, with the weld zone, from Hollinger and Pease (2014). The model consists of 8-node linear brick elements with full integration for stress analysis and 8-node linear heat transfer brick elements for that analysis. The same mesh is used for both the stress and heat transfer element types. The supporting mesh density study is shown in Appendix A of Hollinger and Pease (2014). 


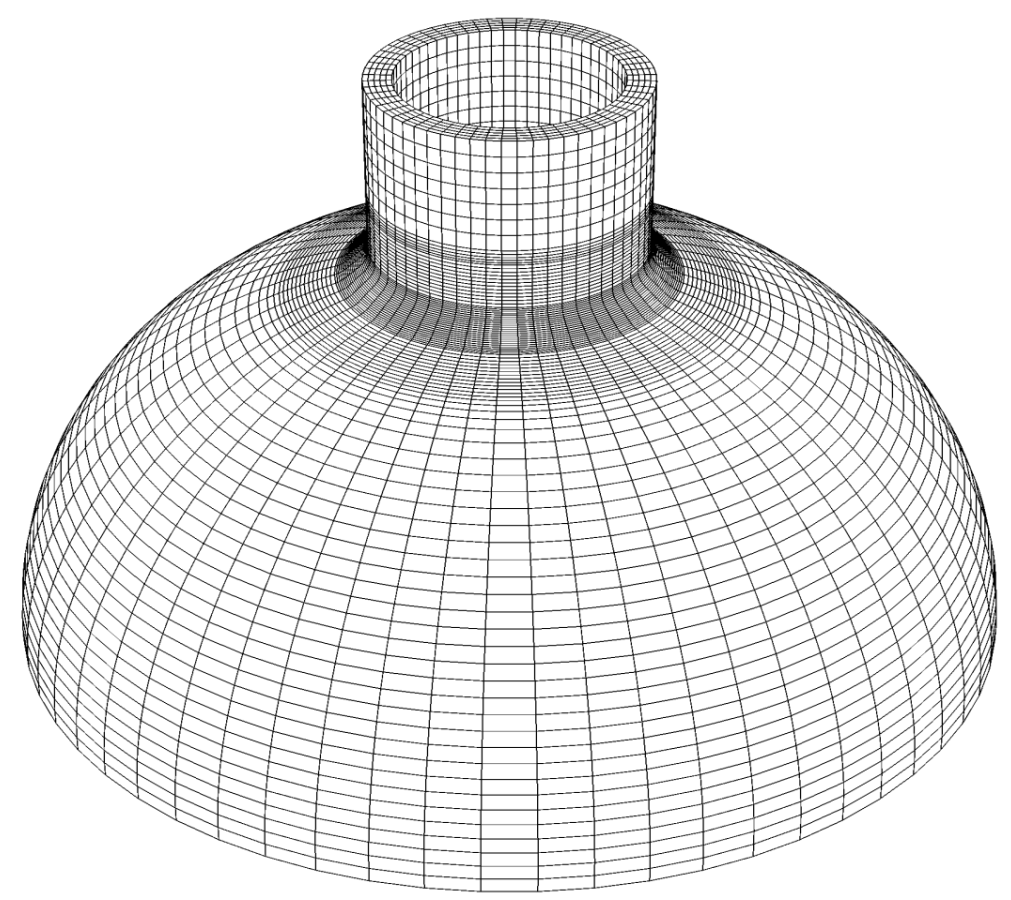

Fig. II-7. Nozzle to Sphere Example Problem FEA Mesh Without Weld Zone

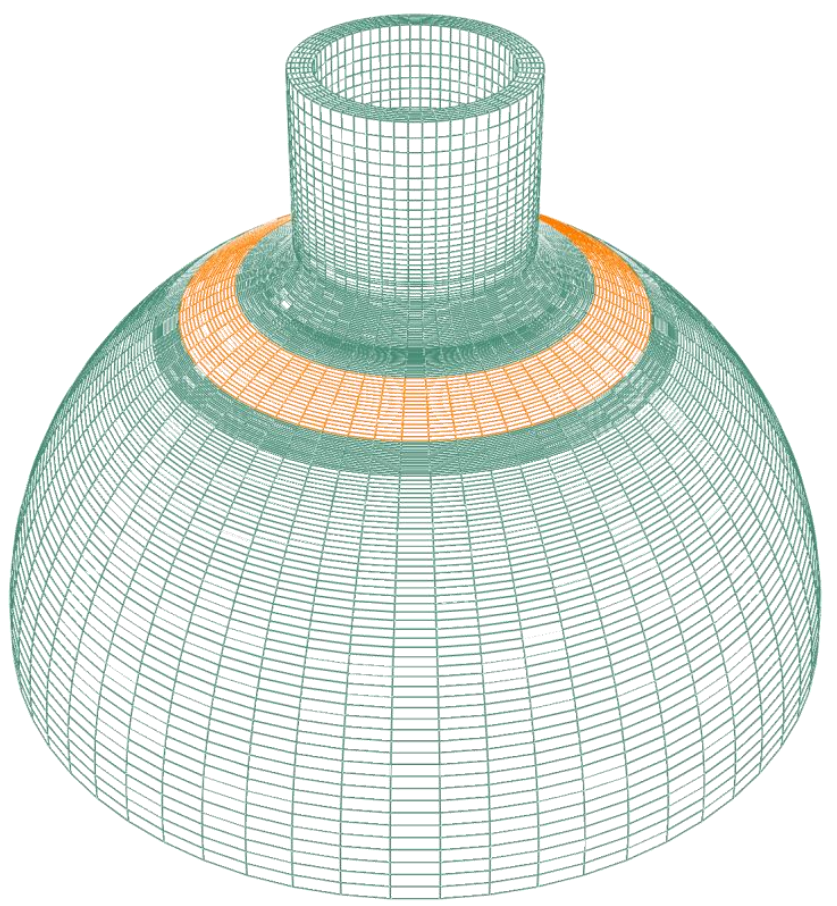

Fig. II-8. Nozzle to Sphere Example Problem FEA Mesh Without Weld Zone

The representative example problem evaluation is based on $316 \mathrm{H}$ forged stainless steel; selected because it is currently included in Subsection HB, Subpart B and properties are readily available. 


\section{II-3.1.3 Methodology}

Two types of analyses are run for each set of composite cycles. A transient heat transfer analysis is performed to establish the temperature field in the vessel throughout the composite cycle. A representative FEA plot is shown below, Fig. I- 9, illustrating the temperature distribution at the end of the Service Level B peak up ramp to $1175^{\circ} \mathrm{F}$.

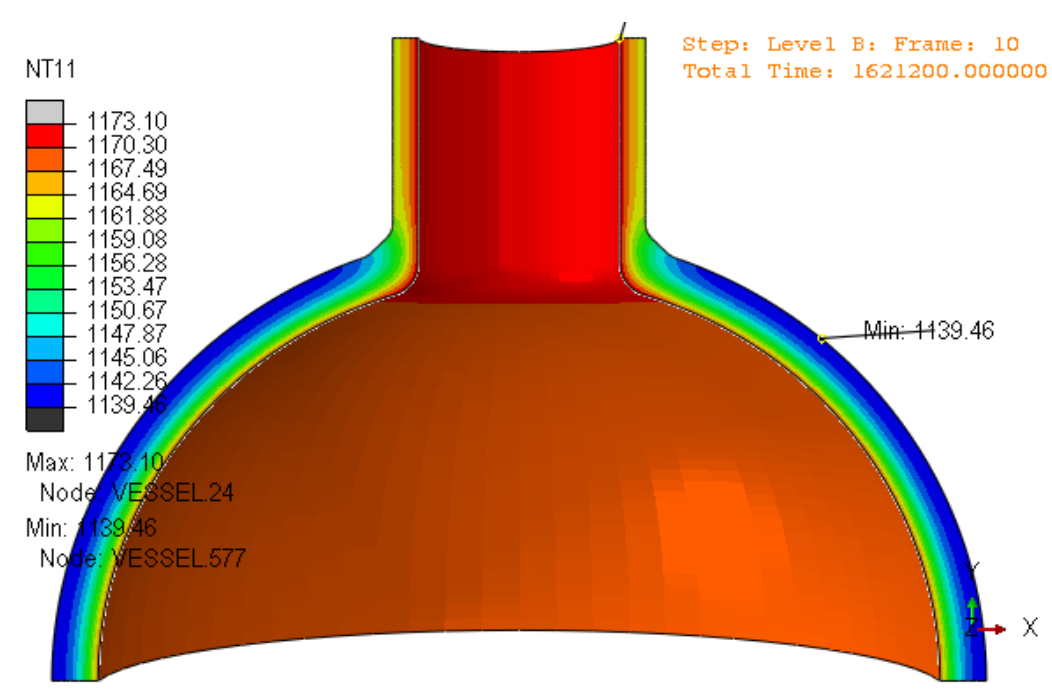

Fig. II-9. Level B Peak Up $\left(1175^{\circ}\right.$ F)

Stress analyses are performed with the time dependent temperature field results from the heat transfer analysis to obtain the stresses and strains in the vessel due to both mechanical loads and thermal. Note: Each cycle of a stress analysis using a "pseudo yield stress" has no direct correlation to the number of design or fatigue cycles and is hence defined as a "pseudo-cycle". Each composite cycle is broken up into discrete steps and when necessary limits to maximum time increments are applied to ensure that the analysis deals with all the changes within a cycle. The step names and durations are plotted with the time history amplitudes in Fig. I-10 and Fig. I-11. 


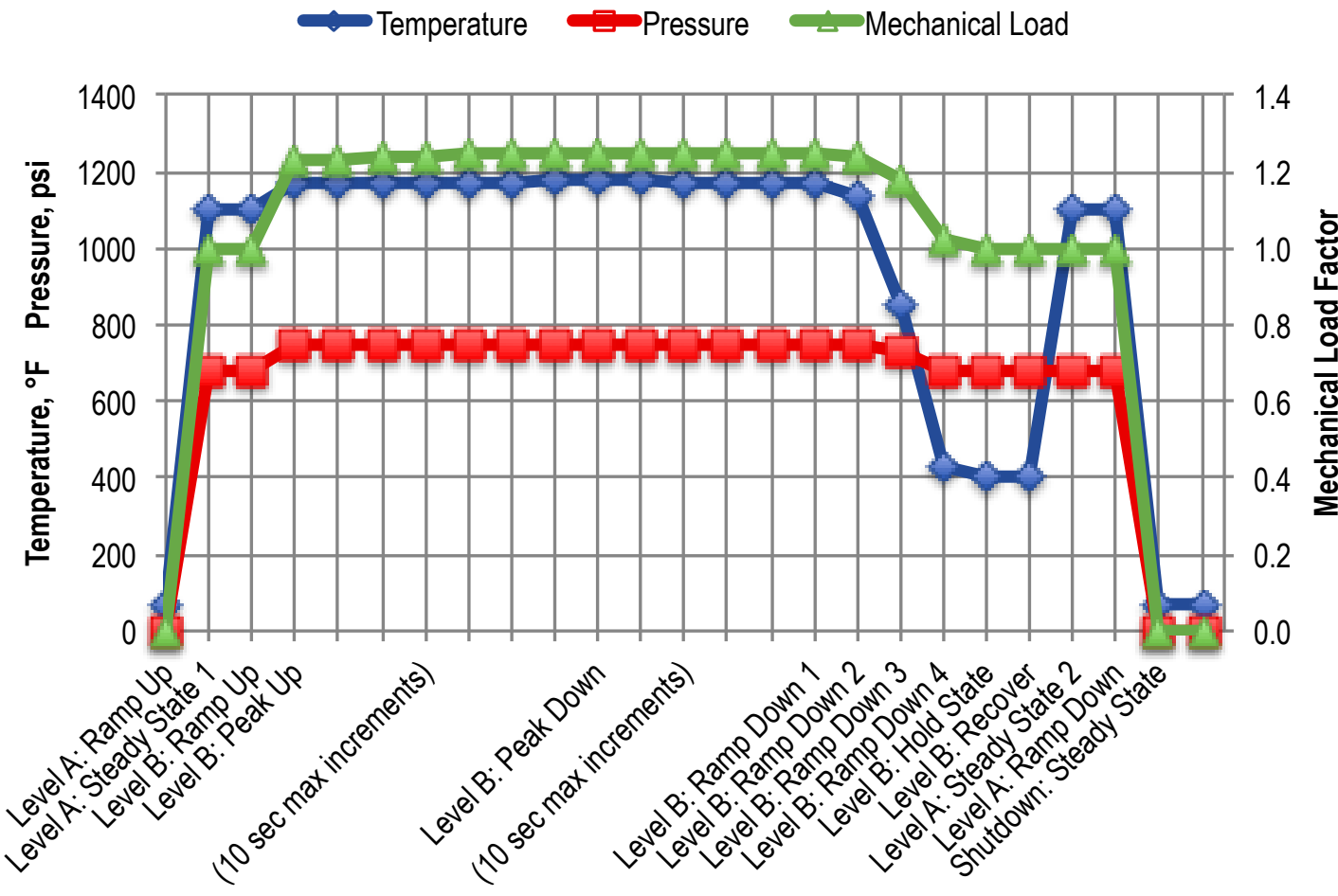

Fig. II-10. Level A\&B Composite Cycle Steps

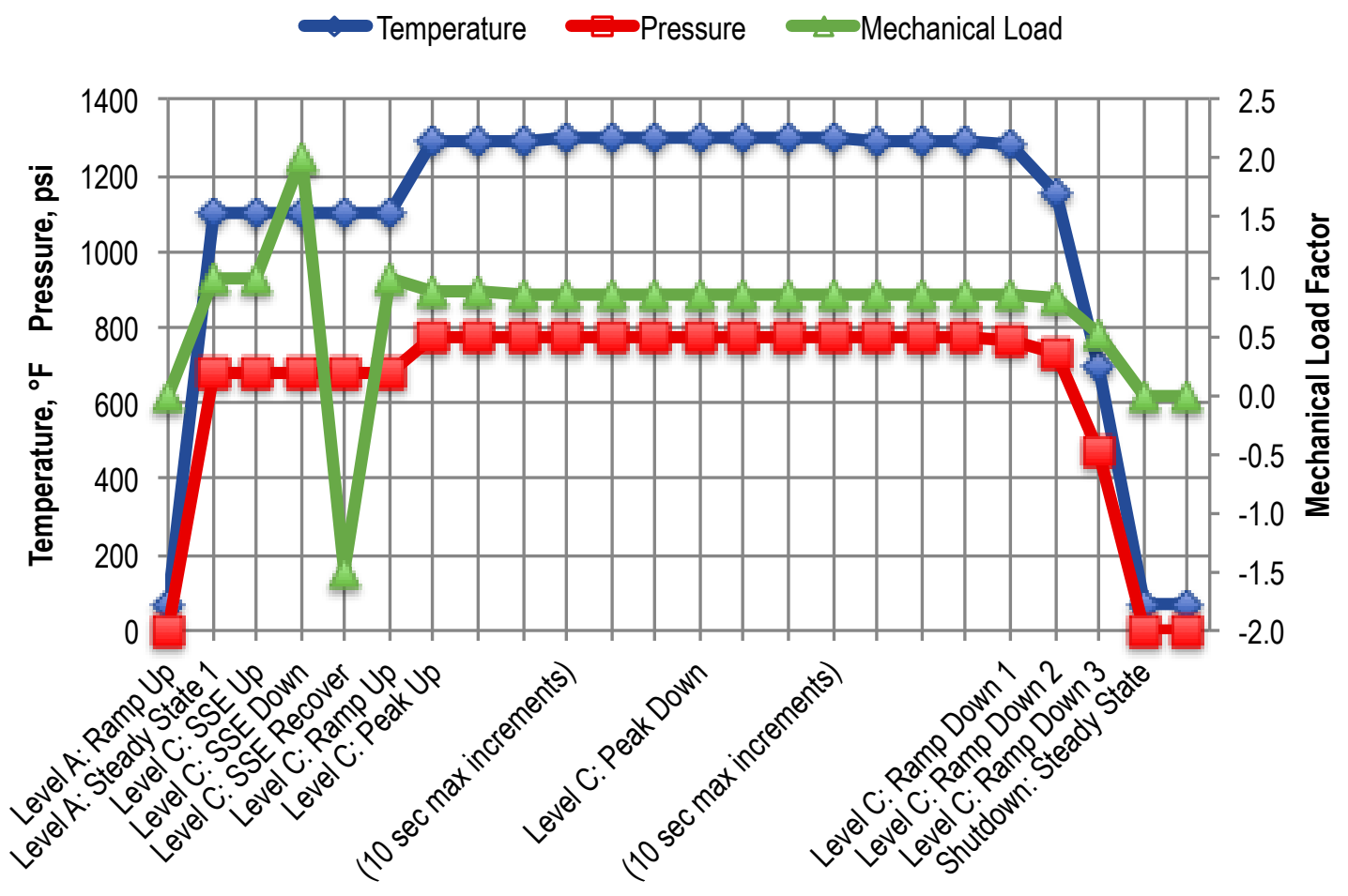

Fig. II-11. Level A \& C Composite Cycle Steps 
A pseudo-cyclic analysis is performed using the restart option to analyze multiple pseudo-cycles of a composite cycle. After the initial pseudo-cycle is analyzed, the analysis is restarted at the end of the previous pseudo-cycle to continue with another set of composite cycle loadings. This restart process is repeated until a sufficient number of pseudo-cycles have been reached.

For the creep-fatigue evaluation, stress analyses are performed where the "pseudo yield stress" is adjusted based on the allowable time duration, $T_{d, k}$, for the current trial, $k$. The allowable time duration is determined by selecting a target cyclic creep damage value, $D_{c, k}$, for trial $k$ (initially selected as 1.0) using the following equation:

$$
T_{d, k}=t_{d} / D_{c, k}
$$

where, $t_{d}$ is the duration of high temperature service.

With the target creep damage selected, a pseudo-cyclic analysis is performed for the current trial. If the pseudo-cyclic analysis does not shakedown for the initial trial (with creep damage of 1.0) then the creep-fatigue evaluation fails since longer $T_{d, k}$ will only make shakedown more difficult.

Shakedown is evaluated at every location in the model by checking the maximum change in plastic strain over every increment of a single pseudo-cycle. Shakedown is achieved when there is no change in plastic strain throughout the whole model during a single pseudo-cycle, i.e. the model is behaving elastic.

Using the strain results from the pseudo-cycle that shakes down, the maximum equivalent strain range, $\Delta \varepsilon_{\text {max }, k j}$, are computed for each cycle type $j$ of trial $k$ over every point in time, $i$, for each potential extreme condition point in time, $o$, at every location in the component:

$$
\Delta \varepsilon_{\max , k j}=\max \left[\frac{\sqrt{2}}{2\left(1+v^{*}\right)} \sqrt{\left(\Delta \varepsilon_{x i}-\Delta \varepsilon_{y i}\right)^{2}+\left(\Delta \varepsilon_{y i}-\Delta \varepsilon_{z i}\right)^{2}+\left(\Delta \varepsilon_{z i}-\Delta \varepsilon_{x i}\right)^{2}+6\left(\Delta \varepsilon_{x y i}^{2}+\Delta \varepsilon_{y z i}^{2}+\Delta \varepsilon_{z x i}^{2}\right)}\right]
$$

where, $v^{*}$ is the Poisson's ratio, and equals to 0.3 [II-Appendix B: Draft EPP Creep-Fatigue Code Case, Section 5.2]; $\Delta \varepsilon_{i}=\varepsilon_{i}-\varepsilon_{o}$ is the change in strain components from potential extreme condition point in time, $o$, to point in time, $i, \mathrm{k}$ to the current point in time, $i$, being evaluated. This ensures that every possible combination of the points in time are considered such that the maximum equivalent strain range is obtained.

A point of consideration, $p$, is selected in the component to evaluate fatigue damage based on the location where the largest strain ranges occur in both the base metal and the weldment. The number of design allowable cycles, $N_{d, k p j}$, are determined for cycle type $j$ of trial $k$ at point $p$ from the design fatigue curve for 316H SS [Subsection HB, Subpart B, Figure HBB-T-1420-1B] where the strain range, $\varepsilon_{t}$, is defined as $\varepsilon_{t}=\Delta \varepsilon_{\max , k j}$ and the maximum metal temperature is $1175^{\circ} \mathrm{F}$ for the $\mathrm{A} \& \mathrm{~B}$ composite cycle and $1300^{\circ} \mathrm{F}$ for the $\mathrm{A} \& \mathrm{C}$ composite cycle. Note: for strain ranges within the weld region, the number of design allowable cycles are reduced by $50 \%$.

The total fatigue damage, $D_{f, k p}$, is computed for trial $k$ at point $p$ : 


$$
D_{f, k p}=\sum_{j} \frac{n_{j}}{N_{d, k p j}}
$$

where, $n_{j}$ is the number of applied cycles for cycle type $j$.

If the total fatigue damage is not less than 1.0 then the creep-fatigue evaluation has failed.

The allowable creep-fatigue damage, $D_{k p}$, is determined for trial $k$ at point $p$ :

$$
D_{k p}=D_{f, k p}+\max \left[\begin{array}{c}
1+\frac{D_{i c}-1}{D_{i f}} D_{f, k p} \\
\frac{D_{i c}}{D_{i f}-1}\left(D_{f, k p}-1\right)
\end{array}\right]
$$

where, $\left(D_{i f}, D_{i c}\right)$ is the creep-fatigue damage envelope intersection parameters [Subsection HB, Subpart B, Figure HBB-T-1420-2], and equals to $(0.3,0.3)$ for $316 \mathrm{H}$ stainless steel

The total creep-fatigue damage for trial $k$ is computed and compared to the allowable damage for trial $k$ at point $p$ :

$$
D_{f, k p}+D_{c, k} \leq D_{k p}
$$

Note: The creep damage used in this equation is not necessarily the creep damage at a specific point, but is the "maximum cyclic creep damage over the structure" as specified in Section 4.4 of the Creep Fatigue Code Case.

If the total creep-fatigue damage exceeds the allowable damage then a reduced target creep damage, $D_{c, k+1}$, is selected for the next trial, $k+1$, based on the following equation:

$$
D_{c, k+1} \leq D_{k p}-D_{f, k p}
$$

The above process is repeated until either the creep-fatigue evaluation passes the criterion of Eqn. (17) or fails due to excessive creep or fatigue damage or both.

\section{II-3.1.4 Results}

Results were generated for two FEA models, base metal only and base metal plus weldment. The results are slightly different due to affect the lower pseudo yield strength of the weldment (reduced by the weld strength reduction factor) has on the surrounding base metal. The following is based on the weldment model with relevant differences noted.

\section{Level A \& B composite cycle evaluation}

The controlling base metal location for both models is at the outer surface of the shell-to-nozzle transition, rotated approximately $45^{\circ}$ from where nozzle bending due to the nozzle end shear load produces maximum strains. The Level A \& B cycle type maximum equivalent strain range at this location for both the base metal only model and the model with the weldment is $0.110 \%$. However, for the Level B 
cycle type they are slightly different, $0.076 \%$ and $0.077 \%$ respectively. The controlling weldment location is on the inside surface of the shell on the outermost weld-base metal interface. The maximum equivalent strain range at this location from both models is $0.083 \%$ for the Level B cycle type and $0.037 \%$ for the Level A cycle type.

The weldment model Level A \& B Composite Cycle analysis with a target creep damage of 0.95 passes after 3 pseudo-cycles. The base metal only model passes with a target creep damage of 0.90, also after 3 pseudo cycles. For the weldment model, the total creep-fatigue damage is 0.954 and the allowable creep-fatigue damage is 0.995 , which is sufficiently greater than the calculated value. This places the creep-fatigue damage within the HBB-T-1420-2 creep-fatigue interaction envelope, thus meeting the criteria for creep-fatigue interaction for the base metal. For the base metal only model, the corresponding total and allowable damages are 0.904 and 0.995 respectively.

In the weld region, the corresponding values of total damage and allowable damage are 0.958 and 0.988 respectively.

\section{Level A \& C composite cycle evaluation}

The base metal only creep-fatigue evaluation for the Level A \& C Composite Cycle with a target creep damage of 1.0 does not pass after 20 pseudo-cycles. The change in plastic strain after each pseudocycle is $0.28 \%$ indicating that stable ratcheting continues and shakedown does not occur. Further reduction of the target creep damage will only produce weaker pseudo-yield stresses, resulting in even more severe ratcheting.

Since the base metal only evaluation did not pass for the Level A \& C Composite Cycle the weldment model evaluation will not pass either.

\section{II-3.2 Creep-Fatigue Code Case to Subsection HB, Subpart B Comparison}

The overall goal of this phase is to assess the design margins in the EPP methodology. This is accomplished through the use of simplified example problem solutions which include comparison to current Subsection HB, Subpart B procedures. Simplified examples are used to avoid the complexities of Subsection HB, Subpart B simplified procedures, particularly when applied to representative geometries and loading.

\section{II-3.2.1 Geometry and material}

Case 1. Plain tube with $\mathrm{r} / \mathrm{t}=4.5$, outer diameter $(\mathrm{OD})=15 \mathrm{in}$, Material: $316 \mathrm{H}$ stainless steel.

Case 2. Plain tube with $\mathrm{r} / \mathrm{t}=3.5, \mathrm{OD}=16 \mathrm{in}$, Material: $316 \mathrm{H}$ stainless steel.

Case 3. Case 1 connected to Case 2, with a 3:1 external taper in wall thickness.

\section{II-3.2.2 Level A/B service loadings}

These calculations will be based on a design pressure of $1.3 \mathrm{ksi}$ in both tubes, and a temperature cycle defined by a uniform $1075^{\circ} \mathrm{F}$ to the temperature distributions defined below.

For tube \#1, consider steady state metal temperatures defined by $1200{ }^{\circ} \mathrm{F}$ in the bore, and $1075{ }^{\circ} \mathrm{F}$ on the OD. Using the formula for thermal stress in a tube with through-wall heat flux in Pitts and Sissom (1998), the radial steady state heat flux for these temperatures is $105 \mathrm{BTU} / \mathrm{in} / \mathrm{in} / \mathrm{hour}$. The steady state bore temperature in tube $\# 2$ for this heat flux and the $1075{ }^{\circ} \mathrm{F}$ tube OD temperature is $1235{ }^{\circ} \mathrm{F}$. A heat flux 
cycle from zero to $105 \mathrm{BTU} / \mathrm{in} / \mathrm{in} /$ hour is used in the following steady state thermal-mechanical calculations.

Thermal-mechanical properties at $1100{ }^{\circ} \mathrm{F}$ are given in Table II-1. Thermal and mechanical elastic stresses are obtained from thick-walled pipe formulas in Roark and Young (1989).

Table II-1. Thermo-mechanical properties of TP316 at $1100{ }^{\circ} \mathrm{F}$

\begin{tabular}{c|c|c|c}
\hline $\begin{array}{c}\text { Spec. Heat } \\
\text { BTU } /\left(\mathrm{lb} \cdot{ }^{\circ} \mathrm{F}\right)\end{array}$ & $\begin{array}{c}\text { Conductivity } \\
\text { BTU } /\left(\mathrm{hr} \cdot \mathrm{in}^{\circ}{ }^{\circ} \mathrm{F}\right)\end{array}$ & $\begin{array}{c}\text { Exp. Coefficient } \\
\text { in/in/ } \mathrm{F}\end{array}$ & $\begin{array}{c}\text { Young's Modulus } \\
\mathrm{ksi}\end{array}$ \\
\hline 143.14 & 1.1055 & $1.029 \mathrm{E}-05$ & 21928 \\
\hline
\end{tabular}

Fig. II-12 shows combined pressure stress and thermal stress contours, and the corresponding linearized stress components. It is seen that the stress contour plot and the linearized plot agree, and the second order mesh density is shown to indicate that this agreement is not due to a coarse mesh.
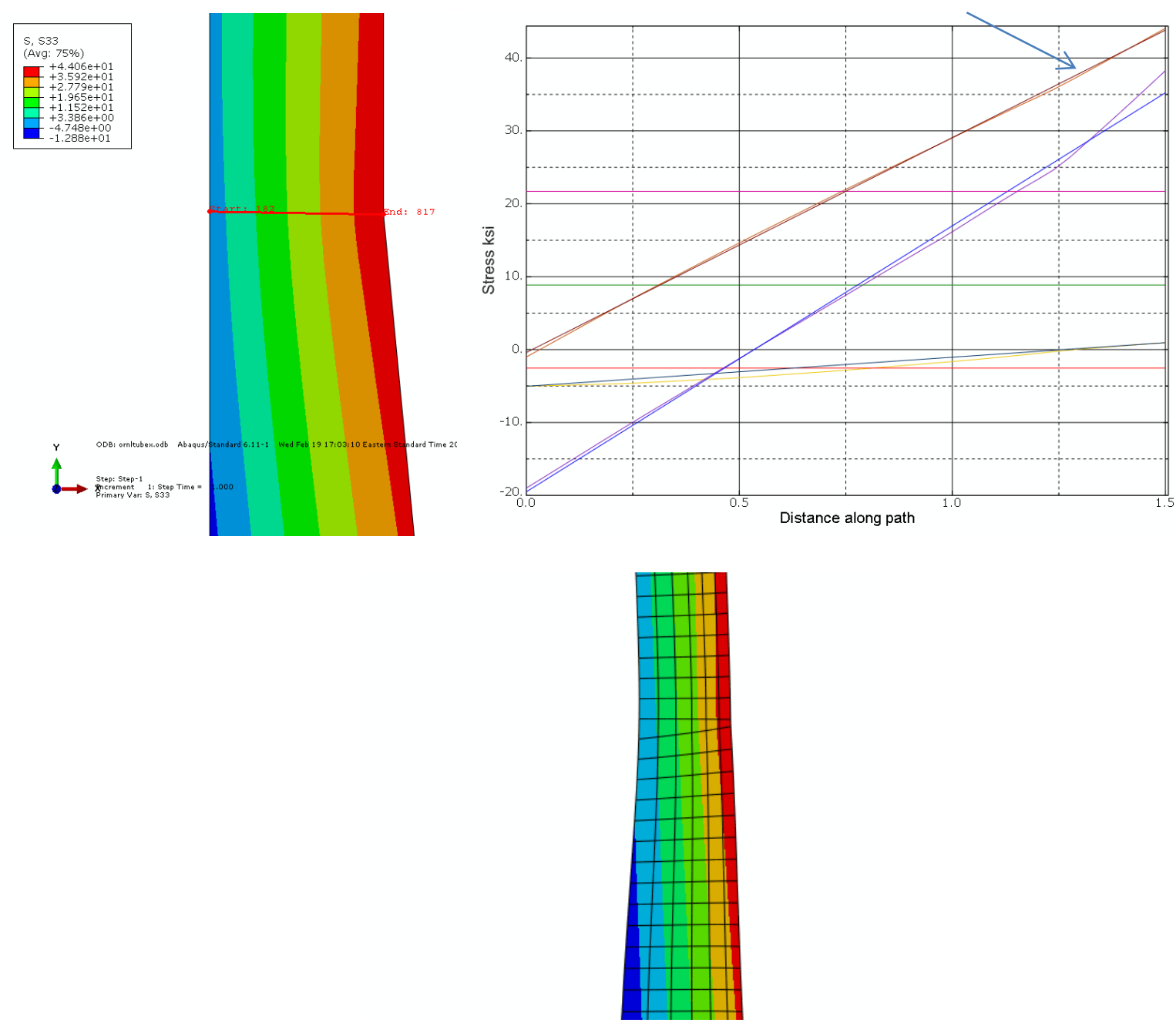

Fig. II-12. Hoop Pressure Plus Thermal Stress. Maximum Value of both Stresses is 44 ksi. Second Order Finite Element Mesh Indicated. 
The equivalence between the maximum stress for these calculations shows that in this case there is no need for a stress concentration factor $K>1$ in the creep-fatigue calculation.

\section{II-3.2.3 HBB-T-1430 limits using elastic analysis}

The HBB-T-1413 calculation of strain range is based on full strain components without distinction between elastic-plastic and thermal components. In these calculations $K=1$ for a non-welded component with stresses as shown in Fig. II-12. The HBB-T-1433 stress and creep damage calculations for a pipe subject to through wall thermal stress cycles proceeds as follows:

- Calculate bore and OD temperatures.

- Calculate axial and circumferential thermal stress and strain.

- Calculate bore radial strain.

- $\mathrm{HBB}-\mathrm{T}-1432$ (a) - (c). Calculate (HBB -T-1413) $\Delta \varepsilon_{\text {equiv }}=\Delta \varepsilon_{\max }=\Delta \varepsilon_{\bmod }\left(K_{n}=K=1\right)$.

- HBB-T-1432 (g). Calculation of $\Delta \varepsilon_{c}$ per cycle from stress $=1.25 \sigma_{c}$ at $1235^{\circ} \mathrm{F}$, where $\sigma_{c}=Z S_{y}$.

- $\mathrm{HBB}-\mathrm{T}-1432$ (h). Total strain range $\Delta \varepsilon_{t}=\Delta \varepsilon_{\mathrm{mod}}+\Delta \varepsilon_{c}$.

- HBB-T-1433 (a). HBB-T-1324. Since $\Delta \varepsilon_{t}>3 S_{m} / E$ relaxation damage calculation per cycle is required.

- HBB-T-1433 Step 4. Calculate initial thermal stress from zero time isochronous data and bore temperature.

- HBB-T-1433 Step 5 (b). Calculate stress relaxation using isochronous data at $1235{ }^{\circ} \mathrm{F}$, limited by $S_{L B}=1.25 \times$ core stress. This limit is reached after 18.5 hours of relaxation. No further (multiaxial) correction is required in Step 5 (b).

- Load controlled stress intensities (primary elastic plus bending value assumed) $=5 \mathrm{ksi}$ and are constant during the cycle. This value is always less than the relaxed stress, and does not affect the damage calculation.

- Calculate fatigue damage based on $\varepsilon_{t}$.

- Calculate creep-fatigue damage with creep-fatigue interaction from Fig. HBB-T-1420-2.

Tube \#2 was assessed for creep-fatigue damage. The results for the thermal stresses and strains for Tube \#2 is shown in Table II-2.

Table II-2. Thermo-mechanical bore strain range: Tube 2 (HBB-T-1413)

\begin{tabular}{c|c|c|c|c|c|c|c}
\hline \multicolumn{3}{c|}{ Bore principal stresses $k s i$} & Temp $^{\circ} \mathrm{F}$ & \multicolumn{4}{c}{ Strains } \\
\hline Hoop & Axial & Radial & & Hoop & Axial & Radial & \\
\hline 4.64 & 1.67 & -1.3 & 1075 & 0.0113 & 0.0112 & 0.0110 & \\
\hline-23.18 & -26.15 & -1.3 & 1235 & 0.0119 & 0.012 & 0.0134 & \\
\hline 4.64 & 1.67 & -1.3 & 1075 & 0.0113 & 0.0112 & 0.011 & $\begin{array}{c}\text { Effective } \\
\text { strain range }\end{array}$ \\
\hline & & & $\begin{array}{c}\text { Strain } \\
\text { ranges }\end{array}$ & 0.0007 & 0.0007 & 0.00243 & $\mathbf{1 . 3 0 E - 0 3}$ \\
\hline
\end{tabular}


Table II-3. Tube 2 strain range per cycle

\begin{tabular}{c|c|c}
\hline Cycle time & $\Delta \varepsilon_{c}$ per cycle & $\varepsilon_{t}$ \\
\hline 100 & $3.481 \mathrm{E}-03$ & $4.768 \mathrm{E}-03$ \\
\hline 300 & $7.421 \mathrm{E}-03$ & $8.527 \mathrm{E}-03$ \\
\hline
\end{tabular}

Table II-4 shows relaxation and creep damage for the strain in Table II-2. The results are limited by the $(1.25 \times$ core stress $)$ relaxation stress limit and the maximum cycle time of 300 hours.

Table II-4. Hot relaxation and creep damage calculation: Tube 2

\begin{tabular}{|c|c|c|c|}
\hline \multicolumn{2}{|c|}{ Relaxation Creep damage } & \multirow{3}{*}{$\begin{array}{l}\text { Strain } \\
1.2901 E-03\end{array}$} & \\
\hline$H B B-T-1433(b)$ & 0.9 & & \\
\hline \multicolumn{3}{|c|}{ stress: Figure HBB-T-1800-B-9 $S_{L B}=12.42 \mathrm{ksi}$} & \\
\hline max stress & $\begin{array}{l}\text { rupture time with } \\
\text { stress } / 0.9\end{array}$ & hours & Damage \\
\hline 19.23 & $1.850 \mathrm{E}+02$ & 0 & 0.00 \\
\hline 16.86 & $4.093 \mathrm{E}+02$ & 1 & 0.01 \\
\hline 13.34 & $1.629 \mathrm{E}+03$ & 10 & 0.03 \\
\hline 12.42 & $2.460 \mathrm{E}+03$ & 18.5 & 0.03 \\
\hline 12.42 & $2.460 \mathrm{E}+03$ & 100 & 0.07 \\
\hline 12.42 & $2.460 \mathrm{E}+03$ & 300 & 0.15 \\
\hline
\end{tabular}

Table II-5 shows the Subsection HB, Subpart B fatigue and relaxation creep damage calculation results, and the creep-fatigue life for the 16" OD tube, for 100 hour and 300 hour cycles respectively. This calculation assumes repeated re-setting and stress relaxation for each cycle as per the requirements of HBB-T-1432. Table II-5 indicates a maximum acceptable life of 1,430 hours for 100 and 300 hour cycles.

Table II-5. Tube 2 creep-fatigue life calculation HBB-T-1411

\begin{tabular}{c|c|c|c|c}
\hline Hours & cycles & cycle time & $\varepsilon_{t}$ & fatigue life \\
\hline 1290 & 12.9 & 100.0 & $4.768 \mathrm{E}-03$ & 324 \\
\hline 1650 & 5.5 & 300.0 & $8.527 \mathrm{E}-03$ & 75 \\
\hline $\begin{array}{c}\text { fatigue } \\
\text { damage }\end{array}$ & creep damage & $c d 1$ & $c f 1$ & Cfdam \\
\hline 3.99E-02 & 0.903 & 0.3 & 0.3 & 1.00 \\
\hline 7.34E-02 & 0.825 & 0.3 & 0.3 & 1.00 \\
\hline
\end{tabular}




\section{II-3.2.4 Analysis of cyclic creep damage using EPP shakedown analysis}

Fig. II-13 shows a series of isochronous stress-temperature data giving rupture in the respective times. The rupture stress includes the Subsection HB, Subpart B factor $K^{\prime}=0.9$. Fig. II-14 and Fig. II-15 show the results of cyclic analysises which identify shakedown or otherwise. Failure to shakedown is indicated by repeated yielding, in this case in the bore of the heavy pipe. Shakedown occurs for 10,000 hours but not for 12,000 hours.

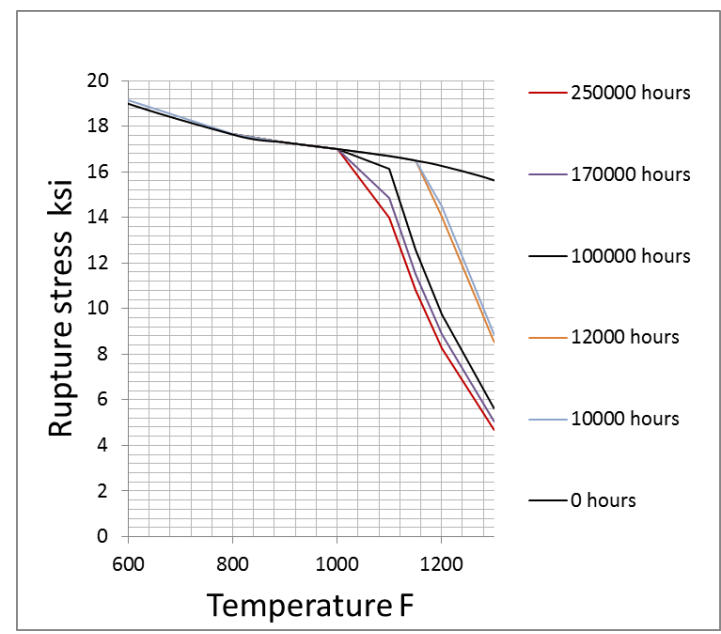

Fig. II-13. 316H Stainless Isochronous Creep Rupture Stress - Temperature Curves
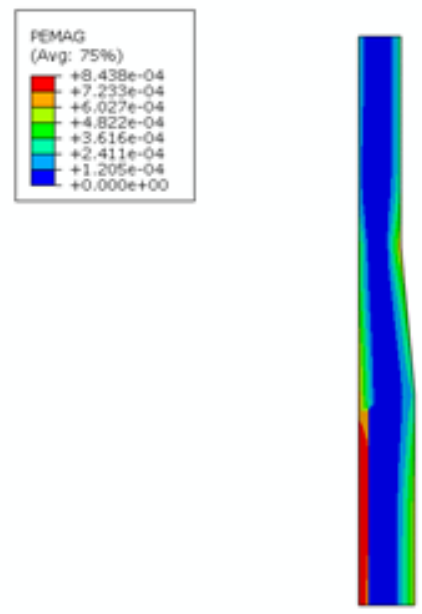

Fig. II-14. Contours of Analysis Plastic Strain. Maximum value in the Bore of Tube \#2 

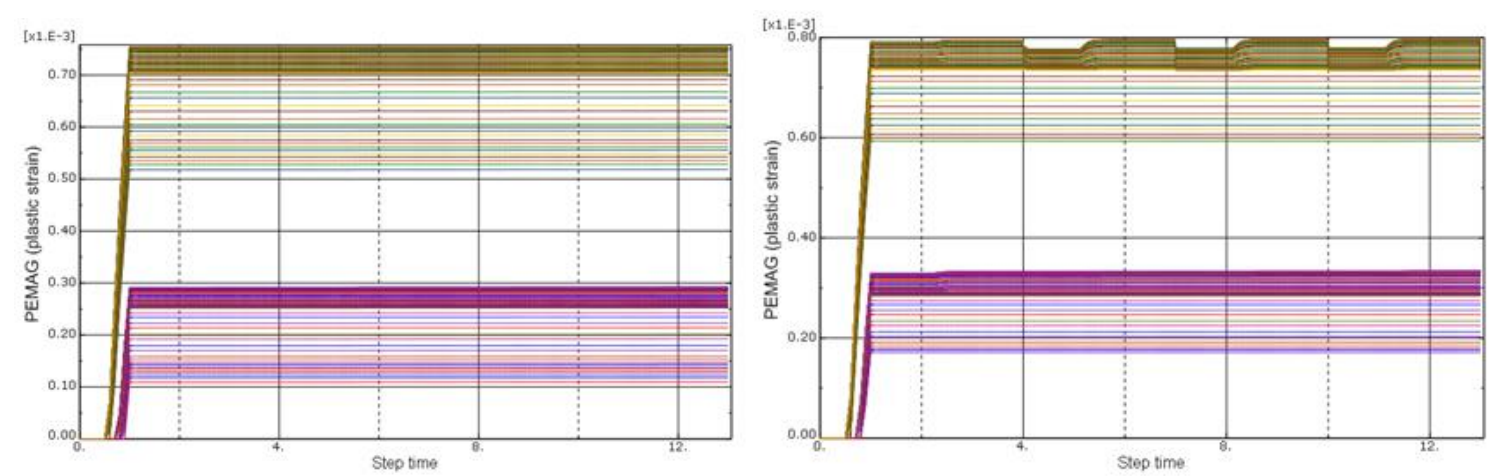

Fig. II-15. Plots of Cyclic Plastic Strain from Tube Bore. Shakedown Obtained for 10,000 Hours Rupture Life, Failure to Shakedown for 12,000 Hours Rupture Life

Table II-6 gives the creep-fatigue calculation with a cyclic creep-fatigue life of 10,000 hours for two cases with different cycle times. Because fatigue damage is insignificant, the results for the two cases are the same.

Table II-6. Tube 2 creep-fatigue life calculation EPP shakedown analysis

\begin{tabular}{c|c|c|c|c}
\hline Hours & cycles & $\begin{array}{c}\text { cycle time } \\
(h)\end{array}$ & $\varepsilon_{t}$ & fatigue life \\
\hline 10,000 & 100.0 & 100.0 & $1.290 \mathrm{E}-03$ & $1.00 \mathrm{E}+05$ \\
\hline 10,000 & 33.3 & 300.0 & $1.290 \mathrm{E}-03$ & $1.00 \mathrm{E}+05$ \\
\hline $\begin{array}{c}\text { fatigue } \\
\text { damage }\end{array}$ & creep damage & $c d 1$ & $c f 1$ & Cfdam \\
\hline $1.00 \mathrm{E}-03$ & 1.00 & 0.3 & 0.3 & 1.00 \\
\hline $3.33 \mathrm{E}-04$ & 1.00 & 0.3 & 0.3 & 1.00 \\
\hline
\end{tabular}

\section{II-3.2.5 Summary}

Creep-fatigue damage was evaluated to compare the results from the current Subsection HB, Subpart B procedures to the results from the proposed creep-fatigue code case using elastic-perfectly plastic methods. The evaluation was done using a relatively thick wall cylinder, 16 inches OD with 2 inches wall thickness. The steady state condition is an inner wall temperature of $1235^{\circ} \mathrm{F}$ and an outer wall temperature of $1075{ }^{\circ} \mathrm{F}$. The heat flux is periodically cycled to zero while maintaining the inner wall temperature constant such that the outer wall temperature equals the inner wall temperature. The material is $316 \mathrm{H}$ stainless steel. The estimated allowable life from the current Subsection HB, Subpart B procedure is 1430 hours as compared to an estimated life of approximately 10,000 hours using the proposed EPP creep-fatigue code case. 


\section{II-4. BOUNDING THEORY EXAMPLE CALCULATION}

\section{II-4.1 Analysis of Strain Controlled Creep-Fatigue Test Specimen}

In this section, the EPP shakedown analysis is applied to the case of a strain-controlled creepfatigue test. The II-Appendix A provides further details of calculations for stress and creep damage for a strain- controlled cyclic test.

Consider an example with ASME Section III, Division 5 Subsection HB, Subpart B Data for $316 \mathrm{H}$ stainless steel at $1400^{\circ} \mathrm{F}$. The test is characterized by a strain cycle $\Delta \varepsilon$ at temperature $T$.

For stress $2.5 \leq \sigma \leq 12 k s i$, creep and damage rates are:

$$
\begin{aligned}
& \frac{d \varepsilon_{c}}{d t}=k \sigma^{n}, \\
& \frac{d D_{c}}{d t}=k^{\prime} \sigma^{n^{\prime}}
\end{aligned}
$$

where constants $k, k^{\prime}, n, n$ ' are shown in Table II-7.

Table II-7. Creep and damage constants for $316 \mathrm{H}$ stainless steel at $1400{ }^{\circ} \mathrm{F}$. Units: ksi, ${ }^{\circ} \mathrm{F}$, hours

\begin{tabular}{c|c|c}
\hline & strain rate $(n, k)$ & damage rate $\left(n^{\prime}, k^{\prime}\right)$ \\
\hline$n, n^{\prime}$ & 5.192 & 4.369 \\
\hline$k, k^{\prime}$ & $2.1992 \mathrm{E}-09$ & $5.2083 \mathrm{E}-08$ \\
\hline
\end{tabular}

The solutions of interest are:

- Assuming the test strain range shakes down, that is $E \Delta \varepsilon \leq 2 \sigma_{y}$, the EPP solution, which has equal and opposite stresses, is:

$$
\begin{gathered}
\sigma_{1}=E \Delta \varepsilon / 2 \\
\sigma_{2}=-\sigma_{1}
\end{gathered}
$$

- Steady cyclic creep solution $\sigma(t)$ satisfied the following equations, derived in II-Appendix A.

$$
\begin{gathered}
\frac{\sigma^{1-n}(t)}{1-n}-\frac{\sigma^{1-n}(0)}{1-n}=-E k t \\
\sigma(t)=\left[\sigma^{1-n}(0)+(n-1) E k t\right]^{\frac{1}{1-n}} \\
D_{c}=\frac{k^{\prime}}{k E\left(n-1-n^{\prime}\right)}\left[\sigma^{n^{\prime}+1-n}(t)\right]_{0}^{\tau / 2}
\end{gathered}
$$

- The ratio of the cyclic creep and EPP solution damage calculations is: 


$$
\frac{n-1}{n-1-n^{\prime}} \frac{\left[\sigma^{n^{\prime}-n+1}(t)\right]_{0}^{\tau / 2}}{\left[\sigma^{1-n}(t)\right]_{0}^{\tau / 2}[[\sigma(0)+\sigma(\tau / 2)] / 2]^{n^{\prime}}}
$$

Examples of relatively rapid and slow cycles for strain range $=0.001$ at $1400{ }^{\circ} \mathrm{F}$ are shown in Fig. II-16 and Fig. II-17. These figures show cyclic relaxation stress histories, the constant EPP reference stresses, and creep damage calculated from the creep and EPP stress histories, respectively. Fig. II-16 represents a cycle time of 1 hour, and Fig. II-17 represents a cycle time of 10 hours. The relaxation stress history is calculated from Eqns. (19) and (20), and the creep damage from Eqn. (21).

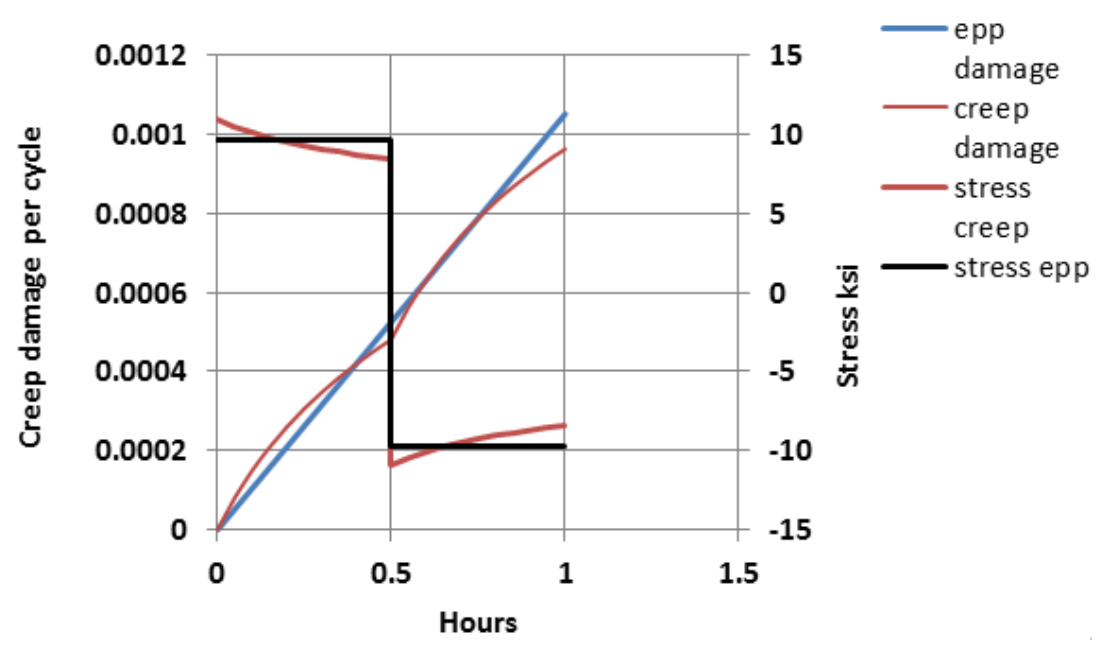

Fig. II-16. Stress and damage histories for 1 hour cycle time

These figures show the conservatism of the EPP creep damage calculation compared with the relaxation creep damage calculation. The conservatism increases for longer cycle times, as shown in Fig. II-17 which is calculated from Eqn. (22).

Fig. II-18 shows the ratio of the relaxation creep damage to the EPP design value, $D_{c} / D_{e p p}$. For realistic values of the creep strain rate and creep damage rate exponents $n$ and $n$ ' as in Table 2.6.1, $D_{c} / D_{e p p} \leq 1$. Values of the creep damage exponent $n^{\prime} \geq \sim 2 n$ are required to give $D_{c} / D_{e p p} \geq 1$. The ratio $D_{c} / D_{e p p}$ always decreases as hold time increases. Alternatively, as $\tau \rightarrow 0, D_{c} / D_{e p p} \rightarrow 1$. 


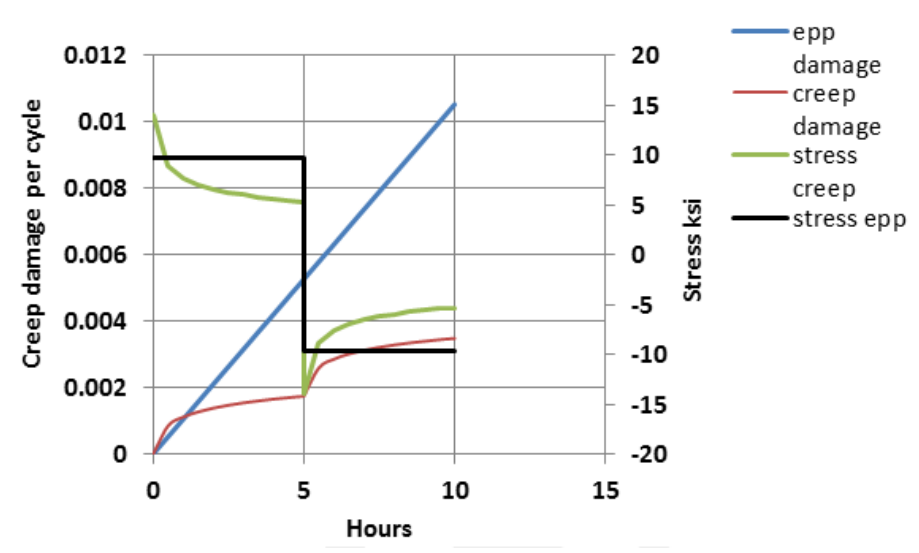

Fig. II-17. Stress and damage histories for 10 hour cycle time

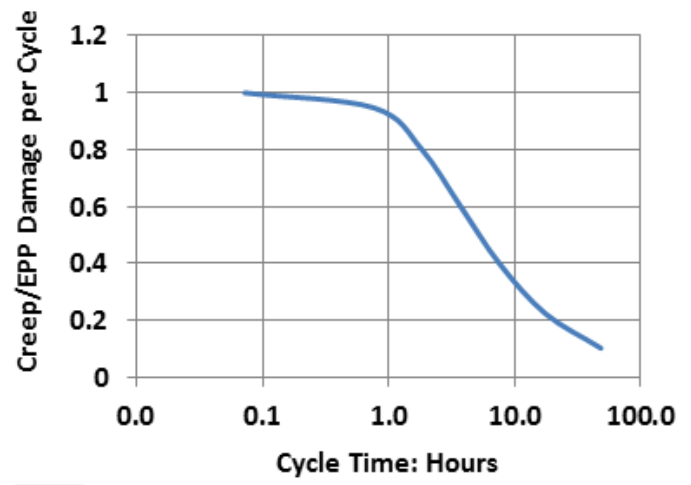

Fig. II-18. Effect of Cycle Time on EPP Conservatism

\section{II-4.2 Process Flow Procedure for Bounding Creep Damage in Creep-Fatigue Specimen}

This procedure illustrates the bounding characteristics of the EPP creep-fatigue evaluation without resorting to theoretical arguments. Thus demonstrating the validity of the basic theory as applied to this specific simplified example.

- The example problem, Fig. II-19 is the same as used in II-3.3.1 and II-Appendix A. It is a uniform bar with a cyclic displacement controlled load. For evaluating creep damage due to the realistic steady cyclic solution, the material behavior is assumed to be elastic-creep. For illustration only, it will be assumed that fatigue damage is negligible. The trial life, $t$, is the longest life for which the applied displacement amplitude, $\delta$, causes the uniform bar to just shake down with a time dependent pseudo yield strength $S_{c t}$. 


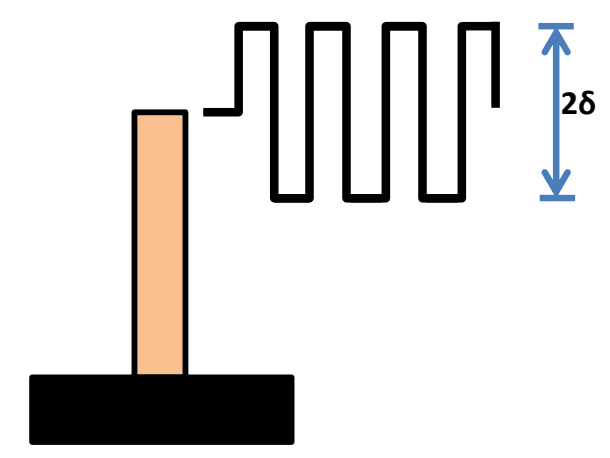

Fig. II-19. Applied Loading

- The trial pseudo yield strength is based on the creep-rupture strength as a function of time and temperature. (Note, the design factor, $K$, is omitted from this example for clarity.)

- Iterate the trial time and corresponding pseudo yield stress until the elastic-perfectly plastic solution reaches the longest time for which elastic shakedown is achieved. (Note, for the code case evaluation, it will be conservative to use a trial time that shakes down but may not be the longest achievable). This is the EPP solution as shown in Fig. II-20, where $0,1, \ldots 5$ are the corresponding loading points in the time independent composite cycle, $\pm \delta$, and $S_{c t}$ is the pseudo yield strength.

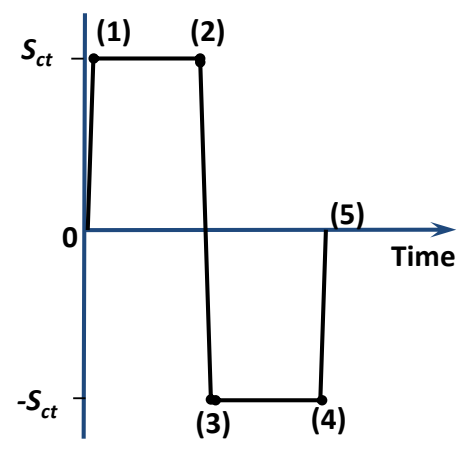

Fig. II-20. EPP Solution

- Since the EPP loading sequence is time independent it also represents the bounding creep damage due to $n$ cycles with period $\tau$ where $n \tau=t$, the trial time used to define $S_{c t}$. See Fig. II-20 repeated below and Fig. II-21. 


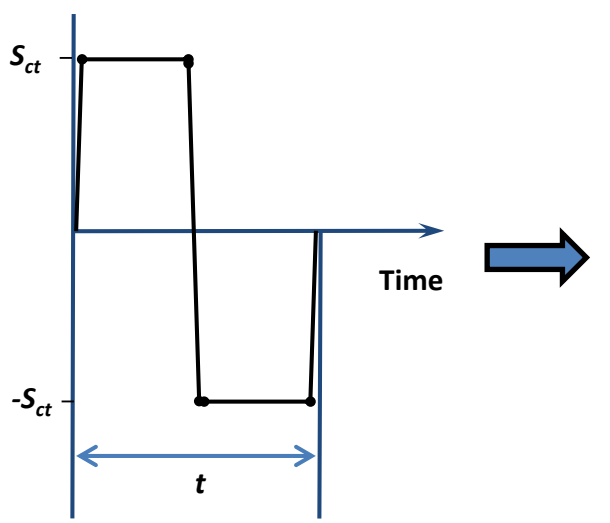

Fig. 20

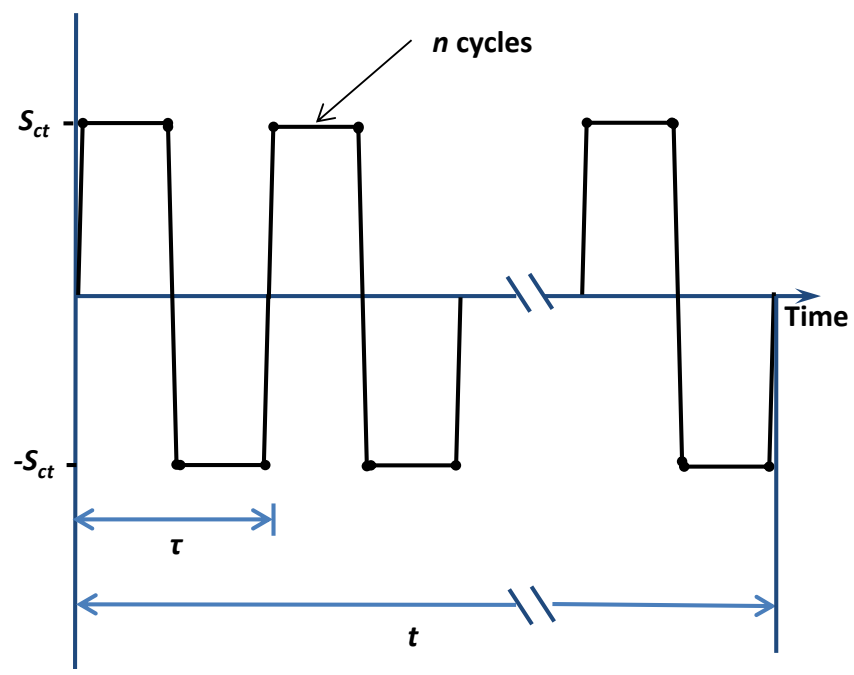

Fig. II-21. EPP Solution with Period $t$

- However, Fig. II-22 is equivalent to the rapid cycle solution (RC) for this problem and it has been shown in II-3.3.1 and II-Appendix A that the rapid cycle solution for this example bounds the actual steady cyclic creep solution for the same loading and period. See Fig. II-21 repeated and Fig. II-22 below.

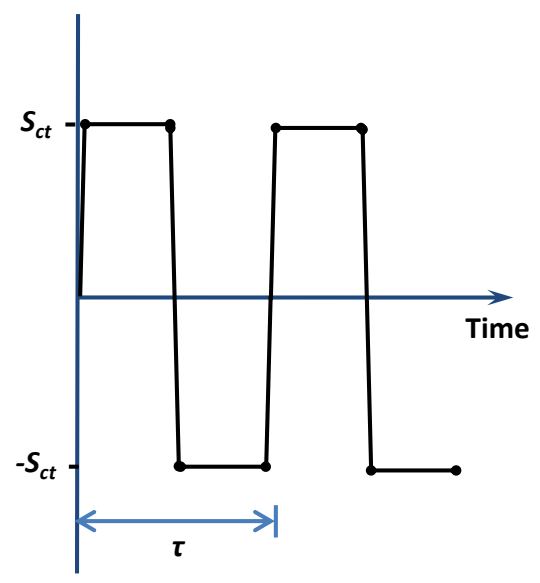

Fig. 21

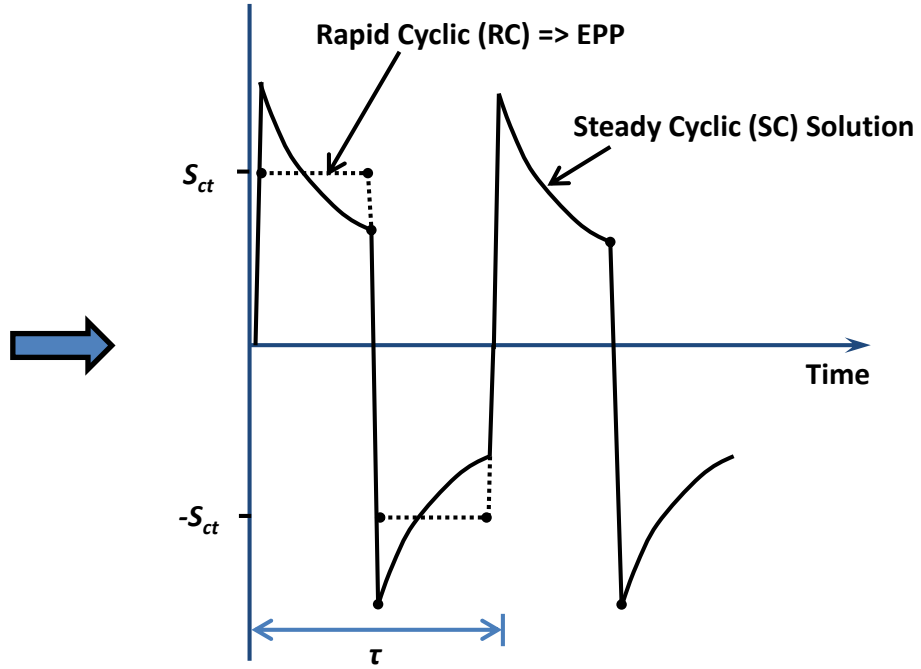

Fig. II-22. Bounding solution Compared to Analytical Solution 


\section{II-5 EXPERIMENTAL RESULTS COMPARISON}

\section{II-5.1 Experimental Procedure}

The experimental procedure is based on modified creep-fatigue test specimens that incorporate elastic follow-up characterization of stress and strain redistribution due to creep. Suitably sized specimens based on elastic-follow-up concepts are cycled to failure and the data generated used to evaluate the applicability of the EPP methodology. Elastic follow-up can cause larger strains in a structure with displacement controlled loading than would be predicted using an elastic analysis. These strain concentrations may result when structural parts of different flexibility are connected in series and loaded by an applied displacement and the flexible parts are highly stressed. This approach to creep-fatigue testing is referred to as the Simplified Model Test (SMT) approach as proposed by Jetter (1998).

The basic concept of the SMT methodology is shown in Fig. II-23. The component design is represented by a stepped cylinder with a stress concentration at the shoulder fillet radius. The component has a global elastic follow-up, $q_{n}$, which is due to the interaction between the two cylindrical sections, and a local follow-up, $q_{L}$, which is due to the local stress concentration. Generally, $q$ is the ratio of the elastic follow-up strain to the elastically calculated strain. If the thick cylinder is displaced radially inward a fixed amount, $\delta_{\text {comp }}$, there will be a maximum strain at the stress concentration. Although the actual strain may be higher, the relevant parameter in this approach is the maximum elastically calculated strain in the component, $\varepsilon_{E \text {, comp }}$. The effects of plasticity, creep and strain redistribution are accounted for in the SMT simulation.

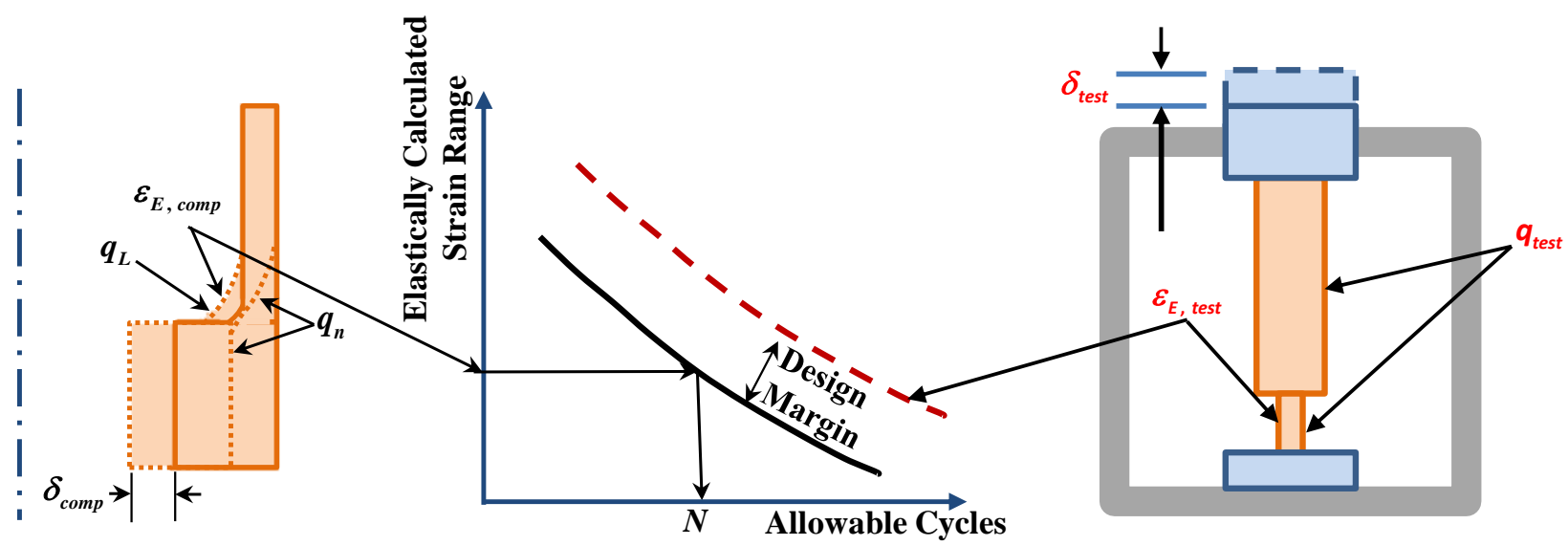

(a) Shell structure with stress concentration and elastic follow-up (b) Design curve

(c) Hold time creep-fatigue test with elastic follow-up

Fig. II-23. SMT methodology

In order to be effective, the SMT specimen must be sized to provide a stress-strain hysteresis loop under cyclic loading which envelopes the hysteresis loop of components of interest. 
Two Alloy 617 specimens were initially tested for the specimen geometry, Type I geometry, shown in Fig. II-24 and consistent results were achieved by Wang et.al. (2013). The applied displacement amplitude of 4.5 mils was selected to allow an elastically calculated strain range of $0.3 \%$ in the necked test section. Fig. II-25is the resultant strain range history measured between a 0.4 -inch section inside the necked test section. Note that the measured strain range is about twice the strain range calculated assuming elastic response to the applied loading.

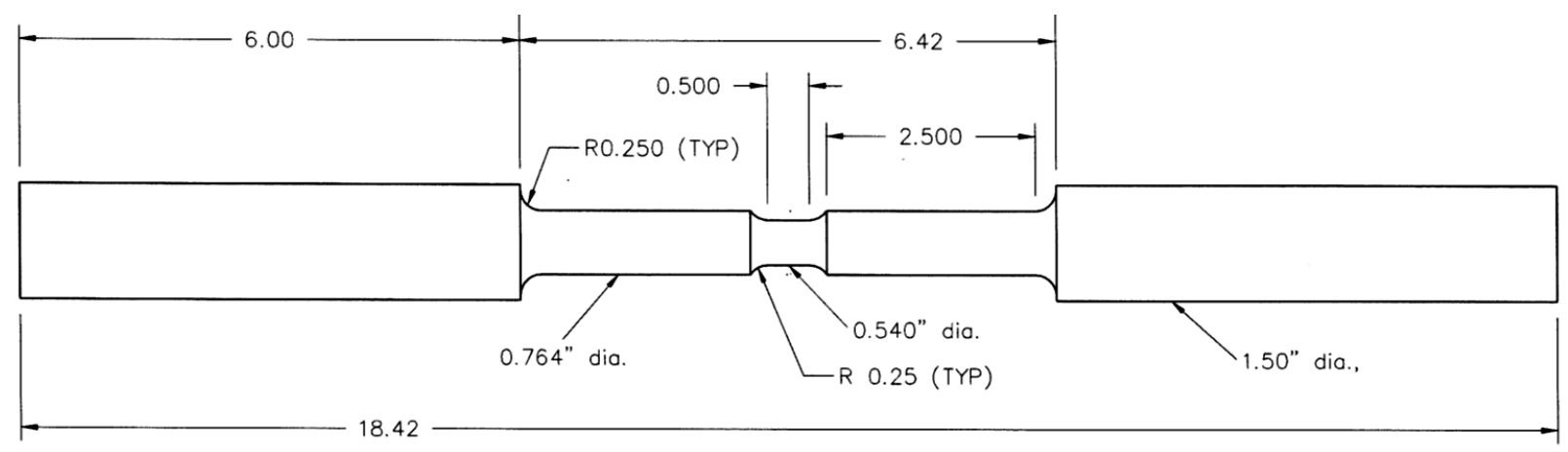

Fig. II-24. Type 1 SMT specimen geometry.

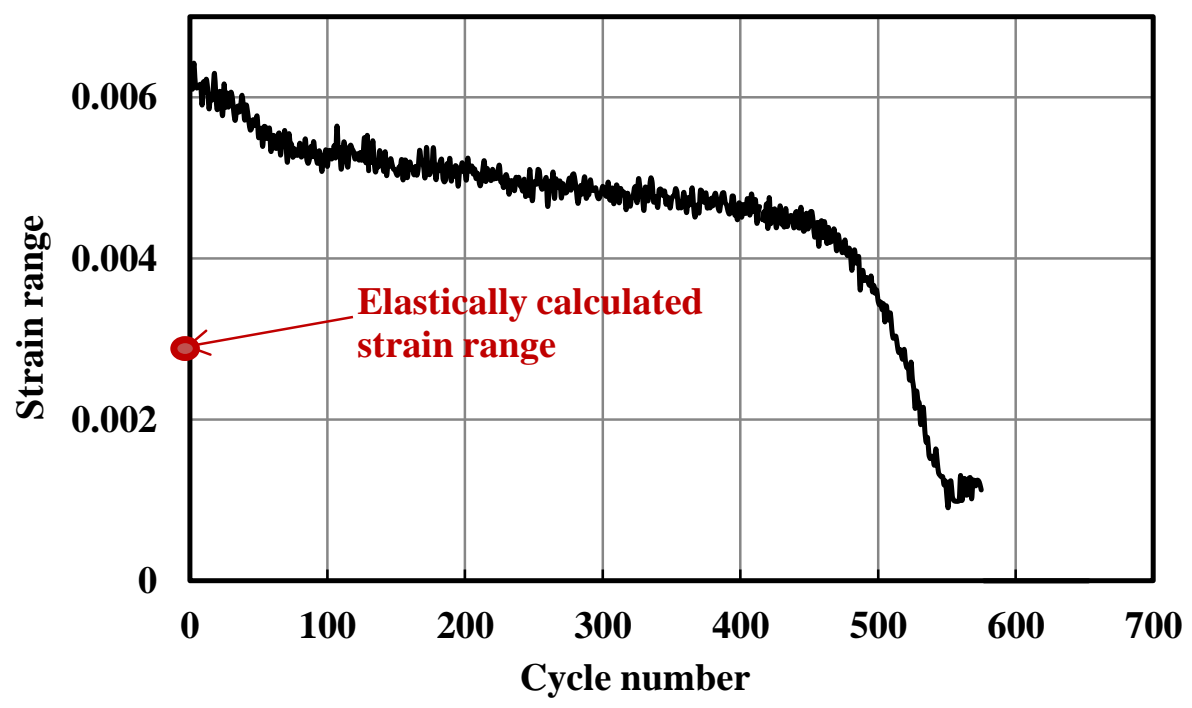

Fig. II-25. Strain range history of Alloy 617 Type 1 SMT

Fig. II-26 shows the stress relaxation history for the first cycle. Also shown as a comparison is the relaxation history of a strain controlled cycle with the same level of strain range as reported by Carroll et al. (2010). Note that the stress relaxation rate is slower and the stress history is higher in the SMT results. This is the expected effect from consideration of elastic follow-up, the stress relaxation rate will be reduced by a factor equivalent to the follow-up factor, $q$, which will result in a higher stress history, and hence more creep damage and shorter creep-fatigue life. 


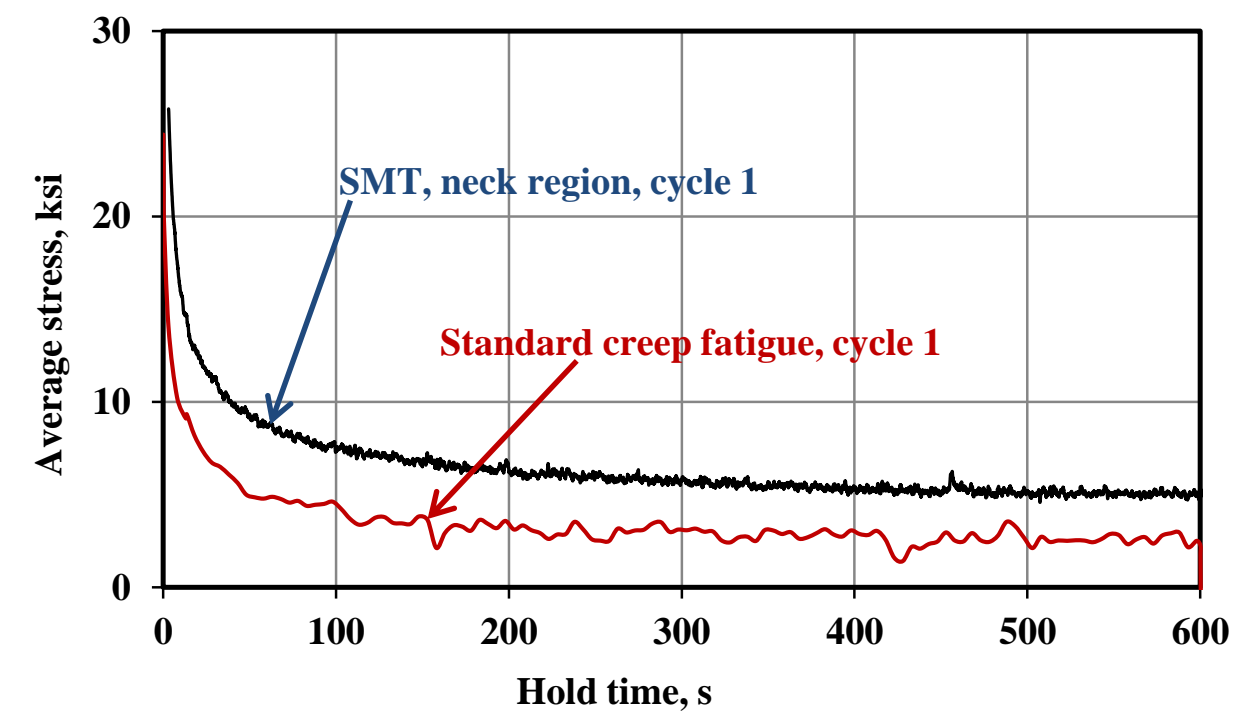

Fig. II-26. Stress relaxation during the hold period for Type 1 SMT necked test section and standard creep-fatigue specimen, Carroll et al. (2010).

\section{II-5.2 Elastic-Perfectly Plastic Simulation on Alloy 617 Creep-Fatigue}

Creep-fatigue tests have been conducted on Alloy 617 standard ASTM creep-fatigue specimens at $850{ }^{\circ} \mathrm{C}$ and $950{ }^{\circ} \mathrm{C}$, and on key-feature test articles of Alloy 617 at $950{ }^{\circ} \mathrm{C}$. The key feature test articles, the so-called Simplified Model Test (SMT) geometries, were developed to mock up the effects of elastic follow-up in reactor pressure boundary components. These data provide an opportunity to assess the conservatism of the EPP creep-fatigue procedure developed for very high temperature applications.

Young's modulus, $E$, shear modulus, $G$, yield strength, $S_{y}$, minimum rupture strength, $S_{r}$, and pseudo yield stress are material parameters required in the EPP creep-fatigue evaluation procedure. The temperature dependence of $E, G$ and $S_{y}$ for Alloy 617, given in the units of MPa, are given as

$$
\begin{gathered}
E\left(T_{k}\right)=-7.57834280 \times 10^{-6} T_{k}^{3}-3.06384586 \times 10^{-3} T_{k}^{2}-52.8928996 T_{k}+227.043102 \times 10^{3} \\
G\left(T_{k}\right)=-6.14747367 \times 10^{-6} T_{k}^{3}+5.87486911 \times 10^{-3} T_{k}^{2}-25.2278723 T_{k}+88.4508513 \times 10^{3} \\
S_{y}\left(T_{k}\right)=240 \times\left(\begin{array}{l}
-2.78261712 \times 10^{-9} T_{k}^{3}+6.45428719 \times 10^{-6} T_{k}^{2} \\
-4.96338300 \times 10^{-3} T_{k}+1.98846231
\end{array}\right)
\end{gathered}
$$

where $T_{k}$ is the absolute temperature in kelvin. The data for $S_{y}$ were based on testing to high temperature ASTM tensile testing standard.

The correlation for the minimum rupture strength in the units of MPa was given by Eno et al. (2008) as: 


$$
S_{r}=A^{-1 / m} \exp \left(-\frac{Q}{m R T_{k}}\right) t_{r}^{1 / m}
$$

where $t_{r}$ is the rupture time in hours and

$$
\begin{gathered}
A=\exp \left(\beta_{0}\right), \quad Q=R \beta_{1}, \quad m=\beta_{2}+\beta_{3} / T_{k} \\
\beta_{0}=-[20.07+0.356 z] \times \ln (10), \quad \beta_{1}=37531 \times \ln (10), \quad \beta_{2}=1.20, \quad \beta_{3}=-7568 \\
z=1.645, \quad R=8.31447215
\end{gathered}
$$

The pseudo yield stress is given as:

$$
\text { pseudo yield stress }=\text { lesser of }\left(S_{y}, K^{\prime} S_{r}\right)
$$

where $K^{\prime}$ is a design factor that has a value of 0.9 .

The EPP creep-fatigue code case specifies the use of a pseudo yield stress corresponding to a trial time $T_{d}^{\prime}$ that is greater than or equal to the design time $t_{\text {design }}$ for the EPP finite element analysis. A trial time of $T_{d}^{\prime}=t_{d e s i g n}$ sets the critical condition for assessing if shakedown to elastic action would take place. That is, if an EPP finite element analysis could not demonstrate shakedown to elastic action when $T_{d}^{\prime}=t_{\text {design }}$ is used to set the pseudo yield stress, shakedown to elastic action would not take place for any other selected time $T_{d}^{\prime}>t_{\text {design }}$ to set the pseudo yield stress.

\section{II-5.3 Standard Alloy 617 Creep-Fatigue Tests}

The geometry of the standard creep-fatigue test specimen, with a gage diameter of $7.49 \mathrm{~mm}$, conforms to the ASTM E2714 standard. The tests were conducted under uniform temperature and strain controlled conditions. Loading and unloading within a creep-fatigue cycle were carried out at a prescribed strain rate, and a strain hold was imposed at maximum tensile strain within the cycle for a specified period. The straining cycles were fully reversed cycles.

For the consideration of these set of tests with respective to the EPP creep-fatigue procedure, the design time is taken to be the life time of the creep-fatigue test specimen, and hence it is calculated as time per cycle multiplied by the observed/measured cycles to failure. The creep-fatigue test conditions and the test data, which were provided by L. Carroll of the Idaho National Laboratory, are shown in Table II-8. 
Table II-8. Test conditions and data of Alloy 617 standard ASTM creep-fatigue test specimens

\begin{tabular}{|c|c|c|c|c|c|c|c|c|c|}
\hline $\begin{array}{l}\text { Case } \\
\text { ID }\end{array}$ & $\begin{array}{c}\text { Spec. } \\
\text { ID }\end{array}$ & $\begin{array}{c}\text { Test } \\
\text { Temp } \\
\text { (deg. } \\
\text { C) }\end{array}$ & $\begin{array}{c}\text { Total } \\
\text { Strain } \\
\text { Range } \\
(\%)\end{array}$ & $\begin{array}{c}\text { Tensile } \\
\text { Hold } \\
\text { Time }(s)\end{array}$ & Env. & $\begin{array}{c}\text { Strain } \\
\text { Rate }(/ s)\end{array}$ & $\begin{array}{c}\text { Cycle } \\
\text { Time (hr) }\end{array}$ & $\begin{array}{l}\text { Cycles } \\
\text { to } \\
\text { Failure }\end{array}$ & $\begin{array}{l}\text { Life } \\
\text { Time } \\
\text { (hr) }\end{array}$ \\
\hline 1 & B-5 & 950 & 0.3 & 180 & air & $1.00 \mathrm{E}-03$ & $5.17 \mathrm{E}-02$ & 3989 & 206 \\
\hline 2 & B-6 & 950 & 0.3 & 180 & air & $1.00 \mathrm{E}-03$ & $5.17 \mathrm{E}-02$ & 2485 & 128 \\
\hline 3 & A-22 & 950 & 0.3 & 600 & air & $1.00 \mathrm{E}-03$ & $1.68 \mathrm{E}-01$ & 4430 & 746 \\
\hline 4 & B-7 & 950 & 0.3 & 600 & air & $1.00 \mathrm{E}-03$ & $1.68 \mathrm{E}-01$ & 4096 & 689 \\
\hline 5 & B-9 & 950 & 0.3 & 600 & air & $1.00 \mathrm{E}-03$ & $1.68 \mathrm{E}-01$ & 2623 & 442 \\
\hline 6 & B-8 & 950 & 0.3 & 1800 & air & $1.00 \mathrm{E}-03$ & $5.02 \mathrm{E}-01$ & 4650 & 2333 \\
\hline 7 & A-23 & 950 & 0.6 & 180 & air & $1.00 \mathrm{E}-03$ & $5.33 \mathrm{E}-02$ & 950 & 51 \\
\hline 8 & B-16 & 950 & 0.6 & 180 & air & $1.00 \mathrm{E}-03$ & $5.33 \mathrm{E}-02$ & 922 & 49 \\
\hline 9 & A-14 & 950 & 0.6 & 600 & air & $1.00 \mathrm{E}-03$ & $1.70 \mathrm{E}-01$ & 547 & 93 \\
\hline 10 & B-18 & 950 & 0.6 & 600 & air & $1.00 \mathrm{E}-03$ & $1.70 \mathrm{E}-01$ & 686 & 117 \\
\hline 11 & B-19 & 950 & 0.6 & 600 & air & $1.00 \mathrm{E}-03$ & $1.70 \mathrm{E}-01$ & 634 & 108 \\
\hline 12 & B-21 & 950 & 0.6 & 1800 & air & $1.00 \mathrm{E}-03$ & $5.03 \mathrm{E}-01$ & 661 & 333 \\
\hline 13 & $4 \_1 \_10$ & 850 & 0.3 & 180 & air & $1.00 \mathrm{E}-03$ & $5.17 \mathrm{E}-02$ & 1944 & 100 \\
\hline 14 & 4_1_12 & 850 & 0.3 & 180 & air & $1.00 \mathrm{E}-03$ & $5.17 \mathrm{E}-02$ & 2547 & 132 \\
\hline 15 & 4_1_20 & 850 & 0.3 & 600 & air & $1.00 \mathrm{E}-03$ & $1.68 \mathrm{E}-01$ & 1475 & 248 \\
\hline 16 & $4 \_1 \_22$ & 850 & 0.3 & 600 & air & $1.00 \mathrm{E}-03$ & $1.68 \mathrm{E}-01$ & 1750 & 295 \\
\hline 17 & 4_2_9 & 850 & 0.3 & 600 & air & $1.00 \mathrm{E}-03$ & $1.68 \mathrm{E}-01$ & 2104 & 354 \\
\hline 18 & 4_7_1 & 850 & 0.3 & 1800 & air & $1.00 \mathrm{E}-03$ & $5.02 \mathrm{E}-01$ & 1200 & 602 \\
\hline 19 & 4 4_7_3 & 850 & 0.3 & 1800 & air & $1.00 \mathrm{E}-03$ & $5.02 \mathrm{E}-01$ & 1255 & 630 \\
\hline 20 & 4_2_1 & 850 & 1.0 & 180 & air & $1.00 \mathrm{E}-03$ & $5.56 \mathrm{E}-02$ & 544 & 30 \\
\hline 21 & 4_2_4 & 850 & 1.0 & 180 & air & $1.00 \mathrm{E}-03$ & $5.56 \mathrm{E}-02$ & 660 & 37 \\
\hline 22 & 4_2_2 & 850 & 1.0 & 600 & air & $1.00 \mathrm{E}-03$ & $1.72 \mathrm{E}-01$ & 487 & 84 \\
\hline 23 & $4 \_2 \_5$ & 850 & 1.0 & 600 & air & $1.00 \mathrm{E}-03$ & 1.72E-01 & 548 & 94 \\
\hline 24 & 4_2_7 & 850 & 1.0 & 1800 & air & $1.00 \mathrm{E}-03$ & $5.06 \mathrm{E}-01$ & 371 & 188 \\
\hline 25 & $4 \_2 \_8$ & 850 & 1.0 & 1800 & air & $1.00 \mathrm{E}-03$ & $5.06 \mathrm{E}-01$ & 453 & 229 \\
\hline
\end{tabular}

The first analysis step of the EPP Creep-Fatigue Code Case is to seek an elastic shakedown response from the loading of a composite cycle using an appropriately chosen pseudo yield stress in an elastic-perfectly plastic model. For the case of a standard creep-fatigue specimen geometry, the stresses and strains in the gage section of the specimen can be taken as one-dimensional.

Under this assumption, whether an elastically shakedown state can be achieved in an elasticperfectly plastic model depends on the relative magnitude of the elastic stress range and "twice yield", generally. There will be no elastic shakedown response if the elastic stress range, calculated as the product of the Young's modulus and the total strain range, exceeds "twice yield".

This elastic shakedown condition is evaluated in Table II-9 for the 25 test cases. The minimum stress to rupture value is calculated for a time equal to the life time of the specimen. As seen from the table, shakedown to elastic action cannot be demonstrated for all the test cases. Thus, the EPP CreepFatigue Code Case would predict zero allowable creep-fatigue cycles for all the cases. Since there were non-zero cyclic lives for these tests, it is concluded that the code case predictions are conservative, and possibly overly conservative. The same conclusion is reached if the design factor is not used in the evaluation. That would correspond to setting $K^{\prime}=1$. 
Table II-9. Evaluation of the elastic shakedown condition for the standard Alloy 617 creep-fatigue test specimen geometry

\begin{tabular}{|c|c|c|c|c|c|c|c|c|c|}
\hline $\begin{array}{l}\text { Cas } \\
\text { e ID }\end{array}$ & $E(M P a)$ & $\begin{array}{l}E^{*} \text { Total } \\
\text { Strain } \\
\text { range } \\
(M P a)\end{array}$ & $\begin{array}{c}S y \\
(M P a)\end{array}$ & $\begin{array}{c}\text { Sr@ } \\
\text { Life } \\
\text { Time } \\
(M P a)\end{array}$ & $\begin{array}{l}P Y S^{2} @ \\
\text { Life } \\
\text { Time; } K^{\prime} \\
=0.9 \\
(M P a)\end{array}$ & $\begin{array}{c}\text { Twice } \\
P Y S \\
(M P a)\end{array}$ & $\begin{array}{c}E^{*} \text { Total } \\
\text { Strain } \\
\text { Range > } \\
\text { Twice } \\
\text { PYS? } \\
(Y / N)\end{array}$ & $\begin{array}{c}\text { Elastic } \\
\text { Shake- } \\
\text { Down } \\
? \\
(Y / N)\end{array}$ & $\begin{array}{c}\text { Allowable } \\
\text { CF Cycles } \\
\text { from EPP } \\
\text { CF Code } \\
\text { Case }\end{array}$ \\
\hline 1 & 143910 & 432 & 115.7 & 35.3 & 31.7 & 63 & $\mathrm{Y}$ & $\mathrm{N}$ & 0 \\
\hline 2 & 143910 & 432 & 115.7 & 38.8 & 34.9 & 70 & $\mathrm{Y}$ & $\mathrm{N}$ & 0 \\
\hline 3 & 143910 & 432 & 115.7 & 27.2 & 24.5 & 49 & $\mathrm{Y}$ & $\mathrm{N}$ & 0 \\
\hline 4 & 143910 & 432 & 115.7 & 27.7 & 24.9 & 50 & $\mathrm{Y}$ & $\mathrm{N}$ & 0 \\
\hline 5 & 143910 & 432 & 115.7 & 30.3 & 27.2 & 54 & $\mathrm{Y}$ & $\mathrm{N}$ & 0 \\
\hline 6 & 143910 & 432 & 115.7 & 21.7 & 19.5 & 39 & $Y$ & $\mathrm{~N}$ & 0 \\
\hline 7 & 143910 & 863 & 115.7 & 46.7 & 42.0 & 84 & $\mathrm{Y}$ & $\mathrm{N}$ & 0 \\
\hline 8 & 143910 & 863 & 115.7 & 47.0 & 42.3 & 85 & $Y$ & $\mathrm{~N}$ & 0 \\
\hline 9 & 143910 & 863 & 115.7 & 41.4 & 37.2 & 74 & $Y$ & $\mathrm{~N}$ & 0 \\
\hline 10 & 143910 & 863 & 115.7 & 39.5 & 35.6 & 71 & $Y$ & $\mathrm{~N}$ & 0 \\
\hline 11 & 143910 & 863 & 115.7 & 40.2 & 36.1 & 72 & $Y$ & $\mathrm{~N}$ & 0 \\
\hline 12 & 143910 & 863 & 115.7 & 32.0 & 28.8 & 58 & $Y$ & $\mathrm{~N}$ & 0 \\
\hline 13 & 153048 & 459 & 147.2 & 87.7 & 78.9 & 158 & $\mathrm{Y}$ & $\mathrm{N}$ & 0 \\
\hline 14 & 153048 & 459 & 147.2 & 83.5 & 75.2 & 150 & $\bar{Y}$ & $\mathrm{~N}$ & 0 \\
\hline 15 & 153048 & 459 & 147.2 & 74.5 & 67.0 & 134 & $\mathrm{Y}$ & $\mathrm{N}$ & 0 \\
\hline 16 & 153048 & 459 & 147.2 & 72.2 & 65.0 & 130 & $\mathrm{Y}$ & $\mathrm{N}$ & 0 \\
\hline 17 & 153048 & 459 & 147.2 & 69.9 & 62.9 & 126 & $Y$ & $\mathrm{~N}$ & 0 \\
\hline 18 & 153048 & 459 & 147.2 & 63.5 & 57.1 & 114 & $Y$ & $\mathrm{~N}$ & 0 \\
\hline 19 & 153048 & 459 & 147.2 & 63.0 & 56.7 & 113 & $\mathrm{Y}$ & $\mathrm{N}$ & 0 \\
\hline 20 & 153048 & 1530 & 147.2 & 108.9 & 98.1 & 196 & $\mathrm{Y}$ & $\mathrm{N}$ & 0 \\
\hline 21 & 153048 & 1530 & 147.2 & 105.2 & 94.7 & 189 & $Y$ & $\mathrm{~N}$ & 0 \\
\hline 22 & 153048 & 1530 & 147.2 & 90.6 & 81.6 & 163 & $Y$ & $\mathrm{~N}$ & 0 \\
\hline 23 & 153048 & 1530 & 147.2 & 88.7 & 79.8 & 160 & $\mathrm{Y}$ & $\mathrm{N}$ & 0 \\
\hline 24 & 153048 & 1530 & 147.2 & 78.4 & 70.5 & 141 & $\mathrm{Y}$ & $\mathrm{N}$ & 0 \\
\hline 25 & 153048 & 1530 & 147.2 & 75.6 & 68.0 & 136 & $\mathrm{Y}$ & $\mathrm{N}$ & 0 \\
\hline
\end{tabular}

\section{II-5.4 Alloy 617 SMT Test Articles}

There were two Alloy 617 SMT test article geometries used in the test program and they are shown in Fig. II-27(a) and (b). They differ mainly in the root radius of the transition region. The test data were provided by Y. Wang of the Oak Ridge National Laboratory.

\footnotetext{
${ }^{2}$ PYS - pseudo yield stress
} 


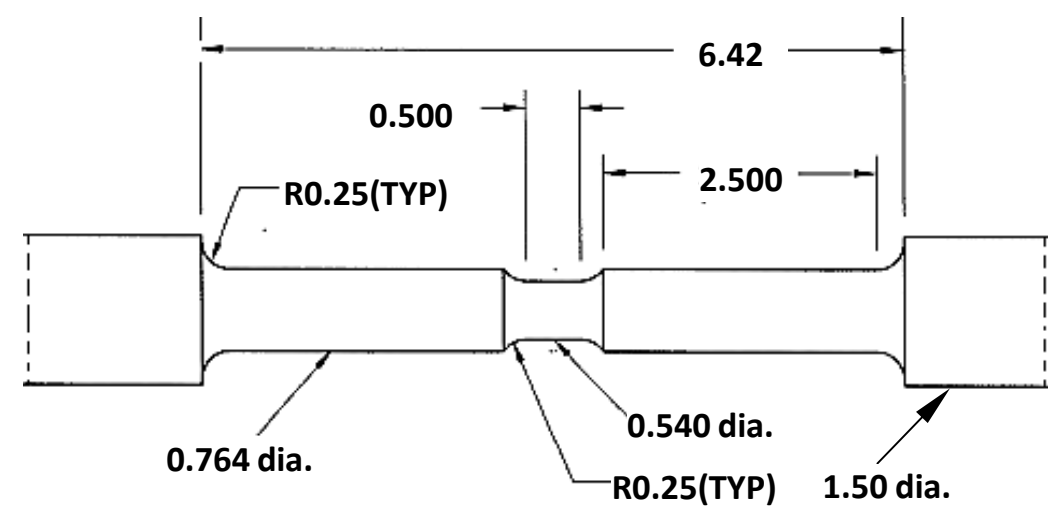

(a) Type I SMT geometry

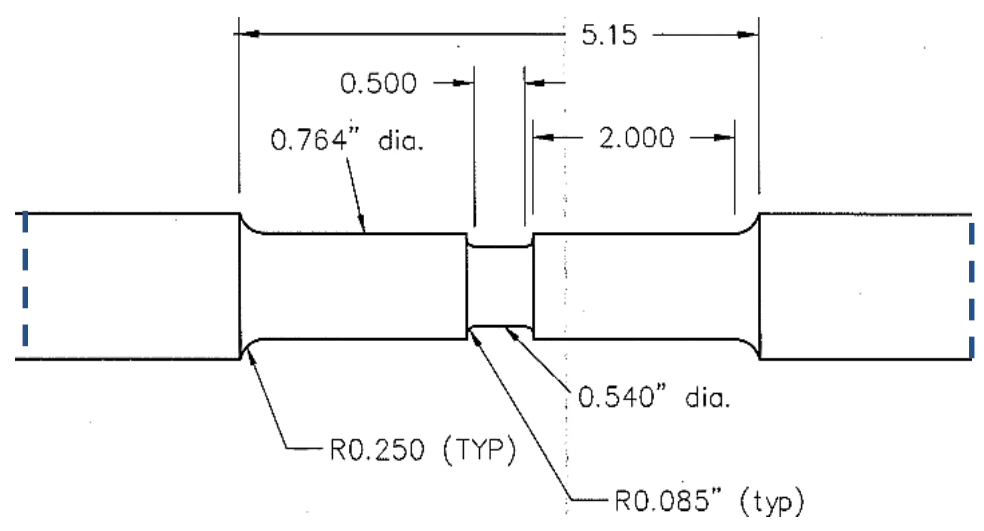

(b) Type II SMT geometry

Fig. II-27. Drawings for the Two SMT Test Articles (Dimensions in Inches)

Extensometer probes were mounted on the driver sections of the SMT test article over a gage length $L$, as shown in Fig. II-28. The change in this gage length, $\Delta L$, is controlled according to a prescribed cyclic profile. Another extensometer was mounted on the test section to measure the strain response independently. 


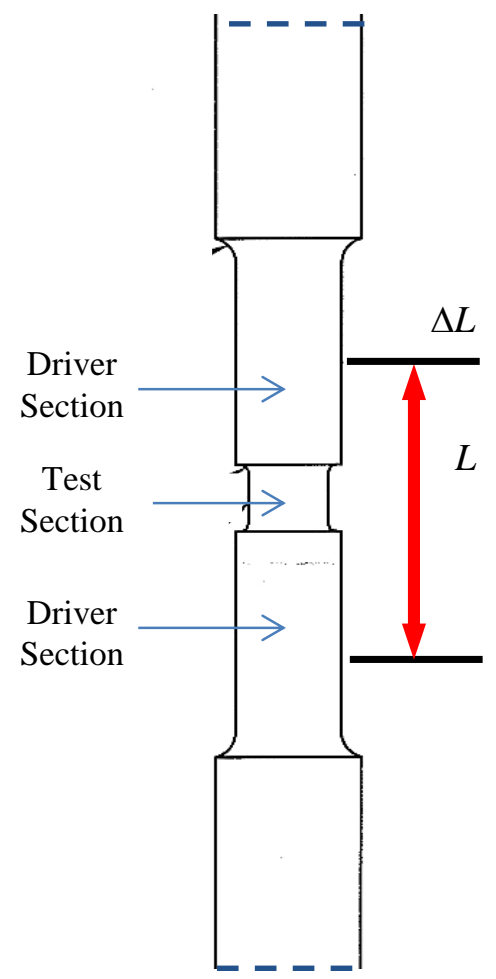

Fig. II-28. Test setup of the SMT specimen.

There were seven SMT tests performed. The details of the test conditions are shown in Table II10. The cyclic profiles of $\Delta L$ prescribed for these tests are shown in Fig. II-29. It is seen that fully reversed cycles, with tensile hold times at the $\Delta L$ peak, were imposed on the SMT test articles. It is also noted that the displacement rate for case (c) is approximately two orders of magnitude slower than the other cases.

Table II-10. SMT test conditions and data for Alloy 617

\begin{tabular}{|c|c|c|c|c|c|c|c|c|}
\hline Case & $\begin{array}{c}\text { Spec. } \\
\text { Geom. } \\
\text { Type }\end{array}$ & $\begin{array}{c}\text { Test } \\
\text { Temp. } \\
\text { (C) }\end{array}$ & $\begin{array}{c}\text { Gage } \\
\text { Length, } \\
L(\mathrm{~mm})\end{array}$ & $\begin{array}{c}\Delta L \text { Cyclic } \\
\text { Profile } \\
\text { (see Fig. } \\
\text { II-29) }\end{array}$ & $\begin{array}{c}\text { Hold } \\
\text { Time } \\
(s)\end{array}$ & $\begin{array}{l}\text { Time per } \\
\text { Cycle }(h)\end{array}$ & $\begin{array}{l}\text { Cycles } \\
\text { to } \\
\text { Failure }\end{array}$ & $\begin{array}{l}\text { Life } \\
\text { Time } \\
\text { (h) }\end{array}$ \\
\hline 1 & Type I & 950 & 127.0 & ( a ) & 600 & 0.17 & 450 & 76.5 \\
\hline 2 & Type I & 950 & 127.0 & (b) & 600 & 0.17 & 1000 & 170.0 \\
\hline 3 & Type I & 950 & 127.0 & (c) & 600 & 0.50 & 950 & 475.0 \\
\hline 4 & Type I & 950 & 127.0 & (d) & 180 & 0.05 & 1050 & 56.0 \\
\hline 5 & Type II & 950 & 73.7 & (e) & 600 & 0.17 & 370 & 62.9 \\
\hline 6 & Type II & 950 & 73.7 & (e) & 600 & 0.17 & 350 & 59.5 \\
\hline 7 & Type II & 950 & 73.7 & (f) & 600 & 0.17 & 940 & 159.8 \\
\hline
\end{tabular}



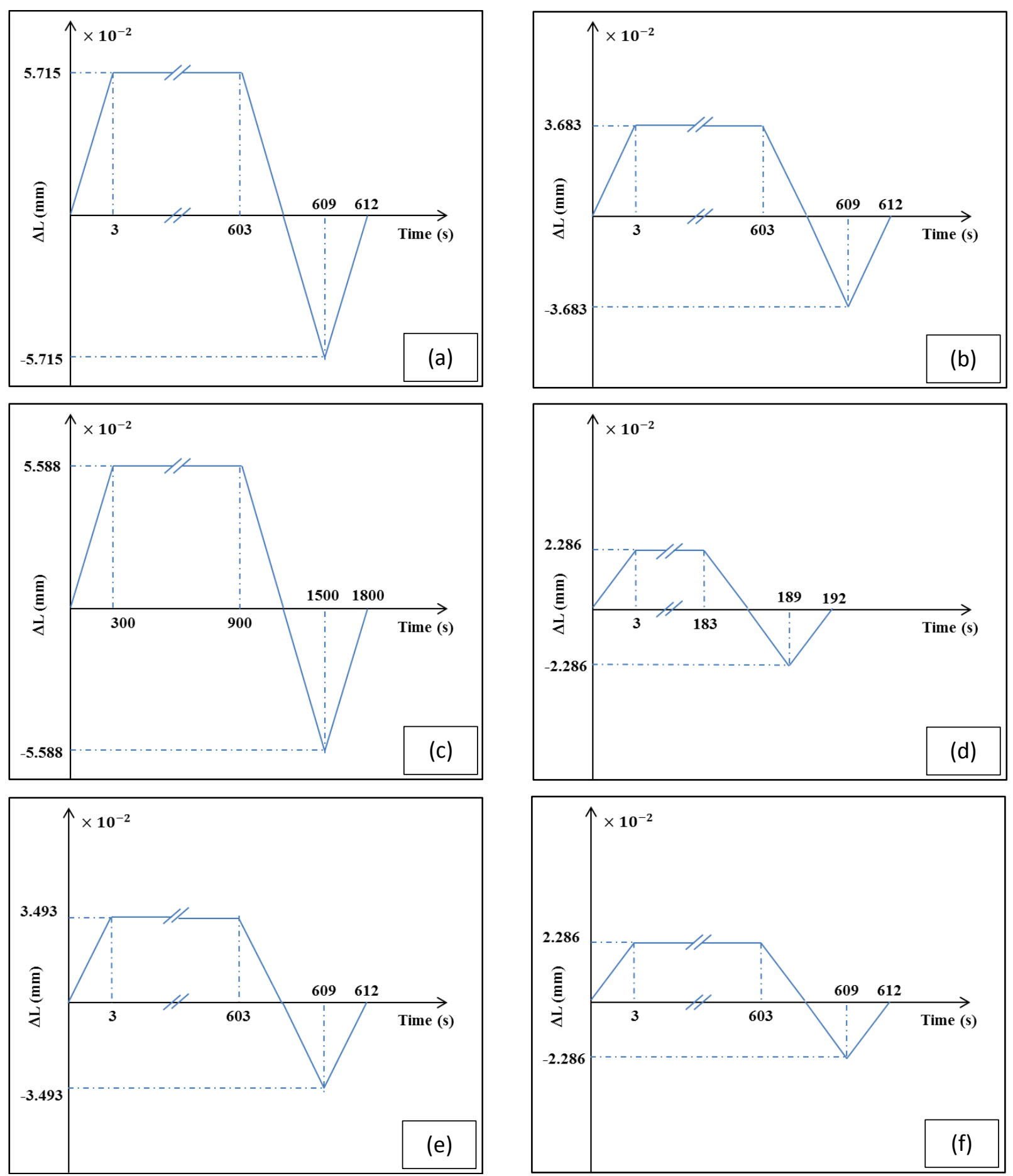

Fig. II-29. Profiles of $\Delta L$ for imposing the prescribed displacements over the gage length $L$ for Alloy 617 . Displacement hold was applied at the maximum tensile $\Delta L$ value. Cycles were fully reversed.

Similar to the case of exercising the EPP creep-fatigue procedure to the Alloy 617 standard creepfatigue test specimens, design times for the case of SMT testing are also taken to be the life times of the SMT test articles, and hence they are calculated as time per cycle multiplied by the observed/measured 
cycles to failure. Such life times calculated for the SMT test cases are shown in the last column of Table II-10.

As discussed previously, the use of the design time as the trial time for the determination of the pseudo yield stress will provide a critical condition for assessing if an elastic shakedown state can be achieved. Thus using such a choice for the trial times, the pseudo yield stresses were computed from Eqs. (25) to (28). EPP finite element analyses were then performed for the seven cases listed in Table II- 10. Typical axisymmetric, quarter-symmetric finite element meshes for Types I and II SMT test articles are shown in Fig. II-30. For each case, finite element analysis for 15 cycles was carried out.

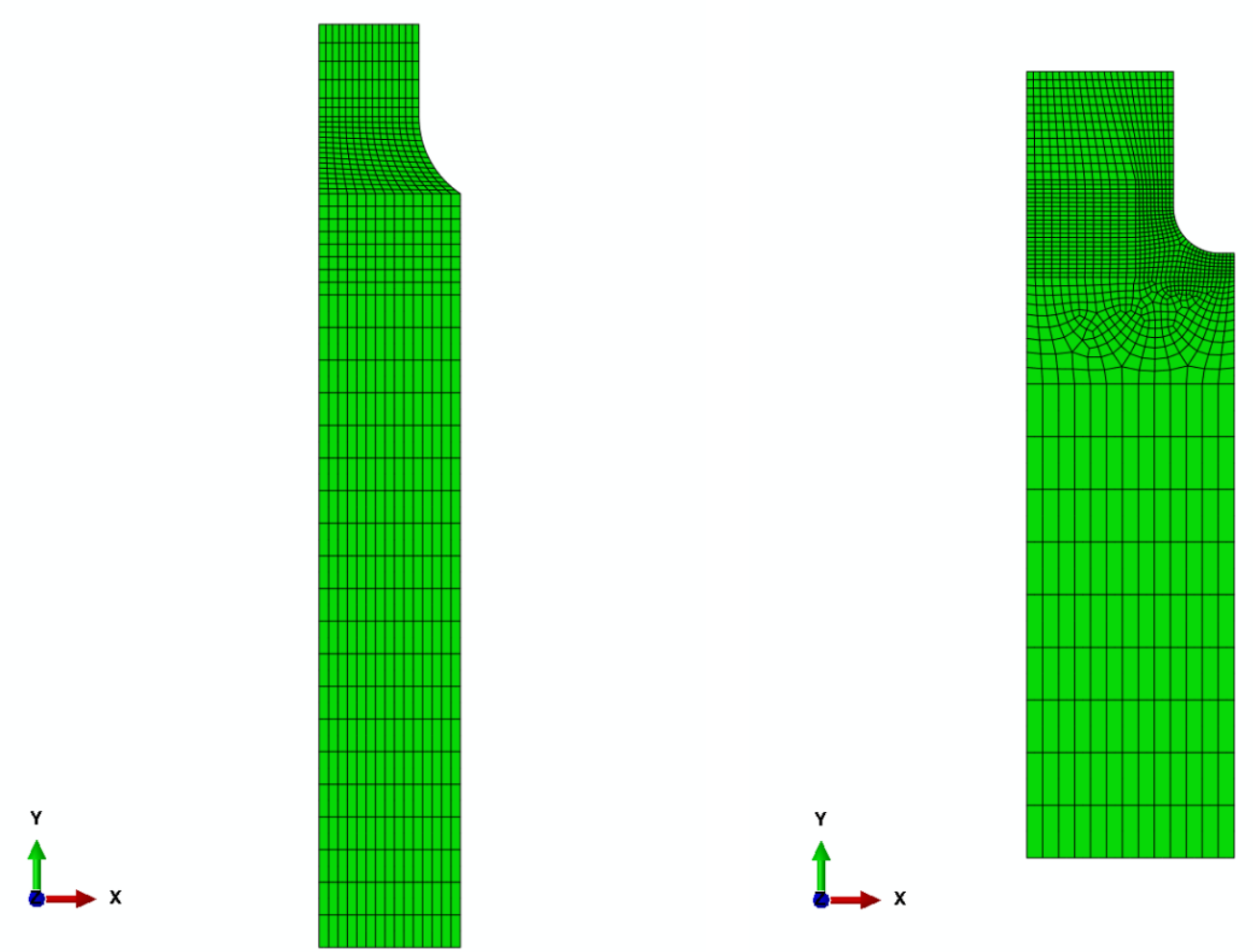

Type I

Type II

Fig. II-30. Typical axisymmetric finite element meshes for Type I and Type II SMT test articles

In the first analysis step of the EPP Creep-Fatigue Code Case, an elastic shakedown state is sought from the finite element results. Achieving an elastic shakedown state means that the incremental response for every integration point in the finite element mesh, and every time increment within a cycle, is elastic. Plasticity accumulated in previous cycles is permitted.

There are a number of ways to assess whether an elastic shakedown state is achieved for a cycle from the finite element results. General purpose finite element code ABAQUS was used for the finite element analyses in this study. In ABAQUS, a history variable called AC YIELD is provided for each integration point to store the information on whether an integration point has active plasticity for the 
current time increment. Such a condition can be detected easily within ABAQUS internal plasticity routines. If plasticity is active for the current time increment, AC YIELD has a value of one, and if not, i.e., the incremental response is elastic, AC YIELD is zero.

Post-processing scripts were developed to extract the information on AC YIELD for every integration point, every time increment, and every cycle. Using these results, we were not able to demonstrate elastic shakedown for each of the seven SMT test cases. Plots of the AC YIELD values for a selected time increment from the $15^{\text {th }}$ cycle are shown in Fig. II-31.

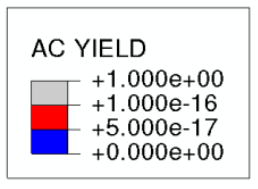

Case 1

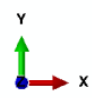

AC YIELD

$+1.000 \mathrm{e}+00$

$+1.000 \mathrm{e}-16$

$+5.000 \mathrm{e}-17$

$+0.000 \mathrm{e}+00$

Case 3

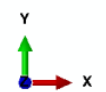

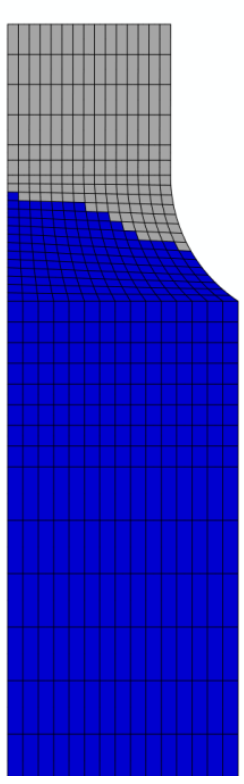

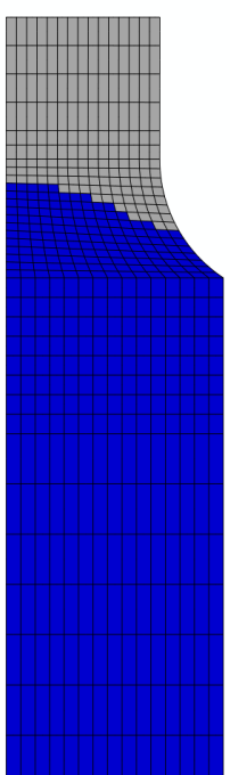

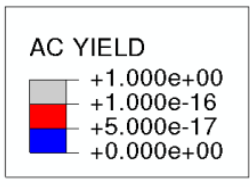

Case 2
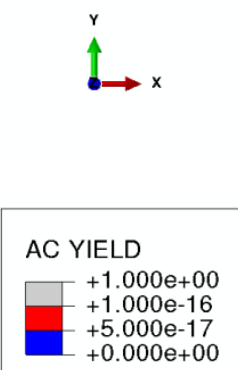

Case 4

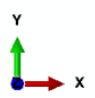

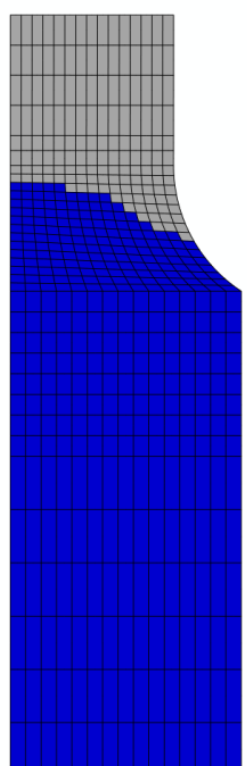

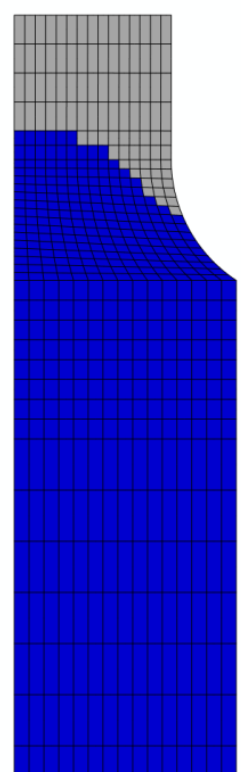



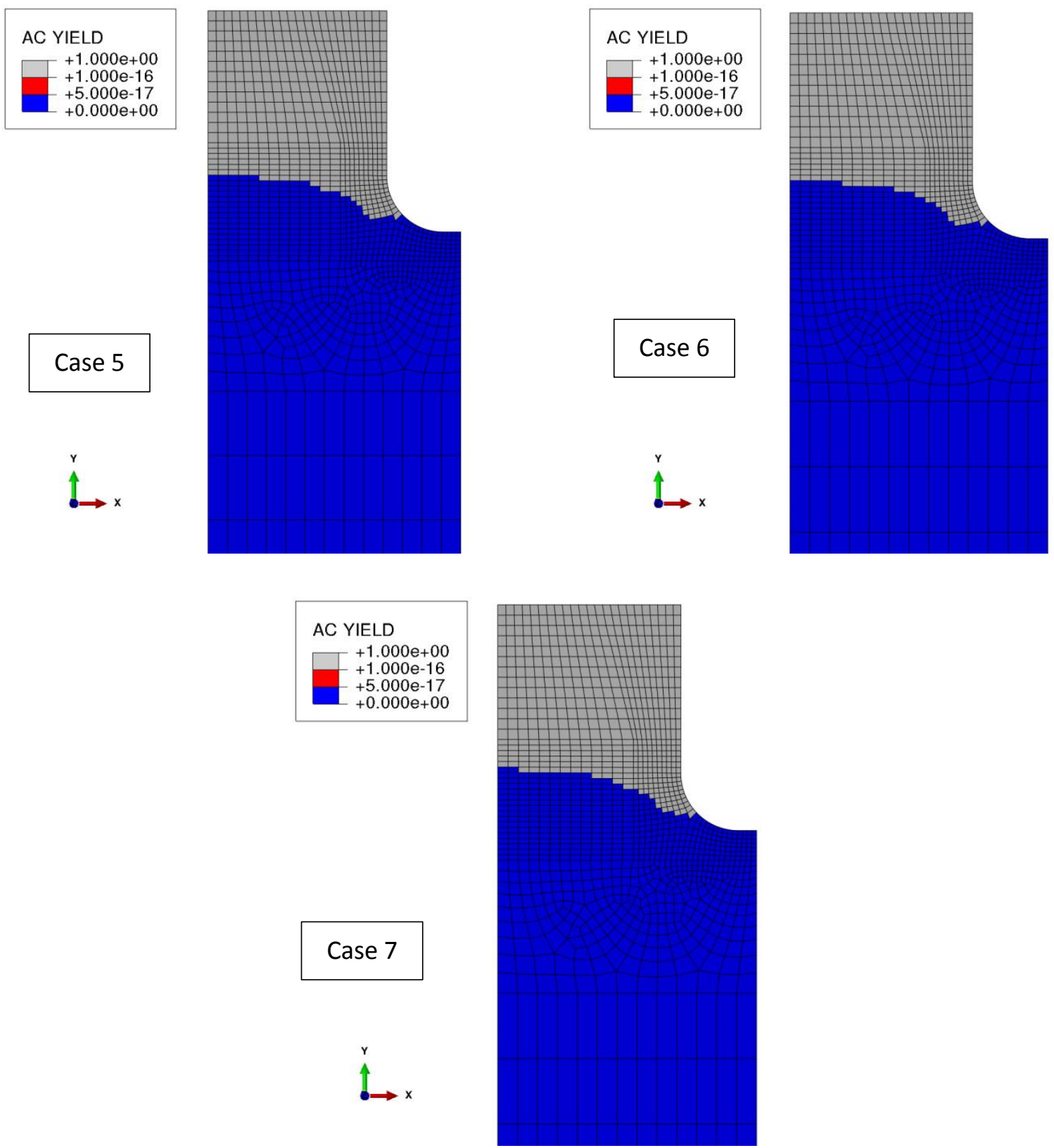

Fig. II-31. Plots of ABAQUS active plasticity variable AC YIELD for Alloy 167. Essentially grey color indicates active plasticity and blue color denotes incremental elastic response.

Some of the input material parameters for the EPP finite element analyses are given in Table II11 for completeness. The EPP Creep-Fatigue Code Case procedure would predict zero allowable creepfatigue cycles for all these seven cases. 
Table II-11. Material parameters used in the EPP finite element analyses for Alloy 617

\begin{tabular}{c|c|c|c|c|c|c|c}
\hline Case & $E(\mathrm{MPa})$ & $G(\mathrm{MPa})$ & Sy $(\mathrm{MPa})$ & $\begin{array}{c}\text { Sr @ Life } \\
\text { Time } \\
(\mathrm{MPa})\end{array}$ & $\begin{array}{c}\text { PYS @ } \\
\text { Life Time, } \\
K^{\prime}=0.9 \\
(\mathrm{MPa})\end{array}$ & $\begin{array}{c}\text { Elastic } \\
\text { Shake- } \\
\text { Down? } \\
(Y / N)\end{array}$ & $\begin{array}{c}\text { Allowable } \\
\text { CF Cycles } \\
\text { from EPP- } \\
\text { CF Code } \\
\text { Case }\end{array}$ \\
\hline 1 & 143910 & 55139 & 115.7 & 43.0 & 38.7 & $\mathrm{~N}$ & 0 \\
\hline 2 & 143910 & 55139 & 115.7 & 36.6 & 33.0 & $\mathrm{~N}$ & 0 \\
\hline 3 & 143910 & 55139 & 115.7 & 29.8 & 26.8 & $\mathrm{~N}$ & 0 \\
\hline 4 & 143910 & 55139 & 115.7 & 45.8 & 41.2 & $\mathrm{~N}$ & 0 \\
\hline 5 & 143910 & 55139 & 115.7 & 44.7 & 40.3 & $\mathrm{~N}$ & 0 \\
\hline 6 & 143910 & 55139 & 115.7 & 45.2 & 40.7 & $\mathrm{~N}$ & 0 \\
\hline 7 & 143910 & 55139 & 115.7 & 37.1 & 33.4 & $\mathrm{~N}$ & 0 \\
\hline
\end{tabular}

It is noted that we arrived at the same conclusion of not being able to demonstrate elastic shakedown when the design factor was not used (i.e., setting $K^{\prime}=1$ ) in establishing the pseudo yield stress for the EPP finite element analyses.

Application of the Code Case rules to these tests led to the predictions of zero allowable creepfatigue cycles, and this simply means that designs under these temperatures and strain cycles are not viable.

\section{II-5.5 316H Stainless Steel SMT Test}

One SMT Type I test article made of $316 \mathrm{H}$ stainless steel was tested by Y. Wang of the Oak Ridge National Laboratory. The details of the test conditions are shown in Table II-12. The cyclic profile of $\Delta L$ prescribed for the $316 \mathrm{H}$ test is shown in Fig. II-32.

Table II-12. SMT test conditions and data for $316 \mathrm{H} \mathrm{SS}$

\begin{tabular}{c|c|c|c|c|c|c}
\hline $\begin{array}{c}\text { Spec. } \\
\text { Geom. } \\
\text { Type }\end{array}$ & $\begin{array}{c}\text { Test } \\
\text { Temp. } \\
(C)\end{array}$ & $\begin{array}{c}\text { Gage } \\
\text { Length, } \\
\text { L }(\mathrm{mm})\end{array}$ & $\begin{array}{c}\text { Hold } \\
\text { Time } \\
(\mathrm{s})\end{array}$ & $\begin{array}{c}\text { Time per } \\
\text { Cycle }(h)\end{array}$ & $\begin{array}{c}\text { Cycles } \\
\text { to } \\
\text { Failure }\end{array}$ & $\begin{array}{c}\text { Life } \\
\text { Time } \\
(h)\end{array}$ \\
\hline Type I & 815 & 127.0 & 600 & 0.17 & 400 & 68 \\
\hline
\end{tabular}




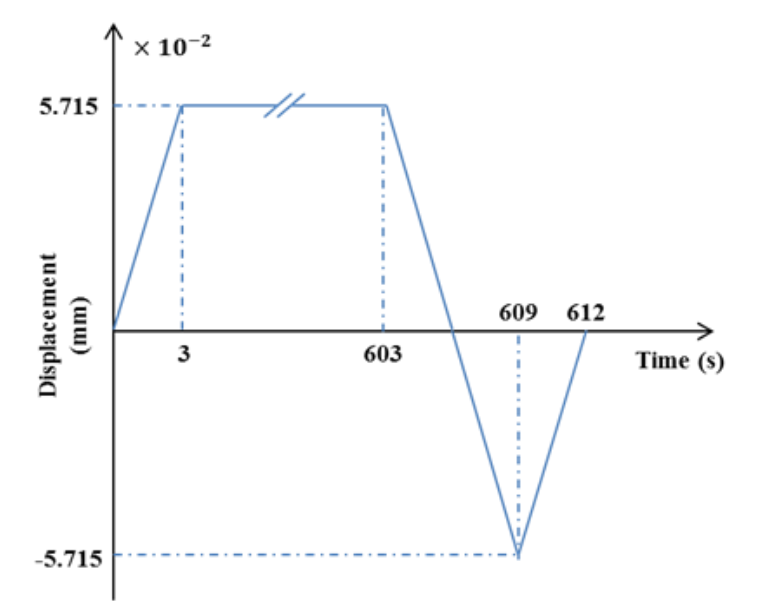

Fig. II-32. Profile of $\Delta L$ for imposing the prescribed displacements over the gage length $L$ for $316 \mathrm{H}$.

EPP finite element analysis was carried out for the conditions described in Table II-12 and Fig. II-32, using the finite element mesh for Type I geometry shown in Fig. II-30. As noted above, the first step in the EPP Creep-Fatigue Code Case is to seek an elastic shakedown state from the finite element result. Following the method employed for the Alloy 617 SMT cases, the contour of the ABAQUS variable AC YIELD is plotted in Fig. II-33. The result indicates that shakedown to elastic action was not achieved for the $316 \mathrm{H}$ case.

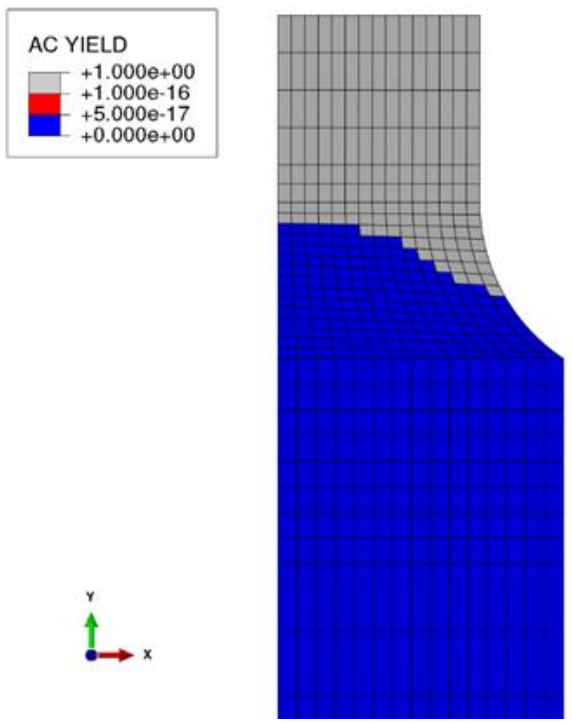

Fig. II-33. Contour plot of ABAQUS active plasticity variable AC YIELD for 316H. Essentially grey color indicates active plasticity and blue color denotes incremental elastic response.

The input material parameters for the EPP finite element analysis are given in Table II-13. The EPP Creep-Fatigue Code Case procedure also predicts zero allowable creep-fatigue cycles for the $316 \mathrm{H}$ case. 
Table II-13. Material parameters used in the EPP finite element analysis for 316H

\begin{tabular}{c|c|c|c|c|c|c}
\hline$E(M P a)$ & $G(M P a)$ & $S y(M P a)$ & $\begin{array}{c}\text { Sr @ Life } \\
\text { Time } \\
(M P a)\end{array}$ & $\begin{array}{c}\text { PYS @ } \\
\text { Life Time, } \\
K^{\prime}=0.9 \\
(M P a)\end{array}$ & $\begin{array}{c}\text { Elastic } \\
\text { Shake- } \\
\text { Down? } \\
(Y / N)\end{array}$ & $\begin{array}{c}\text { Allowable } \\
\text { CF Cycles } \\
\text { from EPP- } \\
\text { CF Code } \\
\text { Case }\end{array}$ \\
\hline 127193 & 48920 & 75.15 & 54.08 & 48.68 & $\mathrm{~N}$ & 0 \\
\hline
\end{tabular}

It was found that even when the design factor was not used (i.e., setting $K^{\prime}=1$ ) in establishing the pseudo yield stress for the EPP finite element analysis, elastic shakedown had not been achieved.

\section{II-5.6 Comparison Based on Allowable Design Life}

In the preceding comparisons, the pseudo yield strength was limited by the tabulated yield strength. The relatively low value of pseudo yield strength prevented elastic shakedown for the high load levels required to achieve relatively short test durations. In a typical component design, the design life would be about three orders of magnitude longer than the test duration and the pseudo yield stress would typically be limited by the creep-rupture strength. Failure to achieve elastic shakedown is a "go, no-go" type criteria and does not provide a quantitative assessment of the design margin. To get such a quantitative assessment it is necessary disregard the yield strength and use an extrapolation of the creeprupture strength to an allowable design life that is shorter, perhaps significantly shorter, than the test duration. As the life is shortened the extrapolated creep rupture stress, and hence the pseudo yield strength, becomes higher. Then, comparing the allowable design life to the measured test life provides a quantitative design margin assessment.

To implement this procedure, three Alloy 617 test cases were selected with varying loading amplitudes as shown in Table II-14. Using the ABAQAS finite element model the required pseudo yield stress for elastic shakedown was determined. From that value, the required time to rupture was determine taking into account the design factor $K^{\prime}$. From the time to rupture and cycle frequency, the allowed number of cycles was determined. The applicable strain range was determined in accordance with the code case and the fatigue damage fraction determined from the allowable number of cycles. The allowable creep damage was then determined from the damage diagram $(0.1,0.1$ intercept $)$ for the calculated fatigue damage. The allowable time was then determined by multiplying the previously determined required time to rupture by the allowable creep damage fraction. The resulting Alloy 617 design margins are illustrated in Fig. II-34.

Table II-14. Experimental data - Alloy 617 at $950^{\circ} \mathrm{C}$

\begin{tabular}{|c|c|c|c|c|c|}
\hline Test Num. & $\begin{array}{c}\text { Amplitude } \\
(\text { mils })\end{array}$ & $\begin{array}{c}\text { Holding time } \\
(\mathrm{s})\end{array}$ & $\begin{array}{c}\text { Loading time } \\
(\mathrm{s})\end{array}$ & $\begin{array}{c}\text { Cycle number } \\
\text { to failure }\end{array}$ & $\begin{array}{c}\text { Allowed } \\
\text { lifetime (hrs) }\end{array}$ \\
\hline 1 & 1.8 & 180 & 3 & 1050 & 56 \\
\hline 2 & 2.9 & 600 & 3 & 1000 & 170 \\
\hline 3 & 4.5 & 600 & 3 & 450 & 77 \\
\hline
\end{tabular}




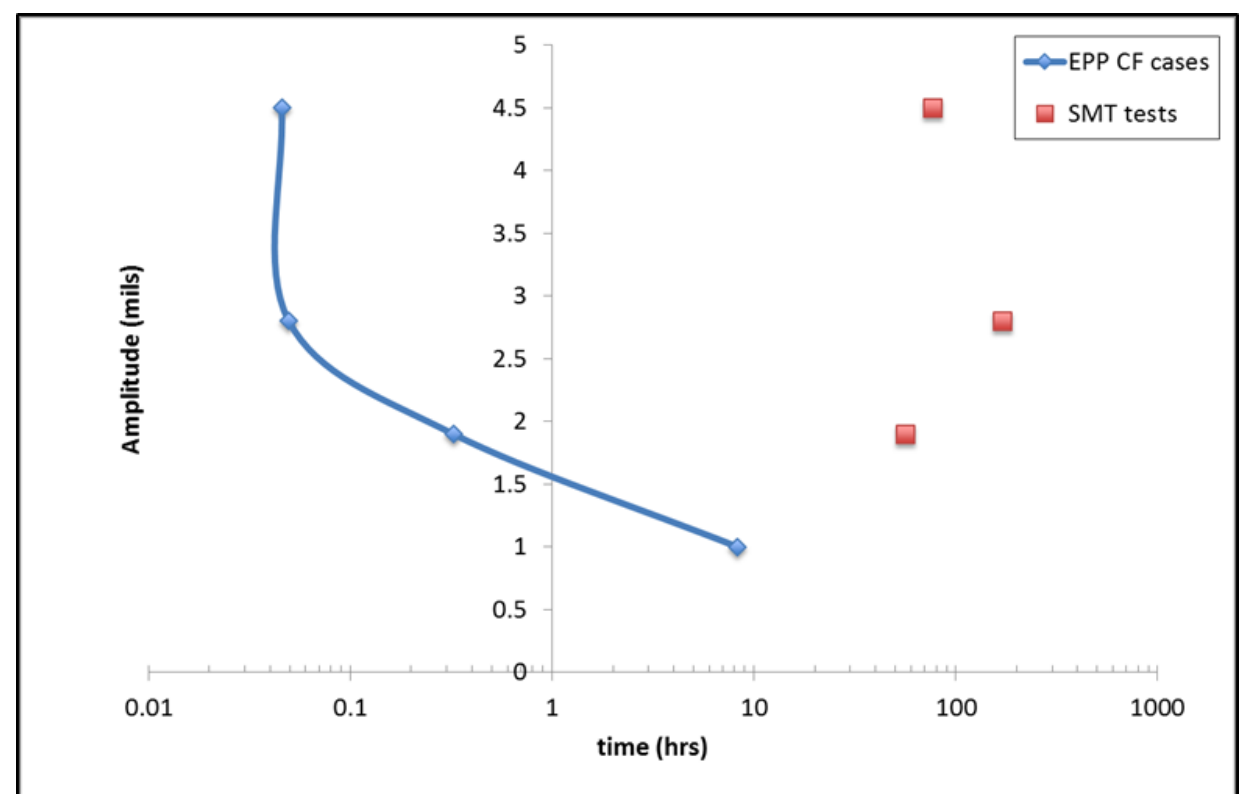

Fig. II-34. Creep-fatigue code case allowable life comparison to Alloy 617 SMT data

As shown in Table II-15 and Fig. II-35, a similar comparison was done for $316 \mathrm{H}$ stainless steel tested at $815^{\circ} \mathrm{C}$.

Table II-15. Experimental data $-316 \mathrm{H}$ stainless steel at $815^{\circ} \mathrm{C}$

\begin{tabular}{|c|c|c|c|c|c|}
\hline Test Num. & $\begin{array}{c}\text { Amplitude } \\
(\text { mils })\end{array}$ & $\begin{array}{c}\text { Holding time } \\
(\mathrm{s})\end{array}$ & $\begin{array}{c}\text { Loading time } \\
(\mathrm{s})\end{array}$ & $\begin{array}{c}\text { Cycle number } \\
\text { to failure }\end{array}$ & $\begin{array}{c}\text { Allowed } \\
\text { lifetime (hrs) }\end{array}$ \\
\hline 1 & 1.9 & 600 & 3 & 410 & 69.7 \\
\hline 2 & 4.5 & 600 & 3 & 13,214 & 1226 \\
\hline
\end{tabular}

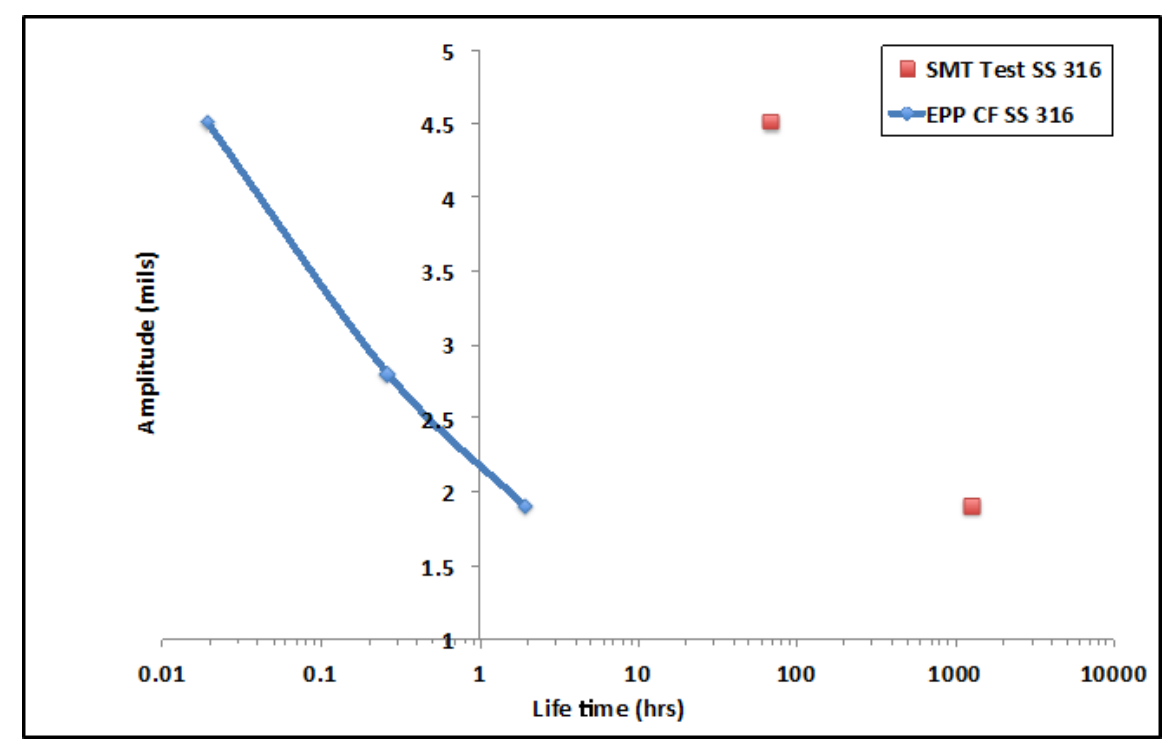

Fig. II-35. Creep-fatigue code case allowable life comparison to $316 \mathrm{H}$ stainless steel SMT data 
From Fig. II-34 and Fig. II-35 it is evident that there is a significant design margin between the Creepfatigue Code Case allowable life and the experimentally measured life for both Alloy 617 and $316 \mathrm{H}$ stainless steel.

\section{II-6 SUMMARY AND CONCLUSIONS}

\section{II-6.1 Background}

The goal of this report is to provide a summary and rationale of the actions taken to illustrate and verify the application of one of the two code cases developed to permit evaluation of strain limits and creep-fatigue damage that take advantage of the unique features of elastic-perfectly plastic analysis methods for Section III, Division 5 Subsection HB, Subpart B applications. This report focuses on the creep-fatigue damage evaluation code case. A motivating factor in developing the code cases is the restriction on the application of current Subsection HB, Subpart B simplified methods to Alloy 617 at very high temperature. The overall strategy is to (1) illustrate the application the code case(s) to an example problem representative of a realistic component with realistic loading conditions, (2) compare the results of an evaluation based on the proposed code case methods to the results from a Subsection HB, Subpart B evaluation using an example(s) with simplified geometry and loading conditions, and (3) compare the code case predictions with test data from key feature experiments on Alloy 617 and $316 \mathrm{H}$ at very high temperature simulating ratcheting and elastic follow-up phenomena.

\section{II-6.2. Theoretical Basis}

The basis for the proposed simplified methods is generally expressed in terms of energy bounding theorems. There is a "hierarchy" of bounding concepts which reflects the trade-off between problem complexity and bounding accuracy. Problems with mechanical load cycles may be bounded by external work bounds and those with thermal and mechanical load cycles may be bounded by internal energy dissipation. This is generally more conservative than for purely mechanical problems, since high internal energy dissipation may be associated with zero net deflection. In both cases, the opportunity for a simplified analysis arises from the use of the "rapid cycle" concept. Rapid cycles have no creep relaxation during the cycle, but generally have the most advantageous residual stress system which ensures that deformation rates over the cycle are as low as possible.. The use of elastic-perfectly plastic (EPP) analysis using an artificial or pseudo yield stress is based on a third assumption - that reducing the yield stress in an analysis is conservative, that is, does not reduce the deformation rates.

The proposed creep-fatigue code case uses a conventional (Subsection HB, Subpart B) creepfatigue damage summation. The cyclic creep component of damage is defined by an elastic-perfectly plastic (EPP) shakedown calculation.

The use of a time-independent shakedown analysis to bound cyclic creep damage depends on the similarity between the mathematical descriptions of secondary creep strain rates and average creep damage rates. Both may be well-characterized by Arrhenius temperature dependencies, and n-power or hyperbolic sine power laws for stress dependencies. This means that the creep and rupture behaviors have common features. For a constant load problem, strain rates generally decrease as the steady state stress distribution is approached in time. If the creep and damage rates exponents $n$ and $n$ ' for creep rate and damage rates, are identical, then creep damage accumulation rate will also be a minimum for the steady state stress distribution. In practice the exponents have to be significantly different for the damage rate not to be a minimum for cyclic (or steady) conditions.

The intent of the shakedown analysis is to conservatively calculate cyclic creep damage. It may be summarized as follows. For a defined load cycle: 
- Define a design rupture time $t$.

- Define a temperature dependent "pseudo" yield stress $S_{c t}$ as the lesser of material minimum yield stress and stress to cause rupture in time $t$.

- Perform a cyclic elastic-plastic analysis to demonstrate shakedown or otherwise of the component.

- If shakedown occurs, then cyclic creep damage is $D=$ design life/t.

\section{II-6.3 Example Problems}

\section{II-6.3.1 Representative example}

The goal of the representative example is to illustrate the code case(s) application to a realistic geometry and loading conditions. The selected geometry is a spherical head with an integrally reinforced nozzle with a flush ground connecting weld. The applied loads are internal pressure and shear and moment loads on the nozzle. Cyclic and sustained loading conditions are evaluated with imposed thermal transients. The material is $316 \mathrm{H}$ stainless steel.

The evaluation of the implementation of creep-fatigue code case was successful. The implementation requires shakedown to elastic behavior with trial-and-error finite element EPP using a pseudo yield strength based on a creep-rupture strength target life iterated with successively longer values until the combined creep damage and fatigue damage satisfy the damage criteria envelope in Subsection $\mathrm{HB}$, Subpart B. If shakedown cannot be achieved within the allowable creep and fatigue damage envelopes, then the applied loadings are not acceptable. The creep damage calculation is a bounding value applicable to all points in the structure and not a specific value for each location. The creep damage value is combined with the maximum value of the fatigue damage to bound the total damage for the component.

Two FEA models were used, with and without the weldment included. There are slight differences in the results due to the influence of the lower pseudo yield strength in the weldment caused by the weld strength reduction factor. The weldment model Level A \& B Composite Cycle analysis with a target creep damage of 0.95 passes after 3 pseudo-cycles. The base metal only model passes with a target creep damage of 0.90, also after 3 pseudo cycles. For the weldment model, the total creep-fatigue damage is 0.954 and the allowable creep-fatigue damage is 0.995 , which is sufficiently greater than the calculated value. This places the creep-fatigue damage within the HBB-T-1420-2 creep-fatigue interaction envelope, thus meeting the criteria for creep-fatigue interaction for the base metal. For the base metal only

model, the corresponding total and allowable damages are 0.904 and 0.995 respectively. In the weld region, the corresponding values of total damage and allowable damage are 0.958 and 0.988 respectively.

The base metal only creep-fatigue evaluation for the Level A \& C Composite Cycle with a target creep damage of 1.0 does not pass after 20 pseudo-cycles. The change in plastic strain after each pseudocycle is $0.28 \%$ indicating that stable ratcheting continues and shakedown does not occur. Further reduction of the target creep damage will only produce weaker pseudo-yield stresses, resulting in even more severe ratcheting.

\section{II-6.3.2 Creep-fatigue code case to Subsection HB, Subpart B comparison}

Creep-fatigue damage was evaluated to compare the results from the current Subsection HB, Subpart B procedures to the results from the proposed creep-fatigue code case using elastic-perfectly plastic methods. The evaluation was done using a relatively thick wall cylinder, 16 inches OD with 2 inches wall thickness. The steady state condition is an inner wall temperature of $1235^{\circ} \mathrm{F}$ and an outer wall 
temperature of $1075{ }^{\circ} \mathrm{F}$. The heat flux is periodically cycled to zero while maintaining the inner wall temperature constant such that the outer wall temperature equals the inner wall temperature. The material is $316 \mathrm{H}$ stainless steel. The estimated allowable life from the current Subsection HB, Subpart B procedure is $1430 \mathrm{hrs}$ as compared to an estimated life of approximately 10,000 hrs using the proposed EPP creepfatigue code case.

\section{II-6.4 Bounding Theory Example Calculations}

Analytic solutions were developed for the example of a creep-fatigue test specimen subjected to cyclic, displacement controlled loading. Using these analytic solution it was demonstrated that the creep damage from the rapid cycle/EPP solution would bound the creep damage calculated from a time fraction damage summation using the calculated stress/time history. These detailed analytic solutions for the creep-fatigue test thus demonstrate the conservatism of the EPP code case methodology for a simplified yet realistic example.

\section{II-6.5 Experimental Results}

Experiments were conducted on standard creep-fatigue test specimens and key feature test articles that were modified from standard creep-fatigue test specimens to replicate the follow-up and stress and strain redistribution characteristics of realistic components and loading at elevated temperature. When the EPP creep-fatigue methodology was applied to evaluate the test results it was shown that the applied test loading did not result in elastic shakedown; thus demonstrating that the code case is conservative in that it would not permit the test loadings in a design application.

\section{II-6.6 Conclusions}

As summarized above, the creep-fatigue code case, (1) can be implemented on a representative component configuration with realistic loading conditions, (2) provides comparable results to current Subsection HB, Subpart B procedures at moderate creep temperatures, and, (3) is conservative with respect to the evaluation of creep-damage on experiments with Alloy 617 and 316H stainless steel at very

high temperatures. Also, the validity of the bounding theory that forms the basis of the creep-fatigue code case based on elastic-perfectly plastic analysis concepts has been demonstrated analytically 


\section{II-APPENDIX A}

The EPP elastic shakedown solution with stress cycle can be given as

$$
\begin{aligned}
& \sigma_{1}=E\left(\varepsilon_{+}-\varepsilon_{-}\right) / 2=E \Delta \varepsilon / 2 \\
& \sigma_{2}=-\sigma_{1}
\end{aligned}
$$

The damage accumulation over a half-cycle from the E-PP elastic shakedown solution, $D_{e p p}$, is given by:

$$
D_{e p p}=k^{\prime} \sigma_{1}^{n^{\prime}} \frac{\tau}{2}
$$

For the case of steady cyclic-creep, the governing equations are

$$
\begin{aligned}
& \dot{\sigma}=E\left(\dot{\varepsilon}-\dot{\varepsilon}_{c}\right) \\
& \dot{\varepsilon}_{c}=k \sigma^{n}
\end{aligned}
$$

Under the constant strain rate condition, $\dot{\varepsilon}=0$, the stress relaxation behavior can be obtained from

$$
\int_{\sigma_{0}}^{\sigma(t)} \frac{d \sigma}{\sigma^{n}}=-E k t
$$

where $\sigma=\sigma_{0}$ at $t=0$. Integrating Eq. (A32), we find

and

$$
\frac{1}{1-n}\left([\sigma(t)]^{1-n}-\sigma_{0}^{1-n}\right)=-E k t
$$

$$
\sigma(t)=\left(\sigma_{0}^{1-n}-(1-n) E k t\right)^{\frac{1}{1-n}}
$$

The stress relaxation expression in Eq. (A34) admits the limit

$$
\lim _{n \rightarrow 1} \sigma(t)=\sigma_{0} \exp (-E k t)
$$

The damage accumulation over a half-cycle from the steady cyclic-creep solution, $D_{c}$, is given by

$$
D_{c}=\int_{0}^{\tau / 2} k^{\prime}[\sigma(t)]^{n^{\prime}} d t
$$

Substituting the stress relaxation expression from Eq. (A34) into Eq. (A36), we find

$$
D_{c}=\frac{k^{\prime}}{k E\left(n-1-n^{\prime}\right)}\left[\left[\sigma\left(\frac{\tau}{2}\right)\right]^{n^{\prime}+1-n}-\sigma_{0}^{n^{\prime}+1-n}\right]
$$


The condition for steady cyclic-creep solution is

$$
\sigma_{0}+\sigma\left(\frac{\tau}{2}\right)=E\left(\varepsilon_{+}-\varepsilon_{-}\right)=E \Delta \varepsilon
$$

and it is illustrated in Fig. A1.

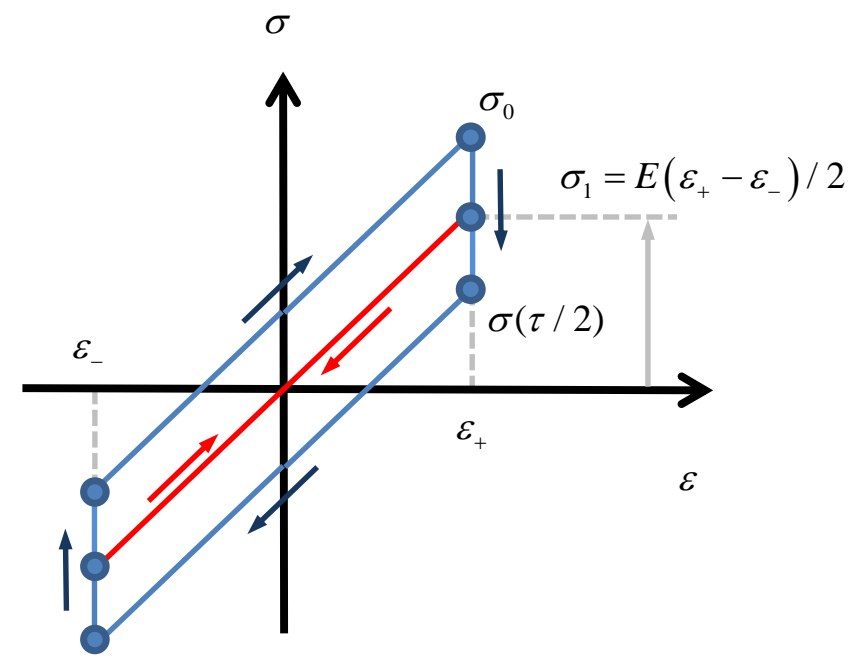

Fig. A1. Steady cyclic creep condition (in blue) and EPP elastic shakedown condition (in red)

Using Eqs. (A30) and (A37), the damage ratio between the steady cyclic-creep solution and the EPP elastic shakedown solution is

$$
\frac{D_{c}}{D_{e p p}}=\frac{1}{k E\left(n-1-n^{\prime}\right)} \frac{\left[\sigma\left(\frac{\tau}{2}\right)\right]^{n^{\prime}+1-n}-\sigma_{0}^{n^{\prime}+1-n}}{\sigma_{1}^{n^{\prime}} \tau / 2}
$$

From Eqs. (A29) and (A38), we find

$$
\sigma_{1}=\frac{1}{2}\left(\sigma_{0}+\sigma\left(\frac{\tau}{2}\right)\right)
$$

and from Eqs. (A33) at half cycle, i.e., at $t=\tau / 2$, we get

$$
E k \frac{\tau}{2}=\frac{1}{1-n}\left[\sigma_{0}^{1-n}-\left[\sigma\left(\frac{\tau}{2}\right)\right]^{1-n}\right]
$$

Substituting Eqs. (A40) and (A41) into Eq. (A39), the damage ratio becomes

$$
\frac{D_{c}}{D_{e p p}}=\frac{(n-1) 2^{n^{\prime}}}{\left(n-1-n^{\prime}\right)} \frac{\sigma_{0}^{n^{\prime}+1-n}-\left[\sigma\left(\frac{\tau}{2}\right)\right]^{n^{\prime}+1-n}}{\left(\sigma_{0}^{1-n}-\left[\sigma\left(\frac{\tau}{2}\right)\right]^{1-n}\right)\left[\sigma_{0}+\sigma\left(\frac{\tau}{2}\right)\right]^{n^{\prime}}}
$$


Under the condition of $n^{\prime}=n$ the damage ratio is further reduced to

$$
\frac{D_{c}}{D_{e p p}}=2^{n}(n-1) \frac{\sigma_{0}-\sigma\left(\frac{\tau}{2}\right)}{\left(\left[\sigma\left(\frac{\tau}{2}\right)\right]^{1-n}-\sigma_{0}^{1-n}\right)\left[\sigma_{0}+\sigma\left(\frac{\tau}{2}\right)\right]^{n}}
$$

To simplify the notation, we introduce the stress ratio $s$ as

$$
s \equiv \sigma_{0} / \sigma\left(\frac{\tau}{2}\right)
$$

The damage ratio then becomes

$$
\frac{D_{c}}{D_{e p p}}=\frac{2^{n}(n-1)(s-1) s^{n-1}}{\left(s^{n-1}-1\right)(s+1)^{n}}
$$

We now investigate the behavior of the damage ratio as a function of $n$ and $s$. Let

$$
f(n, s) \equiv \frac{2^{n}(n-1)(s-1) s^{n-1}}{\left(s^{n-1}-1\right)(s+1)^{n}}
$$

The result in Eq. (A41) implies that as $s \rightarrow 1$ the creep deformation becomes vanishingly small and in the limit of $s=1$ the creep deformation is frozen (e.g., $k=0$ ) and the steady cyclic-creep stress state is reduced to the EPP elastic shakedown solution. This can be seen from Fig. A1. The Taylor series expansion of $f(n, s)$ about $s=1$ gives

$$
f(n, s)=1-a_{0}(s-1)^{2}+a_{0}(s-1)^{3}+O\left((s-1)^{4}\right), \quad a_{0}=\frac{1}{24} n(n+1)
$$

where $O($ ) is the order symbol. This confirms that $f(n, s) \rightarrow 1$ as $s \rightarrow 1$. Also, for values of $s$ slightly larger than one, Eq. (A47) shows that $f(n, s)<1$. Hence the damage accumulation from the steady cycliccreep solution for small amounts of stress relaxation over the half-cycle is less than the damage calculated from the EPP elastic shakedown solution.

For large $s$, we find from Eq. (A46) that

$$
f(n, s) \sim \frac{2^{n}(n-1)}{s^{n-1}\left(1+\frac{n}{s}+\cdots\right)}
$$

so $f \rightarrow 0$ in the limit as $s \rightarrow \infty$. This is the case when the stress relaxation from the steady cyclic-creep solution over the half-cycle is complete, and the damage accumulation is vanishingly small as compared with the corresponding damage accumulation from the EPP elastic shakedown solution.

We now study the behavior of $f(n, s)$ near $n=1$. A Taylor series expansion of $f(n, s)$ about $n=1$ gives 


$$
f(n, s)=b_{0}+b_{1}(n-1)+O\left((n-1)^{2}\right)
$$

where

$$
\begin{gathered}
b_{0}=\frac{2(s-1)}{(s+1) \ln (s)}=1-\frac{1}{12}(s-1)^{2}+\frac{1}{12}(s-1)^{3}+O\left((s-1)^{4}\right) \\
b_{1}=\frac{(s-1)(2 \ln (2)+\ln (s)-2 \ln (s+1))}{(s+1) \ln (s)}=-\frac{1}{8}(s-1)^{2}+\frac{1}{8}(s-1)^{3}+O\left((s-1)^{4}\right)
\end{gathered}
$$

Hence $f \rightarrow b_{0}$ as $n \rightarrow 1$ and Eq. (A50) shows that $b_{0} \leq 1$.

From the above analysis, it can be concluded that the damage ratio is one at $n=1$ and $s=1$. It decays from one to zero as $n$ and $s$ are increased. A three-dimensional plot of $f(n, s)$ for $1 \leq n \leq 10$ and $1 \leq s \leq 10$ is shown in Fig. A2.

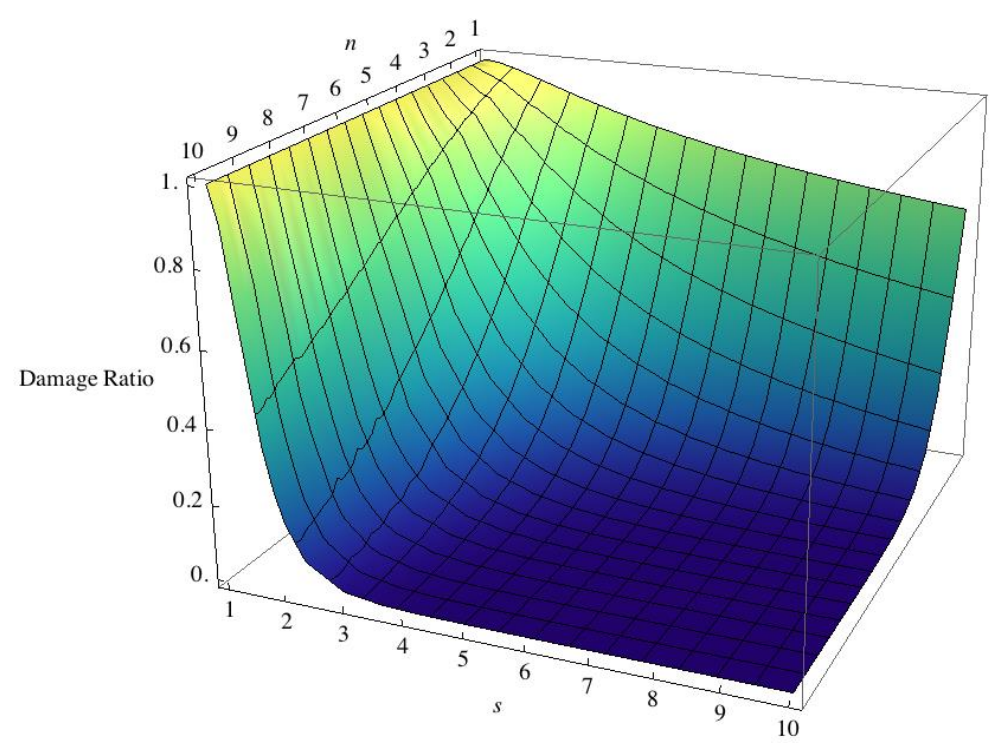

Fig. A2. 3D plot of damage ratio as function of $\boldsymbol{n}$ and $s$.

In summary, under the assumption that the creep rate and damage rate have the same stress dependency, i.e., $n^{\prime}=n$, it is shown that the damage accumulation over a half-cycle of creep-fatigue straining as determined from an elastic, power-law creep model is bounded by, or less than, the corresponding damage accumulation from the EPP elastic shakedown solution:

$$
0 \leq \frac{D_{c}}{D_{e p p}} \leq 1
$$




\section{II-APPENDIX B: DRAFT EPP CREEP-FATIGUE CODE CASE}

The draft EPP creep-fatigue code case is presented in this appendix. It is anticipated that revision will be made to this draft to address comments as the Code committee approval process proceeds.

\section{Code Case XXXX. Calculation of Creep-Fatigue for Division 5 Class A Components at Elevated Temperature Service Using Elastic-Perfectly Plastic Analysis.}

Inquiry: What alternative rules may be used for the calculation of creep-fatigue damage in compliance with HBB-3252 and Appendix HBB-T.

Response: Fatigue and creep damage may be evaluated for the following materials using elastic-perfectly plastic material models instead of the procedures of HBB-T-1420, HBB-T-1430 and HBB-T-1715 when performed in accordance with the requirements of this Code Case.

- $\quad$ Type 304 SS and 316 SS per Table HBB-I-14.1(a)

\section{General Requirements.}

Except as identified herein, all requirements of Section III, Division 5, Subsection HB, Subpart B apply to components designed in accordance with this Code Case.

The design methodology employed for evaluation of creep damage is based on elastic shakedown analyses using an elastic-perfectly plastic material model, small strain theory and a "pseudo" yield strength selected to bound creep damage. In this Code Case, "shakedown" refers to the achievement of cyclic elastic behavior throughout the part, based on real or pseudo yield properties. In this Code Case the term "pseudo yield stress" refers to a temperature dependent minimum stress-to-rupture value based on a selected trial time duration, not to exceed the yield strength of the material at temperature and is explicitly defined in paragraph 4.2. of this Code Case. Guidance on shakedown analysis is provided in Appendix 1.

The combination of Levels A, B, and C Service loadings shall be evaluated for accumulated creep and fatigue damage, including hold time and strain rate effects. For a design to be acceptable, the creep and fatigue damage at each point in the component shall satisfy the following relation:

$$
D_{c}+D_{f} \leq D
$$

where

$$
\begin{aligned}
& D=\text { total creep-fatigue damage, as limited by FIG. HBB-T-1420-2 } \\
& D_{c}=\text { creep damage, as determined in paragraph 4, below, of this Code Case } \\
& D_{f}=\text { fatigue damage, as determined in paragraph } 5, \text { below, of this Code Case }
\end{aligned}
$$

(a) This design methodology is not applicable to structures where geometrical nonlinearities exist, e.g. canopy and omega seals.

(b) The stamping and data reports shall indicate the case number and applicable revision.

\section{Load Definition.}

Define all applicable loads and load cases per HBB-3113.2 Service Loadings.

\subsection{Composite cycle definition.}

For the purpose of performing an elastic-perfectly plastic shakedown analysis, an overall cycle must be defined that includes all relevant features from the individual Level A, B and C Service Loadings identified in the Design Specification. Relevant features include, as a minimum, the time-dependent sequence of thermal, mechanical and pressure loading including starting and ending conditions. Such an overall cycle is defined herein as a composite cycle subject to the following requirements. 
2.1.1. An individual cycle as defined in the Design Specifications cannot be split into individual cycles to satisfy these requirements.

2.1.2. Except as described in 2.1.3. below, a single cycle from each Level A, B and C Service Loading cycle type shall be included in the composite cycle for evaluation of creep-fatigue.

2.1.3. Level C Service Loadings may be combined with the applicable Level A and B Service Loadings to define a composite cycle(s) to be evaluated separately from the cycle defined in 2.1.2. Multiple composite cycles that include Level C Service Loadings may be defined for separate evaluation. The total number of Level C Service Loading cycles shall not exceed 25.

\section{Numerical Model.}

Develop a numerical model of the component, including all relevant geometry characteristics. The model used for the analysis shall be selected to accurately represent the component geometry, boundary conditions, and applied loads. The model must also be accurate for small details, such as small holes, fillets, corner radii, and other stress risers. The local temperature history shall be determined from a thermal transient analysis based on the thermal boundary conditions determined from the loading conditions defined in paragraph 2.

\section{Calculation of Creep Damage.}

Perform a shakedown analysis for each of the composite cyclic histories defined in paragraph 2.1. Each of these cyclic histories must be shown to shakedown based on the pseudo yield stress defined in paragraph 4.2. Additional requirements for welds are found in paragraph 6.

4.1. Step 1: Define $t_{\text {design }}$ as the total time duration for all Level A, B, and C Service Loadings when the temperature is above the range covered by Tables 2A, 2B, and 4 of Section II, Part D.

4.2. Step 2: Select a trial time duration, $T_{d}^{\prime}$ in order to define a pseudo yield stress, $S_{T_{d}^{\prime}}$, at each location, using the temperature determined from the transient thermal analysis. This pseudo yield stress is equal to the lesser of the quantities defined below in 4.2.1. and 4.2.2.

4.2.1. The yield strength $S_{y}$ given in Table I-14.5;

4.2.2. $S_{r}$, where $S_{r}$ is the minimum stress to rupture in time $T_{d}^{\prime}$ from FIGS. HBB-I-14.6 multiplied by the factor, $K^{\prime}$, from Table HBB-T-1411-1 using the tabulated values for Elastic Analysis.

4.3. Step 3: Perform a cyclic elastic-perfectly plastic analysis for each composite cycle defined in paragraph 2 above with temperature-dependent pseudo yield stress $S_{T_{d}^{\prime}}$. The assessment temperature shall

be taken as the local instantaneous temperature at every location in the numerical model of the component. If shakedown occurs, that is, cycles with eventual elastic behavior everywhere, proceed to Step 4. If shakedown does not occur, the applied loading does not meet the requirements of this Code Case.

4.4. Step 4: The maximum creep damage over the structure for the composite cycle under consideration is:

$$
D_{c}=\frac{t_{\text {design }}}{T_{d}^{\prime}}
$$

The above value of $D_{c}$ is used to evaluate total damage in Eq. (53). If the pseudo yield strength in 4.2. Step 2 is governed by the yield strength as defined in 4.2.1., then the trial time duration for use in Eq. (2) is given by the time at which the minimum stress to rupture is equal to the yield strength; $S_{r}=S_{y}$. Linear extrapolation of $S_{r}$ values corresponding to the two longest tabulated times can be used to obtained the trial time duration when necessary. 
4.4.1. Steps 2, 3 and 4 may be repeated to revise the value of $D_{c}$ by selecting alternative values of the trial time duration, $T_{d}^{\prime}$. Longer values of $T_{d}^{\prime}$ will reduce the calculated creep damage. However, these longer values will lead to lower values of the pseudo yield stress, $S_{T_{d}^{\prime}}$, which will make shakedown more difficult.

\section{Calculation of Fatigue Damage.}

The fatigue damage summation, $D_{f}$, in Eq. (53) is determined in accordance with Steps 1 through 3 below. Additional requirements for welds are found in paragraph 6.

5.1. Step 1: Determine all the total, elastic plus plastic, strain components for the composite cycle at each point of interest from the shakedown analysis performed in Step 3 of paragraph 4 above.

5.2. Step 2: Calculate the equivalent strain range in accordance with HBB-T-1413, or HBB-T-1414 when applicable, with Poisson's ratio $v^{*}=0.3$.

5.3. Step 3: Determine the fatigue damage for each composite cycle from the expression:

$$
D_{f}=\sum_{j} \frac{n_{j}}{\left(N_{d}\right)_{j}}
$$

where

$n_{j}=$ number of applied repetitions of cycle type, $j$

$\left(N_{d}\right)_{j}=$ number of design allowable cycles for cycle type, $j$, determined from one of the design

fatigue curves from FIGS. HBB-T-1420-1 corresponding to the maximum metal temperature occurring during the cycle.

The value of $D_{f}$ used to evaluate total damage in Eq. (53) is the maximum value at any location in the numerical model.

\section{Weldments.}

Implementation of the evaluation of creep-fatigue damage in paragraphs 4 and 5 above for weldments requires additional consideration.

6.1. In the weld region, the pseudo yield stress value defined by $T_{d}^{\prime}$ in 4.2.2. is reduced further by multiplying the value of $S_{r}$ for the base metal by the applicable weld strength reduction factor from Table HBB-I-14.10.

6.2. The number of allowable cycles, $\left(N_{d}\right)_{j}$, in the weld region is one half the number of allowable cycles from FIGS. HBB-T-1420-1 for base materials.

6.3. The requirements for analysis of geometry of subparagraph HBB-T-1714 are applicable for satisfaction of the requirements of this Code Case.

6.4. The thermal/physical properties of weldments may be assumed to be the same as the corresponding base metal for the base metal - weld combinations listed in Table HBB-I-14.10.

6.5. Weld region model boundaries.

The weld shown in Figure 1 represents a general full-penetration butt weld in a shell. Other weld configurations are needed for construction of an elevated temperature component in accordance with Subsection HB, Subpart B. Article HBB-4200 refers to various Division 1, Subsection NB-4000 paragraphs for weld configurations and requirements. These Subsection NB weld configurations are represented by the shaded region. 
Figure 1 shows a full-penetration butt weld as an example. As shown, $w_{1}$ and $w_{2}$, as needed to define the weld region for use of this Case, are approximations consistent with the specified weld configuration and parameters. The specified weld region must include applicable stress concentrations in accordance with the requirements for analysis of geometry of Subparagraph HBB-T-1714.

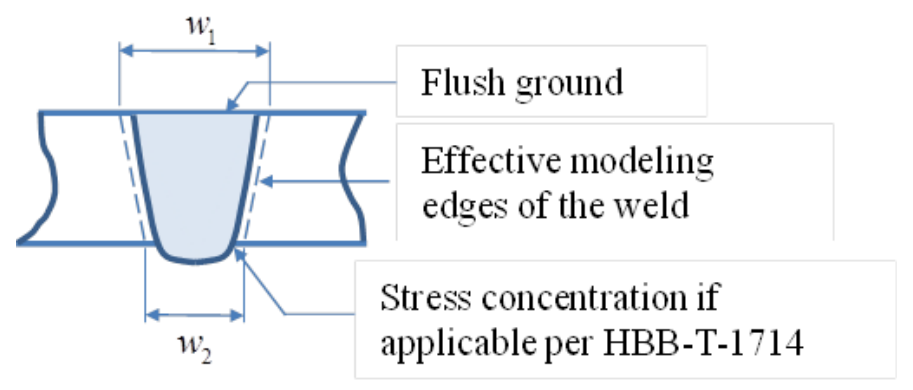

Figure 1. Weld region model boundaries

\subsection{Dissimilar metal welds.}

6.5.1. The requirements for dissimilar metal welds are in the course of preparation.

\section{Appendix 1. Shakedown Analysis.}

The steps to perform a shakedown analysis to calculate bounding cyclic creep damage are as follows:

i) Define Composite Cycle Load Time-Histories and Step(s).

a. It may consist of histories of mechanical loads, pressure loads, displacements, temperatures and thermal boundary conditions.

b. Time-independent parts of the cycle may be truncated because the elastic-perfectly plastic analysis is not time dependent.

c. The cycle should not have discontinuities. Discontinuities arising from the selection of the specified cycles to form a composite cycle should be eliminated by a simple and reasonable transition from one operating state to the next.

d. Subject to the requirements in (ii), the composite cycle time does not affect the result of the shakedown analysis.

e. Temperatures, thermal boundary conditions, boundary displacements and mechanical loads over a cycle should be cyclic; that is, begin and end at the same value.

f. A single analysis step may represent one cycle. Dividing a single cycle into more than one step to facilitate definition of the load cycle, and to ensure that maximum loads are analyzed, is often helpful.

ii) Define Analysis Types.

a. A sequentially coupled thermal-mechanical analysis of the composite cycle may be performed. First, a thermal analysis is performed to generate temperature histories. Next, the mechanical analyses are performed using these temperature histories as inputs. Care must be taken that times in the mechanical analysis step and in the previous thermal analysis are the same or do not conflict, depending on the requirements of the analysis software.

b. Alternatively, a coupled thermal-mechanical analysis may be performed. The composite temperature history to be used in the mechanical analysis should be cyclic, that is the beginning and end temperature distributions should be the same. 
iii) Define Material Properties.

a. For thermal analyses, density, temperature-dependent specific heat and conductivity will generally be required.

b. For the mechanical analyses, the temperature-dependent properties required are elastic modulus, Poisson's ratio and mean expansion coefficient. Density may also be required.

iv) Perform Analyses.

a. Perform an elastic-plastic cyclic mechanical and thermal stress analysis using the temperaturedependent yield stress defined above. Enough cycles are required to demonstrate shakedown or otherwise.

b. Care must be taken to ensure that the analysis deals with all the changes within a cycle. Elasticplastic routines increase increment size where possible, and may miss a detail in the loading. A conservative limit to maximum increment size can address this problem, or division of the cycle into more than one step as in paragraph (i)(f) of this appendix.

v) Shakedown.

(a)Shakedown is defined in this Code Case as eventual elastic behavior everywhere in the model. Failure to shakedown may be identified by plotting histories of equivalent plastic strain. 


\section{REFERENCES}

Carroll, L. J., Cabet, C., Carroll, M. C., and Wright, R. N., (2010), "The Role of Environment on High Temperature Creep-Fatigue Behavior of Alloy 617," Proceedings of the ASME Pressure Vessel and Piping Division Conference, Bellevue, WA, July 18-22, PVP2010-26126, American Society of Mechanical Engineers, New York, NY.

Carter, P., (2005a), "Analysis of cyclic creep and rupture. Part 1: Bounding theorems and cyclic reference stresses,” Int. J Press \& Piping, Vol. 82, pp. 15-26.

Carter, P., (2005b), "Analysis of cyclic creep and rupture. Part 2: Calculation of cyclic reference stresses and ratcheting interaction diagrams," Int. J Press \& Piping, 82, pp. 27-33.

Carter, P., Jetter, R., Sham, T.-L., (2012a), "Application of Elastic-Perfectly Plastic Cyclic Analysis to Assessment of Creep Strain”, PVP 2012 - 28082, American Society of Mechanical Engineers, New York, NY.

Carter, P., Jetter, R., Sham, T.-L., (2012b), "Application of Shakedown Analysis to Evaluation of CreepFatigue Limits”, PVP 2012-28083, American Society of Mechanical Engineers, New York, NY.

Corum, J.M., and Blass, J.J., (1991), Rules for Design of Alloy 617 Nuclear Components to Very High Temperatures, ASME PVP Vol. 215, p.147, American Society of Mechanical Engineers, New York, NY.

Eno, R., G.A. Young, and T.-L. Sham, (2008), “A Unified View of Engineering Creep Parameters," Proceedings of the ASME 2008 Pressure Vessels and Piping Division Conference, Chicago, Illinois, July 2008, Paper No. PVP2008-61129, American Society of Mechanical Engineers, New York, NY

Goodall, I.W., Leckie, F.A., Ponter, A.R.S., Townley, C.H.A, (1979), "The Development of High Temperature Design Methods Based on Reference Stresses and Bounding Theorems," ASME Journal of Engineering Materials and Technology, Vol. 101.

Hollinger, G. L. and Pease, D., J., (2014), "Comprehensive Report For Proposed Elevated Temperature Elastic Perfectly Plastic (EPP) Code Cases Representative Example Problems”, 20362-R-001 Rev.3, Becht Engineering, Liberty Corner, NJ.

Jetter, R.I., (1998), “An Alternate Approach to Evaluation of Creep-Fatigue Damage for High Temperature Structural Design," PVP-Vol. 5 Book No. H01146 - 1998, pp. 199-205, American Society of Mechanical Engineers, New York, NY.

Pitts, D.R., and Sissom, L.E., (1998) Schaum's Outline of Theory and Problems of Heat Transfer, 2nd Ed., McGraw Hill.

Roark, R. J., and Young, W. C., (1989) Roark's Formulas for Stress and Strain, 6th ed., McGraw-Hill, New York.

Swindeman, R., Robinson, D., Williams, B. and Thomas, D., (1982) "Two-Bar Thermal Ratcheting Experiments on 21/4Cr-1Mo steel" ORNL/TM-8001. 
The American Society of Mechanical Engineers, Boiler and Pressure Vessel Code, Section II, Part D, (2013) "Materials, Properties," American Society of Mechanical Engineers, New York, NY.

The American Society of Mechanical Engineers, Boiler and Pressure Vessel Code, Section III, Division 5, Subsection HB, Subpart B, (2015), "Class A Components in Elevated Temperature Service," American Society of Mechanical Engineers, New York, NY.

Wang, Y, Jetter, R., and Sham, T.-L., (2013) "Progress Report on Creep-Fatigue Design Method Development Based on SMT Approach for Alloy 617", ORNL/TM-2013/349, Oak Ridge National Laboratory, Oak Ridge, TN.

Wang, Y, Jetter, R., and Sham, T.-L., (2013) "Progress Report on the Development of Test Procedure for the Two-bar Thermal Ratcheting Experiment for Alloy 617” ORNL/TM-2013/318. 
Page Intentionally Blank 


\section{DISTRIBUTION LIST}

Name

Corwin, W.

Sink, C.

Grandy, C.

Hill, R.N.

Li, M.

Majumdar, S.

Croson, D.

Petti, D.

Wright, J.

Wright, R.N.

Lara-Curzio, E.

Sham, T.-L.

Wang, $\mathrm{H}$.

Wang, $Y$.

Hollinger, G.

Pease, D.

Carter, $\mathrm{P}$.

Jetter, R.I.

$\mathrm{Pu}, \mathrm{C}$.

\section{Affiliation}

DOE

DOE

ANL

ANL

ANL

ANL

INL

INL

INL

INL

ORNL

ORNL

ORNL

ORNL

Becht Engineering Co., Inc.

Becht Engineering Co., Inc.

Stress Engineering Services Inc.

Consultant

University of Tennessee

\section{Email}

william.corwin@nuclear.energy.gov

carl.sink@nuclear.energy.gov

cgrandy@anl.gov

bobhill@anl.gov

mli@anl.gov

majumdar@anl.gov

diane.croson@inl.gov

david.petti@inl.gov

jill.wright@inl.gov

richard.wright@inl.gov

laracurzioe@ornl.gov

shamt@ornl.gov

wangh@ornl.gov

wangy3@ornl.gov

ghollinger@becht.com

dpease@becht.com

peter.carter@stress.com

bjetter@sbcglobal.net

cpu@utk.edu 